Peter Saile

Ein ökonomischer

Ansatz der Theorie

der intermediären

Finanzgewalten - Die

Kirchen als Parafisci 
Peter Saile

\section{Ein ökonomischer Ansatz der Theorie der intermediären Finanzgewalten - Die Kirchen als Parafisci}

Obwohl die intermediären Finanzgewalten (Parafisci) seit den zwanziger Jahren an Bedeutung gewonnen haben, finden sie bislang wenig Berücksichtigung in der finanzwissenschaftlichen Literatur. Auf diese Lücke zielt das vorliegende Buch. Mit einem integrierten Ansatz, der die Ergebnisse einer dogmenhistorischen Betrachtungsweise der Staatstätigkeit aufgreift und ökonomische, gesellschaftliche und staatspolitische Kriterien miteinander verknüpft, werden die Parafisci sowohl gegenüber dem Staat als auch gegenüber den Privaten "zumindest qualitativ" abgegrenzt. Am Beispiel der Kirchen in der Bundesrepublik Deutschland wird ausführlich gezeigt, wie die theoretisch erarbeiteten Kriterien anzuwenden sind. Diese Ausführungen bringen eine konsequente, bislang nirgends dargestellte Diskussion des gesamten Tätigkeitsbereichs der Kirchen aus ökonomischem Blickwinkel.

Peter Saile wurde 1954 in Tübingen geboren. Nach dem Studium der Volkswirtschaftslehre an der Universität Tübingen war er dort als Assistent an der Abteilung Volkswirtschaftslehre, insbesondere Finanzwissenschaft, und an der Konzentrationsforschungsabteilung beschäftigt. Seit 1986 ist er bei einer Industrieund Handelskammer tätig. 
Ein ökonomischer Ansatz der Theorie der intermediären Finanzgewalten - Die Kirchen als Parafisci 


\section{FINANZWISSENSCHAFTLICHE SCHRIFTEN}

Herausgegeben von den Professoren

Albers, Krause-Junk, Littmann, Oberhauser, Pohmer, Schmidt

Band 46

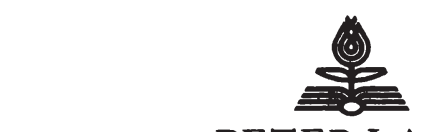

PETER LANG

Frankfurt am Main - Bern - New York - Paris 


\section{Peter Saile}

\section{Ein ökonomischer Ansatz der Theorie der intermediären Finanzgewalten - Die Kirchen als Parafisci}

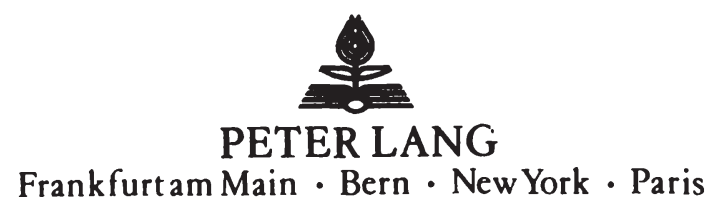


Die Deutsche Bibliothek - CIP-Einheitsaufnahme

Saile, Peter:

Ein ökonomischer Ansatz der Theorie der intermediāren

Finanzgewalten : die Kirchen als Parafisci / Peter Saile. -

Frankfurt am Main ; Bem ; New York ; Paris : Lang, 1992

(Finanzwissenschaftliche Schriften ; Bd. 46)

Zugl.: Tübingen, Univ., Diss., 1990

ISBN 3-631-44652-7

NE: GT

Open Access: The online version of this publication is published on www.peterlang.com and www.econstor.eu under the international Creative Commons License CC-BY 4.0. Learn more on how you can use and share this work: http://creativecommons. org/licenses/by/4.0.

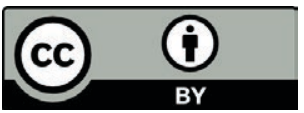

This book is available Open Access thanks to the kind support of ZBW - Leibniz-Informationszentrum Wirtschaft.

\author{
D 21 \\ ISSN 0170-8252 \\ ISBN 3-631-44652-7 \\ ISBN 978-3-631-75214-2 (eBook) \\ (c) Verlag Peter Lang GmbH, Frankfurt am Main 1992 \\ Alle Rechte vorbehalten.
}

Das Werk einschließlich aller seiner Teile ist urheberrechtlich geschützt. Jede Verwertung außerhalb der engen Grenzen des Urheberrechtsgesetzes ist ohne Zustimmung des Verlages unzulāssig und strafbar. Das gilt insbesondere für Vervielfăltigungen, Ūbersetzungen, Mikroverfilmungen und die Einspeicherung und Verarbeitung in elektronischen Systemen.

Printed in Germany 123467 
Die vorliegende Arbeit entstand während meiner Assistentenzeit am Lehrstuhl für Volkswirtschaftslehre, insbesondere Finanzwissenschaft, der Eberhard-Karls-Universität Tübingen und stellt eine leicht veränderte Fassung einer von der Wirtschaftswissenschaftichen Fakultät im wintersemester 1990 angenommenen Dissertation dar.

Herr Professor Dr. Dieter Pohmer, mein verehrter Lehrer, hat die Entstehung der Arbeit mit zahlreichen Hinweisen nachhaltig gefördert. Hierfür schulde ich ihm meinen aufrichtigen Dank. Ebenso möchte ich Herrn Professor Dr. Dieter Cansier für die Bereitschaft zur Ubernahme des Korreferats danken. Mein Dank gilt schließlich meiner früheren Kollegin, Frau Dr. Gisela Jurke, die mir viele wertvolle Hinweise gab und mir immer eine geduldige und kompetente Gesprächspartnerin war. Einschließen in meinen Dank möchte ich auch die ehemaligen Kolleginnen und Kollegen am Lehrstuhl, die mich bei den technischen Arbeiten tatkräftig unterstützt haben. 
Peter Saile - 978-3-631-75214-2

Downloaded from PubFactory at 01/11/2019 07:01:15AM

via free access 
Inhaltsverzeichnis

Seite

A. Einleitung

11

B. Der intermediäre Bereich in dogmengeschichtlicher Betrachtung

I. Die intermediären Finanzgewalten 15

1. Begriff und Kennzeichnung 15

2. Beurteilung und Weiterentwicklungen 20

II. Die "Gemeinwirthschaften" in der älteren

finanzwissenschaftlichen Literatur 27

1. Die Natur der Bedürfnisse und die Bildung von Kollektiven 27

2. Kollektive Befriedigung von Bedürfnissen 37

3. Kritische würdigung 49

C. Ansatzpunkte einer Kennzeichnung des intermediären Bereichs im modernen pluralistischen Gruppenstaat 55

I. Stellung und Aufgaben der Gruppen

in Gesellschaft und Staat 55

1. Die gesellschaftliche Funktion der Gruppen 55

2. Offentlicher und staatlicher Aufgabenbereich in staatsrechtlicher Sicht 61

3. Würdigung 68

II. Kollektive Bedarfsdeckung in ökonomischer sicht 73

1. Der intermediäre Bereich als Teil eines funktionalen Föderalismus 73

2. Gütereigenschaften und Allokationsstörungen 77

a) Nicht-Ausschließbarkeit und

Nichtrivalität $\quad 77$

b) Externe Effekte 78

c) Meritorische Güter 82

3. Folgerungen aus der ökonomischen Theorie für dieBereitstellung öffentlicher Güter 85

a) Wohlfahrtstheoretische Bestimmung der Staatstätigkeit 
b) Nichtstaatliche kollektive Bedarfsdeckung

c) Staatliche Maßnahmen zur Beseitigung allokativer Störungen

4. Grenzen der Aussagefähigkeit der Theorie der öffentlichen Güter

D. Ein integrierter Ansatz zur Abgrenzung der

intermediären Finanzgewalten

I. Grundlagen

II. Der Offentlichkeitsgrad als Maßstab

1. Zum Begriff des Offentlichkeitsgrades

2. Eine weitergehende Definition

3. Offentlichkeitsgrad und Steuerungsmechanismus

III. Das Öffentliche als Bereich der intermediären Finanzgewalten

1. Abgrenzung gegenüber dem privaten Bereich

2. Der notwendig staatliche Bereich

3. Der Bereich des ర̈ffentlichen

IV. Der Einfluß der gesellschaftlichen Gruppierungen auf politische willensbildung und staatliche Entscheidungen

E. Die Kirchen als intermediäre Finanzgewalten

I. Vorbemerkungen

II. Grundlagen und Motive kirchlichen Wirkens

1. Der iberweltliche Charakter

2. Das weltliche Selbstverständnis

3. Die Mitgliedschaft in der Rirche

4. Die besondere Stellung der Kirchen in der Bundesrepublik Deutschland

5. Der రffentlichkeitsauftrag der Kirchen

III. Die kirchlichen Funktionen

1. Wortverkündigung und Sakramentsverwaltung

2. Besondere Formen der Verkündigung

a) Militärseelsorge und Anstaltsseelsorge

b) Verkündigungsauftrag und staatliches Schulwesen

c) Religionsunterricht 
d) Kirchliche Privatschulen

e) Theologische Fakultäten und kirchliche Hochschulen

f) Erwachsenen- und Weiterbildung 170

3. Diakonie

4. Mission und Entwicklungspolitik

IV. Der Öffentlichkeitsgrad kirchlicher Funktionen

1. Die Kirchen als Kollektive

2. Kirchliche Leistungen als Kollektivgüter

a) Leistungen im Bereich des Verkündigungsauftrages

aa) Wortverkündigung und Sakramentsverwaltung

bb) Militärseelsorge und Anstaltsseelsorge

cc) Einfluß auf staatliche Bildungsziele

dd) Religionsunterricht

ee) Kirchliche Privatschulen

ff) Theologische Fakultäten

b) Karitative Leistungen

3. Die Anwendbarkeit gesellschaftlicher Selbststeuerungsmechanismen 
Peter Saile - 978-3-631-75214-2

Downloaded from PubFactory at 01/11/2019 07:01:15AM

via free access 
A. Einleitung

Der Begriff der "intermediären Finanzgewalten" findet sich erstmals bei Fritz Karl Mann'1). Er und insbesondere sein Schüler Walther Herrmann") haben die "hilfsfiskalischen Verzweigungen" des Staates oder - wie man diese Institutionen auch nennt $\left.{ }^{3}\right)$ - die Parafisci in die finanzwissenschaftliche Betrachtung einbezogen. Ihre an juristische Merkmale anknüpfende Charakterisierung dieser spezifischen Wirtschaften erweist sich in heutiger sicht allerdings in mancherlei Punkten als zu eng und unzureichend; die ökonomische Betätigung der für ein pluralistisches Gemeinwesen charakteristischen nichtstaatlichen Gruppen und verbände wird damit nicht erfaßt.

Eine Vielzahl von Gruppen prägt die moderne Gesellschaft. Diesen Gruppierungen wird man nicht dadurch gerecht, daß man sie entweder dem staatlichen oder dem privaten Sektor zuordnet; denn sie sind irgendwo dazwischen anzusiedeln. Welche Funktionen sie wahrnehmen und welchen "Platz" sie im Gemeinwesen einnehmen, sind die zentralen Fragen dieser Arbeit. Dabei wird so vorgegangen, daß die Kennzeichnung der Aufgaben zugleich als Ausgangspunkt für die Standortbestimmung dient. Das bedeutet, daß Kriterien gefunden werden müssen, die es erlauben, die Funktionen dieser gesellschaftlichen Gruppierungen gegenüber den staatlich oder rein privat zu erfülenden Aufgaben abzugrenzen. Implizit gibt die Lösung dieses Problems auch Hinweise darauf, ob der Staat zu viele Aufgaben erfült, derer er sich also entledigen und die er eigentlich an andere Träger verweisen könnte, oder ob er bestimmte Aufgaben, die von anderen befriedigt werden, nicht eher als seine eigenen Angelegenheiten betrachten müßte.

Die ökonomischen Grundgedanken des hier gewählten Ansatzes knüpfen an der in den letzten Jahren in die Finanzausgleichsdiskussion ansatzweise eingegangene Föderalismustheorie an. Während der Föderalismusgedanke lange nur unter dem regionalen Aspekt der Aufgabenverteilung zwischen den verschiedenen 
Gebietskörperschaften gesehen wurde, wurde er in jüngerer Zeit dahingehend erweitert, indem die Aufgabenverteilung im gesamten Gemeinwesen nicht ausschließlich unter regionalen, sondern auch unter funktionalen Gesichtspunkten erörtert wird. Das Hauptaugenmerk gilt dabei dem Problem, wie nach ökonomischen Maßstäben die aufgrund politischer Entscheidung vorgegebenen staatlichen Aufgaben auf die einzelnen Träger aufuteilen und zu finanzieren sind. Offen bleibt bislang die Frage, wie in einem Gemeinwesen grundsätzlich die zu erfüllenden Aufgaben auf staat, Parafisci und Individuum zu verteilen sind. Diesem Aspekt gilt die Aufmerksamkeit, wobei es darauf ankommt, Kriterien zu finden, mit deren Hilfe es möglich wird, diese Bereiche zumindest qualitativ voneinander abzugrenzen.

Die einführende dogmengeschichtliche Betrachtung des intermediären Bereichs in Kapitel B ist bewußt so ausführlich gehalten, weil sie zeigt, daß die mit dieser Arbeit verfolgte $A b-$ sicht nicht prinzipiell neu ist, das wirtschaften und die Funktionen der zwischen Staat und Individuen angesiedelten gesellschaftlichen Gruppierungen aus dem Blickwinkel des gesamten Gemeinwesens näher zu untersuchen.

Obwohl die Föderalismustheorie in die theoretische Finanzausgleichsdiskussion den funktionalen Aspekt bei der Aufgabenverteilung eingebracht hat, behandelt die neuere finanzwissenschaftliche Literatur die Parafisci als Institutionen immer noch stiefmütterlich. Außer dem theoretischen Hinweis auf den funktionalen Aspekt befaßt sich die neuere Literatur zum Finanzausgleich nahezu ausschließlich mit der Verteilung der finanzwirtschaftlichen Kompetenzen auf die verschiedenen Körperschaften. Das liegt wohl daran, daß sich die Diskussion weitgehend auf die ökonomischen Aspekte der Staatsaufgaben reduziert hat. Aus diesem Grunde erscheint es sinnvoll, die Sichtweise der älteren deutschen Finanzwissenschaft, insbesondere mit deren hervorragenden Vertretern Adolph Wagner und Albert E. Fr. Schäffle, wieder aufzugreifen, da diese alle Formen des Wirtschaftens im Gemeinwesen in ihre finanzwissen- 
schaftlichen Untersuchungen einbezogen und im Lichte ökonomischer und politischer Wertmaßstäbe gewirdigt haben.

Im Teil C werden di€ Grundlagen für eine Kennzeichnung des intermediären Bereichs betrachtet, der entsprechend der Definition dieser Arbeit im Bereich des Öfentlichen angesiedelt ist. Dazu ist es erforderlich, zunächst die Begriffe "Staat", "Öffentlichkeit" und "Gesellschaft" bzw. "staatlich", "öffentlich" und "gesellschaftlich" anhand der konkreten Ordnung des Gemeinwesens zu bestimmen. Den Ausgangspunkt der Untersuchung bildet die auf dem Grundgesetz beruhende pluralistische, demokratische Gesellschaft mit einer marktwirtschaftlichen Ordnung, in die die bislang wenig erforschten intermediären Finanzgewalten einzuordnen sein werden. Zu diesem Zweck werden zunächst die Charakteristika des pluralistischen Staatswesens skizziert. Es werden die staatsrechtlichen Rahmenbedingungen herausgearbeitet, die Aufschluß darüber geben sollen, welche Funktionen den Gruppen und Verbänden im Gemeinwesen zuzuweisen sind. Diese Rahmenbedingungen sollen zum einen den grundsätzlichen wirkungsbereich der Gruppen umschreiben und zum anderen Anhaltspunkte für die staatsrechtliche Abgrenzung von staatlichen, öffentlichen und privaten Aufgaben liefern. In der ökonomischen und auch in der staatsrechtlichen Literatur gibt es eine Vielzahl von Definitionen von "staatlich" und "öffentlich". Vor allem in der ökonomischen Literatur ist in der Regel mit öffentlich auch staatlich gemeint. Dieser Definition soll hier nicht gefolgt werden, vielmehr soll das "Öffentliche" als Bereich zwischen Staat und Privaten verstanden werden. Bei der Diskussion von Literaturmeinungen wird jedoch die Terminologie der betreffenden Autoren verwendet.

Im Anschluß daran werden als zweiter Baustein für eine Kennzeichnung des intermediären Bereichs die ökonomischen Beweggründe aufgezeigt, die ursächlich für die Bildung nichtstaatlicher Kollektive sind. Das erfolgt mit Hilfe der ökonomischen Theorie der Kollektive und, da die Typisierung des 
intermediären Bereichs anhand der von ihm erfüllten Aufgaben erfolgen soll, der Erkenntnisse der Theorie der offentlichen Güter.

Im Teil D wird durch die verknüpfung der staatsrechtlichen und der ökonomischen Betrachtungsweise in einem integrierten Ansatz versucht, ein Beurteilungsraster aufzustellen, das es ermöglicht, die verschiedenen Bereiche voneinander abzugrenzen. Die Besonderheit dieses Ansatzes liegt darin, daß er nicht nur die der Marktwirtschaft zugrundeliegenden Zielvorstellungen des klassischen Liberalismus zum Maßstab nimmt. Vielmehr wird hier eine umfassendere Sicht gewählt, die von den aus der Verfassung resultierenden Wertvorstellungen des gesamten Gemeinwesens ausgeht. Mit diesem Vorgehen wird vermieden, daß die Wertmaßstäbe der Marktwirtschaft mit der einseitigen Orientierung an der freiheitlichen zielsetzung zum alleinigen Beurteilungskriterium für andere Bereiche werden. Durch die Einordnung der Marktwirtschaft als Teil des gesamten Gemeinwesens wird zugleich deren instrumenteller Charakter in bezug auf die übergeordnete Allgemeinwohlzielsetzung deutlicher, die neben der freiheitlichen zielsetzung auch andere Wertvorstellungen enthält, auf denen das Gemeinwesen beruht. Auf diese Weise wird es mit dem hier gewählten Ansatz möglich, die Funktionen des öffentlichen Bereichs nicht nur anhand ökonomischer, sondern auch politischer Kriterien zu bestimmen ${ }^{4}$, die hier eine wichtige Rolle spielen.

Im letzten Rapitel $\mathrm{E}$ wird mit Hilfe des zuvor gewonnenen Beurteilungsrasters am Beispiel der Kirchen eine Einordnung dieser Parafisci in das Gemeinwesen vorgenommen. Dabei werden die historisch gewachsenen Strukturen und die nur geschichtlich zu erklärenden staatskirchenrechtlichen Sonderregelungen der Kirchen im Grundgesetz weitgehend außer acht gelassen. Ausgehend von ihrem Selbstverständnis und den daraus abgeleiteten Aufgaben einerseits, den ökonomischen und politischen Kriterien andererseits wird die öffentliche Bedeutung der Kirchen bestimmt. 
B. Der intermediäre Bereich in dogmengeschichtlicher Betrachtung

I. Die intermediären Finanzgewalten

\section{Begriff und Kennzeichnung}

Ende der 20er Jahre machte Fritz Karl Mann ${ }^{1)}$ darauf aufmerksam, daß die finanzielle Belastung der Bürger unzureichend ausgedrückt wird, wenn nur die den öffentlichen Haushalten zuflieBenden Abgaben zugrundegelegt werden. Denn neben diesem öffentlichen Finanzbedarf, dessen Spiegelbild die Abgabenbelastung der Bürger ist, macht er "einen 'versteckten öffentlichen Bedarf' (aus; der Verf.), der uns in wechselnder Gestalt und wechselnder Größe in Staat und Selbstverwaltungskörpern entgegentritt"2). Das Gewicht der sich nicht über den allgemeinen Haushalt finanzierenden Institutionen hat nämlich in den Jahren nach dem Ersten Weltkrieg gegenüber den eigentlichen Fisci beträchtlich zugenommen, ohne großes Aufsehen zu erregen ${ }^{3}$ ). Statt daß der Staat neu auf ihn zukommende Aufgaben, wie es die Regel sei, durch die Schaffung neuer Ämter bewältigte, die ihren finanziellen Bedarf aus allgemeinen Haushaltsmitteln decken, hätte beobachtet werden können, daß der Staat verstärkt von einer anderen sich ihm bietenden Möglichkeit Gebrauch machte: Er übertrug diese Aufgaben an nichtamtliche Stellen, die zumeist in Gestalt einer juristischen Person des öffentlichen Rechts oder des Privatrechts auftraten 4 ). Diese "intermediären Finanzgewalten", die sich zwischen Staat und Bürger schieben ${ }^{5), ~ s t e l-~}$ len "gleichsam eine Verlängerung des Staatswillens" dar. "Sie sind die Handlanger des Staates und der Selbstverwaltungskörper bei der Erfüllung öffentlicher Pflichten"6).

Die Ausgliederungen von staatlichen Funktionen aus den öffentlichen Haushalten wurden u.a. damit begründet, daß selbständige Organe auf bestimmten Gebieten bessere finanzpolitische Leistungen erbrächten und/oder den Staatshaushalt entlasteten, daß mittlere Einheiten organisatorisch überlegen 
und schließlich die Widerstände zur Durchsetzung bestimmter Handlungen geringer seien ${ }^{7}$ ). Die Merkmale, mit deren Hilfe man versuchte, den intermediären Bereich zu kennzeichnen, wurden von den existierenden Institutionen wie den Sozialversicherungsträgern und den Selbstverwaltungseinrichtungen der wirtschaft abgeleitet und sind - was dann nicht verwundert - im wesentlichen juristischer Natur ${ }^{8}$ ).

Staatsrechtlich versteht man unter juristischen Personen des öffentlichen Rechts "die mit eigener Rechtspersönlichkeit ausgestatteten Organisationsgebilde der mittelbaren Staatsverwaltung", die vom Staat anerkannt oder geschaffen wurden, bestimmte öffentliche Aufgaben erfüllen und staatlicher Kontrolle unterliegen $\left.{ }^{9}\right)$. Am deutlichsten wird dies bei den Körperschaften des öffentlichen Rechts, die als "mitgliedschaftlich organisierte, rechtsfähige Verbände des öffentlichen Rechts, welche staatliche Aufgaben mit hoheitlichen Mitteln unter staatlicher Aufsicht wahrnehmen", definiert werden ${ }^{10}$ ). Es handelt sich also bei den juristischen Personen des öffentlichen Rechts um vom Staat geschaffene bzw. mit dem öffentlich-rechtlichen Status ausgestattete Institutionen, die anerkannt öffentliche Aufgaben wahrnehmen ${ }^{11}$ ). Diese Selbstverwaltungskörper führen die vom Staat delegierten Aufgaben unter dessen oberaufsicht durch ${ }^{12}$ ), genießen aber innerhalb ihrer umgrenzten Kompetenz eine eigene Entscheidungsautonomie. Besonders hervorgehoben wird ihre finanzielle Unabhängigkeit vom zentralstaat, der sie, um ihren Finanzbedarf zu decken, mit dem Recht ausstattet, "dem Bürger in die Tasche zu greifen"13). Diese hoheitliche Mittelbeschaffung, das wohl wichtigste Abgrenzungskriterium überhaupt, geht im allgemeinen einher mit einer zwangsmitgliedschaft ${ }^{14}$ ).

Diese Abgrenzung mag zur Untersuchung bestimmter Fragestellungen durchaus geeignet sein, etwa wenn spezielle Probleme der Sozialversicherung unter dem Blickwinkel der Verteilungsproblematik diskutiert werden. Ein neueres Beispiel dafür liefert Helmut Meinhold, der sich bei der Charakterisierung der 
Parafisci an Mann anlehnt und die gesonderten Haushalte der Sozialversicherungen unter dem Aspekt der speziellen Leistungen rechtfertigt. Als wesentlichen Unterschied gegenüber den Haushalten der Gebietskörperschaften führt er die Gültigkeit des Affektationsprinzips bei den Parafisci an, das hier deshalb sinnvoll sei, weil sich die Leistungen dieser Organisationen an den Gegenleistungen der Empfänger ausrichteten. Wegen der vielfältigen sozialpolitischen zielsetzungen, die mit der Sozialversicherung verfolgt werden, und der daraus resultierenden Umverteilungseffekte trifft das auf die Sozialversicherung nur noch begrenzt $\mathrm{zu}^{15}$ ).

Inhaltlich ähnliche Vorstellungen zur Parafiskalität wie Mann entwickelte in der italienischen Finanzwissenschaft Emanuele Morselli. Nach Georgio Stefani ${ }^{16}$ ) wollte er die bis dahin vorherrschende territoriale Betrachtungsweise der Finanzwissenschaft mit der Unterteilung in Staats- und Gemeindefisci überwinden. Außerdem stellte er auf den funktionalen Charakter ab, indem er von einer institutionellen sicht ausging.

Die herkömmliche Einteilung in Staats- und Gemeindefisci erfaßt seiner Ansicht nach nicht alle Bereiche staatlicher Tätigkeit und ist deshalb zu eng. Unter dem Druck neuer, vornehmlich sozialpolitischer Aufgaben hat der Staat für bestimmte qualifizierte Zwecke Institutionen geschaffen oder bereits bestehende damit betraut, ihn bei der Erfüllung seiner Aufgabe, der Dekkung öffentlicher Bedürfnisse, zu unterstützen oder ihm einzelne dieser Aufgaben abzunehmen. Morselli sieht in dieser finanzwirtschaftlichen Spezialisierung von bestimmten Institutionen, die der staatlichen Leitung und Kontrolle unterstehen, eine Anpassung der Verwaltung an die wechselnden staatlichen Aufgaben. Während sich diese grundsätzliche Begriffsfassung im Prinzip nicht von derjenigen Manns unterscheidet, führt Morselli zwei weitere Aspekte an, die eine besondere Betrachtung verdienen. 
Die von ihm als Parafisci bezeichneten Institutionen dienen der Befriedigung öffentlicher Bedürfnisse, und zwar solcher, die eher auf besonderen, veränderlichen Zwecken beruhen, die sich aus den herrschenden sozialen und wirtschaftlichen Anschauungen ergeben 17). Allerdings unterläßt es Morselli, weiter zu fragen, was denn eigentlich öffentliche Bedürfnisse seien. Er versucht nicht, diese mit Hilfe des Bedürfnis- oder Gutscharakters festzulegen, sondern er unterstellt - und damit verbaut er sich einen weitergehenden Ansatz -, daß öffentliche Bedürfnisse gleichbedeutend sind mit staatlicher Erfüllung. Zu dieser Einschätzung, die mit einigen staatsrechtlichen Auffassungen, die unten betrachtet werden, weitgehend uibereinstimmt, gelangt er, weil er es aufgrund des steten Wandels der Staatsfunktionen für unmöglich erachtet, Aufgaben nach ihrem Inhalt einem Träger zuzuordnen, sondern allenfalls nach dem Zweck und den sie wahrnehmenden Institutionen ${ }^{18}$ ).

Der zweite interessante Gedanke bei Morselli berührt den Zusammenhang zwischen dem Empfänger der Leistungen von Parafisci und deren Finanzierung. Morselli untersucht die Parafisci hauptsächlich unter dem Blickwinkel ihrer Besonderheiten gegenüber dem Staatshaushalt und der daraus folgenden Finanzierung ${ }^{19}$ ). Dabei konstatiert er zwar den steuerähnlichen Charakter dieser Abgaben, glaubt aber doch zwei wesentliche Unterschiede ausmachen zu können, die ihre Ursachen in den Eigenheiten dieser Institutionen haben 20 ).

Zum einen sind die Funktionen der Parafisci auf bestimmte Gruppen bezogen, die sich nach wirtschaftlichen und sozialen Merkmalen abgrenzen lassen. Daraus folgert er für die Finanzierung, daß sie nach dem Prinzip der Solidarität erfolgen soll, d.h., daß die Angehörigen dieser Gruppen selbst für die Leistungen der Parafisci aufzukommen haben. Staatliche Subventionen hält er allenfalls bei solchen Zwecken für gerechtfertigt, die von allgemeinem Interesse sind und von den Gruppen nicht genügend berücksichtigt werden ${ }^{21}$ ). Diesen wichtigen Aspekt, daß bestimmte Kollektivtätigkeiten über ihren eigenen Bereich hinaus 
Wirkungen zeigen, die sogar eine Subventionierung angezeigt erscheinen lassen, verfolgt er indessen ebenfalls nicht weiter.

Zum anderen nennt er als weiteres Wesensmerkmal den

"altruistische(n) Grundsatz als Prinzip kollektiver Wohltätigkeit". Hier unterstellt er, daß das "soziale Pflichtbewußtsein" die Ursache für die Erhebung der besonderen Abgaben zu wohltätigen Zwecken sei. Danach verschaffen sowohl die Abgabenverpflichtung - selbst wenn sie zwangsweise erfolge - als auch die damit erbrachten Leistungen ein Gefühl der Befriedigung und stiften insofern bei der Erhebung und Verwendung der Mittel Nutzen 22 ). So interessant diese Vorstellungen für eine allgemeine Theorie der Parafisci klingen mögen, rufen sie bei der von Morselli unterstellten Nähe der Parafisci zum Staat doch erhebliche Bedenken hervor. Wie nämlich weiter unten noch zu zeigen sein wird ${ }^{23}$ ), verkehrt er den Begriff des Altruismus im Sinne von Sax, auf den er sich beruft, ins Gegenteil, wenn er ihn auf staatliche Zwangsleistungen überträgt; denn die Einsicht in die Notwendigkeit der Zwangsleistungen heißt noch lange nicht, sie freiwillig zu entrichten. Der Trugschluß von Morselli beruht wohl darauf, daß er jegliche Sozialpolitik mit altruistischem Verhalten gleichsetzt. Indem er jedoch eingesteht, daß das soziale Bewußtsein im allgemeinen nicht so stark ausgeprägt sei, sieht er diese Schwäche seines Ansatzes selbst ${ }^{24}$ ).

Er schneidet aber einige Problembereiche an, die uns später noch ausführlicher beschäftigen werden: einmal das altruistische Verhalten, durch das bestimmte Formen kollektiver Betätigung beeinflußt sind. Dabei dürfte es das bei der Bereitstellung kollektiver Güter auftretende Problem der "Trittbrettfahrer" bei Morselli wegen des von ihm unterstellten sozialen Pflichtbewußtseins nicht geben, das sich bei den Pflichtigen in einem "geistigen und moralischen Wohlgefühl der inneren Befriedigung" ausdrückt. Ausführlicher werden wir uns weiter unten außerdem mit dem Gedanken befassen, wonach Gruppen 
kollektive Leistungen erbringen, die außerhalb des Kollektivs auf Interesse stoßen.

\section{Beurteilung und Weiterentwicklungen}

Die finanzwirtschaftlichen Einwände gegen die Parafiskalität können wir kurz abtun, da sie den haushaltspolitischen Aspekt berühren und deshalb in dem hier erörterten zusammenhang nicht unmittelbar interessieren. Sie werden in einem Verstoß gegen die Haushaltsgrundsätze, vornehmlich die Grundsätze der Budgeteinheit, der Nonaffektation, der Klarheit, Öffentlichkeit und Vollständigkeit und in den damit einhergehenden Gefahren gesehen 25 ).

Der prinzipielle Gehalt des historischen Parafisci-Begriffs bedarf allerdings einer etwas ausführlicheren würdigung. Die Kritik entzündet sich an der einseitigen zuordnung der Parafisci zum Staat und der damit in der Regel verbundenen Finanzierung über Zwangsabgaben als unabdingbarem Kennzeichen. Smekal 26) stellt dazu treffend fest: "Das starre Festhalten am Kriterium der Zwangsabgabe hat die Theorie der Parafiskalität in eine Sackgasse geführt. Es versperrt die Sicht auf alle jene intermediären Gebilde, die zwar nicht das juristische Merkmal hoheitlicher Mittelbeschaffung aufweisen, aber dennoch in Erfüllung ihrer partikulären Aufgaben fiskalische Entscheidungszentren zur Erstellung von Kollektivleistungen darstellen." Somit sind die Aktivitäten derartiger organisierter Gruppen im gesellschaftlichen Raum praktisch per definitonem nicht im Begriff der intermediären Finanzgewalten enthalten ${ }^{27}$ ).

Smekal und Andreae 28 ) haben diese enge Betrachtungsweise verlassen. Ihr Verdienst ist es, die intermediären Finanzgewalten auf die gesellschaftliche Realität hin erweitert zu haben. Sie rechnen zu den Parafisci sowohl die staatlich abhängigen Fisci im Sinne von Fritz Karl Mann als auch die gesellschaftlichen Gruppen, die öffentliche Funktionen im Bereich zwischen Staat und Privaten wahrnehmen. Nach Smekal "...kann 
die Entstehung IF (intermediärer Finanzgewalten; der Verf.) entweder auf die staatliche Ausgliederung von Teilfunktionen oder auf die Zusammenfassung von Einzelinteressen im nichtstaatlichen Raum zu gesellschaftlich bedeutenden Gruppenorganisationen zurückzuführen sein."29)

Smekal hat der Diskussion der intermediären Finanzgewalten mit dem Abstellen auf die Erfüllung öffentlicher Funktionen und damit der Erfassung "alle(r) finanzwissenschaftlich relevanten Gebilde zwischen Individuum und Staat"30) neue Perspektiven eröffnet. Als typisches Betätigungsfeld für die Parafisci macht er die Gesellschaft aus, deren Strukturen er allerdings nicht tiefer durchleuchtet. Zur systematischen Einordnung der Parafisci zwischen Individuum und Staat zieht er in erster Linie deren Aufgaben heran, die er mit Hilfe der Theorie der Kollektivguiter charakterisiert. Auf diese Weise gelingt ihm zwar im großen und ganzen die Abgrenzung gegenüber dem rein privaten Bereich, obwohl der Offentlichkeitsgrad der Güter, der das Ausmaß der Externalitäten eines Gutes angibt, in der von ihm benutzten Begriffsfassung - wie im Kapitel D noch gezeigt wird - bestimmte öffentliche Funktionen der intermediären Finanzgewalten nicht zum Ausdruck bringt. Der ausschließliche Rückgriff auf ökonomische Merkmale muß aber versagen, wenn es um die $\mathrm{Ab}-$ grenzung gegenüber dem Staat geht, und zwar deshalb, weil ein rein ökonomisches, nur auf den Gütermerkmalen beruhendes Kriterium gerade in dem Zwischenbereich von Staat und Gesellschaft wegen der gegenseitigen Verschränkung nicht ausreicht. Das sieht auch Smekal, und er behilft sich deshalb mit dem bei ihm vom Aufgabencharakter losgelösten institutionellen Merkmal der Selbstverwaltung von Gruppeninteressen 31 ). Die entscheidende Frage aber, warum und bei welchen Aufgaben eine Selbstverwaltung sinnvoll ist, wird von ihm nicht beantwortet. Bedeutung und Funktionen der zahlreichen Organisationen im modernen Gemeinwesen, insbesondere ihr Verhältnis zum Staat und ihre Rolle in der Gesellschaft, können ohne Berücksichtigung politischer Kriterien nicht vollständig erfaßt werden. 
Einen anderen, auch staatsrechtliche Kriterien berücksichtigenden Ansatz hat Wolfgang Kirberger ${ }^{32}$ ) gewählt, um den Funktionsbereich der gesellschaftlichen Gruppierungen neben dem Staat "auszuloten". Als grundlegenden Maßstab für die Einordnung als öffentliche oder private Aufgabe nennt er die kollektiven Wertvorstellungen, die es zu ermitteln gilt ${ }^{33}$ ). Dazu benutzt er ein zweistufiges verfahren ${ }^{34}$ ). Ausgehend von den in der Verfassung niedergelegten grundsätzlichen Staatszielbestimmungen, insbesondere dem Sozialstaatsprinzip, sowie von den durch politische wahlen getroffenen kollektiven Grundentscheidungen über die Aufgabenverteilung sucht er die kollektiven Wertvorstellungen festzustellen. Mit diesem ersten Schritt will er die Frage beantworten, inwieweit eine Aufgabe gemessen an den kollektiven Grundentscheidungen überhaupt als lösungsbedürftig $\mathrm{zu}$ betrachten ist. In einem zweiten Schritt prüft er mit Hilfe ökonomischer Kriterien, ob es sich um private Güter handelt, die über den Markt bereitgestellt werden können $\left.{ }^{35}\right)$. Die Restgröße, also die nicht privaten Güter, umfaßt dann die kollektiv bereitzustellenden öffentlichen Güter. Um die öffentlichen Güter zu bestimmen, wählt Kirberger folglich den indirekten Weg einer Negativdefinition über die positive Festlegung der privat bereitgestellten Güter. Die nicht privaten Güter unterscheidet er also nicht - wie es in dieser Arbeit geschehen soll - weiter in staatliche und öffentliche Güter. Da für seine Zwecke nur die kollektiv lösungsbedürftigen Aufgaben interessieren, ist es für ihn unerheblich, ob die Bedarfsdeckung dieser Güter über den Staat oder über nichtstaatliche Träger, die auch aus altruistischen Motiven heraus tätig sein können, erfolgt.

Ein wesentliches Resultat der Vorgehensweise Kirbergers ist die Feststellung, daß die Einordnung der einzelnen Aufgaben danach, ob sie öffentlich oder privat befriedigt werden, nicht auf Dauer festgelegt wird. Die kollektiven Wertvorstellungen, die ausschlaggebend sind für die zuordnung der Aufgaben, wandeln sich im zeitablauf. Dementsprechend verändert sich die Interpretation der grundlegenden Staatszielbestimmung wie etwa des 
Sozialstaatsprinzips und damit auch die struktur der Staatstätigkeit ${ }^{36}$ ).

Der erste Schritt Kirbergers, die Verfassung als Bezugspunkt für die Aufgabenbestimmung zu wählen, erscheint zunächst vielversprechend. Die Ergebnisse, die er erzielt, bleiben indessen eher unbefriedigend. Er stellt fest, daß die Verfassung selbst nur wenige staatsaufgaben explizit anführt ${ }^{37}$ ). Die meisten müssen über die Interpretation der Staatszielbstimmungen gewonnen werden. Am Beispiel des Sozialstaatsprinzips belegt er, daß bei entsprechender Auslegung, wobei er allerdings die übrigen Grundwerte außer acht läßt, letztlich nahezu alle Aufgaben öffentlicher Natur sind. Aus diesem Grunde reicht bei ihm die Verfassung allein nicht aus. Er zieht deshalb die kollektiven Wertvorstellungen hinzu, die bei Wahlen, bei den Regierenden und Repräsentanten sowie durch die öffentliche Meinung geäußert werden, um so festzustellen, welche Aufgaben überhaupt lösungsbedürftig sind. Die Unergiebigkeit der verfassungsmäßigen Zielsetzungen bei Kirberger ist darauf zurückzuführen, daß er weder die teilweise konfliktäre Natur der Wertvorstellungen der Verfassung sieht noch deren Hinordnung auf das übergeordente Kriterium Allgemeinwohl beachtet, dessen bestmögliche Verwirklichung letztendlich ausschlaggebend für den Charakter einer Aufgabe ist.

Beim zweiten Schritt beläßt er es dabei, die Art der Leistungsbereitstellung danach zu differenzieren, ob sie privat oder öffentlich erfolgen sol138). Als Maßstab dienen ihm dabei ökonomische Rriterien, insbesondere die Funktionsfähigkeit des Marktes als Indiz für eine private und die Theorie der öffentlichen Güter als ein solches für eine öffentliche Aufgabe. Auf die begrenzte Aussagefăhigkeit dieses Instrumentariums und die damit verbundene Abgrenzungsproblematik wegen des breiten Unbestimmtheitsbereiches, der vom Ausmaß der externen Effekte abhängig ist, läßt er sich jedoch nicht weiter ein. Ebensowenig verfolgt er die wegen ihrer Bedeutung für die Aufgabenverteilung wichtige Erkenntnis weiter, daß meritorische Aspekte auf 
kollektiven Wertvorstellungen beruhen, die hauptsächlich auf das Sozialstaatsprinzip, daneben auch auf andere Grundentscheidungen der Verfassung, zurückgehen.

Der Vorschlag Kirbergers, Ansatzpunkte für die Verteilung der Aufgaben da zu suchen, wo die kollektiven Grundentscheidungen für das zusammenleben in der Gesellschaft niedergelegt sind, nämlich in der Verfassung, sowie die Berücksichtigung anderer Entscheidungsmechanismen, die kollektive Wertvorstellungen erzeugen, weist in die richtige Richtung. Es mangelt seinem Ansatz aber daran, daß die Staatsziele nicht deutlicher herausgestellt und diese nicht mit den ökonomischen kriterien in verbindung gebracht werden. So wie sich seine Lösung darstellt, muß gerade in den problematischen Fällen die Bestimmung der einzelnen Aufgaben als "öffentlich" oder "staatlich" unbestimmt bleiben. Allerdings hatte Rirberger auch nicht die Absicht, die als kollektiv lösungsbedürftig ermittelten Aufgaben danach zu unterscheiden, ob sie nun vom Staat oder von anderen gesellschaftlichen Trägern erfüllt werden sollen. Für seine Fragestellung genügt die von ihm vorgenommene Trennung in öffentliche und private Güterbereitstellung.

Einen Ausschnitt aus dem breiten Spektrum der Aktivitäten gesellschaftlicher Gruppierungen haben Ulrich Schmoltzi und Hans Heinrich Nachtkamp betrachtet ${ }^{39}$ ). Sie untersuchen das Angebot der teilweise altruistisch motivierten privaten organisationen ohne Erwerbscharakter in den Bereichen, in denen es von staatlicher Seite gewünscht und deshalb unterstützt wird, und vergleichen es mit dem des Staates. Dabei kommen sie zu dem Ergebnis, daß diese Organisationen eher in der Lage sind als der Staat, die heterogenen Bedürfnisse der Nachfrager über ein vielfältiges Angebot zu befriedigen. Bei den angebotenen Gütern handelt es sich um Mischgüter, die nicht unbedingt eine staatliche Bereitstellung erfordern. Ob in einer pluralistischen Gesellschaft von diesen Organisationen ein den verschiedenen individuellen Interessen gerecht werdendes, differenziertes Angebot erfolgen kann, wird anhand der Guts- 
merkmale Grad der Konsumrivalität und Anwendbarkeit des Ausschlußprinzips überprüft. Schmoltzi zeigt dann, wie dies bei entsprechender staatlicher Unterstützung möglich ist ${ }^{40}$ ).

Die von Schmoltzi und Nachtkamp angestellten tuberlegungen führen scheinbar zu Ergebnissen, die über das hinausreichen, was gemeinhin mit Hilfe der von ihnen verwendeten Kriterien Konsumrivalität der Güter und Anwendbarkeit des Ausschlußprinzips ausgesagt worden ist. Dies liegt daran, daß sie davon ausgehen, daß der Staat die Externalitäten (zumindest teilweise) durch finanzielle Unterstützungen internalisiert. Die Grundfrage aber, warum und bei welchen Gütern es sich um einen erwünschten Bedarf handelt, der den Staat zu Interventionen veranlaßt, bleibt ungeklärt. Allerdings muß gesagt werden, daß es den beiden Autoren in erster Linie gar nicht um diesen Aspekt geht, sondern daß sie vor allem aufzeigen wollen, daß in dem betrachteten Bereich die Allokationseffizienz durch geeignete Finanzierungsformen gesteigert werden kann. 
Peter Saile - 978-3-631-75214-2

Downloaded from PubFactory at 01/11/2019 07:01:15AM

via free access 
II. Die "Gemeinwirthschaften" in der älteren finanzwissenschaftlichen Literatur

1. Die Natur der Bedürfnisse und die Bildung von Kollektiven

Die ökonomische Analyse der intermediären Finanzgewalten bliebe unvollständig, wenn auf die älteren finanzwissenschaftlichen Beiträge zur Erklärung der verschiedenen Formen des Wirtschaftens verzichtet würde. Gerade die deutschsprachigen Staatswirtschaftler des vergangenen Jahrhunderts haben dazu Wesentliches beigetragen. Ihr Hauptanliegen bestand darin, die Notwendigkeit der Staatstätigkeit $\mathrm{zu}$ begründen. $\mathrm{Zu}$ diesem $\mathbf{Z w e c k}$ haben sie alle Formen des privaten und kollektiven wirtschaftens daraufhin untersucht, welche Bedürnisse mit ihnen jeweils befriedigt werden können. Diese älteren Autoren sind deshalb besonders interessant, weil sie in ihre Überlegungen ausdrücklich politische und gesellschaftliche Leitvorstellungen mit einbezogen und sich - im Gegensatz zu den neueren Ansätzen, die zwar in theoretischer Hinsicht tiefer gehen - nicht mit einer rein ökonomischen Beurteilung zufriedengaben. Hervorzuheben ist besonders, daß sie die unterschiedlichen Motive und Antriebskräfte bei den einzelnen Formen des Wirtschaftens herausgearbeitet haben. In den folgenden Ausführungen beschränken wir uns auf die für unser Problem relevanten Aussagen zu den Unterschieden des staatlichen und nichtstaatlichen kollektiven Wirtschaftens.

Gleichwohl erscheint es uns angebracht, auf die Begründungen für die Staatstätigkeit ausführlicher einzugehen, weil damit aufgezeigt werden kann, was letztendlich ausschlaggebend für die staatstätigkeit ist und welche Abgrenzungskriterien zum nichtstaatlichen Bereich sich daraus ergeben.

Die Frage nach Art und Umfang der wirtschaftlichen Staatstätigkeit war und ist noch immer eines der zentralen probleme der Finanzwissenschaft. Es waren zwei geistige Strömungen, der Liberalismus und die organische staatsauffassung, die maßgeb- 
lich das Denken über die wirtschaftliche Rolle des Staates beeinflußt haben.

Die vom Gedankengut des Liberalismus geprägten, vornehmlich angelsächsischen Ökonomen weisen dem Staat nur wenige Grundfunktionen $\mathrm{zu}^{41}$ ). Ihre Staatsauffassung wurzelt in der von individualistischen Vorstellungen ausgehenden Fiktion eines "Gesellschaftsvertrages". Danach verfügt der Staat nur über diejenigen Rechte, die ihm die Bürger im Gesellschaftsvertrag abgetreten haben, um ein geregeltes zusammenleben im Gemeinwesen zu ermöglichen ${ }^{4}$ ). Die Aufgaben des Staates, der dadurch zum "Nachtwächterstaat" degeneriert, begrenzen sich auf den Schutz gegen äußere Feinde und die Rechtssicherheit im Innern ${ }^{43)}$. Die Staatswirtschaft ist nach dieser Auffassung ein unproduktives tubel, und folglich war das kleinste Budget auch zugleich das beste ${ }^{44}$ ). Die Kollektivwirtschaft weist keine Unterschiede zur Privatwirtschaft auf. Die Beziehungen zwischen Staat und Individuum erfolgen analog zum marktwirtschaftlichen Tauschvorgang. Die aus der Konstruktion des Gesellschaftsvertrages abgeleiteten Äquivalenzvorstellungen sahen in den Abgaben nur den Preis für den vom Staat bereitgestellten Schutz ${ }^{45)}$.

In krassem Gegensatz zu dieser individualistischen vertragstheorie standen die zu Beginn des 19. Jahrhunderts in Deutschland aufkommenden idealistischen Gedanken zu wesen und Zweck des Staates. Insbesondere Georg Wilhelm Friedrich Hegels Staatsphilosophie hat auf die Finanzwissenschaft in jener zeit mit deren hervorragenden Vertretern Lorenz von Stein, Albert E. Fr. Schäffle und Adolph Wagner einen nachhaltigen Einfluß ausgeübt 46 ). Der Staat war für Hegel die "Personifikation der ganzen sittlichen Gemeinschaft", er war nicht nur eine "willkürliche Bildung", sondern eine "unumgängliche Bedingung und zugleich höchste Form des gesellschaftlichen Zusammenlebens der Menschen"47). Das Dasein des einzelnen gewinnt durch die Unterordnung unter die überpersönlichen Mächte, die sich im Staat vervollkommnen, erst an Sinn und wert ${ }^{48}$ ). 
Zumeist wurde - insbesondere in der älteren Finanzwissenschaft - bei der Bestimmung der Staatstätigkeit von der Theorie der Kollektivbedürfnisse ausgegangen ${ }^{49}$ ). Kurt schmidt ${ }^{50}$ ) hat in einem dogmengeschichtlichen Abriß der "Lehre von den Kollektivbedürfnissen" die grundlegenden Ansätze daraufhin untersucht, inwieweit sie einer Abgrenzung der öffentlichen (im Sinne von staatlichen) von der privaten Wirtschaft dienlich sind. Die vorgefundenen Auffassungen, die sich vor allem darin unterscheiden, wer die Bedürfnisse empfindet, können danach in drei grundsätzliche Kategorien eingeordnet werden. Bei der ersten ist es die Gemeinschaft, bei der zweiten das Individuum als Mitglied oder im Interesse der Gemeinschaft und bei der dritten das Individuum selbst, die als Träger der Bedürfnisse angesehen werden 51 ).

Kollektive als Träger von Bedürfnissen sind bei den stark von der organizistischen Staatsauffassung geprägten Ansätzen anzutreffen. Schmidt ${ }^{52}$ ) zählt zu ihren Hauptvertretern Friedrich B. W. von Hermann 53) und Carl Menger 54). Beide55) vertreten die Ansicht, daß es Bedürfnisse gibt, die der einzelne nicht als Individuum empfindet, sondern nur die Gemeinschaft als solche. Es handelt sich dabei um Bedürfnisse, die eine zu einer "höheren Einheit organisierte Personenmehrheit" hat, die also eine eigene Persönlichkeit besitzt. Bedürfnisse dieser Art sind z.B. Landesverteidigung und Rechtspflege. Diese beiden Güter, wie auch andere, die zwar ursprünglich auf Privatbedürfnissen beruhten, jedoch von nahezu allen Staatsbürgern geäußert werden, werden zweckmäßigerweise mittels "collectiver Anstalten" befriedigt ${ }^{56}$ ). Für die Abgrenzung von staatlichen und privaten Aufgaben sind diese Ansätze indessen wenig geeignet. Der Grund liegt darin, daß Bedürfnisse nicht von Kollektiven, sondern nur von Individuen empfunden werden können ${ }^{57}$ ).

Diese Kritik versuchten die Vertreter der zweiten Gruppe zu berücksichtigen, bei denen das Individuum als Glied eines Kollektivs besondere Bedürfnisse hat. Hier sind vor allem Emil Sax, Hans Ritschl, Franz Cuhel und Edwin R. A. Seligman zu nen- 
nen 58). Charakteristisch für diese Gruppe ist, daß die ihr zugehörigen Autoren "... das Bedürfnis zwar als eine individuelle Regung ansehen, zugleich aber betonen, daß das Einzelwesen als Glied oder Teil der Gemeinschaft in ihrem Interesse oder durch sie geformt, gewissermaßen aus sich selbst heraustretend oder über sich selbst hinwegsehend, Bedürfnisse besonderer Art, eben Kollektivbedürfnisse, empfinden könne."59) Für Sax kann nicht "... das Abstractum Staat .. zwecke setzen, empfinden und handeln, sondern nur die concreten beseelten Individuen, seine Elemente, vermögen dies". Diese Kollektivbedürfnisse entwickeln die Individuen zusammen mit einer vielzahl von Individuen, die sich in ihrer "Gesammtheit Lebenszwecke setzen". Das Kollektivbedürfnis resultiert folglich aus der "collectivistischen Zusammengehörigkeit"60).

Bei Ritschl sind die besonderen Bedürfnisse die Gesamtheitsbedürfnisse, die ihren Ursprung in der Korporation haben. Die Korporation als zwangsgemeinwirtschaft selbst kann, weil sie keine Psyche hat, keine Bedürfnisse empfinden; sie handelt durch ihre Organe $\left.{ }^{61}\right)$. Das eigentliche Subjekt der Finanzwirtschaft ist "... die ideelle und doch tatsächliche Einheit der Gesamtheit, die hinter der Korporation steht, in der sie nur ihre organisation ... schafft ... So ist ... nicht der Staat das eigentliche Subjekt der Staatswirtschaft, sondern das im Staat geeinte Staatsvolk, die Volksgemeinschaft"62). Dabei ist die Gesamtheit nicht die Summe der Individuen, sondern eine "überindividuelle Gemeinschaft", die unabhängig vom einzelnen diesen überdauert ${ }^{63}$ ). Dem zweck der Gesamtheit, "der allseitigen Förderung des nationalen Lebens, der Wahrung der Unabhängigkeit und Freiheit, der inneren Ordnung des Staates, der Förderung des Ganzen und der Teile", entspringen "objektive Bedürfnisse", die "objektiven Gesamtheitsbedürfnisse"64). Als Träger der Gesamtheitsbedürfnisse tritt nicht das "... vereinzelte Individuum mit seinen egoistischen Interessen (auf; der Verf.), sondern (es erscheint; der Verf.) als das Glied der Gemeinschaft, insoweit es sich als solches fühlt und unabhängig von sich überhaupt für die Gemeinschaft fühlt, empfindet, denkt 
und handelt"65). Dieses Empfinden des einzelnen als Glied der Gemeinschaft für die Gesamtheit, das nach Schmidt Cuhel66) als "Wir-Vorstellung" und Seligman 67) als "Idee der Verpflichtung" und "Gefühl der Loyalität" bezeichnen, nennt Ritschl den "Gemeinsinn", der darin zum Ausdruck kommt, daß das Individuum seine eigenen Interessen hinter die der Gesamtheit zurückstellt und somit für diese opfer bringt ${ }^{68)}$ ).

Von den "Gesamtheitsbedürfnissen" unterscheidet Ritschl die "Sammelbedürfnisse". Es handelt sich dabei um Individualbedürfnisse, zu deren Befriedigung sich mehrere Individuen freiwillig - Ritschl nennt diese freien Gemeinwirtschaften "Assoziationen" - zusammenschließen. Am Charakter dieser Sammelbedürfnisse ändert sich selbst dann nichts, wenn der Staat die Bedarfsdeckung übernimmt ${ }^{69}$ ). Für Ritschl liegt der Grund für den zusammenschluß von mehreren Individuen darin, daß diese Individuen gemeinsame Zwecke verfolgen und daß der Umfang der zu deren Verwirklichung notwendigen Mittelverwendung in diesem Falle die wirtschaftliche Kraft des einzelnen übersteigt ${ }^{70}$ ).

Diese Definition von Ritschl schließt allerdings einen sehr großen Kreis von Aktivitäten ein, wie an den von ihm genannten Beispielen deutlich wird. Er zählt dazu etwa Sportvereine, Genossenschaften, Konsortien, Gesellschaften u.ä. ${ }^{71)}$. Damit erfaßt er primär Bereiche, die heute eindeutig dem marktwirtschaftlichen Sektor zugeordnet werden.

Die gerade angeführten Ansätze gehen vom Individuum als einzig möglichem Träger von Bedürfnissen aus. Indessen müssen die Individuen - sieht man von den Sammelbedürfnissen bei Ritschl einmal ab - besondere Eigenschaften aufweisen, um solche Kollektivbedürfnisse empfinden zu können. Dem einzelnen, und darin liegt der Haupteinwand gegen diese Ansätze, wird eine idealistische Verhaltensweise unterstellt. Diese Schwäche sehen die Vertreter dieser Auffassungen selbst, wenn sie, wie wir später sehen werden, einschränkend zugeben, daß dieser 
"Gemeinsinn" nicht bei allen gleich ausgeprägt ist und deshalb Zwang zur Durchsetzung der Gesamtinteressen erforderlich ist.

Für die Vertreter der dritten Gruppe ist das einzelne Individuum - ohne spezielle Bindung an ein Kollektiv und nicht stellvertretend für es - Träger der Bedürfnisse. Die Verknüpfung von individuellem Bedürfnis und kollektivem Handeln und damit staatlichen Aktionen versucht ein Teil der Autoren (u.a. Adolph Wagner, Antonio De Viti De Marco) über den Ursprung der Kollektivbedürfnisse, ein anderer Teil (Friedrich von Wieser, Erik Lindahl, Margit Cassel, Richard A. Musgrave) über die Befriedigung der Bedürfnisse herzustellen ${ }^{72}$ ).

Adolph Wagner ${ }^{73)}$ unterscheidet zwischen den auf dem "physischgeistigen Wesen des Einzelnen" beruhenden "Individualbedürfnisse(n)" und den Gemeinbedürfnisse(n) (Collectivbedürfnisse(n))", die "beim Einzelnen aus dessen Angehörigkeit zu menschlichen Gemeinschaften" resultieren und die "... daher eine Consequenz der socialen (gesellschaftlichen) Natur des Menschen" sind. Bei den weiteren Ausführungen Wagners könnte man zunächst den Eindruck gewinnen, daß er der gerade erwähnten zweiten Gruppe zuzuordnen sei. Er fährt nämlich fort, daß die "zunächst wesentlich natürlichen Gemeinschaften" (Familien, Geschlecht, volk, Staat usw.) das isolierte Individuum mit "sittlichen Rechten und Pflichten" an sich binden und damit zu einem Teil bzw. "Glied der Gemeinschaft" machen, als deren "Glied" er sich dann auch fühlt74). Die Gemeinschaft verfolge zwar bestimmte Zwecke und sei das "Höhere, Wichtigere und Dauernde", dann betont er jedoch, daß sie "... stets Mittel für die Zwecke des Einzelnen", nicht aber "Selbstzweck" sei ${ }^{75}$ ).

Die Gemeinschaftsinteressen sind auch die "wahren Interessen des Individuums" und gehen, als "Gemeinschaftszweck" gesetzt, den "Individualzwecken" vor. Dabei darf nicht übersehen werden, daß der "Gemeinschaftszweck" diejenigen Individualzwecke enthält, die der einzelne nur als Glied und zusammen mit der Gemeinschaft erfüllen kann ${ }^{76}$ ). Damit gelangt wagner schließlich 
zu einer genaueren Begriffsfassung der Gemeinbedürfnisse: "Es sind solche Bedürnisse, welche die Individuen als Glieder menschlicher Gemeinschaften empfinden, denen sie von Natur und gezwungen oder nach freier Wahl angehören ...; Bedürfnisse ferner, welche sie um ihrer selbst, wie um der Anderen, mit ihnen die betreffende Gemeinschaft bildenden Individuen und um dieser Gemeinschaft Willen befriedigt haben wollen und müssen; und Bedürfnisse endlich, deren Befriedigung es allein möglich macht, dass ein gesellschaftliches zusammenleben, ein wirthschaftliches Zusammenwirken menschlicher, mit eigenem willen begabter Einzelwesen ... stattfinde, ohne allzu störende Reibungen und feindliches Gegeneinanderwirken, als Folge von individuellen Willens- und Handlungsconflicten und mit möglichst zweckmässigen Füreinander-Wirken, als Folge gemeinsamer Willens- und Handlungsrichtung auf die Gemeinschaftszwecke hin, sodass die Interessen der Gemeinschaften und ihrer Glieder thunlichst gefördert werden." Die Gemeinbedürfnisse weisen damit "... durch ihre Natur ..." auf eine Befriedigung durch das "... gemeinwirthschaftliche Princip und System ..." hin. 77)

Außer den Individual- und den reinen Gemeinbedürfnissen führt Wagner als dritte, gegenüber letzteren eher verschwommen abgegrenzte Spezies die "gesellschaftliche( $n)$ oder Classen(Gruppen-)Gemeinbedürfnisse" an. Das sind Bedürfnisse, "... welche aus der Gemeinsamkeit eines wichtigeren Interesses entstehen, das hier eine Anzahl von Personen (aus physischen, wirtschaftlichen, geistigen, sittlichen und religiösen Interessen, der Verf.) zu einer Interessengruppe verbindet und dieselben eben dadurch von anderen Gruppen und Einzelnen trennt" 78). Diese Bedürfnisse würden deshalb in gemeinsamen Veranstaltungen und Einrichtungen befriedigt ${ }^{79}$ ).

Ohne nähere Erläuterungen über die Motive und die Triebkräfte dieser "Gruppen-Gemeinbedürfnisse" trifft indessen das für Ritschl bei den Sammelbedürfnissen Gesagte ebenfalls zu, daß nämlich die Spannweite der darunter fallenden Aktivitäten sehr groß ist. 
Eine verwandte Auffassung zu Wagner vertritt Antonio De Viti De Marco. Während die Produktion der Privatwirtschaft der Befriedigung individueller Bedürfnisse dient, hat die staatstätigkeit die Befriedigung der Kollektivbedürfnisse zum Betätigungsfeld, d.h., die Staatstätigkeit fußt auf dem Kollektivbedürfnis ${ }^{80}$ ). Letzteres entsteht in einem Gemeinwesen "... infolge der Tatsache des gesellschaftlichen Zusammenlebens"81), setzt also das Vorhandensein eines Kollektivs voraus. In diesem Fall treten zu den individuellen Bedürfnissen solche hinzu, die aus dem zusammenleben mit anderen resultieren. Das ist zum einen das Bedürfnis nach einer Rechtsordnung, die dem Schutz des einzelnen und seiner Güter gegenüber den anderen Mitgliedern der Gemeinschaft dient, zum anderen das Bedürfnis des Schutzes und der verteidigung nach außen.

Aber auch diese Bedürfnisse können nur vom einzelnen empfunden werden. Zum Kollektivbedürfnis werden diese individuellen Bedürfnisse dadurch, daß sie von einer vielzahl in gleicher Weise geäußert werden, so möchte beispielsweise jeder vor dem anderen geschützt werden 82 ). Hierin klingt bereits der "zweite Wesenszug" der Kollektivbedürfnisse bei De Viti De Marco an, der darin besteht, "... daß sie aus irgendeinem 'Interessengegensatz' entstehen, der zwischen den Gruppen der nationalen oder internationalen Kollektivität hervortritt"83).

Der andere Teil von Autoren dieser dritten Gruppe sieht keine Unterschiede zwischen Individual- und Kollektivbedürfnissen. Für sie gibt es keine verschiedenen Bedürfniskategorien, sondern nur eine unterschiedliche Befriedigung der Bedürfnisse. Ob ein Gut privat oder staatlich bereitgestellt wird, hängt nach ihrer Auffassung von den Gutsmerkmalen ab, die den Charakter eines Gutes als Individual- oder Kollektivgut ausmachen ${ }^{84)}$. Da die Arbeiten dieser Autoren ihren Niederschlag in der Theorie der öffentlichen Güter gefunden haben, die später noch ausführlich erläutert wird, können wir es an dieser stelle bei einer kurzen skizzierung belassen. 
Schon Friedrich von wieser betonte, daß es nicht auf "die Natur des Bedürfnisses" ankomme, ob ein Bedürfnis individuell oder kollektiv befriedigt werde. So würden häufig Interessen mit kollektiver Bedeutung von privater Seite wahrgenommen, während andererseits in einem kommunistischen staatswesen alle Individualbedürfnisse vom staat befriedigt würden 85 ). Er sieht die eigentliche Ursache für die kollektive Güterbereitstellung darin, daß die Kraft eines einzelnen oft nicht ausreiche, bestimmte Bedürfnisse zu befriedigen. Kollektive bilden sich seiner Meinung nach dann, wenn zur Erreichung "gewisse(r) Erfolge" eine "innigere Art der Verbindung", eine "wahre Gemeinsamkeit", erforderlich sei ${ }^{86}$ ).

Die weiteren Vertreter dieser Gruppe können dahin zusammengefaßt werden, daß sie auf die Besonderheiten des Konsums bei diesen Gütern abstellen. Erik Lindahl zufolge empfinden die Individuen die Kollektivbedürfnisse, die aber nach deren Auffassung durch den Staat befriedigt werden sollten. Der Grund für die staatliche Befriedigung liegt in der Gemeinsamkeit der Konsumtion und Produktion der entsprechenden Güter. Die Notwendigkeit der staatlichen produktion und nicht derjenigen eines beliebigen Kollektivs führt er darauf zurück, daß alle Mitglieder der Gemeinschaft das betreffende Gut konsumieren. Weil nun von der Konsumtion niemand ausgeschlossen werden kann, darf sich auch niemand um den Beitrag zur Produktion, einschließlich der Finanzierung, drücken; notfalls muß das durch staatlichen Zwang verhindert werden 87 ).

Der heute gebrauchten Definition für öffentliche Güter kommt nach Schmidt Margit Cassel bereits sehr nahe $\left.{ }^{88}\right)$. Das charakteristische Merkmal der nichtindividuellen Güter ist für sie der gemeinsame Konsum eines Gutes durch eine Vielzahl von Personen. Kollektivgüter bilden bei ihr eine spezielle Form der nichtindividuellen Güter und zeichnen sich durch passiven Konsum aus. Passiver Konsum bedeutet, daß bei diesen Gütern kein Preismechanismus anwendbar ist. Am deutlichsten wird das bei der wichtigsten Gruppe der Güter des passiven Konsums, bei den un- 
teilbaren Kollektivgütern, deren Nutzung bis zum Erreichen einer gewissen Grenze beliebig ausgedehnt werden kann, ohne daß die Kosten für die Produktion steigen. Da die Preisbildung bei diesen Gütern versagt, müssen die auf sie gerichteten Bedürfnisse von der Gemeinwirtschaft befriedigt werden, weil sonst kein oder nur ein unzureichendes Marktangebot erfolgt ${ }^{89}$ ). Hinter diesen Vorstellungen verbirgt sich nichts anderes als die unter das Stichwort "Marktversagen" fallende Rechtfertigung für staatliche Aktivitäten.

Eine weitere Ursache für die öffentliche Bereitstellung von Gütern liegt für Cassel vor, wenn die "individuelle Wertsetzung", also die individuellen Präferenzen, wie sie in der Preisbildung zum Ausdruck kommen, von dem "sozialen Wert" als dem höherwertigen staatlichen ziel abweichen. In diesem Falle ist ihrer Auffassung nach eine Ausdehnung der Gemeinwirtschaft ebenfalls gerechtfertigt ${ }^{90}$ ). Unterschwellig klingt hier schon der später von Richard A. Musgrave ${ }^{91}$ ) in die Diskussion gebrachte Begriff der meritorischen Bedürfnisse an. Den von Cassel angesprochenen Grundgedanken der Orientierung am "sozialen Wert" werden wir im Kapitel D bei der Diskussion des Öffentlichkeitsgrades und dessen Orientierung am Allgemeinwohl aufgreifen. Musgrave war es dann auch, der eine neue Diskussion mit seinen "social wants" und "merit wants" auslöste, die wir uns im folgenden bei der Theorie der öffentlichen Güter genauer ansehen werden.

Insgesamt wurde aber in diesem Abschnitt deutlich, daß der Versuch, allein über die Art der Bedürfnisse auf die Träger der Bedarfsdeckung zu schließen, nicht ausreicht. Um die verschiedenen Formen des kollektiven Wirtschaftens deutlich zu machen, ist es vielmehr unabdingbar, die Motive und Triebkräfte heranzuziehen, die zur Bildung von Kollektiven führen. 
2. Kollektive Befriedigung von Bedürfnissen

Kollektive als Zusammenschlüsse mehrerer Individuen dienen der Befriedigung verschiedenartiger gemeinsamer Bedürfnisse. Je nach Art der Bedürfnisse sind es unterschiedliche Motive der Individuen, die maßgeblich für das Zustandekommen eines Kollektivs sind. Albert E. Fr. Schäffle, Friedrich von Wieser, Adolph Wagner, Emil Sax und, darauf aufbauend, Hans Ritschl und Antonio De Viti De Marco haben insbesondere versucht, die treibenden Kräfte bei der Befriedigung der kollektiven Bedürfnisse herauszustellen und daraus die organisationsformen für die Bereitstellung der Kollektivgüter abzuleiten.

Albert E. Fr. Schäffle $e^{92)}$, dessen Werk stark von Georg Wilhelm Friedrich Hegels Staatsphilosophie geprägt war ${ }^{93)}$, unterscheidet drei verschiedene wirtschaftliche Organisationsformen. An erster stelle nennt er die von der "öffentlichen Gewalt konstituirten, meist zwingenden wirthschaften". Diese

"Zwangsgemeinwirthschaften" umfassen neben dem Staat und den Gemeinden auch alle übrigen Haushalte öffentlicher Verbände und Anstalten. Die zweite Form sind die "Privatwirthschaften", die die aus "freiem Antrieb von Individuen" resultierenden "Individual-Wirthschaften" und die durch Vertrag entstandenen "Collectiv-Wirthschaften" umfassen. Zu letzteren, den "freien Gemeinwirthschaften", zählt er Vereine, Genossenschaften und Gesellschaften. Als dritte, uns nicht weiter interessierende Gruppe führt er die "Familienwirthschaften" an. Die treibenden Kräfte, die das Entstehen und den zusammenhalt der verschiedenen Wirtschaftsformen bewirken, sind bei ihm Liebe und Gemeinsinn oder/und Sonderinteresse ${ }^{94}$ ).

Die größte Bedeutung mißt er ohne Zweifel den "öffentliche(n) Wirthschaften" oder "Zwangsgemeinwirthschaften" bei, die nur durch staatliche Mitwirkung gegründet oder aufgelöst werden und sich der staatlichen Aufsicht nicht entziehen können95). Das Zwangsmoment und die übergeordnete Rolle des Staates in bestimmten Bereichen hält er für unumgänglich, weil nur so be- 
stimmte Wirtschaftsorganisationen "zum allgemeinen Besten" wirken können, da für "eine Vielzahl von Gemeinschaftszwecken" ein "einheitliche(r) Collectivwille" als "Anstifter" erforderlich sei. Dafür reicht aber oft der "gute Wille, das Verständniß und das Sonderinteresse der Privaten" nicht aus ${ }^{96}$ ). Interessant ist bei Schäffle die Begründung für die staatliche Befriedigung der "... mit der Civilisation wachsenden Gemeinbedürfnisse", die deshalb meist nicht von den Privaten befriedigt werden könnten, "... weil sie nicht individuell vergolten werden, weil der Werth der einzelnen Nutzung nicht ermittelt werden kann, weil die Organisation über die Kraft des Privatkapitals hinausgeht, ..., weil nachhaltige Interessen der ungeborenen Generationen jezt schon versorgt werden müssen, weil oft Kapitalkraft allein zur Leistung nicht ausreicht, sondern nur öffentliche Autorität, die aber von der speculation egoistisch ausgebeutet werden würde, - endlich weil im besonderen Fall Hingebung, Liebe, Begeisterung allein die Organisation bewirken und handhaben kann"97). Schäffle deutet hier bereits einen Großteil der Gründe an, die später wieder von der Theorie der öffentlichen Güter als ursächlich für das Marktversagen und die Notwendigkeit der Staatstätigkeit angesehen werden.

Die "freien Gemeinwirthschaften" fußen bei Schäffle nicht auf Zwang, sondern auf dem freien willen, dem Vertragswillen mehrerer. Dazu zählen einerseits die auf einseitiger oder wechselseitiger Hingebung beruhenden Vereine und Genossenschaften. Die wechselseitige Hingebung bzw. Solidarität äußert sich beispielsweise in der Verfolgung solidarischer Interessen, der Förderung von Standesinteressen, der wechselseitigen Sicherung und der Vertretung von gemeinsamen politischen und religiösen Überzeugungen. Mit der einseitigen Hingebung beziehungsweise Liberalität meint Schäffle "Wohlthätigkeit (caritas)", Widmungen, humanistische Bestrebungen, Hingebung an den "gemeinen Nuzen" und insbesondere kirchliche Aktivitäten98). Zu den "freien Gemeinwirthschaften" zählen andererseits aber auch die nach egoistischen, erwerbswirtschaftlichen Motiven handelnden Erwerbsgenossenschaften 99 ). Die Aufgabenverteilung zwischen die- 
sen verschiedenen "Sonderwirthschaften" ist für ihn indessen nicht fest vorgegeben; denn im Zeitablauf ändern sich zum einen die Vorstellungen über die Befriedigung der Gemeinbedürfnisse, und zum anderen unterliegen die Gemeinbedürfnisse selbst dem zeitlichen Wandel. Deshalb sind laufende Veränderungen innerhalb der "Sonderwirthschaften" möglich100).

Friedrich von Wieser führt für die Bildung staatlicher Kollektive drei Gründe an, "... die die Erreichung eines bestimmten Erfolges von der Bildung collectiver verbände und der Durchführung gemeinschaftlicher Aktionen abhängig machen können"101). Der erste Grund für die Staatstätigkeit liegt für ihn in der "Art der Leistung". "Den Staaten ist von Anfang an die Aufgabe zugefallen, in solchen Stücken das gemeine Wohl zu vertreten, wo nur das solidarische zusammenstehen vieler oder Aller ein Mittel bot, um die den zerstreuten Individuen fehlende Kraft zu schaffen". Aufgaben also, "... für welche nur die vereinigende Kraft Aller ausreicht". Als Beispiele für solche Leistungen, die "gemeinsam vollzogen", überwiegend "gemeinsam getragen" und "gemeinsam genossen" werden, nennt er den Schutz nach außen und die innere Rechtssicherheit.

Ohne der eigentlichen Ursache, den Gutseigenschaften, tiefer auf den Grund zu gehen, charakterisiert von Wieser diese Leistungen wegen ihrer "grössten Wichtigkeit" und ihres "grössten Umfangs" mit dem Merkmal der Unteilbarkeit, indem er anführt, daß es nicht möglich sei, "... den im Grossen herbeigeführten Erfolg einzeln zuzutheilen oder auch nur nach seinen wirkungen zu verrechnen", und daß es notwendig sei, "... ihn allgemein zugänglich zu machen, beziehungsweise der Allgemeinheit ohne weitere Unterscheidung anzurechnen"102).

Als zweiten Grund nennt er Aufgaben, die für die Allgemeinheit wichtig sind und die von der Privatwirtschaft wegen mangelnder Rentabilität nicht wahrgenommen werden. Drittens und endlich sind es wirtschaftliche Monopol- und Machtstellungen, die zu verhindern den staat auf den Plan rufen 103). Mit diesen Aspek- 
ten umschreibt von Wieser zwar wichtige staatliche Funktionen, gleichwohl taugen die von ihm aufgezählten Anlässe wenig für die Aufgabenzuordnung, weil ihnen letztlich die notwendige Konkretisierung fehlt, um einen brauchbaren Maßstab abzugeben.

Für Adolph Wagner weisen die "Gemeinbedürfnisse" "... durch ihre Natur" auf ein ganz bestimmtes Prinzip der Bedürfnisbefriedigung hin. Diese erfolgt mittels der sogenannten "Gemeingüter" über das "gemeinwirthschaftliche system" nach dem "gemeinwirthschaftliche(n) Princip" und nicht nach den "immerhin mit anwendbaren privatwirthschaftlichen und caritativen" Systemen und Prinzipien. Das "caritative" Prinzip ist im wesentlichen auf den privaten sektor beschränkt ${ }^{104}$ ).

Der privaten Versorgung mit Gemeingütern gegen Entgelt räumt er lediglich begrenzte Möglichkeiten ein. Nur "ein beschränkter und nicht der wichtigste Theil dieser Bedürfnisse" läßt eine solche Befriedigung $\left.\mathrm{zu}^{105}\right)$. Sie kommt allenfalls für kleinere räumlich oder gesellschaftlich abgegrenzte Nutzerkreise in $\mathrm{Be}-$ tracht, wie dies z.B. bei Privatschulen der Fall ist. Je größer die Nutzerkreise sind, "un so ausschliesslicher" müsse das gemeinwirtschaftliche system eintreten. Gegen eine Bereitstellung von Gemeingütern nach dem privatwirtschaftlichen Prinzip führt er an, daß viele dieser Güter an anderen als rein ökonomischen Kriterien gemessen werden müßten. Außerdem sei für die Erzeugung dieser Güter hăufig ein hoher finanzieller Aufwand erforderlich und die Herstellung bedinge die Konzentration in "einer oder wenigen Anstalten", die bei privater Bereitstellung die Gefahr der Entstehung von Monopolen heraufbeschwören würden 106). Schließlich sei ein Großteil der Gemeingüter für die gesamte Bevölkerung von so wichtiger Bedeutung, daß sichergestellt sein muß, daß jedem die Befriedigung möglich ist. Bei privater Bereitstellung wären allerdings weite Teile der Bevölkerung von wichtigen Gemeingütern, wie z.B. Schulunterricht, ausgeschlossen, da sie - mangels Bildung nicht willens oder mangels fehlender finanzieller Mittel - nicht in der Lage wären, ihre Bedürfnisse zu befriedigen 107). Von 
"Gemeinwirthschaften" oder vom "caritativen System" könne das "privatwirthschaftliche Princip" allenfalls dort angewendet werden, wo "Einzelne ... allein oder in besonderem, in einem ungefähr messbaren Grade, mehr als Andere ..., als ... (die) Allgemeinheit" von einer Leistung partizipierten 108).

Die Aufgaben der "Gemeinwirthschaften" bestehen für Wagner zum einen darin, die Unvollkommenheiten, Härten und Disharmonien in der Bedürfnisbefriedigung eines Volkes auszugleichen, die das "privatwirthschaftliche System" erzeugt, (also das, was man modern mit der Korrektur der Marktergebnisse ausdrückt), und zum anderen in der Befriedigung der Gemeinbedürfnisse. Nach dem Entstehungsgrund unterscheidet er "zwei wesentlich verschiedene Classen", die"占reien und die Zwangsgemeinwirthschaften"109).

Die Zwangsgemeinwirtschaften als "ungleich wichtigere Classe der Gemeinwirthschaften" fußen auf "zwangsweisem Eingreifen einer mit hinlänglicher Macht ausgestatteten Autorität." Das Einzelinteresse wird um der Gesamtinteressen willen zurückgedrängt. "Die Fürsorge für die wichtigsten Gemeinbedürfnisse ... ist nur durch Zwangsgemeinwirthschaften zu erlangen". Er unterscheidet vier Arten von "Zwangsgemeinwirthschaften" . Neben dem Staat, den (Orts-)Gemeinden und Selbstverwaltungskörperschaften höherer Ordnung faßt er darunter auch diejenigen zusammen, die sich für "einzelne bestimmte Gemeinschaftszwecke aus der Kategorie der örtlichen und der gesellschaftlichen Gemeinbedürfnisse" in der geschichtlichen Entwicklung gebildet haben ${ }^{110}$ ).

Dem Zwang mißt Wagner bei den "Zwangsgemeinwirthschaften" eine doppelte Bedeutung bei. Der Zwang ist zum einen "als absolute Kategorie" für den Staat ein "absolutes Existenzmoment" und zum anderen "als historisch-rechtliche Kategorie" ein "Erziehungsmittel", das dann erforderlich wird, wenn das Selbstinteresse dominiert, also der "erforderliche sittliche Gemeinsinn" fehlt. Der Zwang als Erziehungsmittel soll positiv auf die Sitte, Gewohnheiten usw. einwirken und sich mit der zeit 
selbst überflüssig machen. Der zwang als unbedingtes "Existenzmoment" ist deshalb notwendig, weil die Interessen des einzelnen, der zwangsweise einem Kollektiv angehört, nicht immer gewahrt werden und weil er oft ausschließlich einseitige Leistungen an die Gesamtheit zu erbringen hat ${ }^{111}$ ). Die Notwendigkeit des staatlichen Zwangs begründet Wagner am Beispiel der wichtigsten Gemeinbedürfnisse und Gemeingüter Rechtsschutz und Schutz nach außen: "Solange Menschen 'Menschen' bleiben, (ist, der Verf.) ohne Zwang in den genannten Gemeinwirthschaften nichts zu erreichen"112). Der Zwang dient folglich der Sicherstellung der Befriedigung wichtiger Gemeinbedürfnisse.

Den Zwang als Erziehungsmittel hält Wagner außerdem bei "bestimmte( $n$ ) einzelne( $n$ ) Gemeinschaftszwecke(n)" für angebracht, bei denen das Erreichen des "vom wohl einer Gesammtheit (Gruppe) geforderten Gemeinschaftszwecks" durch einzelne vereitelt bzw. in Frage gestellt werden kann. Als Beispiele für diesen - in der neueren Theorie unter dem Stichwort meritorische Güter diskutierten - Bereich führt er das Impfwesen, den Deichbau und das Schulwesen an 113). Zwang ist für ihn aber auch erforderlich, wenn "die Theilnahme des Einzelnen an den Leistungen (Vortheilen) der Gemeinschaft nach der Natur der betreffenden Gemeingüter nicht wohl behindert werden kann", etwa bei den Gemeingutern Rechtsschutz und Deichbau ${ }^{114}$ ). Damit stellt Wagner praktisch auf nichts anderes ab als auf die Nichtrivalität des Konsums aufgrund der Unteilbarkeit bestimmter Güter. Zwang ist für ihn ferner dann bedingt zulässig, wenn zwar "specielle... Vortheile..." gewährt werden, diese aber im "Gesammtinteresse" liegen, wie z.B. bei der Arbeiterversicherung, die die Gefahr der Entstehung eines revolutionären Potentials in der Gesellschaft mindert. Schließlich sei Zwang ebenfalls berechtigt, wenn durch eine größere Zahl der Teilnehmer und Nutzer einer Gemeinschaftseinrichtung, wie zum Beispiel bei "Brandcassen", ökonomische Vorteile entstehen ${ }^{115}$ ). 
Er räumt allerdings ein, und steht damit vor dem bis heute von der Ökonomie nicht befriedigend gelösten und wohl auch nicht zu lösenden Problem, daß der richtige Bereich der "zwangsgemeinwirthschaftlichen" Betätigung kaum feststellbar sei. Wagner fordert daher eine Volksvertretung, die die Bereiche des Zwanges möglichst richtig bestimmen und in Verhandlungen mit den Vertretern der Autorität gemeinsam den Umfang und die Art der staatlichen Tätigkeit festlegen soll116).

Die "freien Gemeinwirthschaften" bei Wagner entstehen durch den freiwilligen Beitritt zu einem Kollektiv mit dem ziel, einen privaten Vorteil zu erlangen. Maßgebend ist also letztlich ein wirtschaftliches Selbstinteresse, das durch vereinte Kräfte entweder besser oder überhaupt erst befriedigt werden kann 117). Die "freien Gemeinwirthschaften" sind folglich denjenigen bei Schäffle vergleichbar, die auf Solidarität bzw. wechselseitiger Hingebung beruhen, denn Wagner schließt nicht aus, daß bei der Verfolgung des privaten Sonderinteresses gleichzeitig andere zielsetzungen, wie z.B. soziale Aspekte und gemeinnützige Motive, verwirklicht werden 118). Da der Sondervorteil des einzelnen nicht immer meßbar ist, tritt an die Stelle des "privatwirthschaftlichen Princips der speciellen Entgeltlichkeit .. das gemeinwirthschaftliche Princip der generellen Entgeltlichkeit von Leistung und Gegenleistung". An die Stelle des "isolierenden Princips des Einzelinteresses" tritt das "vereinigende Princip der Solidarität", zu dem allerdings weitere Ideale wie "sittliches Pflichtgefühl", "religiöse Motive" und "gemeinnützige Erwägungen" hinzutreten können ${ }^{119}$ ).

"Das Gebiet der freien Gemeinwirthschaften" ist für Wagner "vornehmlich dasjenige der gesellschaftlichen oder Classengemeinbedürfnisse". Die in diesen Bereichen angesiedelten Interessen vertrügen es kaum oder verböten es sogar, von "Zwangsgemeinwirthschaften", wahrgenommen zu werden, weil sie nur Teilen und nicht der gesamten Bevölkerung zugute kämen. Für Wagner gehört zu dem Betätigungsfeld der "freien Gemeinwirthschaften" die Befriedigung bestimmter "örtliche(r) und zeitli- 
che(r) Gemeinbedürfnisse". An Beispielen führt er insbesondere Versicherungsvereine auf Gegenseitigkeit, Genossenschaften u.ä. auf. Die "Sphäre der freien Gemeinwirthschaften" gegenüber den "Zwangsgemeinwirthschaften" und den "speculativen

Erwerbsgesellschaften" "nach einer ein für allemal giltigen Formel" abzugrenzen sei "natürlich" nicht möglich, weil die jeweils zur Anwendung kommende Wirtschaftsform stark von örtlichen und geschichtlichen Umständen abhinge ${ }^{120}$ ).

Schließlich werden Gemeinbedürfnisse durch das "caritative System" befriedigt. Die Triebkraft sieht Wagner in gleicher Weise wie Schäffle in der (einseitigen) "Hingebung", die sich vornehmlich in barmherzigen Werken im "Wohlthätigkeits- und Armenwesen" zeigt. Als weiteres Motiv für das "caritative System" nennt er auch die "Gemeinnützigkeit" als das "Wirken des Gemeinsinns". Darunter versteht wagner wohltätige Werke, die im öffentlichen Interesse sind, beispielsweise Kunststiftungen. Wagner geht davon aus, daß sowohl die Hingebung als auch die Gemeinnützigkeit im wesentlichen auf "den Trieb des inneren Gebots zum sittlichen Handeln" zurückzuführen seien ${ }^{121}$ ).

Wagner mißt dem "caritativen System" eine wichtige Bedeutung bei, weil es im Vergleich zum inflexiblen gemeinwirtschaftlichen System und zum an diesem Bereich uninteressierten privatwirtschaftlichen system und aufgrund dessen, daß es individuell angesetzt werden kann, besonders dafür geeignet sei, die von den beiden anderen Systemen offengelassenen Lücken der Bedürfnisbefriedigung $\mathrm{zu}$ schließen ${ }^{122}$ ). Trotz dieser unbestreitbaren Vorteile des "caritativen Systems" weist Wagner allerdings auch darauf hin, daß dessen Wirken enge Grenzen gesetzt seien. Zum einen deshalb, weil häufig die materiellen Mittel nicht sehr weit reichten, und zum anderen, weil ein zu stark ausgeprägtes oder falsch verstandenes "caritatives SYstem" gesellschaftlich unerwünschte Folgen nach sich ziehen könne. Das ist etwa der Fall, wenn eine Gewöhnung an die Unterstützung eintritt und dadurch Selbsthilfe und eigene Vorsicht erlahmen, wenn Abhängigkeiten der Empfänger von den Ge- 
bern entstehen und/oder die Gefahr der Fehlleitung von Ressourcen droht ${ }^{123)}$.

Im großen und ganzen meinen Schäffle mit der "einseitigen Hingebung", Sax mit dem "Altruismus" und Wagner mit dem "Gemeinsinn" und der "Hingebung" bei der Beschreibung der dem "caritativen Princip" zugrundeliegenden Triebkrăfte allerdings weitgehend dasselbe. Strenggenommen ist das von einseitiger Hingebung geleitete karitative Handeln nur am Wohle anderer ausgerichtet, d.h., der Nutzen des Tuns fließt primăr demjenigen zu, auf den die Handlung bezogen ist, obwohl nicht übersehen werden darf, daß Geben und Schenken für den Gebenden ebenfalls eine Befriedigung sein kann und ihm insofern einen Nutzen stiftet. Unmittelbar klingt dieser Aspekt schon bei Wagner ${ }^{124}$ ) an. Er führt als Beispiel für das karitative Wirken im Bereich der Armen-, Kranken- und Waisenfürsorge oder etwa im Bildungsbereich insbesondere die katholische Kirche an. Allerdings hält er es für nicht ausgeschlossen, daß diese kirchlichen Aktivitäten stark geprägt und geleitet sein könnten vom religiösen Wert der guten Werke 125). Der "Gemeinsinn" ist hingegen nicht ausschließlich einseitig orientiert, sondern das zum wohle des allgemeinen Besten handelnde Individuum befriedigt damit zugleich eigene Bedürfnisse ${ }^{126}$ ).

Sax hat die kollektiven wirtschaften vornehmlich unter dem Blickwinkel der in diesen herrschenden Verhaltensweisen untersucht. Er versteht unter "Collectivismus" "... die Einordnung der Menschen in grössere, stabile Gruppen, welche sich im Verhältniss zu einander wie zu Individuen egoistisch, mutualistisch und altruistisch bethätigen, so dass der Einzelne nur als Mitglied der Gruppe und in Beziehung auf dieselbe in jenen Richtungen motivirt wird"127). Sax betont ausdrücklich, daß es falsch sei, Individualismus mit Egoismus und "Collectivismus" mit Altruismus gleichzusetzen ${ }^{128}$ ). Sowohl der Individualismus als auch der "Collectivismus" könnten von Egoismus, Mutualismus und Altruismus geleitet sein. Im "Collectivismus" ist es jedoch der "Verband", "auf welchen als auf die Gesammtheit seiner 
Glieder unmittelbar das Erhaltungs- und Entfaltungsstreben der Menschen bezogen wird"129).

Der "Mutualismus", der große Ähnlichkeiten mit der "wechselseitigen Hingebung" Schäffles zeigt, ist für ihn die Quelle jener Vereinigungen zu ökonomischen Zwecken, die der einzelne nicht für sich allein, sondern zugleich für andere mitverfolgt. "Hervorragende Fälle" sind für Sax die "Assecuranz" und die"Gebrauchsgemeinschaft" als bestimmte "Classen"-Vereinigungen (Standesvereinigungen), die zwar innerlich "mutualistisch" sind, gegenüber der Außenwelt jedoch sehr wohl eine egoistische Verhaltensweise an den Tag legen können $\left.{ }^{130}\right)$. Mit "Altruismus", der Schäffles "einseitiger Hingebung" oder - zumindest partiell - den hinter dem "caritativem Princip" von Adolph Wagner stehenden Motiven vergleichbar ist, bezeichnet er die Verhaltensweise, die sich in "Güterüberweisungen an Mitmenschen, welche lediglich die Erhaltung und Entfaltung des Lebens dieser bezwecken", äußert ${ }^{131}$ ).

Die Grundgedanken von Albert E. Fr. Schäffle und Emil Sax hat Hans Ritschl aufgegriffen und weitergeführt. Er bezeichnet die von mutualistischen Verhaltensweisen geprägten Kollektive, die durch freiwilligen zusammenschluß zur Befriedigung von "Sammelbedürfnissen" entstehen, ebenso wie Sax als "Assoziationen"132) oder freie Gemeinwirtschaften. Der "Gemeinsinn" wird bei Ritschl zur eigentlichen Triebkraft der Zwangsgemeinwirtschaften, die er wie Schäffle "Korporationen" nennt ${ }^{133)}$. Da der Gemeinsinn nicht bei allen Individuen gleich stark ausgeprägt ist und sich häufig mit dem Egoismus einzelner Individuen überschneidet, übt die Gesamtheit demjenigen gegenüber, der es am rechten Gemeinsinn fehlen läßt, Zwang aus, um ihn zur Erfüllung seiner Pflichten gegenüber der Gesamtheit zu bringen, "sie (die Gesamtheit; der Verf.) zwingt ihn, so zu handeln, 'als ob' er den Gemeinsinn hätte". Zwang wäre nur dann entbehrlich, wenn der Gemeinsinn bei allen in gleichem Maße vorhanden wäre ${ }^{134}$ ). 
Die von Wagner vorgebrachten Rechtfertigungen des staatlichen Zwangs finden sich später bei Antonio De Viti De Marco wieder. Er nimmt an, daß der einzelne sich im Kollektiv wie sonst auch von einem individuellen Egoismus leiten läßt. Er räumt allerdings ein, daß als weitere Verhaltensweisen der "Gattungsegoismus" und altruistisches Verhalten hinzukommen können, die die egoistischen Motive beschränken. Aus dieser hedonistischen Verhaltensweise folgert er zweierlei: Prinzipiell seien alle Kollektivmitglieder aufgrund ihres egoistischen Verhaltens bestrebt, die Kosten für die Produktion öffentlicher Güter möglichst gering zu halten, um ihre steuerlast zu minimieren. Andererseits sei der einzelne darauf bedacht, möglichst viel von den öffentlichen Gütern zu konsumieren und gleichzeitig seinen eigenen Finanzierungsbeitrag niedrig zu halten ${ }^{135}$ ). Damit weist De Viti De Marco genau auf das zentrale Problem der Bereitstellung öffentlicher Güter hin, das später unter dem Begriff des "Trittbrettfahrer-Verhaltens" diskutiert wurde.

Als ein Wesenszug der Kollektivbedürfnisse nach De Viti De Marco wurde bereits erwähnt, daß die Kollektivbedürfnisse auf einem Interessengegensatz beruhten, weil sie nicht von allen Kollektivmitgliedern gleich, sondern nach Art und Umfang unterschiedlich empfunden wïrden. Es obliegt mithin dem staatlichen Eingreifen, "'... das Nebeneinanderbestehen ihrer widerstreitenden Betätigungen zu regeln und möglich zu machen' "136). Im Gegensatz zur privatwirtschaftlichen Sphäre, wo sich die Gesamtnachfrage aus der summe der individuellen Nachfrage ergibt, "... ist die Kollektivnachfrage das Ergebnis der miteinander im Widerspruch stehenden Bewertungen der verschiedenen Gruppen und Individuen" 137).

De Viti De Marco unterscheidet sodann drei Gruppen von Kollektivbedürfnissen, die vom staat befriedigt werden müssen. Zur ersten gehören die Bedürfnisse nach innerem und äußerem Schutz. Dazu kommt eine zweite Gruppe von Bedürfnissen, die ihrem Ursprung nach Individualbedürfnisse sind, sich jedoch infolge des gesellschaftlichen Zusammenlebens zu Kollektivbe- 
dürfnissen entwickelt haben, weil sie Auswirkungen auf die gesamte Gesellschaft zeitigen und der Staat deshalb "zum Schutze der Gesamtheit" eingreifen muß. Hierzu zählt De Viti De Marco das Gesundheitswesen. Eine dritte Gruppe schließlich umfaßt Individualbedürfnisse, die als solche bestehen bleiben, zu denen aber durch die gesellschaftliche Arbeitsteilung ein kollektives Moment hinzutritt, etwa Produzenten mit Monopolstellung oder/und diesen auf Gnade oder Ungnade ausgelieferte Verbrauchergruppen. Hier ist der Staat gefordert, einem Mißbrauch der Machtstellung entgegenzutreten, um die benachteiligten Gruppen zu schützen 138 ).

Die Befriedigung der Kollektivbedürfnisse erfolgt mittels der vom Staat erzeugten öffentlichen Leistungen. Dem von der Gesamtheit empfundenen Kollektivbedürfnis entspricht die vom Staat bereitgestellte öffentliche Leistung. Daraus darf jedoch nicht gefolgert werden, daß der staat alle Kollektivbedürfnisse und die Privatwirtschaft alle Individualbedürfnisse zu befriedigen hätten. Vielmehr erzeugt der Staat manchmal Güter zur Befriedigung von Individualbedürfnissen und umgekehrt wird die Befriedigung bestimmter Kollektivbedürfnisse teilweise von privater Seite übernommen. Maßgebend für die Arbeitsteilung zwischen Privaten und staat sind demnach nicht allein die Bedürfniskategorien, sondern - wie wir sehen werden - daneben auch andere Gesichtspunkte ${ }^{139}$ ).

Ohne störende politische Einflüsse, vornehmlich von Interessengruppen, bestimmt das "... wirtschaftliche Prinzip des höchsten Ertrags die Verteilung der Produktion zwischen der öffentlichen und der privaten Hand", d.h., daß bei der Entscheidung, wer die Güter erzeugen soll, "... die Qualität und die Kosten der privaten und der öffentlichen Produktion" gegeneinander abzuwägen sind ${ }^{140}$ ). Eine Ausnahme von diesem Grundsatz machen die innere und äußere Sicherheit sowie die Verwaltung der Rechtspflege, die immer als ureigene staatliche Aufgaben aufgefaßt wer$\operatorname{den}^{141)}$. 
Wenn man von politischen Einflüssen absieht, dann tendiert der Staat zur Erzeugung solcher Güter, die der Befriedigung kollektiver Bedürfnisse dienen, unter der Voraussetzung, daß die Produktion wirtschaftlicher als bei privaten Unternehmungen erfolgt ${ }^{142}$ ). Die Annahme fehlender politischer Einflüsse auf die Finanzwirtschaft ist realiter jedoch nicht gegeben. Politische Umstände, namentlich der politische Druck verschiedener Interessengruppen, führen zu zahlreichen Abweichungen, die eine $\mathrm{zu}$ niedrige oder $\mathrm{zu}$ hohe Produktion bestimmter Leistungen nach sich ziehen. Der Umfang, in dem das einzelne öffentliche Gut bereitgestellt wird, unterliegt damit auch anderen als nur ökonomischen Gesetzen ${ }^{143}$ ).

\section{Kritische Würdigung}

Sinn und Zweck der vorhergehenden Ausführungen war es, die älteren Ansätze der Theorie der Kollektivbedürfnisse daraufhin zu durchleuchten, inwiefern sie Maßstäbe und Kriterien zu liefern vermögen, die zu einer Bestimmung der verschiedenen Formen des Wirtschaftens beitragen können.

Es wird in den einzelnen Beiträgen deutlich, daß es nicht die Natur der Bedürfnisse ist, die auf eine individuelle oder kollektive Befriedigung hinweist. Es zeigt sich ferner, daß neben dem Staat eine Vielzahl von Zusammenschlüssen in Betracht kommen, "Gemeingüter" zu erzeugen oder bereitzustellen. Auch wurde schon darauf hingewiesen (vgl. etwa Schäffle, Wagner oder De Viti De Marco), daß eine feste und beständige Zuweisung der Aufgaben auf einzelne Träger nicht möglich ist, weil sich die Vorstellungen darüber im Zeitablauf wandeln und laufend neue Bedürfnisse aufkommen und alte wegfallen.

Die Ansätze, bei denen die Kollektive selbst Träger von bestimmten Bedürfnissen sind, vermögen allein schon wegen prinzipieller Probleme der Bedürfnislehre zur Aufgabenverteilung in einem modernen Staatswesen heutiger Prägung wenig beizutragen. Sie stehen in völligem widerspruch $\mathrm{zu}$ den in Art. 1 GG bestimm- 
ten Zwecken des Staates, daß der Staat nicht um des Staates, sondern um der Menschen willen da ist.

Etwas schwieriger liegen die Dinge bei Emil Sax, Hans Ritschl und den in diesem Zusammenhang genannten Autoren, die davon ausgehen, daß die "... Kollektivbedürfnisse von gewissen, mit besonderen Kräften oder Eigenschaften ausgestatteten Personen empfunden werden"144). Diese idealistische Auffassung hilft ebenfalls - zumindest was die Bestimmung der Staatstätigkeit angeht - kaum weiter. Schmidt ${ }^{145}$ ) führt dazu zwei Gründe an: Erstens stellt sich innerhalb der Gesellschaft die Frage, wer diese Individuen sind, die über den "richtigen" Gemeinsinn verfügen. Diese Individuen müßten zunächst gefunden werden. Außerdem müßten diese die "richtige" Gesinnung besitzenden Individuen über die politische Macht verfügen, um die "richtigen" Vorstellungen durchsetzen zu können. Zweitens enthält der aus dem "Gemeinsinn" abgeleitete staatliche Zwang politisch gefährliche Momente. Nach diesen Theorien könnten die jeweils Herrschenden - auch Minderheiten - unter Berufung auf den "rechten" Gemeinsinn jederzeit Andersdenkenden ihre Meinungen oktroyieren. Die Gefahr, den "rechten" Gemeinsinn als Rechtfertigung für die Herrschaft zu mißbrauchen, ist nicht von der Hand zu weisen. Mit einem demokratisch aufgebauten staat sind diese Vorstellungen deshalb nicht zu vereinbaren.

An zahlreichen Beispielen widerlegt außerdem die Realität, daß der "Gemeinsinn" oder andere nicht egoistische, am Kollektivwohl orientierte Verhaltensweisen zur allgemeinen Grundlage der staatstätigkeit gemacht werden könnten. Vielmehr zeigen Schwarzarbeit, Steuerhinterziehung, Subventionserschleichung, Ausnutzung des sozialen Systems usw., daß die Individuen sich - wie Wagner und De Viti De Marco richtig erkannt haben auch im Verband zumeist von egoistischen Motiven leiten lassen. Die Fülle der staatlichen Gesetze, die solchen Mißbräuchen vorbeugen wollen, gibt anschaulich wieder, wie wenig verlaß auf die auf dem Gemeinsinn basierenden oder altruistischen Verhaltensweisen ist. Jedoch kann eine, im Kern dem Gemeinsinn ent- 
sprechende Einstellung dazu führen, daß mehrere Individuen sich dazu entschließen, freiwillig bestimmte Interessen gemeinsam zu verfolgen. Gerade kleinere, nicht oder nicht primär ökonomische zielsetzungen anstrebende Kollektive können hierin ihren Entstehungsgrund haben.

Die Vertreter dieser zweiten Gruppe, bei der das Individuum als Mitglied oder im Intersse der Gemeinschaft besondere Bedürfnisse empfindet, vermögen zwar die staatliche Betätigung nur unzureichend zu erklären, aber sie haben entscheidende Anregungen für nichtstaatliche kollektive Wirtschaften vermittelt. So hat Schäffle die unterschiedlichen kollektiven wirtschaften nach den sie dominierenden Zwecken und Verhaltensweisen klassifiziert. Die von ihm herausgestellten Triebkräfte für das Zustandekommen und die Aktivitäten der nichtstaatlichen Kollektive können auch heute noch Wesentliches zur Erklärung bestimmter Gruppen beitragen. Aber auch die grundsätzlichen Ausführungen von Sax zu den verschiedenen Triebkräften des Wirtschaftens sind in gleicher Weise dienlich.

Wagner und De Viti De Marco gelingt es mit ihren Ansätzen ebenfalls nicht, unmittelbar von den Bedürfnissen auf die Staatstätigkeit zu schließen. Wagner benutzt dazu die Hilfskonstruktion des "gemeinwirthschaftlichen Princips" und De Viti De Marco die "ursprünglichen Kollektivbedürfnisse", unter denen er die oben erwähnten ureigenen Staatsaufgaben innerer und äußerer Schutz und Rechtsordnung versteht. Trotzdem erhalten ihre Ausführungen $z u$ den Kollektivwirtschaften etliche Aspekte, die von so grundsätzlicher Bedeutung sind, daß sie ohne weiteres auch auf moderne Kollektive zutreffen.

Wagner hat sich noch ausführlicher als Schäffle mit den verschiedenen Organisationsformen des Wirtschaftens im Gemeinwesen befaßt. Er hat insbesondere die verschiedenen Formen des kollektiven Wirtschaftens betrachtet und sich vornehmlich darum bemüht, anhand ökonomischer, politischer und gesellschaftlicher Kriterien sowie mit Hilfe der die "Gemeinwirth- 
schaften" leitenden Motive die nichtstaatlichen von den staatlichen "Gemeinwirthschaften" abzugrenzen.

Der Schwerpunkt der Betrachtungen von De Viti De Marco liegt auf der Staatswirtschaft. Andere Kollektive erwähnt er allenfalls am Rande. Ihm kommt vor allem das Verdienst zu, darauf hingewiesen zu haben, daß es sehr häufig politische und gesellschaftliche Einflüsse, namentlich von Interessengruppen, sind, die bestimmte Aufgaben zu Staatsaufgaben werden lassen. Außerdem arbeitet er aus ökonomischer Perspektive die Notwendigkeit des Zwangs als Mittel zur Durchsetzung der staatlichen Zielsetzungen heraus. Mit seiner Begründung des Zwangs weist er - wie grundsätzlich schon Wagner - bereits auf die zentrale Problematik hin, vor der die Finanzwissenschaft bei der Bestimmung der Staatstätigkeit heute noch steht. Eine Lösung, die angibt, wie die wahren Präferenzen bei staatlichen Gütern erkundet werden können und wie das damit zusammenhängende Trittbrettfahrer-Verhalten vermieden werden kann, ist nicht in Sicht.

Obwohl die historischen Ansätze in vielerlei Hinsicht Anlaß zur Kritik bieten, u.a. deshalb, weil sie teilweise von überkommenen, heute nicht mehr akzeptierten staatsauffassungen ausgehen, wurde doch deutlich, daß sie mit der Charakterisierung der verschiedenen Formen des kollektiven Wirtschaftens wichtige Hinweise zur Bestimmung des öffentlichen Sektors geben können. Diese älteren Beiträge enthalten, insbesondere was die nichtstaatlichen "Gemeinwirthschaften" angeht, Gesichtspunkte, die im Laufe der zeit immer mehr aus dem Blickfeld der Ǒkonomen verschwanden. Der Grund hierfür mag darin liegen, daß sich die neuere Nationalökonomie zu stark auf den Gegensatz Staatswirtschaft einerseits und Privatwirtschaft andererseits beschränkt und dabei fast ausschließlich ökonomisch rationales verhalten unterstellt hat. Damit ging - sieht man von einigen betriebswirtschaftlichen Publikationen zum Genossenschafts- und Verbändewesen $a b$, deren andersgeartete zielsetzung hier aber nicht interessiert ${ }^{146)}$ ) - die sicht für andere Formen der wirtschaftlichen Betätigung, die zwischen Markt und Staat lie- 
gen, verloren. Im Gegensatz zu der heute oft anzutreffenden engen Perspektive, unter der einzelne Probleme und Bereiche diskutiert werden, zeichneten sich diese älteren Autoren gerade durch die weite, auch nicht ökonomische Aspekte berücksichtigende Betrachtungsweise des Wirtschaftens in all seinen Erscheinungsformen aus.

Die älteren Ansätze haben mit der Verbindung von ökonomischen, staatspolitischen, sozialen und anderen Kriterien einen Weg aufgezeigt, an den anzuknüpfen sich lohnt, um den Bereich der intermediären Finanzgewalten zu erfassen. Eine Weiterentwicklung dieses historischen Denkansatzes kann sich auf das inzwischen erheblich verfeinerte ökonomische Instrumentarium, namentlich auf die Erkenntnisse der Theorie der öffentlichen Güter, stützen. Unter Berücksichtigung der heute gültigen gesellschaftlichen Wertvorstellungen, die wir im folgenden betrachten, den für das wirtschaften ausschlaggebenden Verhaltensweisen und den treibenden Kräften der finanzpolitischen willensbildung wird im weiteren Verlauf der Arbeit versucht, die Aufgaben der im öffentlichen Bereich angesiedelten intermediären Finanzgewalten $z u$ bestimmen. Dies ist allerdings nur in qualitativer Hinsicht möglich; denn in welchem Umfang eine einzelne Aufgabe erfüllt werden soll, läßt sich nicht fassen, weil der verfassungsrechtlich vorgegebene Rahmen hier einen weiten Interpretationsspielraum beläßt, der von der politischen willensbildung ausgeschöpft werden kann. 
Peter Saile - 978-3-631-75214-2

Downloaded from PubFactory at 01/11/2019 07:01:15AM

via free access 
C. Ansatzpunkte einer Kennzeichnung des intermediären Bereichs im modernen pluralistischen Gruppenstaat

I. Stellung und Aufgaben der Gruppen in Gesellschaft und staat

1. Die gesellschaftliche Funktion der Gruppen

Diese Arbeit geht von dem demokratischen, pluralistischen, weltanschaulich neutralen Staat des Grundgesetzes aus. Es ist deshalb erforderlich, zunächst die Grundstrukturen des staatlichen und gesellschaftlichen Systems, in dem die verschiedenen Gruppen wirken, aufzuzeigen. Durch die Beschränkung auf den Staat des Grundgesetzes ist es nicht notwendig, mit einer allgemeinen Diskussion über Wesen und Funktion des Staates zu beginnen, sondern es genügt, die hinter der verfassung des Grundgesetzes stehenden Wertvorstellungen zugrundezulegen.

Dem Staat als politischem und sozialem zusammenschluß von selbstbestimmten geistig freien Menschen kommt als höchste Instanz zur Wahrung von Ordnung und Freiheit im Bereich des menschlichen Zusammenlebens eine besondere Ordnungsfunktion im Gemeinwesen $\mathrm{zu}^{1}$ ). Der staat ist aber trotz dieser ubergeordneten Rolle nicht Selbstzweck, sondern entsprechend dem Bekenntnis des Grundgesetzes zum Menschen als letztem und oberstem Wert um des Menschen willen $\mathrm{da}^{2}$ ). Das hat zur Konsequenz, "... daß der Mensch mit seinen Bedürfnissen, zielen und Wertvorstellungen Ausgangspunkt auch aller Staatsfunktionen sein muß."3). In einem demokratischen Gemeinwesen kann deshalb die Herrschaftsgewalt, über die der Staat zur Durchsetzung der ordnenden Funktion über andere Gruppen und Kräfte des menschlichen Zusammenlebens verfügt, allein über eine Legitimation durch das Volk kommen, wobei allerdings die Herrschaftsgewalt durch die Grundrechte begrenzt wird ${ }^{4}$ ). Dieser Grundvorstellung der modernen Demokratie, die ihren gedanklichen Ursprung im Rousseauschen Gesellschaftsvertrag hat ${ }^{5}$ ) und die in der Souveränität des Volkes besteht, wird im Grundgesetz mit Art. 20, Abs. II konkreti- 
siert. Das Grundgesetz übernimmt jedoch nicht ausschließlich den Leitgedanken des klassischen Liberalismus vom unabhängigen, autonomen Individuum, sondern betont die Gemeinschaftsbezogenheit und Gemeinschaftsgebundenheit der Eigenwert besitzenden Person 6).

Die Idee des klassischen Liberalismus beschränkt nämlich den Staat auf ein Minimum an (Schutz-)Funktionen. Sie vertraut darauf, daß bei staatlicher Neutralität im Sinne des Gewährenlassens und der Nichteinmischung die freie Entfaltung der gesellschaftlichen Kräfte zu den besseren Ergebnissen füren wird als staatliche Interventionen ${ }^{7}$ ). Hinter dieser liberalen Staatstheorie steht die Vorstellung von der Gesellschaft als nichtstaatlicher Sphäre. $\mathrm{zu}$ diesem vor staatlichen Interventionen geschützten gesellschaftlichen Bereich zählt die klassische liberale Staatsauffassung das Privatleben, Kirche und Religion, Kunst, Wissenschaft, Wirtschaft und öffentliche Meinung ${ }^{8}$ ). Zwar gewährt auch die Verfassung des Grundgesetzes vornehmlich durch Grundrechte diesen der gesellschaftlichen Sphäre zuzuordnenden Bereichen einen besonderen Schutz, allerdings sind sie durch entsprechende Grundrechtsbeschränkungen nicht völlig staatsfrei. Um soziale Ungerechtigkeiten und andere unerwünschte Folgen, wie z.B. Wettbewerbsverzerrungen, die ein Laissez-faire-Liberalismus mit sich bringt, zu vermeiden, sind regulierende Eingriffe des Staates unumgänglich ${ }^{9}$ ).

Ferner ist der hinter der liberalen Auffassung stehende Gedanke, daß sich ausschließlich staat und autonomes Individuum gegenüberstünden, überholt und entspricht nicht mehr der Wirklichkeit ${ }^{10}$ ). In der modernen pluralistischen Gesellschaft stehen dem Staat nicht nur Individuen gegenüber, sondern daruiber hinaus eine Vielzahl von gesellschaftlichen Gruppierungen. "Die Verbände, ihr Wirken und ihre Einflußnahme gehören heute zur gesellschaftlichen wirklichkeit und zu einem demokratischpluralistischen System, das Freiheit und offenheit verbiirgt"11). 
Die Aktivitäten der nichtstaatlichen Gruppen in der demokratischen Gesellschaft nehmen in staatsrechtlicher sicht ihren Ursprung in den Freiheitsrechten, so etwa das kirchliche wirken in der verfassungsrechtlich garantierten Glaubensfreiheit ${ }^{12)}$. Obwohl es dem weltanschaulich neutralen staat verboten ist, sich die Anschauungen der einzelnen Gruppen zu eigen zu machen, heißt Neutralität für ihn nicht Gleichgültigkit, sondern offenheit gegenüber der Pluralität der Wertvorstellungen seiner Bürger ${ }^{13}$ ). Der freiheitliche Staat hat für die Bürger die Freiheits- und Entfaltungsräume sowie die gesellschaftlichen Bedingungen zu schaffen, die es den Bürgern ermöglichen, ihre geistigen und kulturellen Interessen zu verfolgen. Neutralität bedeutet für den Staat also nicht mehr völlige Enthaltsamkeit in den oben erwähnten gesellschaftlichen Bereichen, wie es der Auffassung des klassischen Liberalismus entsprach, sondern für ihn leitet sich beispielsweise aus der Glaubensfreiheit die pflicht ab, dafür Sorge zu tragen, daß die Bürger, die die Wahrnehmung ihrer religiösen Interessen für ihre Existenz als unentbehrlich erachten, nicht darin behindert werden. Gleichzeitig hat er jedoch darauf zu achten, daß niemand gegen seinen willen von den entsprechenden Gruppen vereinnahmt wird ${ }^{14}$ ).

Zur Wahrnehmung der gleichartigen gesellschaftlichen Interessen organisieren sich die Individuen in Gruppen ${ }^{15}$ ). Das Individuum verfolgt eine Fülle von Interessen, kann mehreren Gruppen gleichzeitig angehören und außerdem von einer Gruppe in die andere wechseln. Das gesellschaftliche System ist folglich nicht mehr geschlossen wie im Ständestaat. Es unterliegt vielmehr einem laufenden Wandel. Dieser Pluralismus von grundsätzlich offenen Gruppen ist es, der die heutige Gesellschaft prägt und mitbestimmt ${ }^{16}$ ).

Das einzelne Mitglied erwartet von der Gruppe die gemeinschaftliche Befriedigung gemeinsamer Interessen und eine angemessene Vertretung von bestimmten gruppenspezifischen Interessen gegenüber dem Staat und anderen gesellschaftlichen 
Gruppierungen, wenn es ihm nicht selbst möglich ist, diese wirkungsvoll durchzusetzen ${ }^{17}$ ).

Aus den bisherigen Überlegungen resultieren zwei grundsätzliche Aktionsfelder des gesellschaftlichen Wirkens der Gruppen. Diese Aktionsfelder stehen nicht isoliert nebeneinander, sondern in einem engen Zusammenhang. Der erste Bereich ihres Tuns ist nach innen, d.h. auf die Gruppe bzw. die Gruppenmitglieder gerichtet, und umfaßt die gruppeneigenen Gestaltungs- und Entscheidungsmöglichkeiten ${ }^{18)}$; der zweite, nach außen gewandte, beinhaltet eine aktive Beeinflussung des gesellschaftlichen Lebens und die Interessenvertretung gegenüber dem Staat und anderen sozialen Gebilden ${ }^{19}$ ). Aber nicht nur das zuletzt genannte Aktionsfeld, sondern auch die Befriedigung von gruppenspezifischen Interessen hat Auswirkungen auf die allgemeinen gesellschaftlichen Verhältnisse und bleibt nicht auf die jeweiligen Interessenträger beschränkt ${ }^{20}$ ).

Die nach außen gehenden Aktivitäten und nach außen vertretenen Interessen der Gruppen harmonieren nicht immer mit dem Allgemeinwohl. Im Gegenteil: Sie können dieses sogar gefährden. Es kann einzelnen Gruppen durchaus gelingen, relativ viel Macht und Einfluß zu erlangen und ihre Interessen zu Lasten Dritter, d.h. gegenüber schwächeren Gruppen und den nicht Organisierten, durchzusetzen ${ }^{21}$ ). Nicht zuletzt ist darin ein Grund dafür zu sehen, daß einzelnen Interessenverbänden in der Offentlichkeit häufig mit Ablehnung und Skepsis begegnet wird. Eschenburgs Schrift "Herrschaft der Verbände?" bringt diese Befürchtung mehr als deutlich zum Ausdruck ${ }^{22}$ ).

Weil die von den verschiedenen gesellschaftlichen Gruppierungen vertretenen Sonderinteressen in den wenigsten Fällen miteinander in Einklang stehen, sondern oft einander entgegengesetzt sind, ergeben sie in der Summe auch nicht das Gemeinwohl. Andererseits ist das Gemeinwohl in einem pluralistischen Gemeinwesen wiederum nicht unabhängig von den Interessen der einzelnen Gruppen; denn deren Interessen sind insofern ebenfalls ge- 
meinwohlbezogen, als das Gemeinwohl aus der Integration der verschiedenen politischen und gesellschaftlichen kräfte resultiert, zu denen auch die gesellschaftlichen Gruppen zählen 23). Das Bundesverfassungsgericht führt dazu aus, daß die Gruppen in einem demokratischen Gemeinwesen nicht isoliert nebeneinanderstehen, sondern daß dieses vielmehr "...durch die ständige Auseinandersetzung zwischen den verschiedenen sich begegnenden sozialen Kräften, Interessen und Ideen um die politischen Ziele" gekennzeichnet ist ${ }^{24}$ ). Um die Gemeinwohlinteressen gegenüber den Partikularinteressen der gesellschaftlichen Gruppen vertreten $\mathbf{z u}$ können, muß der Staat diesen übergeordnet und mit den entsprechenden Machtmitteln ausgestattet sein 25). Die Zuständigkeitsbereiche der einzelnen gesellschaftlichen Gruppen, die nicht vom gesamten Volk legitimiert sind, müssen folglich so abgegrenzt werden, daß das wirken und der Einfluß der Gruppen nicht das politische Mandat des Staates als Vertreter des Allgemeinwohls in Frage stellen 26 ).

Die vorhergehenden Ausführungen zeigen, daß die Charakterisierung der Gesellschaft als des Feldes der "Sonderinteressen" und des Staates als der "gemeinsamen Sphäre", mithin nicht zutrifft und verkennt, daß die verfolgung von Sonderinteressen durch einzelne Gruppen häufig Wirkungen über deren eigenen Gestaltungsbereich hinaus auf das übrige Gemeinwesen auslöst ${ }^{27}$ ) und daß die verschiedenen gesellschaftlichen Gruppierungen an der staatlichen Macht teilhaben und mitbestimmen ${ }^{28}$ ). Eine einfache Gliederung des Gemeinwesens in Staat und Gesellschaft ist somit nicht mehr möglich. Beide sind vielmehr miteinander "verschränkt"29). Eine Beibehaltung des Unterschiedes von Staat und Gesellschaft hat keine Berechtigung mehr als artikulierte Trennung zweier sozialer Reiche, als Gegensatz von Freiheit und Zwang, Autonomie und Herrschaft, sondern nur als beschreibende Abbreviatur zweier Sphären des Gemeinwesens, zwischen dem engeren Raum der Institutionen der Leitung und Administration auf der einen und dem weiteren Kreis der vielgliedrigen Gruppen und Gebilde auf der anderen Seite. Aber auch der letztere Bereich ist auf das 
Ganze bezogen und bildet einen Teil des politischen Prozesses, der Richtungsbestimmung (Willensbildung) der Gesamtheit. In dieser Funktion wird er daher als der Bereich des 'Offentlichen' verstanden".30)

Die insbesondere die politischen, wirtschaftlichen und sozialen Belange des Gemeinwesens beeinflussende mitverantwortliche Gestaltung der Gesellschaft durch die Gruppen begründet deren öffentliche Funktion ${ }^{31)}$. Die Aktivitäten der Gruppen beschränken sich nicht nur auf ihren eigenen Bereich, sondern erstrecken sich auch auf die Allgemeinheit. Das verleiht ihnen den öffentlichen Charakter, der sie in der Gesellschaft von der rein privaten Sphäre der Individuen abhebt.

Der "Ort" der Interessenauseinandersetzung und der Betătigung der Gruppen ist das "Öffentliche", die Sphäre, die zwar noch nicht staatlich ist, aber über das Private hinausgeht, mit anderen Worten: der Bereich des "organisierten gesellschaftlichen Lebens". Hier werden Leistungen erbracht, die keine staatlichen sind, denen jedoch weite Teile der Allgemeinheit einen hohen Wert beimessen 32 ). Eine Vielzahl von Gruppen fült den Zwischenraum zwischen Individuum und staat aus und wirkt in mannigfacher Weise auf das gesellschaftliche und staatliche Leben ein 33 ). Der moderne demokratische staat zeigt sich deshalb als "... eine Gruppengesellschaft, in der intermediäre Gewalten einen weiten Entfaltungsraum haben und an der sozialen und politischen Bestimmung einen starken Anteil nehmen" 34 ).

Dieser Öffentlichkeitsbegriff kennzeichnet "eine den Staat umlagernde Zone .... die zwar der Sphäre privater, 'staatsfreier' Gesellschaft entwachsen, aber doch nicht der organisierten Staatlichkeit selbst zuzurechnen ist"35). In diesem öffentlichen Raum entfalten die gesellschaftlichen Gruppierungen ihr Wirken, das im folgenden năher betrachtet wird. 
2. Öffentlicher und staatlicher Aufgabenbereich in staatsrechtlicher sicht

In der rechtswissenschaftlichen Literatur fehlt es nicht an Versuchen, die Begriffe der öffentlichen und der staatlichen Aufgaben festzulegen. Trotz der fast unübersehbaren Flut von Veröffentlichungen $\mathrm{zu}$ dieser Frage können die bisherigen Ergebnisse nicht befriedigen: "... Es fehlt noch immer an einer eindeutigen Staatsaufgabenlehre"36) und somit auch an einer eindeutigen Festlegung der öffentlichen Aufgaben. Das zeigt sich schon daran, daß in der rechtswissenschaftlichen Diskussion die Begriffe "öffentlich" und "staatlich" nicht einheitlich verwendet werden bzw. einige Autoren überhaupt nicht zwischen "Öffentlich" und "staatlich" differenzieren37). Die herrschende Lehre geht indessen von einer Trennung dieser Begriffe aus. Allerdings wird eingeräumt, daß eine strikte Grenzziehung zwischen staatlichen und öffentlichen Aufgaben in weiten Bereichen nicht möglich sei, weil zum einen die staatlichen Aufgaben einem steten Wandel unterlägen ${ }^{38}$ ) und zum anderen staat und Gesellschaft gerade in den relevanten Bereichen nicht mehr isoliert nebeneinander stünden, sondern miteinander in vielfältiger Weise verknüpft seien ${ }^{39}$ ).

Die einzelnen Definitionen können danach geordnet werden, ob sie eine Abgrenzung nach materiellen oder formalen Kriterien vornehmen. Betrachten wir die zuerst genannten. Einige Autoren nehmen an, daß es "originäre" Staatsaufgaben gäbe, ohne allerdings näher zu konkretisieren, was originär staatlich ist. Andere sehen "wesensmäßig" staatliche Aufgaben dann, wenn die Zielsetzung in der Verwirklichung des Allgemeinwohls liegt. Sie scheitern aber an der Unbestimmtheit des Allgemeinwohlbegriffs. Die Charakterisierung, daß es sich um staatliche Aufgaben handele, wenn zu deren Durchsetzung und Erfüllung ein hoheitlicher Mitteleinsatz erforderlich sei, versagt ebenfalls, weil sie die entscheidende Frage offen läßt, warum und bei welchen Aufgaben das der Fall sein soll40). 
Ein sehr detaillierter Vorschlag stammt von Hans Peters $\left.{ }^{41}\right)$. Die von Peters zugrundegelegten Kriterien sind der Öffentlichkeitscharakter, d.h. das öffentliche Interesse an diesen Aufgaben, und die Art bzw. der Träger der Aufgabenerfüllung. Offentliche Aufgaben sind danach solche, "... an deren Erfüllung die Öffentlichkeit maßgeblich interessiert ist. Sie können durch Private so gut erledigt werden, daß der Staat weder ein Bedürfnis anzuerkennen noch den Wunsch zu haben braucht, sie zu regeln oder sie gar in eigene Regie zu nehmen, ... er überläßt das Ganze der privaten Sorge der Beteiligten und hält sich selbst zurück"41a). Neben diesem Fall der rein privaten Erledigung öffentlicher Aufgaben unterscheidet er je nach der Intensität des öffentlichen Interesses weitere Formen der öffentlichen Aufgaben. Der Staat kann die Erfüllung öffentlicher Aufgaben durch Private überwachen oder abstrakte Regelungen aufstellen, die die Erfüllung der Aufgaben normieren. Von staatlichen Aufgaben, die bei ihm einen Unterfall der öffentlichen darstellen, kann man seiner Auffassung nach erst dann sprechen, wenn staatliche Behörden nach staatlicher Normierung Aufgaben erfüllen ${ }^{42}$ ). Peters nennt mit dem öffentlichkeitscharakter und der Art beziehungsweise dem Träger der Aufgabenerfüllung im Prinzip die entscheidenden Merkmale für die Erfüllung öffentlicher und staatlicher Aufgaben. Allerdings bleibt die entscheidende Frage, welche Aufgaben von öffentlichem Interesse sind und vor allem, warum diese von öffentlichem Interesse sind, offen. So fehlt letztlich die Antwort, was ausschlaggebend für die Unterscheidung von staatlichen und öffentlichen Aufgaben ist und was schließlich den staat veranlaßt, bestimmte Aufgaben selbst zu übernehmen.

Die andere Gruppe von Autoren versucht durch die Heranziehung formaler Kriterien Antworten auf diese Fragen zu geben, indem sie die Verfassung als Ausgangspunkt ihrer Utberlegungen wählt. In der Verfassung sind "die Grundentscheidungen über die politische, soziale, wirtschaftliche und kulturelle Ordnung des Volkes ..." niedergelegt 43 ). Diese Wertentscheidungen spiegeln den Grundkonsens wider, auf dem das demokratische Gemeinwesen 
beruht, vorausgesetzt die Bürger bekennen sich zu ihnen 44). Entscheidend sind demnach die in der Verfassung enthaltenen zielsetzungen.

So geht Hans Herbert von Arnim ${ }^{45}$ ) bei der Staatstätigkeit davon aus, daß alles staatliche Handeln sich am Gemeinwohl zu orientieren habe. Dem Vorwurf, dem sich die andere Gruppe der Autoren, die sich an materiellen Kriterien orientiert, ausgesetzt sieht, daß das Gemeinwohl nicht faßbar sei, begegnet er damit, daß er dieses nicht isoliert betrachtet, sondern versucht, das Gemeinwohl konkret für die Staats- und Gesellschaftsordnung der Bundesrepublik Deutschland aus den verfassungsrelevanten Wertentscheidungen des Grundgesetzes abzuleiten ${ }^{46}$ ).

Als "Meßlatte" der Gemeinwohlverwirklichung dienen die Grundwerte, die als "letzte" Werte hinter den Regelungen des Grundgesetzes stehen und für alle Menschen gelten ${ }^{47}$ ). Die fundamentale Wertentscheidung dazu liefert Art. 1 GG "... mit dem Bekenntnis zum Menschen als letztem Wert, dem alles staatliche Tun zu dienen hat"48). Da der Mensch mit seinen Bedürfnissen und Wertvorstellungen Ausgangspunkt aller staatsfunktionen ist, gibt es folglich keine eigenen Interessen des Staates. Sein Tun hat sich vielmehr ausschließlich daran zu orientieren, ein Instrument zur besseren Verwirklichung der Interessen der Menschen zu sein. Verstößt der staat dagegen, handelt er gemeinwohlwidrig49). Aus dem Gebot zum Schutz der Menschenwïrde in Art. 1 GG resultieren unmittelbar die Grundwerte Freiheit und Gerechtigkeit. Aus der freiheitlichen zielsetzung lassen sich die weiteren Grundwerte Sicherheit und Wohlstand ableiten 50 ). Diese Grundwerte sollen im folgenden unter dem uns interessierenden Blickwinkel näher betrachtet werden.

Die freiheitliche zielsetzung geht von einem Menschen aus, der sein Leben eigenverantwortlich und selbständig gestaltet. Die Grenzen seiner freien Betätigung werden ihm durch seine Gemeinschaftsbezogenheit abgesteckt ${ }^{51}$ ). Die freiheitliche Zielsetzung sichert dem einzelnen in Form der Grundrechte auch heute noch 
weitgehend die Freiheit vor dem staat in dem oben als Gesellschaft bezeichneten Bereich und so seine persönlichen Entfaltungsmöglichkeiten, wenngleich - wie die "Verschränkung" zeigt - eine völlige staatliche Abstinenz nicht gegeben ist ${ }^{52}$ ). Die formale Gewährleistung der Entfaltungsmöglichkeiten im gesellschaftlichen Bereich kann jedoch nutzlos werden, wenn für ihre Verwirklichung die materiellen Voraussetzungen fehlen. Die Berufsfreiheit nutzt beispielsweise wenig, wenn es keine Arbeitsplätze gibt. Auch kann die Freiheit einzelner, insbesondere wirtschaftlich Schwächerer, durch die wirtschaftliche Macht Stärkerer eingeschränkt werden. Gerade die Benachteiligung der im Wirtschaftsprozeß schwächeren Mitglieder des Gemeinwesens hat zu der Erkenntnis geführt, daß ein uneingeschränkter Liberalismus versagen muß, und hat außerdem deutlich gemacht, daß der Staat zu regulierenden Eingriffen aufgerufen ist, um den Freiheitsrechten auch materielle Geltung für alle zu verschaffen 53 ).

Der Grundwert der Gerechtigkeit interessiert uns im Hinblick auf die Bestimmung der öffentlichen und der staatlichen Aufgaben insbesondere unter dem Aspekt der sozialen Gerechtigkeit, die ihren Ausdruck im Sozialstaatsprinzip findet. Allerdings darf die wirtschaftlich-soziale Gerechtigkeit nicht im sinne einer völligen Gleichheit verstanden werden. Eine solche Auffassung wïrde der nach der freiheitlichen Zielsetzung angestrebten eigenverantwortlichen Selbstentfaltung des Menschen geradezu widersprechen 54 ).

Während die Wohlstandszielsetzung in der Ökonomie - unter Beachtung der Nebenbedingung der freiheitlichen und der Gerechtigkeitszielsetzung - die Maxime für alles Wirtschaften, einschließlich der staatlichen Aktivitäten, abgibt ${ }^{55}$ ), wird ihr in verfassungstheoretischer sicht eine dienende Funktion für andere Grundwerte zugeordnet. Sie erhöht die materielle Unabhängigkeit und Sicherheit der Bürger, vermindert damit soziale Konflikte und leistet so einen Beitrag, die ökonomischen Begrenzungen der Freiheit zu verringern 56 ). 
Auf eine ausführliche Erörterung der wirtschaftlichen Konsequenzen eines Utbermaßes an sozial oder anders motiviertem staatlichem wirken soll hier verzichtet werden. Sie sind in der ökonomischen Diskussion hinlänglich etwa unter dem stichwort Auswirkungen auf die Risiko- und Leistungsbereitschaft ((dis-) incentives), diskutiert worden ${ }^{57)}$. An dieser Stelle soll lediglich auf einige Gefahren hingewiesen werden, die mit wohlgemeinten, aber überdimensionierten staatlichen Eingriffen zur Förderung von Freiheit, Sicherheit, Wohlstand und vornehmlich sozialer Gerechtigkeit verbunden sind. Solche Eingriffe können nämlich genau das Gegenteil von den beabsichtigten Wirkungen erreichen und die Werte, denen sie dienlich sein sollen, aushöhlen.

$\mathrm{Zu}$ weit gehende staatliche Aktivitäten im wirtschaftlichen und sozialen Bereich können sich leicht gegen die durch den Grundwert Freiheit garantierte Eigenverantwortung und Selbstbestimmung des Menschen richten. Das tritt einerseits beispielsweise dann ein, wenn staatliche Leistungen, die zur sinnvollen Absicherung gegen soziale Risiken und Notsituationen gedacht sind, durch mißbräuchliche Inanspruchnahme insgesamt diskreditiert werden, oder wenn diese Leistungen so bemessen sind, daß Anreize für eigene Initiativen zur Behebung der Situation wegfallen, weil sich die Empfänger an die Leistungen gewöhnen und damit vom staat abhängig werden. Andererseits fördert es die Eigenverantwortung und Selbstbestimmung des Menschen ebenfalls nicht, wenn die staatlichen Abgabepflichten die aus der persönlichen Entfaltungsmöglichkeit resultierenden wirtschaftlichen "Früchte" so stark beanspruchen, daß sich die aufgewandte Mühe nicht mehr lohnt.

Das "Zuviel" an sozialer Gerechtigkeit bewirkt auf diese Weise letztlich eine doppelte Beschränkung des Grundwertes Freiheit: Zum einen, weil dadurch bei den Leistungsempfängern Abhängigkeit statt Eigenverantwortlichkeit erzeugt wird und zum anderen, weil damit die Selbstverwirklichung auf wirtschaftlichem Gebiet erheblich beschnitten wird. Die Grenzen staatlicher 
Betätigung liegen also dort, wo die fundamentalen Wertentscheidungen, auf denen die Gemeinschaft beruht, in ihrem Kern getroffen werden 58 ).

Neben der Allgemeinwohlzielsetzung des Staates ist die Trennung zwischen Staat und Gesellschaft ein weiterer Baustein im Ansatz von Arnims. Er weist auf die gegenseitige Durchdringung im modernen Gemeinwesen hin und lehnt die überkommene Trennung in zwei unabhängige Bereiche $\mathrm{ab}^{59}$ ). Die Verschiedenheit könne weder darin gesehen werden, daß in den zwei Sphären jeweils inhaltlich grundsätzlich verschiedene Interessen verfolgt werden, weil eben - wie deutlich wurde - in dem Bereich des Öffentlichen die Grenzen fließend seien, noch darin, daß es sich um zwei gegenseitig abgegrenzte Bereiche handele, sondern die Verschiedenheit liege "... in der Organisation und im Verfahren der Interessenwahrnehmung", also den unterschiedlichen gesellschaftlichen und staatlichen willensbildungs- und Entscheidungsverfahren 60). Eine Unterscheidung von staat und Gesellschaft in dem gerade beschriebenen Sinne nach der Verschiedenheit der gesellschaftlichen und staatlichen Willensbildungs- und Entscheidungssysteme ist nach von Arnim u.a. deshalb erforderlich, da "nur auf dieser Grundlage eine Begrenzung staatlicher Aktivität möglich (ist; der Verf.)". Aber auch "die Entwicklung einer staatlichen Aufgabenlehre (setzt; der Verf.) die Unterscheidung von Staat und Gesellschaft als notwendige Bedingung voraus; als weitere - hinreichende - Bedingung für die Entwicklung einer Staatsaufgabenlehre muß darüber hinaus noch die Erkenntnis hinzukommen, daß gesellschaftliche Steuerungsmechanismen - soweit sie funktionieren - ein höheres Niveau der Grundwerterealisierung bewirken können als staatliche." 61)

Die Wertung des Art. 1 GG und die daraus resultierenden Grundwerte, die den instrumentellen Charakter der staatlichen Aktivitäten als Dienst am Menschen betonen, bilden die Grundlage für die Beurteilung der staatlichen Aktivitäten im Hinblick auf die Allgemeinwohlverwirklichung. Die Anerkennung des 
Grundwertes Freiheit impliziert zunächst einmal, daß die Verfolgung der menschlichen Interessen und Bedürfnisse grundsätzlich dem einzelnen Menschen zur freien Entscheidung überlassen werden muß. Die gesellschaftlichen Selbststeuerungsmechanismen regeln ohne staatliche Einwirkungen Art und Weise der individuellen Bedürfnisbefriedigung. Erst dann, wenn die gesellschaftlichen Selbststeuerungsmechanismen versagen, weil sie die Entfaltungsmöglichkeiten einzelner beeinträchtigen bzw. behindern und/oder die anderen Grundwerte nicht genügend verwirklicht werden, sind staatliche Entscheidungsverfahren gefragt 62 ).

Daraus folgt für die Aufgabenverteilung im Gemeinwesen, daß derjenige Träger eine Aufgabe zu erfüllen hat, der die höchste Allgemeinwohlverwirklichung erreicht. Als Maßstab, nach dem die Steuerungsmechanismen beurteilt werden, dienen die sowohl für den Staat als auch für die Gesellschaft geltenden Grundwerte, anhand derer die Allgemeinwohlzielsetzung konkretisiert wird. Für die Übernahme einer Aufgabe resultiert daraus, daß die Bedarfsdeckung durch den steuerungsmechanismus zu erfolgen hat, bei dem die Grundwerte, und damit das Allgemeinwohl, am besten verwirklicht werden. Das Vorgehen bei einer einzelnen Aufgabe sieht dann so aus, daß zunächst geprüft wird, zu welchen Ergebnissen die gesellschaftlichen Steuerungsmechanismen führen. Diese Ergebnisse müssen im Lichte der Verwirklichung der einzelnen Grundwerte begutachtet und mit denjenigen verglichen werden, die staatliche Entscheidungsmechanismen zustande bringen wiirden 63).

Wie die Resultate der einzelnen Steuerungsmechanismen an dem Grad der Grundwerteverwirklichung zu messen sind, kann exemplarisch an der freiheitlichen zielsetzung verdeutlicht werden. Demnach realisiert der Vertrag als gesellschaftliches Selbststeuerungsinstrument ein weit höheres Maß an Freiheitsverwirklichung und folglich Allgemeinwohl als ein staatiches Gesetz, weil er zum einen die Entscheidung dem freien willen der Beteiligten überläßt und zum anderen mehr als das Gesetz 
der Einzelfallgerechtigkeit dient ${ }^{64}$ ). Die Beurteilung dieses Beispiels erfolgt allerdings unter restriktiven Annahmen, weil hier nämlich von den anderen Grundwerten abgesehen oder unterstellt wird, daß sie in gleicher Weise erfültt werden.

Die genauere Beurteilung der Steuerungsmechanismen muß nach von Arnim ferner berücksichtigen, daß der Vergleich der Resultate der gesellschaftlichen und der staatlichen Entscheidungs- und Willensbildungsprozesse nicht ein verzerrtes, den staatlichen Steuerungsmechanismus begünstigendes Bild liefert. Das ist der Fall, wenn institutionelle Hemmisse, die gemeinhin mit dem Begriff des Staatsversagens umschrieben werden und die den staatlichen Steuerungsmechanismus bei der Leistungsbereitstellung beeinträchtigen, nicht berücksichtigt werden ${ }^{65}$ ). Eine letzte Frage, die schließlich zu prüfen ist, falls von den staatlichen Entscheidungsmechanismen die besseren Ergebnisse erwartet werden, ist die, ob sich die dafür erforderlichen staatlichen Maßnahmen auch im politischen willensbildungs- und Entscheidungsproze $\beta$ durchsetzen lassen 66 ).

\section{Würdigung}

Die oben dargestellten Ansätze bilden eine wichtige Grundlage zur Bestimmung der intermediären Finanzgewalten. Als deren Wirkungsfeld haben wir das "Offentliche" ausgemacht, den Bereich des organsierten gesellschaftlichen Lebens, der durch die gegenseitige Verschränkung von staat und Gesellschaft gekennzeichnet ist. In dieser den "Staat umlagernden zone" entfalten die intermediären Finanzgewalten ihre Aktivitäten bzw. erfüllen öffentliche Aufgaben. Wie wir allerdings gesehen haben, wird der Begriff "öffentliche Aufgabe" auf sehr unterschiedliche Weise abgegrenzt. Wir wollen uns im folgenden - auch im Hinblick auf unser Vorgehen im Teil D - an die Definition von Peters anlehnen, der die staatlichen Aufgaben als einen Sonderfall der öffentlichen betrachtet. Diese Definition weicht indessen - wie in den folgenden Abschnitten deutlich wird - von der in der ökonomischen Literatur ab, die im allgemeinen von 
öffentlichen Aufgaben oder öffentlichen Gütern spricht und diese mit staatlicher Bedarfsdeckung gleichsetzt. Um hier Mißverständnisse zu vermeiden, werden wir im Kapitel $D$ auch bei der ökonomischen Diskussion von öffentlichen und staatlichen Aufgaben sprechen.

Zur Klärung der von Peters offengelassenen Frage, warum eine Aufgabe von öffentlichem Interesse ist und was den staat zur Ubernahme einer Aufgabe veranlaßt, kann der Ansatz von Arnims beitragen, die höchstmögliche Allgemeinwohlverwirklichung zum Kriterium für die Aufgabenverteilung zu wählen. Zur Konkretisierung des Allgemeinwohls dienen die hinter dem Grundgesetz stehenden Grundwerte. Mit ihrer Hilfe ist zu beurteilen, ob mit gesellschaftlichen oder mit staatlichen Steuerungsmechanismen bei der Erfüllung einer Aufgabe ein höheres Allgemeinwohl erreichbar ist.

Um die abstrakten staatsrechtlichen Kriterien in Gestalt der Grundwerte meßbar zu machen, muß ihnen ein operationaler Maßstab beigegeben werden, mit dessen Hilfe die Effizienz der staatlichen und gesellschaftlichen Steuerungsmechanismen verglichen werden kann. Um bei jeder einzelnen Aufgabe feststellen zu können, ob sie effizienter von staatlichen oder von gesellschaftlichen Steuerungsmechanismen erfüllt werden können, bedarf es ökonomischer Maßstäbe, die es ermöglichen, die Resultate der verschiedenen Steuerungsmechanismen im Hinblick auf die Grundwerteverwirklichung zu bewerten.

Die Zugrundelegung der Wertordnung des Grundgesetzes zur Bestimmung öffentlicher und staatlicher Aufgaben erweitert den ordnungspolitischen Rahmen, in dem sich die ökonomische Theorie bewegt. Die ökonomischen Modelle fußen nämlich auf der liberalen Staatsauffassung, deren oberste zielsetzung in der individuellen Freiheitsverwirklichung besteht. Unter ökonomischem Blickwinkel wird das höchste Allgemeinwohl erreicht, wenn die Individuen sich frei entfalten können. Der Markt sorgt dann auf diese Weise für den maximalen Wohlstand. Die Vernachlässigung 
der übrigen Grundwerte führt Jedoch dazu, daß einzelne Aktivitäten, etwa die Bedarfsdeckung über sogenannte meritorische Güter, mit Hilfe des ökonomischen Instrumentariums nicht hinreichend erklärt werden können bzw. im Lichte der ökonomischen Maßstäbe suboptimale Ergebnisse liefern können.

Die ausschließliche Orientierung an der freiheitlichen zielsetzung im Sinne der liberalen Staatsauffassung trifft nämlich, wie wir gesehen haben, nicht einmal auf den relativ staatsfreien Raum der Gesellschaft $z u$, weil die Allgemeinwohlorientierung die Berücksichtigung aller Grundwerte verlangt. Die Verschränkung von Staat und Gesellschaft des Grundgesetzes zeigt sich auch daran, daß die Realisierung der freiheitlichen zielsetzung nicht immer nur durch den Vorrang des gesellschaftlichen Steuerungsmechanismus erreicht wird, sondern daß es im modernen pluralistischen Gemeinwesen - wie oben an den Beispielen staatlicher Maßnahmen zur Sicherstellung der materiellen Freiheit in einzelnen Bereichen deutlich wurde - zahlreiche Situationen gibt, die staatliche Interventionen und Leistungen bedingen, damit bestimmte freiheitliche zielsetzungen überhaupt erst zur Geltung gelangen können.

Im Bereich des marktwirtschaftlichen Wettbewerbs, in dem die gesellschaftlichen Selbststeuerungsmechanismen dominieren und in dem die Verfolgung der freiheitlichen zielsetzung zu einem hohen Grad an Allgemeinwohlverwirklichung beiträgt, weil der marktwirtschaftliche Wettbewerb für eine effiziente Allokation der Faktoren und damit für einen optimalen Wohlstand sorgt, sind beispielsweise staatliche Entscheidungsmechanismen notwendig, um durch das Setzen von Rahmenbedingungen die Entstehung wirtschaftlicher Macht und der daraus resultierenden unerwïnschten Folgen in Form einer Freiheitsbeschränkung der Benachteiligten zu vermeiden. Dazu zählt ferner die auf das Sozialstaatsprinzip zurückzuführende Gewährleistung eines Existenzminimums durch staatliche Leistungen; denn das auf dem Grundwerte Freiheit beruhende Recht auf Daseinsentfaltung des Menschen setzt eine gewisse ökonomische Ausstattung voraus, die 
erst eine unabhängige und selbstverantwortliche Gestaltung des Lebens ermöglicht67). Ebensowenig ist die Neutralität des Staates gegenüber der in den Freiheitsrechten begründeten Pluralität der Anschauungen und Wertvorstellungen der Bürger immer mit staatlicher Enthaltsamkeit gleichzusetzen. Vielmehr kann ein staatlicher Beitrag geradezu eine Bedingung dafür sein, daß ein pluralistisches Angebot überhaupt erst ermöglicht wird und nicht nur als eine auf dem Papier stehende Leerformel erscheint, weil dafür die materiellen Grundlagen nicht vorhanden sind.

Es wurde deutlich, daß zur Beurteilung der Aktivitäten im gesellschaftlichen und im staatlichen Raum im Hinblick auf ihre Bedeutung für das Allgemeinwohl die Grundwerte zwar einen Gradmesser für die Allgemeinwohlverwirklichung abgeben, daß sie gleichwohl aber nicht dazu geeignet sind, die Resultate der gesellschaftlichen und staatlichen steuerungsmechanismen vergleichbar zu machen. Um die Effizienz der Steuerungsmechanismen messen zu können, bedarf es ökonomischer Kriterien.

Die Vorgehensweise bei der konkreten Bestimmung einer Aufgabe hat nach von Arnim in der Weise zu erfolgen, daß mit Hilfe der ökonomischen Kriterien die Ergebnisse der Aufgabenerfüllung durch gesellschaftliche oder staatliche Steuerungsmechanismen ermittelt und dann der Bewertung durch die Grundwerte unterworfen wird68). Als weiteres Resultat der bisherigen Utberlegungen zur Verteilung der Aufgaben auf die verschiedenen Träger im Gemeinwesen kann im Hinblick auf die Verwirklichung der freiheitlichen zielsetzung festgehalten werden, daß bei ihrem Funktionieren die gesellschaftlichen Steuerungsmechanismen den Vorzug vor staatlichen erhalten. Diese Erkenntnis beinhaltet in ihrem Kern nichts anderes als die Gültigkeit des Subsidiaritätsprinzips im Verhältnis von Staat und Bürger, obwohl das Subsidiaritätsprinzip selbst im Grundgesetz nirgends explizit verankert ist $^{69}$ ). 
Peter Saile - 978-3-631-75214-2

Downloaded from PubFactory at 01/11/2019 07:01:15AM

via free access 
II. Kollektive Bedarfsdeckung aus ökonomischer Sicht

1. Der intermediäre Bereich als Teil eines funktionalen Föderalismus

Die Erkenntnisse der ökonomischen Theorie des Föderalismus haben in der Finanzausgleichsdiskussion dazu geführt, daß die Problemstellung auf die zuvor ausschließlich von staatsrechtlicher Seite betrachtete Frage nach dem "zweckadăquaten Staatsaufbau" hin erweitert wurde; die bislang im vordergrund stehende Fragestellung der Verteilung der finanzwirtschaftlichen Kompetenzen auf die verschiedenen regionalen Aufgabenträger weicht zusehends einer funktionalen sicht, die auch die Aufgaben der nichtregionalen staatlichen Kollektive einbezieht.

Die normative Fragestellung dieser ökonomischen Theorie des Föderalismus ersetzt die überwiegend verwendeten staatsrechtlichen Normen durch ökonomische Kriterien, "... auf deren Basis die Verteilung von Aufgaben (die aus vorgelagerten, allgemeinen gesellschaftspolitischen zielen abgeleitet werden) sowie der damit korrespondierenden Ausgaben- und Einnahmenbedarfe auf mehrere Ebenen von Gebietskörperschaften beurteilt wird."70) Sie bedient sich dabei der Hilfe der Theorie der öffentlichen Güter ${ }^{71}$ ) und deren Anwendung auf Kollektive ${ }^{72}$ ). Daraus folgt zwangsläufig, daß das Hauptaugenmerk auf die Allokationszielsetzung gerichtet ist, wenngleich bei der Entscheidungsfindung auch verteilungs-, wachstums- und stabilitätspolitische Aspekte zu berücksichtigen sind. Unter dem Allokationsgesichtspunkt hat die Aufgabenverteilung dann eine Antwort darauf $\mathrm{zu}$ geben, in welchem Umfang die (der Art nach vorgegebenen) staatlichen Aufgaben erfüllt werden sollen, bzw. festzulegen, wie groß der Staatsanteil (bei normativ vorgegebenen Aufgaben) sein soll. Sie hat aber auch dafür zu sorgen, daß die Struktur der öffentlichen Leistungen mit den Präferenzen der Bürger in Einklang gebracht wird ${ }^{73}$ ). Mit letzterem soll aus ökonomischer Sicht der optimale zentralisierungsgrad für jede einzelne Aufgabe im Hinblick auf die Erfüllung der vorgegebenen 
staatswirtschaftlichen zielsetzungen herausgefunden werden ${ }^{74}$ ). Die grundlegende Behandlung des Finanzausgleichs leidet jedoch bislang an der unzureichenden Abstimmung der staatsrechtlichen und ökonomischen Analyse; denn beide Disziplinen bleiben weitgehend unter sich und verknüpfende Ansätze sucht man nahezu vergebens ${ }^{75)}$.

Ein solch verknüpfender Ansatz geht auf Walter Wittmann zurück. Er unterscheidet bei der Verteilung der vorgegebenen staatlichen Aufgaben auf die verschiedenen Ebenen staatspolitische, finanzwirtschaftliche und institutionell technische sowie ökonomische Kriterien ${ }^{76}$ ), wobei für ihn die ökonomischen vor den staatspolitischen rangieren 77 ). Zu den staatspolitischen zählt er das Subsidiaritätsprinzip, das aber für sich allein genommen wenig für die Verteilung der Aufgaben hergebe, weil es außer dem Grundsatz des Staatsaufbaus "von unten nach oben" im Einzelfall keine weiteren Entscheidungshilfen liefere ${ }^{78)}$, ferner das Solidaritätsprinzip und die Verwirklichung des Gemeinwohls ${ }^{79}$ ). Wittmann zeigt, daß die ökonomischen Maßstäbe der Größendegression und der externen Effekte durchaus geeignet sein können, zur Operationalität der vorgegebenen staatspolitischen Zielsetzungen beizutragen 80 ). Für die Anwendung auf ein bestimmtes Gemeinwesen müssen indessen die staatspolitischen zielsetzungen inhaltlich mit Hilfe der in der jeweiligen verfassung niedergelegten Grundentscheidungen konkretisiert werden.

Die Frage nach dem optimalen Staatsaufbau beschränkte sich bislang vorwiegend darauf, welchen regionalen Gebietskörperschaften die einzelnen vorgegebenen staatlich zu erfüllenden Aufgaben zuzuweisen sind. Eine Erweiterung der Föderalismusdiskussion um die intermediären Finanzgewalten, wie sie Mann schon früher - wenn auch unter institutionellen Aspekten - in die finanzwissenschaftliche Betrachtung einbrachte, hat erst in jüngster zeit stattgefunden $\left.{ }^{81}\right)$. Ursächlich für diese unzureichende Beachtung jener Einheiten dürften vor allem die Besonderheiten ihrer Leistungen und die andersgearteten Entschei- 
dungskompetenzen sein; denn unter dem Blickwinkel ihres finanzpolitisch bedeutsamen Anteils am staatlichen Gesamthaushalt hätten diese funktionalen Einheiten stärker berücksichtigt werden müssen 82 ).

Den Grundgedanken, prinzipiell alles staatliche Tun unter funktionalem Aspekt zu betrachten 83 ), haben wir schon bei Morselli gesehen. Bei dieser Sicht wird der regionale Föderalismus zu einem Unterfall bzw. zu einer "Spielart des funktionalen Föderalismus" 84 ).

Die intermediären Finanzgewalten (in der Begriffsfassung von Mann) werden als nicht regionale Körperschaften, die spezielle staatliche Funktionen wahrnehmen, in die allgemeine Finanzausgleichsdiskussion einbezogen 85 ). Die ökonomische Rechtfertigung kleinerer finanzwirtschaftlicher Einheiten trifft für die Parafisci in gleicher Weise wie für regionale Körperschaften $\mathrm{zu}$, wenn es darum geht, durch dezentral angebotene öffentliche Leistungen den eigengearteten Präferenzen der Bürger besser gerecht zu werden 86 ).

Eine umfassende Betrachtung der Allokationsaufgabe muß mithin neben den regionalen die funktionalen staatlichen Kollektive als Nutzer und/oder Anbieter von staatlichen Leistungen einschließen 87 ). Die gesamte gesellschaftliche Realität wird damit freilich noch keineswegs abgebildet. Der Grund dafür liegt in einem zu eng gefaßten Begriff der öffentlichkeit, der in der wirtschaftswissenschaftlichen Diskussion, wie bereits erwähnt, im allgemeinen mit staatlich gleichgesetzt wird. Das hat zur Folge, daß die Analyse zwangsläufig auf die Parafisci oder - um einen anderen Begriff Manns zu verwenden - hilfsfiskalischen Verzweigungen beschränkt bleibt und die vielfältigen Aktivitäten der Gruppen im Bereich des Öffentlichen - im Sinne dieser Arbeit - nicht erfaßt.

Eine Erweiterung der Finanzausgleichsdiskussion um die nichtstaatlichen gesellschaftlichen Gruppierungen hat Horst Zim- 
mermann auf der Grundlage des auf olson zurückgehenden ökonomischen Gruppenbegriffs vorgenommen 88 ). Den wichtigsten Vorteil gruppenspezifischer Leistungen sieht er in der größeren Nähe zu den Nachfragern und damit in einer besseren Abstimmung mit den Präferenzen der Bürger durch ein differenziertes Angebot. Dabei kann es dem Staat vorbehalten bleiben, durch die Vorgabe gewisser quantitativer und/oder qualitativer Standards oder mittels finanzpolitischer Instrumente dafür zu sorgen, daß die Leistungen in dem gewünschten Umfang sichergestellt werden $\left.{ }^{89}\right)$. Zimmermann siedelt den intermediären Bereich unter $\mathrm{zu}$ hilfenahme der ökonomischen Theorie der Kollektive zwischen dem Staat als dem alle Individuen und Gruppen umfassenden Gebilde, also gleichsam der größten Gruppe, die die Güter mit den höchsten externen Effekten bereitzustellen hat, und den reinen Privatwirtschaften an ${ }^{90}$ ). Die Abgrenzung von zimmermann bleibt aber, weil er staatsrechtliche Aspekte nicht berücksichtigt und sich vornehmlich auf ökonomische Kriterien stützt, nach denen die vorgegebenen Aufgaben auf die verschiedenen Träger zu verteilen sind, zu allgemein. Ferner vermögen seine Ausführungen zahlreiche Aktivitäten gesellschaftlicher Gruppierungen nicht zu erklären, weil sie altruistische Triebkräfte nicht einbeziehen.

Will man, wie es der Absicht dieser Arbeit entspricht, das Wirken der Vielzahl von gesellschaftlichen Gruppierungen im Bereich des Öfentlichen als Teil eines funktionalen Föderalismus auffassen, dann muß der weite Bereich zwischen Staat und Individuum bestimmt und das öffentliche Betätigungsfeld gegenüber dem staatlichen und dem gesellschaftlich-privaten abgegrenzt werden. Um die Funktionen der intermediären Finanzgewalten von der Aufgabenseite her zu charakterisieren, müssen folglich politische wertvorstellungen und ökonomische kriterien herangezogen werden. Im folgenden sollen als ökonomische Merkmale die Gutseigenschaften näher daraufhin betrachtet werden, inwieweit sie Aufschluß über Allokationsstörungen oder Marktversagen geben und welche Formen der kollektiven Befriedigung der entsprechenden Bedürfnisse daraus aus ökonomischer sicht resultieren. 
2. Gütereigenschaften und Allokationsstörungen

a) Nicht-Ausschließbarkeit und Nichtrivalität

Im walrasianischen Gleichgewichtsmodell sorgt der marktliche Wettbewerb über den Preismechanismus für eine optimale Allokation der Ressourcen. Die im reinen Marktmodell enthaltenen restriktiven Annahmen treffen indessen für die Realität nicht zu. Weil die unterstellten Bedingungen eines vollkommenen Marktes in Wirklichkeit nicht erfüllt sind und die tatsächlichen Gutseigenschaften von den modellmäßigen abweichen, versagt bei bestimmten Gütern der Marktmechanismus und bewirkt eine unteroptimale Allokation 91 ).

Das Marktversagen hat Paul A. Samuelson an dem extremen Fall ("polar case") 92) der vollständig öffentlichen Konsumgüter gezeigt. Unter "collectiv consumption goods ..." versteht er Güter "... which all enjoy in common in the sense that each individual's consumption of such a good leads to no subtraction from any other individual's consumption of that good"93). Charakteristisch für das (rein) öffentliche Gut bei Samuelson ist also der gleiche gemeinsame Konsum aller. Wegen des gleichen gemeinsamen Konsums herrscht kein Wettbewerb, jeder konsumiert das Gut. Das bedeutet, daß das marktwirtschaftliche Prinzip nicht anwendbar ist. Auch über Wahlverfahren läßt sich der Umfang, in dem die Bedarfsdeckung bei den Individuen erfolgen soll, nicht bestimmen, da diese ihre wahren Präferenzen nicht angeben, wenn sie nicht gleichzeitig ihre zahlungsbereitschaft äußern müssen 94 ).

Etwas später brachte Musgrave seine Erklärung für das Marktversagen 95). Er geht davon aus, daß der Markt in den meisten Fällen zu einer optimalen Allokation der Ressourcen führt und auch für eine zufriedenstellende Bereitstellung solcher Güter sorgt, bei denen geringe Ineffizienzen auftreten. Nur dann, wenn der Marktmechanismus völlig versagt, wird man mit dem Problem konfrontiert, wie der staat zu einer besseren Allokation 
beitragen kann. "This ist the case of social wants proper ... Social wants are those wants satisfied by services that must be consumed in equal amounts by all. People who do not pay for the services cannot be excluded from the benefits that result, and since they cannot be excluded from the benefits, they will not engage in voluntary payments. Hence, the market cannot satisfy such wants. Budgetary provision is needed if they are to be satisfied at all"96). Die Bereitstellung dieser Güter wird allerdings dadurch erschwert, daß die wahren Präferenzen unbekannt sind und die Individuen wegen der Nichtausschließbarkeit auch keine Veranlassung haben, sie zu äußern 97 ).

Musgrave führt also das Marktversagen bei der Befriedigung der "social wants" ebenso wie Samuelson auf den nichtrivalisierenden Konsum und die Nichtanwendbarkeit des marktwirtschaftlichen Ausschlußprinzips zurück. Obwohl beide Kriterien im allgemeinen gemeinsam auftreten, kann es bei manchen Gütern der Fall sein, daß nur eines der beiden vorliegt. Die Rivalität des Konsums verlangt, daß der Nutzen eines Gutes nur demjenigen zufließt, also bei demjenigen internalisiert wird, der dafür einen Preis entrichtet. Wer dazu nicht bereit ist, wird vom Konsum ausgeschlossen 98). Insbesondere bei Gütern, um die die Konsumenten nicht zu rivalisieren brauchen, funktioniert in der Regel das Ausschlußprinzip nicht. Ferner gibt es Güter mit rivalisierendem Konsum, bei denen jedoch das Ausschlußprinzip wegen technischer Schwierigkeiten bei der Durchführung oder wegen Unwirtschaftlichkeit nicht anwendbar ist ${ }^{99}$ ).

b) Externe Effekte

An Samuelson schloß sich eine heftige Diskussion an, die vor allem seinen zu eng gewählten Begriff der öffentlichen Güter und den damit verbundenen bei allen gleichen gemeinsamen Konsum kritisierte. Es wurde eingewendet, daß reine Kollektivgüter selten seien. Die Realität zeige vielmehr Fälle, die als Mischgüter zu bezeichnen seien. Der gleiche gemeinsame Konsum aller 
sei deshalb unrealistisch und die daraus resultierenden wirtschaftspolitischen Konsequenzen wirklichkeitsfremd ${ }^{100}$ ).

Die Mischgüter können eine effiziente Allokation beeinträchtigen, weil um ihren Konsum zwar rivalisiert wird, aber gleichzeitig externe Effekte auftreten. Diese Güter, die zwischen den beiden Extremfällen des rein privaten und des reinen öffentlichen Gutes angesiedelt sind, sind in der Realität die weitaus häufiger anzutreffenden Fälle als reine öffentliche Gü$\operatorname{ter}^{101)}$.

Von positiven oder negativen externen Effekten spricht man, "... wenn und soweit (private) Aktivitäten in Konsum und Produktion sich nicht in privaten Erlösen bzw. Kosten niederschlagen"102). Francis M. Bator unterscheidet nach der Entstehungsursache drei verschiedene Formen von externen Effekten. Diese Formen treten zwar häufig nicht einzeln, sondern gemeinsam auf, jede einzelne von ihnen reicht aber für das Auslösen des Marktversagens aus ${ }^{103}$ ).

Ein erster Grund für externe Effekte ist nach Bator in der Eigentumsordnung zu suchen ("ownership externalities"). Der Marktmechanismus funktioniert hier nicht, weil Nichtzahler nicht von der Nutzung eines Gutes ausgeschlossen werden können, da die Rechtsordnung die Anwendung von Ausschlußpraktiken nicht erlaubt ${ }^{104}$ ). Externe Effekte können ferner technisch begründet sein ("technical externalities"). Steigende Skalenerträge bzw. sinkende Grenzkosten verhindern, daß Unternehmer zu Grenzkosten anbieten; denn sie würden in diesen Fällen Verluste machen 105). Diese Form der Externalitäten, die letztlich zu einer "unbefriedigenden Marktpreisbildung" führen, 106) interessiert im folgenden nicht weiter. Drittens sind die externen Effekte zu nennen, die mit öffentlichen Gütern verbunden sind ("public good externalities") 107).

Damit legt Bator allerdings einen weitgehenden Begriff der Externalitäten zugrunde. Externalitäten sind danach alle Abwei- 
chungen von den marktwirtschaftlichen Optimalbedingungen und werden so $\mathrm{zu}$ einem Gradmesser für Allokationsstörungen. Für diese erweiterte, nicht unproblematische Begriffsfassung spricht, "...daß sie einen allen Fällen des Marktversagens gemeinsamen Kern freilegt: die mögliche Diskrepanz zwischen individueller und kollektiver Rationalität, verursacht durch einen in der individualistischen Wirtschaftsordnung prinzipiell angelegten - um die 'externen' Effekte - verengten Entscheidungshorizont."108) So problematisch diese Definition ist, weil sie den Kreis der öffentlichen Güter sehr weit faßt ${ }^{109}$ ), erscheint sie für die Zwecke dieser Arbeit doch geeignet, da sie als Maßstab für die marktwirtschaftlichen störungen dienen kann und auch die Einbeziehung der meritorischen Güter erlaubt, auf die noch eingegangen wird.

Auch Musgrave und Samuelson stellen in ihren neueren Veröffentlichungen bei der Definition der öffentlichen Güter in erster Linie auf die externen Effekte als Merkmal ab110). Definiert man öffentliche Güter auf diese Weise und läßt man zusätzliche Unterscheidungsmerkmale vorläufig außer Betracht, dann zeichnen sich vollständig öffentliche Güter dadurch aus, daß sie ausschließlich externe Effekte aufweisen, die zu einer identischen Bedarfsdeckung aller führen und die an dem einen Ende einer Skala liegen, an deren anderem Ende die rein privaten Güter angesiedelt sind. Dazwischen liegen - mit abnehmendem Grad an Externalitäten - die Mischgüter. Letztere umfassen einen sehr weiten Güterbereich, da nahezu von jedem Gut mehr oder weniger positive oder negative Externalitäten ausgehen. Entscheidend für die Charakterisierung eines Gutes wird somit das Ausmaß seiner externen Effekte. Je höher der Grad der Externalitäten bei einem Gut liegt, desto weniger wird es über den Preismechanismus erfaßt ${ }^{111}$ ). Voraussetzung für die Nicht-Ausschließbarkeit sind folglich nicht internalisierbare positive oder negative externe Effekte, die bewirken, daß "...die Nutznießer externer Vorteile nicht von der Nutzung ausgeschlossen werden können und sich die von den externen Nachteilen Betroffenen nicht zu wehren vermögen".112) Die Folge ist eine - Je nach- 
dem, ob positive oder negative externe Nutzen vorliegen - Unter- oder Ubberversorgung des Marktes. Im Extremfall, wenn der gesamte Nutzen eines Gutes externer Natur ist, rivalisiert der Konsum überhaupt nicht und der marktwirtschaftliche Preisbildungsmechanismus versagt vollständig ${ }^{113}$ ).

Den Nutzen eines reinen öffentlichen Gutes können alle Individuen in gleichem Maße in Anspruch nehmen, unabhängig vom Ort, an dem die Leistung bereitgestellt wird, sowie unabhăngig von der Nutzungsweise und/oder der Nutzungsintensität eines Gutes durch andere Mitglieder des Kollektivs.114) Das spezifische Wesensmerkmal öffentlicher Güter sind "...Externalitäten, die 'arise from the act of producing' (Buchanan) und die aus der Unteilbarkeit der Leistungen oder der 'nonrivalness' der Nachfrage nach diesen Leistungen herrühren. Aufgrund der spezifischen Gutseigenschaften entstehen bei diesen Gütern folglich die Konsumexternalitäten zwangsläufig dann, wenn diese Güter produziert oder bereitgestellt werden.115)

In der Realität hat man es jedoch selten oder gar nicht mit reinen, sondern mit unvollständig öffentlichen Gütern zu tun, bei denen immer zumindest ein Teil des Nutzens unmittelbar auf einen bestimmten Nutzer(-Kreis) zurechenbar ist. Bei Mischgütern ist es für die Wohlfahrt des einzelnen Nutzers daher durchaus nicht unerheblich, wieweit er vom Ort der Leistungsbereitstellung entfernt ist und in welcher Weise diese Guter von anderen Kollektivmitgliedern genutzt werden ${ }^{116)}$.

Je nach der Entfernung zum Ort der Bereitstellung messen die einzelnen Individuen den unvollständig öffentlichen Gütern eine unterschiedliche Bedeutung $\mathrm{zu}$, mit der Folge, daß diese Güter mit verschiedenen Gewichten in die Nutzenfunktionen der einzelnen Individuen eingehen ${ }^{117}$ ). Das legt den Schluß nahe, daß die Inanspruchnahme und damit der Nutzen eines Gutes mit der räumlichen Entfernung immer mehr abnehmen und die externen Effekte schließlich dort bedeutungslos werden, wo der Nutzen des Gutes den Opportunitätskosten seines Erwerbs, wie z.B. An- 
reise- oder Transportkosten, Informationskosten etc., entspricht ${ }^{118}$ ).

Bei gegebener Kapazität kann selbst bei reinen öffentlichen Gütern die Bedürfnisbefriedigung durch die Nutzungsweise und Nutzungsintensität des Gutes eingeengt werden. Vom Erreichen der Kapazitätsgrenze an werden die einzelnen Individuen bei zutritt neuer Nutzer in ihrer Bedürfnisbefriedigung eingeschränkt. Die externen Effekte nehmen ab, ein gleicher gemeinsamer Konsum ist nicht mehr gegeben, er beginnt zu rivalisieren ${ }^{119}$ ). Das öffentliche Gut geht jedoch nicht automatisch in ein privates Gut über, sondern verliert durch die Beeinträchtigung im Konsum zunehmend seine ursprünglichen Eigenschaften ${ }^{120}$ ).

c) Meritorische Güter

Die von Musgrave als "merit wants" bezeichneten öffentlichen Güter nehmen eine Sonderstellung ein. Er versteht darunter Leistungen, "... die dem Ausschlußprinzip unterliegen. Sie (die Bedürfnisse; der Verf.) werden durch den Markt innerhalb der Grenzen, die die wirksame Nachfrage auferlegt, befriedigt und gelangen dann in den Bereich öffentlicher Bedürfnisse, wenn sie als so bedeutend angesehen werden, daß für ihre Befriedigung durch das öffentliche Budget über das hinaus Sorge getragen wird, was der Markt zur Verfügung stellt und was von privaten Käufern bezahlt wird. ... Andererseits können gewisse Bedürfnisse auch als unerwïnscht angesehen und ihre Befriedigung durch strafsteuern ... gedrosselt werden"121). Ein wesentliche Unterschied zu den rein öffentlichen Gütern liegt also darin, daß der Staat in die Konsumentensouveränität eingreift ${ }^{122}$ ).

Als Rechtfertigung für die staatlichen Eingriffe in die Konsumentenpräferenzen werden in erster Linie verzerrte Präferenzen bei den Individuen angeführt, die in unzureichender und unrichtiger Information - beispielsweise durch die Werbung - und in Irrationalität begründet sein können. Ursächlich für meritorische staatliche Interventionen können außerdem Verteilungs- 
aspekte sowie Aspekte öffentlicher Güter sein ${ }^{123)}$. Während Musgrave hinter dem Umverteilungsgedanken eine paternalistische Verhaltensweise vermutet ${ }^{124}$ ), zeigt er an den Beispielen der Lernmittelfreiheit und der freien ärztlichen Betreuung, daß die meritorischen Güter aufgrund externer Effekte auch den Charakter von öffentlichen Gütern haben und daß das Ausschlußprinzip lediglich auf Teile des Nutzens anwendbar ist ${ }^{125}$ ). Bruno F. Gröbner ${ }^{126)}$ sieht den Wesensunterschied zu den öffentlichen Gütern in der Rechtfertigung. Sind es bei den öffentlichen Gütern die externen Effekte, so sind es bei den meritorischen Gütern überwiegend bestimmte staatliche zielsetzungen, die eine Staatstätigkeit bedingen.

Diese Trennung trifft allerdings nicht ganz den Kern des Problems. Dabei wird nämlich verkannt, daß die meritorischen Eingriffe bei den "ursprünglich" privaten Gütern ebenfalls externe Effekte erzeugen. Denn es treten externe Effekte beim Konsum auf, wenn der staat zur Durchsetzung bestimmter sozialpolitischer Vorstellungen mit hoheitlichen oder finanzpolitischen Instrumenten korrigierend in die Marktergebnisse eingreift, um, unabhängig von den Präferenzstrukturen der einzelnen Individuen, die den Nutzen der entsprechenden Güter durchaus unterschiedlich einschätzen können - eine stärkere/schwächere Inanspruchnahme der betreffenden Güter und/oder eine Ausweitung/Reduzierung des Nutzerkreises zu erreichen ${ }^{127}$ ).

Die Interventionen in die Konsumentensouveränität leitet Musgrave aus der sozialen Führerrolle einer informierten Gruppe ab. Damit setzt er sich, und dessen ist er sich voll bewußt, derselben Kritik aus, die gegen die Auffassung von Ritschl vorgebracht wurde, daß nämlich solche Vorstellungen mit einem demokratischen Gemeinwesen nicht verträglich seien ${ }^{128}$ ). Die Einwände richten sich insbesondere gegen die Einschränkung der Konsumentensouveränität. Mit der Preisgabe des Grundsatzes der Konsumentensouveränität, so wurde argumentiert, habe diese Theorie keinen Platz mehr in der auf der individualistischen Staatsauffassung fußenden normativen Theorie der öffentlichen 
Güter, weil von dem Grundsatz des ökonomisch rational handelnden Individuums, das seine Bedürfnisse selbst am besten einzuschätzen weiß, abgegangen wird. Die Grundgedanken der meritorischen Güter würden letztlich auf der mit dem individualistischen Ansatz nicht zu vereinbarenden organischen Staatstheorie beruhen 129). Andererseits stellt sich bei näherem Hinsehen die Frage nach dem Eingriff in die Konsumentensouveränität auch bei den rein öffentlichen Gütern und insofern unterscheiden sich rein öffentliche und meritorische Güter unter diesem Aspekt gar nicht so sehr. Denn bei der Bereitstellung der öffentlichen Güter sind die wahren Präferenzen nicht bekannt, so daß bei diesen Gütern der exakte Umfang, in dem die Bedarfsdeckung erfolgen soll, ebenfalls nicht angegeben werden kann. Eine Bereitstellung öffentlicher Güter aufgrund politischer Entscheidungen, die in einem Ausmaß erfolgt, die nicht die Präferenzen der Nachfrager trifft, setzt sich folglich über die Konsumentenpräferenzen hinweg130). Freilich gibt es auch Stimmen, die die Annahme einer vollständigen Konsumentensouveränität unter Berufung auf die tatsächlichen Verhältnisse in Zweifel ziehen. Cornelius Liedtke beispielsweise glaubt sagen zu können, daß mit der eingeschränkten Konsumentensouveränität eine "... weitgehend realistische Beschreibung des Wissensstandes und des tatsächlichen Verhaltens der wähler-Konsumenten" gelingt 131). Vorausgesetzt, das träfe zu, dann ließen sich leicht die meritorischen Interventionen in die Allokation auch wohlfahrtspolitisch rechtfertigen. Die staatlichen Maßnahmen würden insgesamt zu einer höheren Wohlfahrt führen, weil sie, was indessen füglich in Frage zu stellen ist, von den "wahren" Präferenzen ausgehen wuirden 132 ). 
3. Folgerungen aus der ökonomischen Theorie für die Bereitstellung öffentlicher Güter

a) Wohlfahrtstheoretische Bestimmung der staatstätigkeit

Musgrave und Samuelson haben die öffentlichen Güter in die allgemeine Gleichgewichtstheorie eingebaut. Damit gelang ihnen - theoretisch bestechend - die Ableitung einer wohlfahrtsoptimalen Situation bei gleichzeitiger Bestimmung der Staatstätigkeit nach Art und Umfang. Die formal saubere Darstellung der wohlfahrtsmaximalen staatstätigkeit muß sich allerdings einiger Annahmen bedienen, die diese Modelle wegen ihrer Realitätsferne unpraktikabel erscheinen lassen ${ }^{133}$ ).

Reine öffentliche Güter wurden oben dadurch charakterisiert, daß die Individuen diese Güter ohne zu bezahlen konsumieren können, d.h., sie brauchen ihre wahren Präferenzen nicht aufzudecken. Die zuvor erwähnten Modelle setzen aber implizit bekannte Nachfragefunktionen der Individuen nach öffentlichen Gütern voraus. Die freiwillige Bekanntgabe der Präferenzen kann jedoch gerade bei öffentlichen Gütern wegen des "Trittbrettfahrer-Verhaltens" nicht erwartet werden. Die Uberwindung dieser Schwierigkeit wird in der Einführung eines politischen Wahlmechanismus gesehen, bei dem die Individuen durch die gleichzeitige Abstimmung über öffentliche Ausgaben und deren Finanzierung zur offenlegung ihrer Präferenzen gezwungen werden sollen 134 ).

Als Wahlverfahren kommen in Demokratien nur Mehrheitsentscheidungen in Betracht, bei denen Einstimmigkeit praktisch nie zu erzielen ist. Das bedeutet zwangsläufig, daß die überstimmten Minderheiten Nutzeneinbußen erleiden und die wohlfahrtsoptimale Situation nicht erreicht wird134a). Hinzu kommt, daß die Abstimmungsverfahren selbst nicht ohne Probleme sind. Einmal kann wahlstrategisches Verhalten eine offenlegung der wahren Präferenzen verhindern. Darüber hinaus hat Kenneth $\mathrm{J}$. Arrow gezeigt, daß bei dem von ihm angenommenen Wahlverfahren bei mehr- 
gipfligen Präferenzstrukturen keine eindeutigen Lösungen erzielt werden können ${ }^{135)}$. Gegen die Praktikabilität derartiger Wahlverfahren spricht ferner, daß insbesondere in Flächenstaaten mit einer großen Bevölkerung eine Abstimmung über jede öffentliche Ausgabe undurchführbar ist. Das ist allenfalls in kleineren, überschaubaren Kollektiven möglich. In großen Demokratien muß auf die indirekte Repräsentation, also die Abstimmung uiber Repräsentanten zurückgegriffen werden. Diese Vertreter pflegen jedoch nicht nur die Interessen der von ihnen vertretenen Individuen wahrzunehmen, sondern verfolgen im allgemeinen - wie besonders die ökonomische Theorie der Politik herausgearbeitet hat - durchaus auch ihre eigenen zielsetzungen. Eine unverfälschte Durchsetzung der wählerpräferenzen ist somit selbst für die Mehrheit nicht mehr gewährleistet ${ }^{136)}$.

Mit der Zuhilfenahme einer durch Wahlverfahren ermittelten sozialen Wohlfahrtsfunktion gelingt es zwar den wohlfahrtstheoretischen Modellen, die öffentlichen Güter nach Umfang und Struktur zu bestimmen, gleichwohl bleibt das Verfahren aber aus den oben erwähnten Gründen unpraktikabel. Es handelt sich letztlich um eine Lösung, die die aus der Nichtanwendbarkeit des Ausschlußprinzips und der Nichtrivalität des Konsums resultierenden Probleme lediglich theoretisch zu lösen ver$\operatorname{mag}^{137}$ ).

b) Nichtstaatliche kollektive Bedarfsdeckung ${ }^{137 a}$

Treten allokative Störungen aufgrund externer Effekte bei kollektiv nutzbaren Gütern auf, dann bedarf es zu deren Beseitigung nicht automatisch staatlicher Maßnahmen. Für den Fall, daß das Ausschlußprinzip anwendbar ist, ist eine Internalisierung der externen Effekte möglich, d.h., das "...kontrollierende Wirtschaftssubjekt (kann; der Verf.) mit der Drohung der Ausschließung aller Zahlungsunwilligen prinzipiell eine Kompensation der externen Vorteile durchsetzen"138). In Analogie zum Marktprozeß treten die von den Externalitäten Betroffenen, 
also Verursacher und Belastete bzw. Nutznießer, in private Verhandlungen ein, um eine Vereinbarung über eine Abgeltung der externen Effekte zu erreichen. Ob tatsächlich eine vollständige Kompensation der externen Effekte erfolgt, hängt zum einen von der tatsächlichen Höhe der Ausschließungskosten ab, d.h. wie sehr eine Drohung der Ausschließung Aussicht auf Erfolg hat, und zum anderen von der Bereitschaft der Verhandlungspartner, ihre wahren Präferenzen zu zeigen ${ }^{139}$ ).

"Demgegenüber ist ein ähnlich günstiges allokatives Ergebnis vom marktwirtschaftlichen System weit weniger zu erwarten, wenn technische oder ökonomische Gründe von vornherein keine potentielle Ausschließung zulassen." Bei der Untersuchung, inwieweit in einem solchen Falle eine Bedarfsdeckung von privater seite erfolgt, spielt es eine große Rolle, "...ob die Vorteile eines kollektiv nutzbaren Gutes einer großen oder einer kleine Gruppe von Wirtschaftssubjekten zugute kommen"140).

Eigentlich sollte man - wie es die traditionelle Gruppentheorie tat - annehmen, daß eine größere Anzahl von Individuen mit gleichen Bedürfnissen sich zusammenschließt, um die Bedürfnisse gemeinsam in der Gruppe zu verfolgen und zu befriedigen ${ }^{141)}$. Das trifft jedoch nur bedingt $\mathrm{zu}$.

Mancur Olson 142) hat gezeigt, daß bei großen Gruppen nicht alle Mitglieder im Gruppeninteresse tätig werden, wenn sie ökonomisch ratioal handeln und von altruistischem und irrationalem Verhalten abgesehen wird. Daher sind bei größeren Gruppen Zwang oder selektive Anreize zur Kollektivbildung erforderlich. Die selektiven Anreize müssen so ausgestaltet sein, daß nur diejenigen, die zur Bereitstellung des Kollektivgutes beitragen, in den Genuß von zusätzlichen, Privatgutcharakter besitzenden Leistungen des Kollektivs kommen. Der Anreiz muß allerdings so hoch sein, daß sich der Beitritt zu einem Kollektiv für das einzelne Individuum lohnt ${ }^{143}$ ). Die selektiven Anreize, die ausschließlich den Mitgliedern eines Kollektivs zufließen, können so zur Voraussetzung für das zustandekommen der kol- 
lektiven Organisationen werden. Erst in zweiter Linie kann dann das Kollektiv darangehen, sich um das eigentliche Kollektivgut zu sorgen ${ }^{144}$ ). Das bedeutet nichts anderes, als daß der kollektive zweck erst über den Umweg des als selektiver Anreiz wirkenden Privatgutes erreicht wird.

Ohne Zwang oder ohne selektive Anreize, die nichts mit dem gemeinsam interessierenden Gut zu tun zu haben brauchen, ist der einzelne bei rationalem Verhalten in einer großen Gruppe freiwillig weder dazu zu bewegen, an der Bildung einer Organisation zur Befriedigung des gemeinsamen Bedürfnisses teilzunehmen, noch ist er bereit, einen Beitrag zur Bereitstellung des entsprechenden Gutes zu leisten. Der Grund dafür liegt in den Eigenschaften der Kollektivgüter und ist derselbe, der auch ein Marktversagen verursacht. Das Ausschlußprinzip ist nicht anwendbar, folglich kann keiner von der Nutzung ausgeschlossen werden ${ }^{145)}$. Wenn ein einzelner in einer großen Gruppe seinen Beitrag verweigert, bleibt das ohne merklichen Einfluß auf die Kosten und Nutzen der anderen Kollektivmitglieder. Handeln nun aber alle Individuen nur in ihrem Selbstinteresse, dann kommt freiwillig kein Angebot des Gutes zustande.

Bisher wurde zwar deutlich, daß bei ökonomisch rationalem Verhalten kein oder nur ein unzureichendes Angebot von öffentlichen Gütern zustande kommt. Dies trifft jedoch auf öffentliche Güter, deren Externalitäten nur eine begrenzte Reichweite haben, also nur kleine Gruppen berühren, nicht uneingeschränkt zu. Hier sind u.U. freiwillige Vereinbarungen mit dem ziel der gemeinsamen Bedarfsdeckung möglich. In kleinen Kollektiven mit gemeinsamen Interessen kann es der Fall sein, daß der Vorteil eines einzelnen sogar die Gesamtkosten der Bereitstellung übersteigt und dieser deshalb die Kosten alleine übernimmt. Für kleine Gruppen gilt generell, daß die Bereitstellung um so wahrscheinlicher ist, je inhomogener die Vorteilseinschätzungen der einzelnen Kollektivmitglieder sind. Diejenigen, denen am meisten an dem Gut liegt, werden eher bereit sein, Kosten für diese Güter zu tragen. Das kann zu einer "Ausbeutung 
der Großen durch die Kleinen" führen, weil Kollektivmitglieder mit einem geringeren Interesse eine Art "free rider-Position" einnehmen können, da sie ja davon ausgehen können, daß diejenigen mit den höchsten Präferenzen auch bereit sind, höhere Kostenanteile zu übernehmen 146). Aber auch bei homogenen Präferenzstrukturen ist eine kollektive Bedarfsdeckung nicht ausgeschlossen, da kleine Gruppen überschaubar sind und die Verhaltensweisen der einzelnen Mitglieder spürbare Auswirkungen auf alle anderen Mitglieder haben. Der von der Gruppe ausgeübte soziale Druck und etwaige bestehende soziale Beziehungen genügen oft, um "unsolidarisches" Verhalten einzelner Mitglieder zu verhindern 147 ).

Differenzierter und unbestimmter sieht das Ergebnis bei Gruppen mittlerer Größe aus. Bei sehr homogenen Präferenzstrukturen erscheint ein Angebot unwahrscheinlich. Die Gruppe selbst ist zwar noch überschaubar, jedoch fühlt sich niemand veranlaßt, die Initiative zu ergreifen. Anders mag es u.U. sein, wenn entweder inhomogene Präferenzstrukuren vorliegen und einzelne, die ein besonders großes Interesse an einer Leistung haben, die Initiative für die Bereitstellung des Gutes ergreifen 148). Oder wenn aufgrund von "Strafen" sozialer Natur, die in ihrer wirkung staatlichen Zwangmitteln gleichkommen können, etwa sozialem Druck, und aufgrund von sozialen Anreizen, die in Prestige, Ansehen, Ruhm usw. bestehen können, die Mitglieder veranlaßt werden, sich im Gruppeninteresse zu verhalten 149).

Eine weitere Ursache, die erschwerend auf die freiwillige Bildung von Organisationen zur Befriedigung von Kollektivbedürfnissen einwirkt, ist nach olson darin zu sehen, daß mit zunehmender Zahl der Gruppenmitglieder die Kosten der Kollektivbildung aufgrund von vermehrten Verhandlungs-, Informationsund anderen Kosten steigen. Das heißt, je größer die Gruppe ist, um so schwieriger wird es, eine Übereinkunft zu erzielen 150 ). 
Ein Grund für die Entstehung kleinerer und mittlerer freiwilliger Rollektive kann z.B. in der Unzufriedenheit mit staatlichen Leistungen liegen. Die staatliche Bedarfsdeckung orientiert sich gewöhnlich an den Bedürfnissen des "median voters" . Das führt bei Minderheiten mit abweichenden Präferenzstrukturen zu einer Unterversorgung, weil keine oder nicht genügend Rücksicht auf deren heterogene Präferenzstrukturen genommen wird 151).

Die bisherigen Ưberlegungen fußten auf der in der ökonomischen Theorie im allgemeinen zugrundegelegten Annahme des ökonomisch rationalen Verhaltens, d.h. des Strebens nach Eigennutz und der Maximierung der eigenen individuellen Wohlfahrt. Mit dieser Beschränkung auf den ökonomischen Rationalitätsbegriff versperrt die Theorie sich selbst den Blick auf das gesellschaftlich durchaus bedeutsame Wirtschaften von Kollektiven, deren Handeln nicht oder nicht primär vom ökonomischen Rationalkalkül geleitet wird, sondern deren Verhaltensweisen von moralischen Beweggründen, Ideologien, Weltanschauungen, religiösen Überzeugungen usw. beeinflußt werden 152). Selbst wenn die Bedeutung des uneigennützigen Verhaltens in wirtschaftlichen Angelegenheiten nicht so groß eingeschätzt wird ${ }^{153)}$, können - wie insbesondere die älteren Finanzwissenschaftler gezeigt haben - altruistische Triebkräfte namentlich im sozialen, kulturellen und religiösen Bereich ursächlich für eine freiwillige Bereitstellung von kollektiven Leistungen sein.

Altruistisches Handeln liegt strenggenommen lediglich vor, wenn keinerlei Gegenleistung erfolgt. Nun ist allerdings nicht jede freiwillige unentgeltliche Leistung so uneigennützig wie es zunächst scheint. So kann, wie wir schon bei Adolph Wagner gesehen haben, wohltätiges Tun zweifellos demjenigen einen Nutzen stiften, der eine moralische Befriedigung darin sieht, anderen etwas zu geben oder anderen zu nützen. Ganz uneigennützig ist es auch nicht, wenn jemand zwar für eine freiwillige Leistung keine finanzielle Gegenleistung erhält, dafür jedoch 
nicht geldwerte Leistungen wie Ehre, Ansehen usw. als gleichoder höherwertige Gegenleistung betrachtet ${ }^{154}$ ).

Man könnte nun daran gehen, diese anderen Verhaltensweisen durch die Verwendung eines Rationalitätsbegriffes zu erfassen, der über den in ökonomischen Theorie gebräuchlichen hinausgeht. Rational wäre es dann, wenn Individuen ihre Entscheidungen auf der Grundlage einer konsistenten Präferenzordnung träfen, d.h. die einzelnen Alternativen nach der relativen wichtigkeit oder Nützlichkeit auswählen würden 155). In eine so bestimmte Präferenzordnung könnten nicht nur dem Eigennutz i.e.S. unterliegende Bedürfnisse eingehen, sondern auch ziele, die das Individuum unter anderen als ökonomischen Verhaltensmustern auswählt(156). Für die Erklärung bestimmter Kollektive, die nicht bzw. nicht ausschließlich auf Eigennutz beruhen, könnte ein so weitgefaßter Rationalitätsbegriff hilfreich sein 157).

Diese mögliche Erweiterung des Rationalitätsbegriffs in dem Sinne, daß jegliches Handeln zu bestimmten Zwecken rational sei, weil es der Befriedigung individueller Bedürfnisse diene und insofern einen Nutzen abwerfe, ist nicht unproblematisch. Olson lehnt sie mit der Begründung $a b$, daß seine Theorie "keine solche umfassende und fragwïrdige Definition von Rationalität" erfordere ${ }^{158}$ ).

Seiner Auffassung nach haben solche Motive wie gesellschaftliche Stellung und Geltung durchaus eine große Bedeutung für die Bildung freiwilliger Kollektive. Da er diese als individuelle Güter betrachtet, die in gleicher Weise wie finanzielle Gegenleistungen als selektive Anreize wirken, stehen sie auch nicht im Gegensatz zum ökonomisch rational handelnden Individuum ${ }^{159}$ ). Anders sieht es seiner Meinung nach allerdings bei Anreizen aus, die etwa moralischer, erotischer oder psychologischer Natur sind. Er verkennt nicht, daß diese zu einer freiwilligen Bereitstellung eines Kollektivgutes beitragen können, führt das dann aber darauf zurück, daß diese Motive bei den im gemeinsamen Interesse handelnden Individuen als selek- 
tive Anreize wirken. Einer Heranziehung solcher Triebkräfte zur Erklärung des gruppenorientierten Handelns hält er indessen entgegen, daß erstens diese Verhaltensweisen bei den Individuen empirisch nicht nachweisbar seien, folglich die Theorie ebenfalls nicht nachprüfbar wăre. Zweitens seien solche Rechtfertigungen für kollektives Handeln überflüssig, weil es dafür genügend andere Erklärungen gäbe und drittens gibt er schließlich zu bedenken, daß die meisten Gruppen für ihre eigenen und nicht für die Zwecke anderer Gruppen arbeiten wïrden. Daher sei es nicht einsichtig, daß Individuen aus moralischen Beweggründen aktiv würden $\left.{ }^{160}\right)$. Aufgrund des Verzichts auf moralische Beweggründe mu $\beta$ er allerdings zugeben, daß seine Theorie auf bestimmte Kollektive nicht unbedingt anwendbar ist. Das trifft vornehmlich auf philanthropische und religiöse Gruppen $\mathbf{z u}$, bei denen die Beziehungen zwischen den Mitgliedern und der Organisation im Hinblick auf die Ziele und Interessen sehr vielfältig sein können, Jedoch auch auf solche Gruppen, deren ziele "wirtschaftlich" nicht rational sind ${ }^{161)}$.

Allerdings stößt die Internalisierung der Externalitäten auf freiwilliger Basis bei der praktischen Anwendung auf erhebliche Schwierigkeiten. Namentlich bei größeren Gruppen ist kaum eine Einigung zu erzielen. Das liegt hauptsächlich daran, daß sich Verhandlungen nur lohnen, wenn die damit verbundenen Transaktionskosten deutlich geringer sind als ein zu erwartender Verhandlungsgewinn. Während das bei kleineren, überschaubaren Gruppen noch am ehesten möglich erscheint, wird es um so unwahrscheinlicher, je größer der einzubeziehende Personenkreis wird ${ }^{162}$ ). Für den Fall, daß sich die Verhandlungspartner einig werden, heißt das nicht automatisch, daß die Ergebnisse auch unter Wohlfahrtsaspekten optimal sind. Gerade bei kleineren Gruppen ist nicht auszuschließen, daß einzelne Verhandlungsteilnehmer über eine größere Verhandlungsmacht verfügen und das Resultat zu ihrem Vorteil beeinflussen können ${ }^{163)}$.

Ohne Zwang und selektive Anreize erfolgt eine freiwillige kollektive Bereitstellung reiner öffentlicher Güter, oder von 
Gütern mit einem hohen Anteil an externen Effekten eher, wenn nicht ökonomisch rationales, sondern altruistisches Verhalten vorliegt. Auch heute noch spielen namentlich bei der kollektiven Bereitstellung in der sozialen, kulturellen, religiösen und wissenschaftlichen Sphäre Triebkräfte mit, die nicht ausschließlich auf die enge Konsummaximierung abstellen, sondern die darauf abzielen, etwas Nützliches für die Gesellschaft tun zu wollen 164). Organisationen, deren Mitglieder uneigennützig handeln, sehen bewußt über das Trittbrettfahrer-Verhalten ihrer Abnehmer hinweg, indem sie nicht die privaten Kosten und Erträge, sondern die sozialen Kosten und Erträge ihren Dispositionen zugrunde legen 165). Dabei ist es völlig unerheblich, ob hinter diesem uneigennützigen Handeln egoistische Motive stehen, die der Befriedigung moralischer, sittlicher, gesellschaftlicher oder anderer Werte und Bedürfnisse dienen.

\section{c) Staatliche Maßnahmen zur Beseitigung allokativer störungen}

Grundsätzlich gilt für eine marktwirtschaftliche Ordnung, daß die Allokationsfunktion dem Markt überlassen bleiben soll, soweit dort im Vergleich zum Staat die besseren Ergebnisse erzielt werden. Geringe marktliche Ineffizienzen geben noch keinen Hinweis für eine bessere Befriedigung durch den Staat; denn dessen Mängel und Unwirtschaftlichkeiten, die gemeinhin unter dem Stichwort "Staatsversagen" behandelt werden, dürfen nicht vernachlässigt werden ${ }^{166)}$. Da sich in einem marktwirtschaftlichen System die Allokation der Faktoren an den Marktpreisen orientiert und Externalitäten zu einem teilweisen oder vollständigen Marktversagen führen, kommt es zu einer nicht optimalen Situation. Bei positiven (negativen) externen Effekten wird zuwenig (zuviel) von dem entsprechenden Gut angeboten 167). Die Frage nach staatlichen Allokationsmechanismen stellt sich jedoch erst, wenn die Externalitäten ein solches Ausmaß angenommen haben, daß erhebliche Beeinträchtigungen bei der Versorgung zu befürchten wären. 
Für die Fälle, in denen die nichtstaatlichen Internalisierungsmaßnahmen versagen, stehen verschiedene staatliche Möglichkeiten der Beseitigung der von externen Effekten verursachten allokativen Störungen offen. Die einfachste Art, negative externe Effekte zu vermeiden, bestünde in der entsprechenden Gestaltung der Rechtsordnung. Mit einem Verbot der Handlungen, die negative externe Effekte hervorrufen, könnten die von Privaten ausgehenden Externalitäten unterbunden werden ${ }^{168)}$. Entsprechend könnte bei positiven Externalitäten so verfahren werden, daß die Nutznießer positiver externer Effekte verpflichtet werden, dafür eine Entschädigung zu entrichten. Die Regulierung mit Hilfe von Geboten und Verboten, also hoheitlichen Eingriffen des Staates, kann in abgestufter Dosierung erfolgen. Außer mit absoluten Geboten und Verboten kann der staat mit der den Privaten einen größeren Freiheitsraum belassenden Vorgabe von Normen und Standards versuchen, die Aktivitäten zu lenken und auf diese Weise ein von ihm erwünschtes allokatives Ergebnis herbeizuführen 169). Indessen ist eine solche Gestaltung, über gesetzliche Regelungen alle externen Effekte zu unterbinden, für jede Gemeinschaft, in der Menschen zusammenleben, unrealistisch. Diese Vorgehensweise hätte nämlich eine vollständige Isolierung der einzelnen Individuen zur Folge. "Jegliche interindividuellen, also gesellschaftlichen Beziehungen würden unmöglich gemacht ${ }^{170}$ ). Gesetzliche Regelungen des gesellschaftlichen Lebens dürfen demnach nicht zu einer Kappung der sozialen Beziehungen führen. Ihre primäre Aufgabe besteht vielmehr darin, für das Zusammenleben im Gemeinwesen einen ordnenden Rahmen abzustecken ${ }^{171)}$.

Neben diesen Interventionen mit Hilfe hoheitlicher Ge- und Verbote kommen vor allem die finanzwirtschaftlichen Instrumente zur Beseitigung der Allokationsstörungen in Betracht ${ }^{172}$ ). Außer der staatlichen Güterbereitstellung sind das Steuern und Transfers, mit denen der staat versucht, so auf die Entscheidungskalküle der Individuen einzuwirken, daß sie ihre Entscheidungen in die gewünschte Richtung ändern 173). 
Bei den als Mischgüter bezeichneten Leistungen ist nicht von vorneherein eine staatliche Allokationstätigkeit notwendig. Es handelt sich um "teilbare" und "über den Markt verteilbare Güter", die durch Externalitäten gekennzeichnet sind, die beim Verbrauch auftreten. Bei diesen Gütern rivalisiert ein mehr oder minder großer Teil im Konsum und unterliegt dem Ausschlußprinzip. Gleichzeitig sind mit ihrem Konsum externe Effekte in unterschiedlichem Ausmaße verbunden. Läßt man sozialpolitische Zielsetzungen vorläufig außer Betracht, dann begründen die externen Effekte bei den Mischgütern im allgemeinen noch keine staatliche Bedarfsdeckung, weil in gewissen Grenzen eine private Bereitstellung erfolgt. Der staat kann dabei versuchen, mit Steuern und Transfers, deren richtige Dosierung indessen nicht leicht ist, weil ihr Umfang dem "Wert" der zu internalisierenden externen Effekte anzugleichen ist, die positiven bzw. negativen Externalitäten in private Erträge bzw. Kosten umzuwandeln 174 ).

Anwendung finden die finanzwirtschaftlichen Instrumente etwa beim Verursacherprinzip, bei dem diejenigen, die negative Externalitäten verursachen, mit Steuern belastet und diejenigen, die positive externe Effekte erzeugen, mit Transfers entschädigt werden. In seiner strengen Version fordert das Verursacherprinzip indessen, daß diejenigen, die eine Entscheidung getroffen haben, verpflichtet werden, diejenigen $z u$ entschädigen, die von den Folgen dieser Entscheidung negativ betroffen sind, bzw. daß diejenigen, die positive Externalitäten erzeugen, einen Anspruch auf Belohnung durch die Nutznießer haben 175). In dieser Form stellt das Verursacherprinzip eine Kombination aus hoheitlicher staatlicher Regulierung und finanzwirtschaftlichen Instrumenten dar und bedeutet letztlich eine staatliche Zwangsinternalisierung der externen Effekte.

Zur Durchsetzung der meritorischen zielsetzungen wirkt der Staat mit hoheitlichen Mitteln und finanzwirtschaftlichen Instrumenten so auf die Präferenzen der Bürger ein, daß diese ihr Verhalten in dem erwünschten Sinne verändern 176). Besonders 
ausgeprägt geschieht dies natürlich bei der hoheitlichen Regulierung durch Gebote und Verbote, etwa bei einer "oktroyierten Bedarfsdeckung"177), die als Daten in die Entscheidungskalküle der Wirtschaftssubjekte eingehen. Weniger ausgeprägt und dem marktwirtschaftlichen System konformer ist der Einsatz finanzwirtschaftlicher Instrumente, die den Wirtschaftssubjekten mehr Freiräume lassen und nur "die Bedingungen der Wahlfreiheit" modifizieren ${ }^{178)}$.

Ebenfalls mit einem finanzwirtschaftlichen Instrument wird der Staat schließlich tätig, wenn er bei vollständigem Marktversagen die Produktion bzw. die Bereitstellung der Güter selbst übernimmt ${ }^{179}$ ). Darunter fallen die reinen öffentlichen Güter in der Definition von Musgrave und Samuelson. Die Bedarfsdeckung muß bei diesen Gütern durch den Staat erfolgen, da der Markt bei ökonomisch rationalem Handeln versagt, d.h. niemand freiwillig bereit ist, für ein solches Gut einen Preis zu entrichten 180). Aufgrund der Gutsmerkmale kann niemand von der Nutzung ausgeschlossen werden, und jeder verfügt über die Möglichkeit der Inanspruchnahme. Wie das Beispiel der Landesverteidigung zeigt, genießt jeder den Schutz, unabhängig davon, wie sehr er den Schutz wïnscht oder - etwa bei einem Pazifisten - diesen sogar ablehnt ${ }^{181}$ ). Unbestritten ist das Marktversagen zumindest für die "traditionellen Aktivitäten"182) des Staates wie z. B. innere und äußere Sicherheit.

In welchem Umfang diese Güter vom Staat bereitgestellt werden sollen, kann indessen mit ökonomischen Kriterien allein nicht exakt entschieden werden. Dafür müssen zusätzlich politische Entscheidungsprozesse berücksichtigt werden 183). Diese politischen Entscheidungsprozesse haben im demokratischen Gemeinwesen die Funktion, den Willen der Staatsbürger zum Ausmaß der staatlichen Allokationspolitik zum Ausdruck zu bringen 184). "Wenngleich die Bewertung dieser kollektiven Bedarfsdeckung durch die einzelnen Individuen nach ihrer unterschiedlichen Präferenzstruktur divergiert, fließen die Leistungen (überwiegend) unteilbar allen $z u$, so daß die 'Vergesellschaftung' der Kosten 
und die Qualitätsbestimmung dieser öffentlichen Güter durch die demokratische Willensbildung sachgerecht erscheinen."185)

Bei der Diskussion um die Beseitigung der allokativen Störungen mit Hilfe finanzwirtschaftlicher Instrumente darf aber nicht übersehen werden, daß - mit Ausnahme der reinen oder nahezu vollständig öffentlichen Güter - Güter mit Externalitäten im Konsum bis zu einem gewissen Grade von der privaten Produktion bereitgestellt werden. Erfolgen von seiten des Staates Interventionen in die Allokation in einer der oben beschriebenen Formen, dann hängt es von deren Intensität $a b$, in welchem Umfang ein privates Angebot zustande kommt. Ob für die Privaten überhaupt ein Anreiz für die Bedarfsdeckung verbleibt, wird hauptsächlich von den Vorgaben bestimmt, die der staat hinsichtlich Preis und/oder Qualitätsstandards bei einem Gut verlangt ${ }^{186}$ ).

Führt die staatliche Normsetzung hinsichtlich Qualität und Quantität eines Gutes in der Konsequenz dazu, daß von allen Anbietern dieselbe einheitliche Leistung verlangt wird, dann entfällt für die Anbieter jeglicher Grund für einen Qualitätswettbewerb. Ein vielfältiges Angebot, das durch qualitätsmäßige Unterschiede versucht, auf die heterogenen Präferenzstrukturen der Nachfrager einzugehen, ist damit nicht mehr möglich ${ }^{187}$ ). Sollen die Leistungen unterhalb der Selbstkosten oder unentgeltlich erfolgen, bedarf es einer staatlichen Subventionierung, wobei in diesem Falle für die Anbieter jegliche Anreize für einen Preiswettbewerb fehlen. Treffen bei einem Gut restriktive staatliche Normierung und Preissetzung zusammen und kommt außerdem eine Konsumpflicht hinzu, dann haben die Anbieter weder die Möglichkeit des Preis- noch die des Qualitätswettbewerbs und werden ein Angebot unterlassen. Die Subventionierung dieser Güter ist ökonomisch nicht mehr sinnvoll. Der Staat muß diese Leistungen selbst bereitstellen. Das trifft weitgehend insbesondere auf sozialpolitisch motivierte Aktivitäten des Staates wie etwa im allgemeinen Bildungs- und Gesundheitswesen $\mathbf{z u}^{188}$ ). 
4. Grenzen der Aussagefähigkeit der Theorie der öffentlichen Güter

Mit den Uberlegungen in diesem Abschnitt soll herausgefunden werden, inwieweit die an den Gutseigenschaften anknüpfende Theorie der öffentlichen Güter einen Beitrag zu der Frage zu leisten vermag, wer im Gemeinwesen welchen Bedarf und in welcher Form befriedigt.

Unter Zuhilfenahme restriktiver Annahmen gelingt es zwar im Modell mit Hilfe des neoklassischen Gleichgewichtsinstrumentariums und der Theorie der öffentlichen Güter, die staatliche Betätigung nach Art und Umfang zu bestimmen, jedoch fehlt den Modellen jeglicher Realitätsbezug ${ }^{189}$ ). So lehnt beispielsweise Günter Hesse die Theorie der öffentlichen Güter als eigenständige Theorie zur Bestimmung der Staatstätigkeit entschieden $a b$, weil nach seiner Auffassung das der neoklassischen Gleichgewichtstheorie zugrundegelegte Verständnis des ökonomisch rational handelnden, voll informierten, alles wissenden Individuums völlig unvereinbar mit dem tatsächlichen Bild des Menschen als Teil eines riesigen Beziehungsgeflechtes in der Gemeinschaft sei(190). Ferner seien die Externalitäten eines Gutes kein generelles Kriterium, sondern sie würden ausschließlich auf den Normen und Rechten einer bestimmten Eigentums - und damit Rechtsordnung beruhen ${ }^{191)}$. Sie könnten mithin nicht Grundlage einer allgemeinen Theorie des Marktversagens sein. Geht man jedoch von einem konkreten Gemeinwesen und dem dieses bestimmenden Wertesystems aus, braucht die voller Bedenken steckende Anschauung von Hesse, die sicherlich ihre Berechtigung für eine allgemeine normative Theorie hat, nicht geteilt $\mathrm{zu}$ werden. Bei einer festgelegten Eigentums- und Rechtsordnung kann das Merkmal der externen Effekte dazu dienen, Güter zu charakterisieren und erste Hinweise auf den Träger und die Form der Bedarfsdeckung zu geben.

Es wurde deutlich, daß sich einigermaßen sichere Aussagen allenfalls bei öffentlichen Gütern machen lassen, die von einem 
großen Kollektiv genutzt werden und die ausschließlich (oder fast ausschließlich) Externalităten aufweisen. Weil hier freiwillig kein Angebot zustande kommt, bedarf es hoheitlicher Allokationsmechanismen. Außerdem erscheint bei diesen Gütern die Beteiligung aller an den Kosten angemessen, da der Nutzen dieser Güter nahezu unteilbar allen zufließt. Die

"Vergesellschaftung" der Kosten macht jedoch die Ausstattung des Staates mit hoheitlichen Rechten erforderlich, damit dieser die Bürger zwingen kann, einen Beitrag zur Bereitstellung der Kollektivgüter zu leisten. Der staatliche zwang bei der Beseitigung der allokativen Störungen steht keineswegs im widerspruch zum selbständig und selbstverantwortlich handelnden Individuum des demokratischen Staatswesens. Auch ohne sich auf die "Vertragstheorie" des Staates berufen zu müssen, gibt die Verfassung des demokratischen Gemeinwesens die Grundlage für den staatlichen Zwang ab; denn sie kann als ein Mindestmaß an demokratischem Grundkonsens aufgefaßt werden, den - wenn schon nicht alle - doch zumindest die überwiegende Mehrheit der Bürger akzeptieren.

Wir haben aber auch gesehen, daß es namentlich bei kleineren, überschaubaren Kollektiven zu einer freiwilligen gemeinsamen Bedarfsdeckung kommen kann. Eine freiwillige Bedarfsdeckung kann ferner durch selektive Anreize oder durch Triebkräfte, die vom strengen ökonomischen Rationalprinzip abweichen, ausgelöst werden. Werden indessen Kollektivgüter auf altruistischer Grundlage bereitgestellt, dann bedeutet das, daß die externen Effekte bewußt erzeugt werden. Eine Abgeltung dieser Externalitäten über das marktliche Preissystem oder andere Internalisierungsmechanismen wird nicht angestrebt und ist auch nicht erforderlich. Man kann somit bei denjenigen, die diese unentgeltlichen Leistungen in Anspruch nehmen, überhaupt nicht von Trittbrettfahrer-Verhalten sprechen. Es zeigt sich mithin hier ganz deutlich der Unterschied zu den Externalitäten, wie sie herkömmlicherweise verstanden werden und bei denen die durch das unerwünschte Trittbrettfahrer-Verhalten hervorgerufene unteroptimale Allokation durch geeignete Maßnahmen zu be- 
seitigen versucht wird. Bei altruistisch motivierten Aktivitäten weist zwar das Gut ebenfalls externe Effekte auf, die dem Nutznießer zukommen, diese brauchen indessen - sofern es sich um positive externe Effekte handelt - nicht ausgeglichen zu werden, weil sie der Verursacher bewußt erzeugt. Es ist deshalb nicht ganz einsichtig, wenn man vorschlägt ${ }^{192}$ ), der staat habe in diesen Fällen die Externalitäten abzugelten. Bewußt geschaffene und gewollte positive Externalitäten geben dem staat, vorausgesetzt er ist mit dem Umfang und der Qualität der Bedarfsdeckung zufrieden, im allgemeinen noch keine Veranlassung zu finanziellen Unterstïtzungen.

Ferner machen die bisherigen Ausführungen deutlich, daß sich für nichtstaatliche Anbieter ein weiter Entfaltungsraum insbesondere für solche öffentliche Güter eröffnet, deren Externalitäten lediglich eine begrenzte Reichweite haben, und für solche Leistungen, die trotz staatlicher Allokationsmaßnahmen einen Qualitätswettbewerb zulassen. Nichtstaatliche Anbieter, seien es private marktmäßige Anbieter oder freiwillige Kollektive, haben hier mit einem differenzierten Angebot die Möglichkeit, die durch ethische, kulturelle, religiöse, weltanschauliche und andere Wertvorstellungen geprägten heterogenen Präferenzen zu berücksichtigen 193). Erbringt der Staat selbst vergleichbare kollektive Leistungen, dann kann es aus ökonomischer sicht um der Befriedigung dieser heterogenen Präferenzen willen angezeigt sein, die privaten Anbieter im Ausmaß der Einsparungen beim staatlichen Angebot zu subventionieren. Auf diese Weise wird ein pluralistisches Angebot gewährleistet, wie es beispielsweise bei weltanschaulich oder konfessionell ausgerichteten privaten Schulen der Fall ist ${ }^{194}$ ).

Außerdem bringt die Theorie der öffentlichen Güter klar zum Ausdruck, daß - von den staatlichen Grundfunktionen als wenigen Ausnahmen abgesehen - selbst (fast) reine öffentliche Güter allein mit Hilfe ökonomischer Kriterien nur schwer einem Trăger zugewiesen werden können. Unmöglich erscheint es auch, ausschließlich anhand ökonomischer Maßstäbe verläßliche Aussagen 
über die Träger der Bedarfsdeckung bei den zahlreichen Mischgütern zu machen. Bei diesen Gütern erfolgt zwar von privater Seite ein Angebot, das indessen wegen der auftretenden Externalitäten nicht optimal ist. Bei den meritorischen Gütern liegt die besondere Problematik darin, daß aufgrund verzerrter Präferenzen bei den Konsumenten die Externalitäten nicht Bestandteil der individuellen Nutzeneinschätzungen sind und deshalb staatliche Eingriffe in die Konsumentensouveränität erforderlich sind. Den Mischgütern und den meritorischen Gütern ist aber gemeinsam, daß Konsumexternalitäten die Ursache der unteroptimalen Versorgung durch den Markt sind. Für die Beurteilung der optimalen Versorgung bei beiden Güterarten und die Bestimmung des "erwünschten" Bedarfs, die gleichzeitig die Frage nach den anzuwendenden Internalisierungsmechanismen und damit nach dem Träger einer Aufgabe beantworten, sind politische neben ökonomischen Bewertungen unumgänglich.

Im Hinblick auf die uns interessierende Fragestellung nach den Funktionsabgrenzungen von staatlichen und nichtstaatlichen Kollektiven in der öffentlichen Sphäre läßt die Theorie der öffentlichen Güter - wie wir gesehen haben - einiges offen und unbestimmt; sie stößt hier an Grenzen, die sie allenfalls mit äußerst realitätsfernen Annahmen zu überwinden vermag. Andererseits hat der öffentliche Bereich in der modernen, auf den individualistischen Vorstellungen des Utilitarismus fußenden ökonomischen Theorie keine allzu große Beachtung gefunden. Dies dürfte seinen Grund wohl darin haben, daß das Wirtschaften primär unter dem Blickwinkel des funktionierenden Marktes gesehen wurde. Die ökonomische Diskussion hat sich so, mit wenigen Ausnahmen, zusehends nur noch mit den Bereichen des Marktes und des staates befaßt. Die besondere stellung und die Funktionen der zahlreichen nichtstaatlichen Kollektive im öffentlichen Raum gerieten folglich weitgehend in den Hintergrund.

Um diesen öffentlichen Bereich zu erfassen, dürfen nicht nur die vom ökonomisch rationalen Verhalten geleiteten Kollektive betrachtet werden, sondern auch diejenigen, bei denen andere 
Motive vorherrschen. Man muß ferner versuchen, den engen, die Realität unzureichend erfassenden Erklärungshorizont der ökonomischen Erkenntnisse durch die Einbeziehung der relevanten politischen und gesellschaftichen Faktoren zu erweitern und $z u$ vervollständigen. Diese Verknüpfung der staatsrechtlichen mit den ökonomischen Maßstäben wird Gegenstand der nachfolgenden Uberlegungen sein. Der zielsetzung entsprechend wird dort der Schwerpunkt allerdings auf diejenigen Güter gelegt, die im öffentlichen Raum für die Aktivitäten der intermediären Finanzgewalten in Betracht zu ziehen sind. 
D. Ein integrierter Ansatz zur Abgrenzung der intermediären Finanzgewalten

I. Grundlagen des integrierten Ansatzes

Mit dem Ausdruck "integrierter Ansatz" wird hier der Versuch bezeichnet, ökonomische und staatsrechtliche Elemente bei der Kennzeichnung der Aufgaben der intermediären Finanzgewalten miteinander zu verknüpfen. Die bisherigen Ausführungen machten deutlich, daß weder staatsrechtliche noch ökonomische Kriterien allein imstande sind, die Verteilung der Aufgaben im Gemeinwesen zu lösen. Bei der Konkretisierung der einzelnen Aufgaben verweisen die staatsrechtlichen Ansätze auf ökonomische Maßstäbe, umgekehrt benötigt die ökonomische Theorie politische Bewertungen. Der folgende Ansatz will beide Betrachtungsweisen zusammenführen und mit den aufgestellten Kriterien einen Weg für eine prinzipielle Abgrenzung des öffentlichen Bereichs vom staatlichen einerseits und vom privaten Bereich andererseits aufzeigen und damit gleichzeitig Maßstäbe für die Verteilung der Aufgaben auf Staat, intermediäre Finanzgewalten und Private an die Hand geben. Eine genaue Bestimmung des Umfangs, in dem einzelne Aufgaben erfüllt werden sollen, ist mit dieser Vorgehensweise allerdings - wie noch zu zeigen sein wird - nicht möglich.

Den Ausgangspunkt unserer Utberlegungen zur Einordnung der intermediären Finanzgewalten in das gesellschaftliche Gefüge bilden die für das Gemeinwesen maßgeblichen Gestaltungsprinzipien der Verfassung. Wir nehmen an, daß diese Gestaltungsprinzipien, ohne die kein geregeltes zusammenleben in der Gemeinschaft möglich ist und die wir als "demokratischen Grundkonsens" bezeichnet haben, von allen Bürgern (oder zumindest der überwiegenden Mehrheit der Bevölkerung) akzeptiert werden. In den konkreten Ordnungsrahmen, den diese obersten zielsetzungen in Gestalt der Grundwerte vorgeben, müssen die intermediären Finanzgewalten bei der Erfüllung ihrer öffentlichen Aufgaben eingefügt werden. 
Die hinter dem Grundgesetz stehenden Grundwerte machen die Allgemeinwohlzielsetzung faßbar. Mit dem Grad der Verwirklichung der Grundwerte wird zugleich ausgedrückt, inwieweit die Allgemeinwohlzielsetzung erreicht wird. Da die Grundwerte sowohl im Bereich des Staates als auch im gesamten Gemeinwesen Gültigkeit haben, bewirkt deren Umsetzung, daß Staat und Gesellschaft nicht mehr isoliert nebeneinanderstehen, sondern miteinander verschränkt sind. Denn der Staat greift einerseits zur Erhöhung des Allgemeinwohls in die gesellschaftlichen Abläufe ein und andererseits erfüllen nichtstaatliche Kollektive zahlreiche öffentliche Aufgaben, die im Sinne des Allgemeinwohls sind bzw. das Allgemeinwohl berühren. Die mitverantwortliche Gestaltung des Gemeinwesens durch diese Gruppen beruht vor allem darauf, daß sie Leistungen bereitstellen, die sowohl in ihrem eigenen als auch von allgemeinem Interesse sind bzw. gruppenüberschreitende Auswirkungen haben. Das heißt, daß die Leistungen häufig nicht auf eine bestimmte soziale Gruppe beschränkt bleiben, sondern auf das übrige Gemeinwesen übergreifende Effekte zeitigen. Die Funktion dieser Gruppen als mitverantwortliche Gestalter des Gemeinwesens gewinnt ferner durch deren Einflußnahme auf die politische willensbildung an zusätzlichem Gewicht. In dieser mitverantwortlichen Gestaltung des Gemeinwesens manifestiert sich letztlich ihr öffentlicher Charakter und macht deutlich, daß sich ihr wirken nicht auf den rein privaten Bereich beschränkt.

Wie wir weiter vorne gesehen haben, erfüllen die intermediären Finanzgewalten öffentliche Aufgaben in der öffentlichen Sphäre, eine den Staat "umlagernde Zone", die dem privaten Bereich der Gesellschaft entwachsen, aber selbst noch nicht dem staatlichen Sektor zuzuordnen ist. Unabhängig davon, ob ihre Entstehung auf staatliche Ausgliederung zurückgeht (Parafisci im Sinne Fritz Karl Manns) oder sie urprünglich als Gruppen im privaten gesellschaftlichen Bereich angesiedelt waren, ist ihr wesentliches Kennzeichen die "Verschränkung", die daran ersichtlich ist, daß an der Erfüllung einer Aufgabe ein öffentliches Interesse besteht und bei der Bereitstellung der Leistung staatliche 
und/oder gesellschaftliche steuerungsmechanismen zusammenwirken. Legt man die Abgrenzungskriterien von Peters für die Definition von Aufgaben zugrunde, dann unterscheiden sich staatliche von öffentlichen Aufgaben durch die ausschließliche oder nahezu ausschließliche Anwendung staatlicher Steuerungsmechanismen. Die Bewertung des für staatliche und öffentliche Aufgaben gleichermaßen zutreffenden Merkmals des "Offentlichkeitsgrads" erfolgt am Maßstab der Grundwerteverwirklichung, der an die mit Hilfe der ökonomischen Theorie ermittelten Ergebnisse der gesellschaftlichen und staatlichen Steuerungsmechanismen bei der Güterbereitstellung angelegt wird. Private Aufgaben zeichnen sich demnach dadurch aus, daß mittels gesellschaftlicher Steuerungsmechanismen die höchste Allgemeinwohlverwirklichung erreicht wird ${ }^{1}$ ).

Aus der Verpflichtung des Staates auf die Allgemeinwohlzielsetzung resultiert für die Aufgabenverteilung die Konsequenz, daß im Gemeinwesen die einzelnen Aufgaben nach Maßgabe der bestmöglichen Grundwerteverwirklichung den verschiedenen Trägern zu übertragen sind. Ausgehend von der für ein demokratisches Gemeinwesen und für die Marktwirtschaft grundlegenden zielsetzung der freien und selbstverantwortlichen Entfaltung der Individuen folgt für den Staat, daß er sich überall dort zu enthalten hat, wo die gesellschaftlichen Selbststeuerungsmechanismen funktionieren und gemessen an allen Grundwerten bessere Ergebnisse als die staatlichen Entscheidungsmechanismen liefern. Aufschlüsse und Hinweise auf die anzuwendenden Steuerungsmechanismen gibt das Kriterium "Öffentlichkeitsgrad", in dem die ökonomischen und politischen Bewertungen einer Leistung ausgedrückt werden.

Mit dem రffentlichkeitsgrad als Maßstab, der im folgenden noch näher zu bestimmen sein wird, wird versucht, die bei der Bereitstellung von Gütern auftretenden Externalitäten auf bestimmte soziale Gruppen und die Allgemeinheit zu erfassen und dabei die politische Beurteilung der Bedarfsdeckung einzubeziehen, um auf diese Weise den spezifisch öffentlichen Charakter 
der gruppenbezogenen Aktivitäten zu messen. Die Effekte, die von der gezielten Einflußnahme der Gruppen auf die politische Willensbildung und die Staatstätigkeit ausgehen, sowie die daraus resultierenden Probleme werden bei der politischen Bewertung berücksichtigt. 
II. Der Öffentlichkeitsgrad als Maßstab

\section{Zum Begriff des Ŏffentlichkeitsgrades}

Der im folgenden verwendete Begriff des Öffentlichkeitsgrades lehnt sich an die Definition an, die Bonus ${ }^{2}$ ) in die Diskussion gebracht hat. Er definiert den öffentlichkeitsgrad an Hand der Außerkraftsetzung des Marktmechanismus bei einzelnen Gütern und der dabei auftretenden Allokationsstörungen ${ }^{3)}$, und mißt ihn an dem "... Ausmaß der Divergenz zwischen privatem und volkswirtschaftlichem Kalkül", also dem "Anteil der externen Effekte am Gesamtwert der Aktivität im Pareto-Optimum."4) Der Offentlichkeitsgrad beruht bei ihm im wesentlichen auf zwei Ursachen: erstens auf den externen Effekten bei öffentlichen Gütern und zweitens auf der Ausschaltung des Preismechanismus bei privaten Gütern aufgrund politischer Entscheidungen. Daneben nennt er als weitere Gründe die Utberlastung von Netzen und die Úberfüllung öffentlicher Anlagen ${ }^{5}$ ). Durch die Entkoppelung von Preis und Menge und die externe Festlegung einer der Größen entstehe für die Individuen eine Anreizwirkung zu strategischem Verhalten, weil sie nicht mehr gezwungen seien, ihre wahren Präferenzen zu äußern. Gesamtwirtschaftliches und individuelles Rationalkalkül fielen auseinander. Die Folge seien schwerwiegende Versorgungsstörungen, die immer weitergehende staatliche Zwangsregulierungen erforderlich machen würden ${ }^{6}$ ). Unter ordnungspolitischen Gesichtspunkten hält Bonus es deshalb für unabdingbar, den störenden రffentlichkeitsgrad so weit wie möglich herabzusetzen, entweder durch staatliche Interventionen oder durch verstärkte Anwendung des Preismechanismus bei einem institutionell erzeugten Offentlichkeitsgrad ${ }^{7}$ ).

Der Ansatz von Bonus leidet unter einer zu engen Betrachtung, weil er nicht auf die für die Ausschaltung des Preismechanismus maßgeblichen politischen Gründe eingeht. Insbesondere läßt er unberücksichtigt, daß bei bestimmten Gütern der Preismechanismus bewußt ausgeschaltet wird, um höherbewertete gesellschaftliche zielsetzungen, und damit ein höheres Allgemeinwohl, ver- 
wirklichen zu können. Dieser Blickwinkel ist ihm versperrt, weil er innerhalb eines wohlfahrtstheoretischen Modells argumentiert und er deshalb den öffentlichkeitsgrad eines Gutes ausschließlich mit dem ökonomischen Maßstab des funktionierenden Marktes messen kann.

In einem ähnlichen Sinne wie Bonus verwendet Lepelmeier ${ }^{8}$ ) den Offentlichkeitsgrad. Der Offentlichkeitsgrad als "... Gradmesser für das Mischungsverhältnis von privaten und öffentlichen Elementen bei einem konkreten Gut ..." beruht bei ihm entweder auf den Gütereigenschaften oder aber ist im Sinne der meritorischen Güter "politisch induziert"9). Lepelmeier drückt die von Smekal für die Abgrenzung der Parafisci gegenüber dem privaten Bereich verwendeten Merkmale der politischen Relevanz und der funktionalen Repräsentanz mit Hilfe des రffentlichkeitsgrades aus und verwendet diesen als Unterscheidungsmerkmal gegenüber dem privaten Sektor. Die auf den Gutseigenschaften beruhenden externen Effekte bestimmen durch ihre Intensität und Streuung die funktionale Repräsentanz der Parafisci ${ }^{10}$ ). Mit der funktionalen Repräsentanz bezeichnet man die umfassende sachliche und räumliche vertretung der intermediären Finanzgewalten für eine bestimmte Gruppe. "Aufgrund dieser funktionalen Totalrepräsentanz haben ihre Handlungsweisen auf alle Angehörigen der entsprechenden Gruppe, auch auf solche, die nicht als Mitglieder organisiert sind, Auswirkungen"11). Mit Hilfe des politisch induzierten offentlichkeitsgrades bei meritorischen Gütern drückt Lepelmeier die politische Relevanz "der jeweiligen Leistungserstellung" aus ${ }^{12}$ ). Ohne auf die tieferen Begründungen für die politische Relevanz einzugehen, dient sie ihm als weiterer Maßstab zur Einordung der funktionalen Gruppen zwischen privatem und öffentlichem Sektor ${ }^{13}$ ). Neben den von Smekal genannten Merkmalen des Strebens der Gruppen nach Beteiligung am politischen Willensbildungsprozeß durch Einflußnahme auf die Politik und durch Unterstützung des Staates hebt er bei der politischen Relevanz als Kennzeichen besonders hervor, daß die politischen Entscheidungsträger in den Leistungsprozeß der Gruppen intervenieren. Er weist ferner darauf hin, 
daß politische Relevanz und funktionale Repräsentanz eigentlich nie getrennt voneinander auftreten, sondern daß sie sich in gleicher Weise wie die korrespondierenden Kriterien der externen Effekte und der meritorischen Aspekte häufig überlagern und funktionale Repräsentanz selbst politische Relevanz verkörpern $k n^{14}$ ). Beispielsweise ist das der Fall, wenn Leistungen, an deren Erfüllung der Staat ein großes Interesse hat, von großen Kollektiven bereitgestellt werden. Hohe funktionale Repräsentanz verbunden mit einem hohen Organisationsgrad der entsprechenden sozialen Gruppe führen im allgemeinen auch zu einer höheren politischen Relevanz aufgrund ihres politischen Gewichts. Das erhöht die Möglichkeit der Einflußnahme auf die politische Willens- und Entscheidungsbildung und macht staatliche Interventionen zugunsten der sozialen Gruppe wahrscheinlicher.

Weitergehende zusammenhänge von funktionaler Repräsentanz und politischer Relevanz werden indessen von Lepelmeier nicht näher erläutert. Bei genauerem Hinsehen erweist sich die von ihm vorgenommene Begrenzung der funktionalen Repräsentanz auf die Wirkungen der Gruppenaktivitaten auf eine bestimmte soziale Gruppe als nicht ausreichend, weil er die über diese soziale Gruppe auf die Allgemeinheit hinausreichenden (Außen-)Wirkungen nicht erfaßt $\left.{ }^{15}\right)$. Außerdem gibt Lepelmeier wenig Aufschluß über die Einmischungen des Staates in die gesellschaftlichen Aktivitäten als dem zweiten Aspekt der Verschränkung zwischen Staat und Gesellschaft. Er weist zwar auf den politisch induzierten Offentlichkeitsgrad bei bestimmten Gütern hin, setzt sich dann aber nicht weiter mit diesem Problem auseinander, so daß er voll der Kritik der meritorischen Güter ausgesetzt ist. Das Hineinwirken des Staates in die Gesellschaft und seine Einflußnahme auf die Gruppenaktivitäten kann eine Rechtfertigung nur erhalten, wenn man die Wertvorstellungen des modernen pluralistischen Staates zur Erklärung heranzieht. Obwohl Smekal, an den Lepelmeier anknüpft, die politische Relevanz und die gegenseitige Verschränkung bei der Einflußnahme der Gruppen auf die politische Willensbildung und Entscheidung sieht ${ }^{16}$ ), 
bleibt letztlich bei ihm wie bei Lepelmeier die gegenseitige Verschränkung von staat und Gesellschaft, die einerseits auf den Außenwirkungen der Gruppenaktivitäten und andererseits auf dem Hineinwirken des Staates in den gesellschaftlichen Bereich beruht und das "Offentliche" der Gruppen ausmacht, teilweise erklärungsbedürftig.

Die Abgrenzung der Parafisci gegenüber dem Staat nehmen Smekal und Lepelmeier nicht mit Hilfe des Offentlichkeitsgrades, sondern mit den Merkmalen der Selbstverwaltung und der finanziellen Autonomie bei der Verfolgung ihrer Gruppeninteressen vor ${ }^{17}$ ). Sie gehen vom "status-quo" der bestehenden Parafisci und Gruppierungen aus und unterlassen es zu fragen, ob die Selbstverwaltung und Finanzautonomie bei den einzelnen Gruppen von den Aufgaben her, die sie erfüllen, begründet und notwendig sind.

Als Ansatzpunkt für die Abgrenzung gegenüber dem Staat müssen die von den Gruppen zu erbringenden Leistungen gewählt werden. Der dabei auftretende Öffentlichkeitsgrad der Güter gibt über die anzuwendenden Steuerungsmechanismen zum Erreichen der höchsten Allgemeinwohlverwirklichung die Intensität der Verschränkung von Staat und Gesellschaft wieder und kann somit als Maßstab für die für Parafisci wesentlichen Kennzeichen der Selbstverwaltung und der Finanzautonomie und damit für die Aufgabenerfüllung in weitgehend eigener Verantwortung dienen.

\section{Eine weitergehende Definition}

Die obigen Ausführungen haben gezeigt, daß mit dem Öffentlichkeitsgrad von Gütern, so wie er von Lepelmeier und Smekal gebraucht wird, die intermediären Finanzgewalten nur unvollkommen charakterisiert werden können und er deshalb für eine begründete Abgrenzung gegenüber dem staatlichen Sektor nicht geeignet ist. Eine weitergehende Begriffsbestimmung des Öffentlichkeitsgrades muß das Öffentliche der intermediären Finanzgewalten operationabel machen, indem die neben den gutsbedingten Exter- 
nalitäten zweite Komponente des öffentlichkeitsgrades, die auf politischen Interventionen beruht, inhaltlich konkretisiert wird.

In Anlehnung an die Vorgehensweise der oben beschriebenen älteren Finanzwissenschaftler - namentlich Schäffle, wagner und Sax - soll mit Hilfe ökonomischer Maßstäbe und unter zugrundelegung der hinter der konkreten Verfassung des Grundgesetzes stehenden Wertvorstellungen der öffentlichkeitsgrad der Güter ermittelt werden. Der Öffentlichkeitsgrad wird damit $z u$ einer Konkretisierung der im Ansatz von Peters (C.II.2.) offen gebliebenen entscheidenden Frage, warum eine Aufgabe von öffentlichem Interesse ist.

Smekal und Lepelmaier haben gezeigt, daß auch der erste Entstehungsgrund des öffentlichkeitsgrades, die gutsbedingten Externalitäten, durch die Intensität und Streuung der externen Effekte politische Relevanz verkörpern kann. Ausschließlich politische Relevanz drückt der zweite Entstehungsgrund aus, der auf einer politisch induzierten Außerkraftsetzung des Marktmechanismus beruht. Kriterium für die Außerkraftsetzung des Marktmechanismus und die Anwendung staatlicher Steuerungsmechanismen bei der Bereitstellung von Gütern ist der Grad der Allgemeinwohlverwirklichung. Für die Bestimmung der optimalen Versorgung hat das zur Folge, daß die Ergebnisse der Marktprozesse an der Grundwerteverwirklichung gemessen werden, um so die Differenz zwischen der marktwirtschaftlichen und der volkswirtschaftlich gewollten Bedarfsdeckung zu ermitteln. Auf welche Weise diese Allokationsstörung beseitigt werden kann, d.h., welche (Steuerungs-) Instrumente am besten geeignet sind, die gewünschte Versorgung mit bestimmten Leistungen zu erreichen, muß mit ökonomischen Maßstäben festgestellt werden. In Betracht kommt dafür eine breite Palette von Instrumenten, die - wie wir gesehen haben - von der Unterstützung gesellschaftlicher Steuerungsmechanismen bis zur vollständigen staatlichen Bereitstellung reichen. Da sich alle Bewertungen über die Bedarfsdeckung eines Gutes im Öffentlichkeitsgrad niederschlagen, 
ist damit ein Ansatzpunkt gegeben, über die anzuwendenden Steuerungsinstrumente, die für die gewünschte Bereitstellung von Leistungen erforderlich sind, die beiden zur Charakterisierung der intermediären Finanzgewalten wichtigen Maßstäbe Selbstverwaltung und Finanzautonomie einzubeziehen. Denn beide Kriterien finden ihren Ausdruck darin, wieviel Gestaltungsspielraum und Einfluß auf Umfang und Qualität eines Gutes die Steuerungsinstrumente, über die zugleich die Form der Finanzierung festgelegt wird, einem Parafisci bleiben.

Um das von uns als das "spezifisch Öffentliche" der intermediären Finanzgewalten Bezeichnete zu erfassen, ist es zunächst notwendig, mit Hilfe der Streuung und der Intensität der gutsbedingten externen Effekte die von diesen betroffene bzw. die für die Bereitstellung des Gutes in Betracht kommende soziale Gruppierung und damit deren funktionale Repräsentanz auszumachen. Einzubeziehen sind aber auch diejenigen externen Effekte, die über die primär betroffene soziale Gruppierung hinaus auf die Allgemeinheit ubergreifen und politische Relevanz verkörpern. Damit sind nicht die Externalitäten gemeint, die bei einer freiwilligen Bereitstellung durch einzelne Mitglieder einer bestimmten Gruppe bei den nichtorganisierten, die free-rider-Position einnehmenden Mitgliedern auftreten, sondern die Auswirkungen, die von der Bereitstellung eines Gutes über die Gruppe hinaus auf die nicht unmittelbar beteiligte Allgemeinheit ausgehen. Verdeutlichen läßt sich das am Beispiel der Gewerkschaften: Wegen der Allgemeinverbindlichkeitserklärung und der regelmäßigen Übernahme der Tarifabschlüsse für alle Arbeitnehmer in einem Unternehmen kommen nicht nur die gewerkschaftlich organisierten, sondern alle Arbeitnehmer in den Genuß der vereinbarten Einkommenserhöhungen. Die Wirkungen bleiben jedoch im Falle überhöhter Tarifabschlüsse nicht auf die Beteiligten, nämlich Arbeitnehmer und Unternehmer, beschränkt, wenn daraus Arbeitslosigkeit und/oder Inflation resultieren. Die Kosten erhöhter Arbeitslosigkeit belasten über erhöhte Bundeszuschüsse an die Bundesanstalt für Arbeit den Steuerzahler und bei höheren Beiträgen zur Arbeits- 
losenversicherung alle sozialversicherungspflichtigen Arbeitnehmer und alle Unternehmer, auch diejenigen, die nicht an der verursachenden Vereinbarung beteiligt waren. Die gesellschaftliche Bewertung der soeben dargestellten Außenwirkungen auf die Allgemeinheit trägt in hohem Maße zur politischen Relevanz einer Gruppe bei.

Das ist allerdings nur die eine Seite der das "Offentliche" ausmachenden Verschränkung zwischen staat und Gesellschaft ${ }^{18)}$. wie oben (C.I.) deutlich wurde, vollzieht sich das Wirken der intermediären Finanzgewalten nicht ausschließlich im staatsfreien Raum; der Staat des Grundgesetzes interveniert vielmehr in vielfältiger Weise unter Berufung auf die dem Allgemeinwohl dienenden Grundwerte in die gesellschaftliche Sphäre. Das zur Kennzeichnung des intermediären Bereichs gewählte Merkmal des రffentlichkeitsgrades eines Gutes muß daher so bestimmt werden, daß es beide Formen der Verschränkung von staat und Gesellschaft ausdrückt, nämlich politische Relevanz aufgrund einer hohen funktionalen Repräsentanz und aufgrund des politisch induzierten Öffentlichkeitsgrades bei meritorischen Gütern.

Diese Überlegungen haben für die Definition des nicht nur die gutsbedingten, sondern auch die auf gesellschaftlicher Bewertung beruhenden Externalitäten zum Ausdruck bringenden Offentlichkeitsgrades zur Folge, daß diese Externalitäten das Abweichen der Marktergebnisse von der höchstmöglichen Allgemeinwohlverwirklichung ausdrücken. Das Ausmaß der allokativen Störung wird in der Weise gemessen, daß das durch den Markt zustandegebrachte Ergebnis bei der Bereitstellung eines Gutes verglichen wird mit dem Angebot, das für das höchste Allgemeinwohl gemessen an der Verwirklichung der einzelnen Grundwerte erforderlich wäre.

Die Kritik an den meritorischen Gütern entzündet sich vor allem an dem staatlichen Eingriff in die Konsumentensouveränität. In einem modernen, auf der individualistischen staatsauffassung des Liberalismus aufbauenden Demokratie gebe es dafür keine 
Rechtfertigung. Bei der Definition des Öffentlichkeitsgrades haben wir jedoch neben der Berücksichtigung der gutsbedingten Externalitäten auch die auf politischer Bewertung beruhenden meritorischen Güter einbezogen, die im Grunde mit Musgraves merit wants identisch sind. Es stellt sich folglich die Frage nach der zulässigkeit und Stimmigkeit unserer Definition. Der Vorwurf gegen Musgrave richtet sich gegen den Bruch in der Argumentation, daß die von ihm begründeten meritorischen Güter nicht in das von ihm verwendete normative Modell passen, dem die Annahmen eines liberalen, auf der individualistischen Staatslehre aufbauenden Gemeinwesens zugrunde liegen. Dieser Vorwurf kann gegen die im Offentlichkeitsgrad zum Ausdruck gebrachten politischen Bewertungen nicht geltend gemacht werden, da der Öffentlichkeitsgrad auf der konkreten Verfassung des Grundgesetzes basiert. Solange die Verfassung und die in ihr enthaltenen Wertungen von allen oder zumindest den meisten Bürgern als allgemeiner Konsens anerkannt werden, ist die politische Bewertung anhand der gemeinsamen Werthaltungen zulässig und nicht systemwidrig.

Die den Öffentlichkeitsgrad ausmachenden Externalitäten beruhen entweder auf den Gutseigenschaften oder auf politischen Entscheidungen. Die gutsbedingten externen Effekte haben wir im letzten Kapitel eingehend behandelt; sie brauchen deshalb hier nicht noch einmal dargestellt zu werden. Wie wir gesehen haben, handelt es sich zum einen um Externalitäten, die bei ökonomisch rationalem Handeln aus der Konsumtion oder/und der Produktion resultieren und den Marktmechanismus je nach Grad der Externalitäten teilweise oder ganz außer Kraft setzen.

Wie die vorstehende Kritik an Bonus und Lepelmeier gezeigt hat, bleibt die rein ökonomische Betrachtung des politisch induzierten Öffentlichkeitsgrades unbefriedigend. Die oberste Zielsetzung für das gesamte Gemeinwesen ist die Verfolgung des Allgemeinwohls, das in den hinter der Verfassung stehenden Grundwerten konkretisiert wird. Die auf den liberalen Vorstellungen des Individualismus gründende ökonomische Theorie geht davon aus, 
daß die Wohlstandszielsetzung im Bereich des Marktes am besten dadurch verwirklicht wird, daß den Wirtschaftssubjekten die wirtschaftliche Betätigung selbst überlassen bleibt. Ein funktionierender Markt sorgt folglich für den größten Wohlstand, wenn der Verfolgung des Grundwertes Freiheit Priorität eingeräumt wird. Nur unterscheidet sich die reale Verfassung des Grundgesetzes von der reinen liberalen Staatsauffassung dadurch, daß das freiheitliche Prinzip nicht verabsolutiert und auf alle anderen Bereiche des Gemeinwesens übertragen wèrden darf. Denn das staatliche und teilweise auch das öffentliche Handeln unterscheiden sich vom Markt eben dadurch, daß unter Marktbedingungen eine unzureichende Bedarfsdeckung erfolgt, weil, abgesehen vom Marktversagen aufgrund der gutsbedingten Externalitäten, für das Allgemeinwohl wichtige Wertvorstellungen unberücksichtigt bleiben. Der Markt mit seiner Priorität für die freiheitliche zielsetzung bleibt auf den Bereich der Wirtschaft und die Verfolgung der Wohlstandszielsetzung beschränkt, wobei nach der Verfassung auch der Bereich des Marktes nicht mehr völlig staatsfrei ist, sondern staatliche Interventionen durchaus angezeigt sein können.

Die Wohlstandszielsetzung und das zu ihrer Verwirklichung angewandte Marktprinzip sind demnach keine obersten zielsetzungen des Gemeinwesens, sondern dem Allgemeinwohl nachgeordnet und verpflichtet. Der Markt hat folglich für das übergeordnete Allgemeinwohl eher einen instrumentalen Charakter ${ }^{19}$ ). Eine am Allgemeinwohl orientierte Bedarfsdeckung darf deshalb nicht nur an der größtmöglichen Einräumung von individuellen Freiheitsrechten und der Verwirklichung der ökonomischen Wohlstandszielsetzung im Sinne der individuellen Nutzen- und Gewinnmaximierung gemessen werden, sondern muß auch berücksichtigen, daß die Einräumung der formalen Freiheit wertlos sein kann, wenn die ökonomischen Voraussetzungen für ihre Inanspruchnahme fehlen (vgl. oben C.I.2.). Das heißt, daß neben den beiden Grundwerten Freiheit und Wohlstand zusätzlich die Grundwerte Gerechtigkeit und Sicherheit herangezogen werden müssen. Aus den Grundwerten ergeben sich die Rahmenbedingungen für das 
Wirtschaften. Diese Rahmenbedingungen verändern sich aber im Laufe der zeit, oder es kommen neue hinzu, wie z. B. der Umweltschutz. Die ökonomischen Modelle abstrahieren davon jedoch weitgehend und verabsolutieren das Marktprinzip, so daß dessen instrumenteller Charakter nicht mehr deutlich wird.

Bleiben die Ergebnisse der Steuerung durch den Markt hinter dem zurück, das nach der gesellschaftlichen Beurteilung nach Maßgabe der Grundwerte für wünschenswert erachtet wird, dann bedarf es, sofern nicht andere gesellschaftliche Selbststeuerungsmechanismen greifen, für eine bessere Allgemeinwohlverwirklichung staatlicher Interventionen, die die marktwirtschaftlichen Allokationsmechanismen ergänzen oder gar ersetzen.

Der Offentlichkeitsgrad ist demnach Ausdruck unbefriedigender Marktergebnisse bezogen auf das Allgemeinwohl, das weiter gefaßt ist, als die im Marktmodell verwendete Wohlfahrtsmaximierung. Werden diese allokativen Störungen mittels staatlicher oder gesellschaftlicher steuerungsmechanismen beseitigt, dann resultieren daraus in demselben Ausmaß Externalitäten der Produktion oder beim Konsum, in dem die Bereitstellung von der marktmäßigen und über Marktpreise abgegoltenen Nachfrage abweicht. So gesehen könnten die gutsbedingten Externalitäten ebenfalls auf die gesellschaftliche Bewertung anhand der Grundwerte zurückgeführt und als ein Unterfall aufgefaßt werden, nämlich als Maß für die unzureichende Verwirklichung der Wohlstandszielsetzung durch den Markt, die in der ökonomischen Theorie ihren Ausdruck im Wohlfahrtsoptimum findet. Aufgrund dieser Uberlegungen könnte man für die Definition des ర̆ffentlichkeitsgrades die Unterscheidung nach gutsbedingten und durch gesellschaftliche Bewertung induzierte Externalitäten aufgeben und ihn ganz einfach als Gradmesser der allokativen Störungen, ausgedrückt durch die korrespondierenden Externalitäten, im oben angesprochenen Sinne bezeichnen. 
3. Offentlichkeitsgrad und Steuerungsmechanismus

Nach den bisherigen Ausführungen gibt der Öffentlichkeitsgrad den Anteil der (positiven oder negativen) Externalitäten am Gesamtnutzen eines Gutes an und legt drei grobe Güterkategorien fest: Güter ohne externe Effekte mit einem Offentlichkeitsgrad von null. In diesem Fall stimmt die über den Marktmechanismus erfolgte Bedarfsdeckung eines Gutes mit der überein, die nach einer Bewertung anhand der Grundwerte erwünscht ist. Der Extremfall sind Güter mit ausschließlich externen Effekten, d.h., der Marktmechanismus bzw. (in den allermeisten Fällen) auch andere gesellschaftliche Selbststeuerungsmechanismen versagen bei der Bereitstellung dieser Güter vollständig. Deshalb müssen diese Güter vom Staat bereitgestellt werden. Dazwischen liegt der weite Bereich der Güter, deren Öffentlichkeitsgrad zwischen diesen beiden Polen liegt, und bei denen die Bedarfsdeckung über den Markt mit zunehmendem Anteil der Externalitäten abnimmt. Dieser zuletzt genannte Bereich bedarf einer ausführlicheren Betrachtung.

Der anzuwendende Steuerungsmechanismus wird durch die im ర̈ffentlichkeitsgrad ausgedrückten allokativen störungen als der Diskrepanz zwischen Marktergebnis und höchstmöglicher Allgemeinwohlverwirklichung bestimmt. Welche Mechanismen schließlich eingesetzt werden, hängt von der Streuung der Externalitäten, die die von den externen Effekten begünstigte oder benachteiligte soziale Gruppe und deren Größe festlegen, von der Intensität der Externalitäten, die den Grad des marktwirtschaftlichen Versagens anzeigt, von den für die kollektive Bedarfsdeckung maßgeblichen Triebkräften und vor allem von den politisch induzierten Entstehungsursachen der externen Effekte ab.

Wie oben deutlich wurde, sind es die Gutsexternalitäten und die politischen Bewerturgen, die ursächlich für das Auftreten der allokativen Störungen sind. Im ersten Fall bewirkt die Beseitigung der allokativen Störung eine Steigerung des Wohlstandes 
und eine bessere Verwirklichung der freiheitlichen zielsetzung. Die auf den Gutseigenschaften beruhenden Externalitäten und die dadurch bedingte teilweise Nichtanwendbarkeit des Ausschlußprinzips führen dazu, daß die Nutzen und Kosten nicht auf das eigenverantwortlich handelnde Individuum beschränkt bleiben, sondern die Wohlfahrt anderer Individuen positiv oder negativ beeinflussen. Die tiefere Ursache dafür ist im Wesen der Rechtsordnung angelegt, die die Eigentumsrechte nicht voll gewährleistet bzw. nicht voll gewährleisten kann, weil rechtliche, technische und wirtschaftliche oder vor allem gutsbedingte Beschränkungen der Anwendung von Ausschlußmechanismen entgegenstehen. Bei negativen Externalitäten werden dadurch automatisch andere Individuen in ihren Freiheitsrechten eingeengt, wenn die Rechtsordnung Handlungen nicht sanktioniert, die diese Effekte bewirken. Eine Internalisierung negativer Externalitäten mindert zwar - völlig korrekt - die freie Entfaltung der Handelnden, weil ihnen als Verursachern die Kosten der externen Effekte auferlegt werden bzw. die Erzeugung negativer Externalitäten untersagt wird, verhindert aber die von den externen Effekten ausgehende Einschränkung bei den Betroffenen bzw. schafft diesen einen Ausgleich. Insofern trägt die Internalisierung negativer Externalitäten zu einer Steigerung der Freiheits- und Wohlstandsverwirklichung und damit zu einem höheren Allgemeinwohl bei.

Bei gutsbedingten positiven Externalitäten trägt der Verursacher die Kosten eines Gutes, er ist allerdings nicht alleiniger Nutznießer. Andere Individuen können davon ebenfalls, ohne einen Beitrag zu leisten, profitieren. In den Fällen, in denen das Ausschlußprinzip nicht anwendbar ist, ist es nicht möglich, daß dem Verursacher der externen Effekte auch allein die Ergebnisse seines Tuns zugute kommen, das der Eigenverantwortlichkeit seines Handelns entsprechen wïrde. Seine Freiheit ist insofern begrenzt. Andererseits erhöhen sich die wohlfahrt und damit die Entfaltungsmöglichkeiten bei den von den positiven externen Effekten Betroffenen. Es liegt nun in der freien Entscheidung des Verursachers der externen Effekte, andere In- 
dividuen am Nutzen eines Gutes teilhaben zu lassen, indessen alleine mit den Kosten belastet zu sein. Wenn folglich einzelne bewußt Güter trotz positiver Externalitäten bereitstellen, steuern sie zu einer Erhöhung der Wohlfahrt insgesamt bei. Daß ein Gut trotz positiver externer Effekte bereitgestellt wird, ist jedoch allenfalls bei einer geringen Intensität und streuung der Externalitäten denkbar. Ansonsten ist bei ökonomisch rationalem Handeln eher damit zu rechnen, daß jeder versucht, die Trittbrettfahrer-Position einzunehmen. Aus diesem Grunde unterbleibt eine Bereitstellung des entsprechenden Gutes, oder es erfolgt nur eine unteroptimale versorgung. Dies hat zur Konsequenz, daß die Wohlfahrt aller geschmälert wird. Deshalb gelangt eine gesellschaftliche Bewertung des Gutes unter dem Blickwinkel der Wohlstandszielsetzung zu dem Ergebnis, die auftretenden Externalitäten zu internalisieren.

Die zweite Kategorie von Externalitäten weist gegenüber der soeben betrachteten lediglich den Unterschied auf, daß die externen Effekte erst durch die gesellschaftliche Bewertung des Marktergebnisses entstehen, während bei den zuvor behandelten die gutsbedingten Externalitäten ursächlich für ein unbefriedigendes Marktresultat sind. Es werden also bewußt positive externe Effekte erzeugt oder negative Externalitäten verhindert, um eine bessere Grundwerteverwirklichung zu erreichen. Die im folgenden Kapitel noch genauer zu erörternde Unterstützung des Privatschulwesens als Voraussetzung dafür, daß überhaupt erst ein pluralistisches Angebot entstehen kann und nicht nur formal auf dem Papier steht, oder die materielle Unterstützung von in Not geratenen Bürgern, die gewährleistet, daß diese überhaupt in die Lage versetzt werden, die formal bestehenden Freiheiten des Gemeinwesens in Anspruch zu nehmen, verdeutlichen diesen Aspekt. Prinzipiell - und darauf wurde oben (vgl. Kap. C.) ebenfalls hingewiesen - dürfen die einzelnen Grundwerte aber nicht isoliert betrachtet und verfolgt werden, sondern sie müssen - wie das Beispiel einer überzogenen Verfolgung der (sozialen) Gerechtigkeits- und der Wohlstandszielsetzung, die in das Gegenteil umschlagen kann, gezeigt hat (vgl. C.I.2.) - 
in ihrer Gesamtwirkung auf das Allgemeinwohl gesehen werden. Hierin ist zugleich - wenn auch mit einem beträchtlichen politischen Interpretationsspielraum - die Bremse angelegt, die das Uberhandnehmen der staatlichen Steuerungsmechanismen verhindern soll.

Der Internalisierungsbedarf bei einem Gut, also die Notwendigkeit, die im ర̈ffentlichkeitsgrad angezeigte allokative Störung zu beseitigen, hängt in beiden gerade diskutierten Ausprägungen des Offentlichkeitsgrades von der Intensität und der Streuung der externen Effekte ab. Wie die Ausführungen zur freiwilligen Bildung von Kollektiven gezeigt haben, bedeutet das Vorhandensein von Externalitäten nicht automatisch die Notwendigkeit von staatlichen Steuerungsmechanismen. Von staatlichen Interventionen kann auch abgesehen werden, wenn die Intensität der externen Effekte nur gering ist und die oben (vgl.C.I.2.) mit Staatsversagen umschriebenen Ineffizienzen staatlicher Steuerungsmechanismen den zusätzlichen Nutzen übersteigen. Die Wahrscheinlichkeit einer freiwilligen kollektiven Bedarfsdeckung ist bei kleinen und mittleren Kollektiven am größten. Das trifft für die Güter zu, deren Externalitäten nur eine geringe Reichweite haben, also eine überschaubare soziale Gruppe betreffen. Mit zunehmender Reichweite der Externalitäten, d.h., mit wachsender Gruppengröße wird das unbestimmter, da die verfolgung gemeinsamer Interessen mit der Einnahme der Trittbrettfahrer-Position rivalisiert. Aber auch bei größeren Gruppen kann die Möglichkeit der freiwilligen kollektiven Bedarfsdeckung dadurch erhöht werden, daß die Mitglieder einer sozialen Gruppe durch die verschiedenen Ausprägungen selektiver Anreize oder die subtilen Formen des Zwangs dazu bewegt werden. Generell kann wohl davon ausgegangen werden, daß mit zunehmender Streuung und Intensität der Externalitäten die gesellschaftlichen Steuerungsmechanismen zusehends von den staatlichen verdrängt werden.

Während bei den gutsbedingten Externalitäten die Trittbrettfahrer-Problematik zumindest bei kleinen und mittleren 
Kollektiven ohne staatliche Steuerungsmechanismen überwunden werden kann, ist dies bei den auf politische Bewertung zurückzuführenden allokativen störungen eher unwahrscheinlich. tber den Markt oder andere gesellschaftliche Steuerungsmechanismen erfolgt bei diesen Gütern eine Bereitstellung in der Regel nur in Höhe der individuellen Bedürfnisschätzungen, die aber von der durch politische Bewertung zum Ausdruck gebrachten gesellschaftlichen Bedarfseinschätzung abweicht. Diese Differenzen müssen mit Hilfe staatlicher Steuerungsmechanismen ausgeglichen werden, für die der aus der Allgemeinwohlzielsetzung abgeleitete Grundsatz des Vorrangs der gesellschaftlichen vor den staatlichen Steuerungsmechanismen, also das Subsidiaritatsprinzip, gilt. Der staatliche Instrumentaleinsatz hat sich folglich bei der Bedarfsdeckung daran zu orientieren, was bereits durch die gesellschaftlichen Steuerungsmechanismen abgedeckt ist und ist dementsprechend abgestuft einzusetzen.

Etwas anders liegen die Dinge bei den externen Effekten, die auf altruistischen, vom strengen ökonomischen Rationalkalkül abweichenden Verhaltensweisen beruhen. Diejenigen, die altruistisch handeln, stellen bewußt bestimmte Leistungen zur Verfügung, die ausdrücklich anderen zugute kommen sollen. Altruistisches Verhalten tritt vornehmlich bei denjenigen gesellschaftlichen Gruppierungen auf, die uneigennützig vorwiegend im sozialen, mildtătigen sektor Güter für das Gemeinwesen bereitstellen. Wenngleich, wie bereits Wagner feststellte, deren Möglichkeiten aus verschiedenen Gründen begrenzt sind, üben sie im gesellschaftlichen Raum eine wichtige Funktion aus, und die gesellschaftliche Bewertung dieser Aktivitaten ist daher durchaus positiv, weil neben dem wohlfahrtssteigernden Effekt ein vielfăltiges, den heterogenen Präferenzen der Nachfrager gerecht werdendes Angebot geschaffen wird, das dem pluralistischen Charakter des Gemeinwesens Rechnung trăgt. Die Andersartigkeit der Leistungen muß dabei nicht unbedingt auf unmittelbaren qualitätsmäßigen Unterschieden bei den Gütern beruhen, sondern sie kann mit dem unterschiedlichen Umfeld, in dem die Leistung erbracht wird, zu tun haben ${ }^{20}$ ). Beispiele dafür sind etwa staat- 
liche im Vergleich zu konfessionellen Altersheimen oder Krankenhäusern. Egner ${ }^{21}$ ) weist allerdings darauf hin, daß diese Unterschiede in der Leistungsbereitstellung teilweise abgenommen haben und daß die ehemals für kirchliche Anstalten prägenden Verhaltensweisen wiє Nächstenliebe und Hingabe einer immer mehr um sich greifenden Versachlichung gewichen sind. Die Ursache dafür sieht er nicht zuletzt in einer veränderten Struktur des Pflegepersonals, das immer mehr "verweltlicht" ist. Als weitere Ursache sei hinzugefügt, daß dazu auch vermehrte staatliche Normsetzungen und Interventionen beitragen.

Unterstellt man ökonomisch rationales Verhalten, dann könnte man zunächst glauben, daß die altruistisch Handelnden von ihrem Tun keinen Nutzen haben. Berücksichtigt man hingegen, daß neben dem ökonomisch rationalen Verhalten auch andere Motive, beispielsweise religiöse oder weltanschauliche, das Verhalten und das Zusammenleben der Menschen bestimmen, dann muß diese Aussage relativiert werden; denn das "uneigennützige" Wirken kann den so Handelnden durchaus Nutzen stiften, weil sie auf diese Weise die aus ihren Wertvorstellungen resultierenden Bedürfnisse befriedigen können. Bei diesen gewollten positiven Externalitäten besteht demzufolge kein Bedarf für staatliche Internalisierungsmaßnahmen; die gesellschaftlichen Selbststeuerungsmechanismen sorgen hier unbeeinträchtigt für ein uneingeschränktes Angebot, da im Unterschied zum ökonomischen Rationalverhalten keine Trittbrettfahrer auftreten.

Der anzuwendende Steuerungsmechanismus wird außerdem von der Streuung der Externalitäten beeinflußt. Als Träger der Bedarfsdeckung ist zunächst an die durch die Streuung der Externalitäten bestimmte soziale Gruppe zu denken. Diese Gruppe kann die Bereitstellung freiwillig übernehmen oder - wenn die Intensität der Externalitäten entsprechend groß ist - aufgrund staatlichen Zwangs. Der staatliche Steuerungsmechanismus wird um so dominanter, je mehr er auf Preis, Menge und Qualität der kollektiv angebotenen Leistung Einfluß nimmt. Je weniger Spielraum für das Kollektiv bleibt, um so unwahrscheinlicher wird eine frei- 
willige Bedarfsdeckung, und um so notwendiger ist es, daß der Staat die Kollektive zwangsweise zur Leistungsbereitstellung verpflichtet, um die Möglichkeit eines den heterogenen Präferenzen gerecht werdenden Angebots zu wahren, bevor er selbst die Bedarfsdeckung übernimmt.

Die Mitwirkung des Staates bei der Bereitstellung von Gütern durch gesellschaftliche Gruppen bedeutet aus der Sicht des Gemeinwesens, daß diese Leistungen erbringen, die über das reine Gruppeninteresse hinausgehen. Die Wirkungen über die eigene Gruppe hinaus einerseits und die staatliche Einflußnahme andererseits zeigen, daß sich solche Gruppen nicht im rein privaten Bereich bewegen, sondern im Bereich des Öffentlichen mit politischer Relevanz. Politische Relevanz resultiert ferner aus der Streuung der Externalitäten, die unabhängig vom Organisationsgrad, der für das politische Gewicht der freiwilligen Kollektive nicht unerheblich ist, die funktionale Repräsentanz einer Gruppe anzeigen. Je mehr Mitglieder ein Kollektiv umfaßt und je höher sein Organisationsgrad ist, um so größer ist sein politisches Gewicht. Aufgrund ihrer politischen Relevanz, die dadurch noch verstärkt wird, wirken die im Bereich des Öffentlichen stehenden Gruppen an der politischen Willens- und Entscheidungsbildung mit. Die politische Relevanz einer Gruppe beinhaltet jedoch - wie im folgenden Abschnitt IV ausführlich gezeigt wird - für die Effizienz der staatlichen Steuerungsmechanismen und damit letztlich für das Gemeinwohl - erhebliche Risiken, weil sie es den politisch mächtigen Gruppen leichter möglich macht, Gruppeninteressen zu Lasten Dritter durchzusetzen. 
Peter Saile - 978-3-631-75214-2

Downloaded from PubFactory at 01/11/2019 07:01:15AM

via free access 
III. Das Offentliche als Bereich der intermediären Finanzgewalten

1. Abgrenzung gegenüber dem privaten Bereich

Eindeutig dem privaten Bereich zuzuordnen ist die Bereitstellung derjenigen Güter, deren Öffentlichkeitsgrad null oder nahezu null ist. Hier sorgt der Marktmechanismus für den höchsten Grad an Allgemeinwohlverwirklichung. Vertragliche Gestaltungen werden der freiheitlichen zielsetzung am ehesten gerecht, weil sie das eigenverantwortliche Handeln und die freie Entfaltung des einzelnen entsprechend seiner Präferenzstruktur gewährleisten. Die Zuordnung von Gütern zum privaten Bereich, deren Bereitstellung durch den marktwirtschaftlichen Preismechanismus geregelt wird bzw. bei denen das Ausschlußprinzip anwendbar ist, bereitet somit keine großen Schwierigkeiten.

Schwieriger gestaltet sich die Abgrenzung des Bereichs der intermediären Finanzgewalten gegenüber kleineren Kollektiven, die auf der Basis freiwilliger Vereinbarungen zustande kommen. Hierunter fallen namentlich kleinere Vereine und andere ähnliche Gruppierungen. Okonomisch gesehen handelt es sich um kleine Kollektive mit einer relativ homogenen Präferenzstruktur, die sich freiwillig zur Verfolgung bestimmter gemeinsamer Sonderinteressen bilden, die vornehmlich kulturelle, soziale, sportliche und ahnliche Belange zum Inhalt haben. Die Motive der einzelnen Kollektivmitglieder für ihren Beitritt können egoistischer, mutualistischer oder altruistischer Natur sein. Insbesondere für die treibenden Kräfte der Kollektivbildung sowie deren Organisation und Führung können soziale Bedürfnisse wie Ansehen, Ehre, Ruhm usw. als selektive Anreize hinzukommen, die von den betreffenden Personen höher eingeschätzt werden als der mit den Funktionen verbundene, im allgemeinen unentgeltliche Einsatz.

Entscheidender bei diesen Kollektiven ist aber, daß das Ausschlußprinzip nahezu vollständig anwendbar ist und somit die 
Leistungen und Nutzen auf die Mitglieder beschränkt werden können. Da kaum Externalitäten auf das übrige Gemeinwesen ausgehen, weil diese Kollektive primär auf die Verfolgung der speziellen Interessen ihrer Mitglieder abstellen und außerdem verhältnismäßig klein sind, weisen die von diesen Kollektiven bereitgestellten Leistungen lediglich einen geringen

Ǒfentlichkeitsgrad auf. Beurteilt man hingegen die Aktivitäten kleinerer Kollektive wie Vereine, Bürgerinitiativen im Hinblick auf die wirkungen auf andere funktionale oder regionale Kollektive, dann könnte die Zuordnung zum rein privaten Bereich eher fragwürdig werden. Es ist nämlich ohne weiteres vorstellbar, daß sie durch eine hohe funktionale Repräsentanz einen wie oben erwähnt - durchaus auch unerwiinschten Einfluß auf die politische Willensbildung erlangen können. Andererseits dürfen die gelegentlich von ihren Leistungen ausgehenden Außenwirkungen auf ihre nähere Umgebung nicht übersehen werden. Beispiele hierfür sind etwa Beiträge zur örtlichen Kultur, soziale Leistungen und andere Formen der aktiven Mitgestaltung des (lokalen) pluralistischen gesellschaftlichen Lebens, die im Allgemeinwohlinteresse sind 22 ).

Obwohl die Bedarfsdeckung über die für den öffentlichen Bereich typischen gesellschaftlichen selbststeuerungsmechanismen erfolgt, weil im allgemeinen selektive Anreize und nicht nur egoistische Verhaltensweisen bei diesen Kollektiven eine Rolle spielen, könnte der Bedarf, der in der Befriedigung der gleichartigen Interessen der Mitglieder besteht, weitgehend durch den Markt gedeckt werden. Aufgrund des geringen Öffentlichkeitsgrades wäre deshalb eine Ansiedlung im öffentlichen Bereich nicht angemessen. Gleichwohl sind die Grenzen nicht starr, wie die Beispiele so mancher Bürgerinitiativen zeigen, die sich aus kleinen Anfängen heraus zu öffentlich bedeutsamen Gruppen entwickelt haben 23 ).

Etwas anders sieht es allerdings bei den großen Dachverbänden aus, deren politische Relevanz, die aus der Repräsentanz zahlreicher kleinerer Kollektive nach außen erwächst, nicht unter- 
schätzt werden darf. Diesen Aspekt der im Hinblick auf die Gemeinwohlzielsetzung weitgehend unerwünschten Einflußnahme und Teilhabe an der politischen willensbildung und den darauf zurückzuführenden öffentlichkeitsgrad, der bei diesen Organisationen tatsächlich vorhanden ist, werden wir indes im nächsten Abschnitt betrachten.

2. Der notwendig staatliche Bereich

Die in der Verfassung getroffenen Wertentscheidungen geben als demokratischer Grundkonsens dem Staat als oberste Zielsetzung die bestmögliche Allgemeinwohlverwirklichung auf, die ihre Konkretisierung in den Grundwerten finden. Die dem Staat aufgegebene dienende Funktion am Menschen hält ihn dazu an, einen für alle verbindlichen Ordnungsrahmen, der sich an den Grundwerten orientiert, zu schaffen. Daraus erwächst für den Staat die Verpflichtung, die Einhaltung des Ordnungsrahmens zu gewährleisten und die Freiheits- und Entfaltungsräume zu sichern, die es den Individuen erlauben, ihren Bedürfnissen und Interessen nachzugehen.

Aus dem zuletzt genannten Aspekt resultieren Aufgaben, die das Zusammenleben im Gemeinwesen mit sich bringt und deren Inhalt darin besteht, die Bedingungen für ein höchstmögliches Maß an Grundwerteverwirklichung sicherzustellen. Das schließt ein, daß durch entsprechende Regelungen dafür gesorgt wird, daß die gesellschaftlichen Selbststeuerungsmechanismen im Sinne der Allgemeinwohlverwirklichung funktionieren können.

Die sich daraus für das Funktionieren des Gemeinwesens ergebenden unumgänglichen Aufgaben, nämlich äußere und innere Sicherheit und grundlegende Normen für die Gesundheitsfürsorge, zeichnen sich in der ökonomischen Beurteilung dadurch aus, daß ihr Konsum nicht oder nur unwesentlich rivalisiert und das Ausschlußprinzip nicht anwendbar ist. Die Streuung der externen Effekte erstreckt sich auf das gesamte Gemeinwesen, weil die Leistungen allen (nahezu) unteilbar zufließen. Die hohe Inten- 
sität und Streuung der externen Effekte verleiht diesen Gütern einen Offentlichkeitsgrad, der gegen eins tendiert. Wie insbesondere Olson gezeigt hat - jedoch machten auch schon wagner, Schäffle und De Viti De Marco im Grundsatz darauf aufmerksam -, kommt wegen des Trittbrettfahrer-Verhaltens kein freiwilliges Angebot zustande, obwohl die Bereitstellung von allen als vorteilhaft erachtet wird. Die gesellschaftlichen Selbststeuerungsmechanismen versagen bei diesen Gütern im Hinblick auf die für ein funktionierendes Gemeinwesen erforderlichen Regelungen des zusammenlebens vollständig und müssen durch staatliche Entscheidungsmechanismen ersetzt werden.

Die Erfüllung dieser Aufgaben setzt allerdings voraus, daß der Staat über die entsprechenden zwangsmittel verfügt und den übrigen gesellschaftlichen Gruppierungen übergeordnet ist, weil es in vielen Fällen unumgänglich ist, die Handlungsfreiheiten einzelner zum Wohle aller zu begrenzen. Die ökonomischen Begründungen dafür haben schon wagner und De Viti De Marco gegeben, die auf den "Interessengegensatz" hinwiesen, der aus gegensätzlichen individuellen Vorstellungen resultieren kann; die politische Rechtfertigung für die staatliche Hoheitsgewalt liefert die Verfassung, die als demokratischer Grundkonsens die Wertordnung des Gemeinwesens enthält, zu der sich die Bürger bekennen, und die sich deshalb auch den dafür erforderlichen Einschränkungen und Regelungen zu unterwerfen haben.

Neben diesen für jeden freiheitlichen staat unumgänglichen Funktionen treten allerdings in hochentwickelten modernen Gesellschaften weitere Aufgaben auf, die sinnvollerweise vom Staat wahrgenommen werden müssen. Gemeint sind damit die - hier jedoch nicht interessierenden und nur der vollständigkeit halber erwähnten - staatlichen Interventionen in die Marktprozesse zur Verfolgung z. B. struktur-, konjunktur-, wachstums- und verteilungspolitischer Zielsetzungen für das gesamte Gemeinwesen. Alle diese Funktionen werden grundsätzlich vom Markt erfüllt. Der Öffentlichkeitsgrad dieser Leistungen beruht ausschließlich auf ordnungspolitisch häufig nicht unumstrittenen 
politischen Bewertungen, die eine Korrektur der Marktergebnisse aufgrund staatlicher Eingriffe zur Folge haben.

3. Der Bereich des Öffentlichen

Nach der Bestimmung der notwendig staatlichen und der dem rein privaten Sektor zurechenbaren Funktionen verbleibt ein (großer) Rest an Aufgaben, die teils von den im Bereich des Öffentlichen angesiedelten intermediären Finanzgewalten erfüllt werden können, teils aber auch einer staatlichen Unterstützung bedürfen oder dem Staat übertragen werden können.

Bei den nach der bisherigen Abgrenzung noch verbleibenden Gütern handelt es sich um solche, die der Markt nicht oder nur unvollkommen befriedigt und eine Bedarfsdeckung auch dadurch nicht erreicht wird, daß staatliche Interventionen unterstützend zum Marktmechanismus hinzutreten. Andererseits besteht an diesen Gütern - wie an dem hohen Öffentlichkeitsgrad abzulesen ist - ein großes öffentliches Interesse, das auf der funktionalen Respräsentanz urd/oder der politischen Relevanz beruht. Gleichwohl handelt es sich nicht von vornherein um Güter, für deren Bereitstellung der Staat zu sorgen hat. Das Charakteristikum des auf dem Grundgesetz und den dahinter stehenden Grundwerten aufbauenden Gemeinwesens der Bundesrepublik ist zwar die gegenseitige Verschränkung von Staat und Gesellschaft, allerdings verlangt die freiheitliche zielsetzung die $\mathrm{Zu}-$ rückhaltung des Staates und damit den Vorrang nichtstaatlicher Steuerungsmechanismen.

In ökonomischer Sicht kann an die Gedanken des funktionalen Föderalismus angeknüpft werden. Eine Internalisierung der Externalitäten durch die betroffenen Gruppen macht die Betroffenen $\mathrm{zu}$ den Beteiligten und führt ökonomisch zu einer Wohlfahrtssteigerung, weil bei einer Bedarfsdeckung durch die jeweils betroffene soziale Gruppe deren eigengearteten Präferenzstrukturen besser als mit einem staatlichen Koordinierungsmechanismus entsprochen werden kann. Maßgeblich für die Zuordnung zum 
staatlichen oder öffentlichen Bereich wird damit der anzuwendende Steuerungsmechanismus, der, wie gezeigt wurde, von den Einflußfaktoren des Öffentlichkeitsgrades bestimmt wird. Die Schwierigkeit, die dabei allerdings auftritt, liegt darin, daß staatliche und gesellschaftliche steuerungsmechanismen bei der Bereitstellung ein und desselben Guts wegen der gegenseitigen Verschränkung von Staat und Gesellschaft nebeneinander eingesetzt werden (können) 24 ).

Wie oben gezeigt wurde, spielt es für die Internalisierungsmaßnahmen keine Rolle, ob es sich um externe Effekte handelt, die durch die gesellschaftliche Bewertung entstehen, oder um solche, die in den Gütereigenschaften begründet sind. Differenziertere Betrachtungen müssen indessen - wie ebenfalls schon deutlich wurde - bei den Gütern angestellt werden, bei denen altruistische bzw. vom strengen ökonomischen Rationalkalkül abweichende Verhaltensweisen 25 ) auftreten. Ein staatlicher Interventionsbedarf besteht nicht, weil die Handelnden die auftretenden Externalitäten bewußt schaffen und die Bedarfsdeckung über die gesellschaftliche Selbststeuerung deshalb funktioniert. Ein zusätzlicher staatlicher Handlungsbedarf kann sich allenfalls aufgrund der gesellschaftlichen Bewertung anhand der Grundwerte ergeben, wenn bestimmte Aktivitäten, etwa die Sicherstellung und Ausweitung eines pluralistischen Leistungsangebotes, über die freiwillig erbrachte Bedarfsdeckung hinaus ausgedehnt werden sollen. Allerdings dürfen die staatlichen Maßnahmen nicht die durch altruistisches Verhalten erzeugte Güterbereitstellung einbeziehen, da die externen Effekte für die Handelnden internalisierte Nutzen darstellen und insoweit Privatgutcharakter tragen ${ }^{26}$ ). Staatliche Internalisierungsmaßnahmen können sich folglich bei altruistisch motivierten Leistungen nicht auf den gesamten öffentlichkeitsgrad erstrecken, sondern nur auf den Teil, der nicht schon durch gesellschaftliche selbststeuerungsmechanismen abgedeckt ist. Insofern besteht also kein Unterschied zu den Externalitäten, die bei ökonomisch rationalem Verhalten auftreten. 
Als staatliche Steuerungsmechanismen, die ergänzend zu den gesellschaftlichen hinzutreten oder diese ersetzen, kommen Gebote und Verbote, Steuern und Transfers, staatliche Bereitstellung der Güter oder Kombinationen dieser drei Möglichkeiten in Betracht. Inwieweit sie die gesellschaftlichen Selbststeuerungsmechanismen verdrängen und Einfluß auf Umfang und Qualität der Bedarfsdeckung nehmen, hängt ganz von ihrer Ausgestaltung $a b^{27}$ ). Eindeutig zum öffentlichen Bereich gehören die Güter, die von den betroffenen sozialen Gruppen freiwillig angeboten werden und bei denen diese Gruppen allein über Umfang und Qualität der Bedarfsdeckung sowie über die Finanzierung entscheiden. Das andere Extrem, und damit eine staatliche Aufgabe, liegt vor, wenn der Staat Umfang und Qualität der Leistung, die Art der Finanzierung sowie die soziale Gruppe, die das Gut zu finanzieren hat, bestimmt. Dazwischen liegt eine ganze Bandbreite von möglichen gesellschaftlichen und staatlichen Steuerungsmechanismen, bei denen der staat mit unterschiedlicher Intensität auf die Güterbereitstellung und deren Finanzierung Einfluß ausuibt.

Daraus ergeben sich umgekehrt als Voraussetzungen für die Zuordnung zum Bereich des Öffentlichen, daß die zur Anwendung gelangenden Steuerungsmechanismen den eine Leistung anbietenden sozialen Gruppen gewährleisten, über Umfang, Qualität und Finanzierung der Bedarfsdeckung zu entscheiden bzw. ihnen einen entsprechenden Gestaltungsspielraum belassen. Diese Bedingungen, die zugleich Ausdruck der die intermediären Finanzgewalten kennzeichnenden Merkmale Selbstverwaltung und Finanzautonomie sind, sind erfült, wenn sich die staatlichen Interventionen darauf beschränken, Rahmenbedingungen zu setzen oder versuchen, mittels Steuern und Transfers die Bedarfsdeckung sowohl umfangmäßig als auch qualitativ zu beeinflussen.

Bei mittleren und größeren Kollektiven steht dem Funktionieren der gesellschaftlichen Selbststeuerungsmechanismen als größter Hinderungsgrund die Einnahme der "Trittbrettfahrer-Position" entgegen. In diesen Fällen kann es durchaus zweckmäßig sein, 
daß der Staat die Leistung nicht selbst bereitstellt und damit zu einer staatlichen Aufgabe macht, sondern daß er durch die Ausübung staatlichen Zwangs die Betroffenen zur Leistungserbringung im Wege der Zwangsmitgliedschaft verpflichtet. Eine Ansiedlung im staatlichen Bereich ist damit nicht verbunden, solange die Kollektive selbst über Art und Umfang sowie Finanzierung der Güterbereitstellung bestimmen können. Die Zwangsmitgliedschaft ist vielmehr Ausdruck des im Öffentlichkeitsgrad eines Gutes begründeten öffentlichen Interesses und hat gegenüber einer staatlichen Bedarfsdeckung den zumindest theoretischen Vorteil, daß die Internalisierung der externen Effekte durch die unmittelbar Betroffenen erfolgt und somit deren Präferenzen besser berücksichtigt werden können.

Für die Zuordnung zum staatlichen oder öffentlichen Bereich spielt daher das Element der Zwangsmitgliedschaft nicht die ausschlaggebende Rolle. Voraussetzung für die Ansiedlung im öffentlichen Bereich sind vielmehr ein wesentlicher Gestaltungsspielraum für die die Bedarfsdeckung übernehmehmenden Kollektive bei der Bestimmung von Umfang und Qualität sowie der Finanzierung der angebotenen Güter. Ohne hier im einzelnen auf den öffentlichkeitsgrad und die anzuwendenden Steuerungsmechanismen einzugehen, ist diese Grenze beispielsweise bei der Bundesanstalt für Arbeit mit Sicherheit überschritten. Es besteht Zwangsmitgliedschaft für bestimmte Berufsgruppen und der Staat hat sowohl die finanziellen Beiträge als auch weitgehend Umfang und Qualität der Leistungen gesetzlich geregelt. Die "Mitglieder" haben darauf keinerlei unmittelbaren Einfluß. Etwas abgeschwächt gilt das aber auch für die gesetzliche Rentenversicherung. An der Grenze stehen die gesetzlichen Krankenkassen, denen zumindest ein geringer Gestaltungsspielraum hinsichtlich der Bedarfsdeckung und der Finanzierung verbleibt. Anders sieht es dagegen bei den gesetzlich geregelten Selbstverwaltungsorganen der Wirtschaft aus. Die gesetzlichen Bestimmungen im IHK-Gesetz und in der Handwerksordnung setzen lediglich Rahmenbedingungen, die sowohl hinsichtlich der 
angebotenen Leistungen als auch der Finanzierung einen beträchtlichen Gestaltungsspielraum belassen.

Eine Zuordnung einer Aufgabe zum öffentlichen oder staatlichen Bereich ist bei den im Grenzbereich angesiedelten Kollektiven jedoch nicht unveränderlich, weil die Bewertung der einzelnen Aufgaben mit dem Maßstab der Grundwerte, die ja interdependent und teilweise konfliktär sind, einen Interpretationsspielraum für politische Entscheidungen einräumen. Die Grundwerte als demokratischer Grundkonsens beinhalten Mindestforderungen, geben aber die Möglichkeit, einzelne Grundwerte zu präferieren. Das heißt allerdings zugleich, daß die Aufgabenverteilung nicht für alle zeiten festgelegt ist, sondern mit wandelnden gesellschaftlichen Auffassungen wechselt. In der Realität kommen überdies, wie im nächsten Abschnitt gezeigt wird, Einflüsse gesellschaftlicher Gruppierungen hinzu, die den Offentlichkeitsgrad bei der Bedarfsdeckung in nicht erwünschter Weise verzerren. Nur am Rande sei hier erwähnt, daß entsprechende Tendenzen auch beim Staat, allerdings in umgekehrter Richtung auf die Parafisci hin, zu beobachten sind, wenn man etwa an die Besetzung der Spitzenpositionen in den öffentlich-rechtlichen Rundfunkanstalten denkt. 
Peter Saile - 978-3-631-75214-2

Downloaded from PubFactory at 01/11/2019 07:01:15AM

via free access 
IV. Der Einfluß der gesellschaftlichen Gruppierungen auf politische Willensbildung und staatliche Entscheidungen

Hier soll der Aspekt der Verschränkung von Staat und Gesellschaft in Gestalt der Vertretung der Mitgliederinteressen durch Gruppen gegenüber der Allgemeinheit und die damit verbundenen Wirkungen am Beispiel der Interessenverbände verdeutlicht werden. Die Absicht der gezielten Einflußnahme auf politische Willensbildung und staatliche Entscheidungen ist ein wichtiges Charakteristikum der im Bereich des öffentlichen angesiedelten sozialen Gruppierungen, insbesondere der reinen Interessenverbände. Da die Bedeutung der Verbände und ihre Rolle im Gemeinwesen in den wesentlichen Grundzügen bereits in Kapitel C diskutiert wurde, braucht an dieser Stelle darauf nicht noch einmal eingegangen $\mathrm{zu}$ werden ${ }^{28}$ ). Im folgenden wollen wir uns ausschließlich mit den ökonomischen Aspekten der verbandlichen Einflußnahme auf die politische Willensbildung und deren Auswirkungen auf die Staatstätigkeit befassen.

Unbestreitbar kommt den Interessenverbänden im pluralistischen demokratischen Gemeinwesen im Hinblick auf die Freiheitsverwirklichung eine wichtige und legitime Funktion zu: Sie dienen der "Freiheitsverwirklichung in Gemeinschaft"29), und zwar in der Form, daß sie durch die grundgesetzlich garantierte Vereinigungsfreiheit zur "Sicherung eines gesellschaftlichen Meinungs-, Willensbildungs- und Selbstorganisationsprozesses" beitragen ${ }^{30}$ ). Ihre politische Aufgabe, und damit ihr öffentlicher Status, beruhen auf der - im soziologischen Sinne - Repräsentation, d. h. der Selektion, Aggregation, Definition, Präsentation und Integration der gesellschaftlich relevanten Interessen vorwiegend im politischen, sozialen, wirtschaftlichen und kulturellen Bereich in und gegenüber staat und Gesellschaft ${ }^{31}$ ). Ihr Einfluß, der auf die Teilhabe am demokratischen Willensbildungsprozeß beschränkt bleiben müßte ${ }^{32}$ ), dürfte indessen, wie Kirsch ${ }^{33}$ ) glaubt, wegen des hohen Informationsniveaus der Verbände in den sie berührenden Problemen überdurchschnittlich hoch sein. Im Gegensatz zu den Parteien übernehmen 
sie keine unmittelbare politische verantwortung, und sie haben kein Recht auf die Teilnahme an staatlich demokratischen Entscheidungsprozessen ${ }^{34}$ ).

Die politische Wirklichkeit zeigt, daß die Verbände in vielfältiger Weise in die staatlichen Willensbildungsprozesse einbezogen sind, etwa bei der Konzertierten Aktion, bei Anhörungen in Gesetzgebungsverfahren, bei der Mitarbeit in Kommissionen und Beiräten etc. Sie erfüllen auf diese Weise eine Vielzahl von öffentlichen Aufgaben und bringen für den Staat eine spürbare Entlastung. Ein Bild von der Fülle der Mitwirkungsformen und der beteiligten gesellschaftlichen Gruppierungen vermittelt Kirberger ${ }^{35)}$. Gegen seine Darstellung ist jedoch einzuwenden, daß er - völlig unkritisch - nur den staatsentlastenden Effekt sieht, darüber aber unerwähnt läßt, daß die Verbände dies nicht uneigennützig tun, sondern daß ihnen sehr daran liegt, ihre Interessen durchzusetzen und Einfluß auf die staatlichen Entscheidungsprozesse zu gewinnen, der ihnen eigentlich nach staatsrechtlicher Auffassung versagt bleiben müßte ${ }^{36}$ ).

Insbesondere Schmidt ${ }^{37}$ ) hat, ausgehend von den treibenden Kräften der finanzpolitischen Willensbildung, auf die teilweise bedenklichen Einflüsse der Verbände auf die Staatstätigkeit durch das Zusammenwirken mit Parteien und Bürokratie aufmerksam gemacht. Die Funktion der Verbände sieht Schmidt einerseits im Kanalisieren und politischen Vertreten von gleichartigen Sonderinteressen und andererseits im "Anbieten" von Programmen. Unter letzterem versteht er, Verbandsinteressen $z u$ formen und zu gestalten und für sie mit dem ziel zu werben, über den "Absatz" der Programme den politischen Einfluß der Verbände zu stärken ${ }^{38)}$. Eine erfolgreiche Vertretung der Interessen ihrer Mitglieder sei für die Verbände schon deshalb vonnöten, weil sie sonst bei einer den Vorstellungen der Mitglieder nicht entsprechenden Politik Gefahr liefen, daß die Mitglieder enttäuscht abwandern ${ }^{39}$ ). 
Ansatzpunkte für die fragwürdige Einwirkung auf die staatlichen Entscheidungsprozesse finden die Verbände zum einen von außen durch die Einflußnahme auf die Politiker und zum anderen von innen durch die gezielte Mitarbeit in den Parteien ${ }^{40)}$. Möglichkeiten der Beeinflussung bieten vor allem Geld, das den Parteien zugewendet wird, die Aktivierung von wählerstimmen, die u.U. als Drohpotential gegenüber den Politikern eingesetzt werden kann, sowie der Sachverstand der Verbände in den speziellen Sachfragen, über den die Politiker nicht auf allen Gebieten verfügen können 41 ).

Für die eigentliche Einflußnahme auf die staatlichen Entscheidungsprozesse wählen die Verbände direkte und indirekte Wege: indirekt, indem sie versuchen, den Parteien Wahlversprechungen abzuringen, wobei im Hintergrund die zu mobilisierenden Wählermassen als Druckmittel stehen, und auf die Aufstellung von Parteiprogrammen und von Kandidaten einzuwirken. Direkten Einfluß nehmen sie, indem sie in den Parteien mitarbeiten und sich aus ihren Reihen Kandidaten für die Parteien aufstellen lassen, die, wenn sie gewählt werden, bevorzugt in die für ihren verband interessanten Ausschüsse drängen. Darüber hinaus setzen die Verbände durch das Unterhalten von Beziehungen zu Parlament, Regierung, Opposition und auch zur Bürokratie, die die staatlichen Entscheidungen maßgeblich vorbereitet, praktisch auf allen Ebenen der staatlichen Entscheidungsprozesse an ${ }^{42}$ ).

Ausgehend von diesen Zusammenhängen folgert Schmidt in einer differenzierten Analyse, die auch den Zwang der Parteien berücksichtigt, wegen der Wiederwahl Allgemeininteressen zu verfolgen, daß die Verbände vor allem darauf aus seien, vorhandene Ausgabenspielräume in ihrem sinne zu beeinflussen, d.h. ihre Sonderinteressen $\mathrm{zu}$ verwirklichen. Die Staatsquote brauchte deshalb zwar nicht zu steigen, jedoch nehme der Anteil der "gruppenbezogenen Staatsausgaben" zu Lasten der "gruppenindifferenten öffentlichen Ausgaben" tendenziell zu43). Die Begründungen der Verbände für gruppenbezogene Leistungen erfolgen häufig mit dem Verweis auf das Allgemeinwohl, wenn- 
gleich es sich eindeutig um Gruppeninteressen handelt. Die Durchsetzung von Verbandsinteressen führt so dazu, daß ideelle, die Allgemeinheit betreffende Leistungen zurückgedrängt und dadurch namentlich Randgruppen, die über keine entsprechende Lobby verfügen, benachteiligt werden 44 ).

Die vielfältigen Formen der Einflußnahme der Verbände auf die staatlichen Entscheidungsprozesse ziehen außer der Ausweitung der gruppenbezogenen Staatsausgaben weitere unerwünschte Konsequenzen nach sich. Zum einen mindern sie in nicht unerheblicher Weise die Effizienz der staatlichen Entscheidungsmechanismen 45). Dieser Effekt wird dadurch noch verstärkt, daß Parteien und Interessenverbände zusehends bei der Besetzung von stellen in der Bürokratie Beamte ihrer "Couleur" über die fachlichen Qualifikationen stellen, um sich so eine "genehme" Verwaltung zu schaffen ${ }^{46)}$ ). Zum anderen geht mit der Ausdehnung (ungerechtfertigter) gruppenbezogener Leistungen, zumeist in Form von Subventionen und Steuervergünstigungen, eine

Schwächung des marktwirtschaftlichen Steuerungsmechanismus einher, weil seine regulierende Funktion ausgeschaltet oder zumindest behindert wird47). Schmidt sieht letztlich in dem gestiegenen Einfluß der Verbände einen Autoritätsverfall des Staates, dessen Handlungsfähigkeiten mehr und mehr eingeengt werden, falls dieser Entwicklung nicht durch sich "staatsmännisch" verhaltende Politiker, die am Allgemeinwohl und nicht so sehr an Parteiinteressen orientiert sind, Einhalt geboten wird ${ }^{48)}$.

Aus diesen Wirkungen der gezielten Einflußnahme auf die Allgemeinheit ergeben sich mehrere Folgerungen für den Offentlichkeitsgrad der intermediären Finanzgewalten. Das politische Gewicht dieser Aktivitäten hängt in erster Linie von der funktionalen Repräsentanz einer Gruppierung ab. Eine große Zahl an Mitgliedern bzw. die Verkörperung von wirtschaftlicher Macht sowie ein hoher Organisationsgrad verleihen den (Interessen-) Verbänden, um die es hier hauptsächlich geht, die entsprechenden Einflußmöglichkeiten; ihre politische Relevanz und ihr öffentlicher Status werden dadurch verstärkt. 
Wie allerdings die Ausführungen oben gezeigt haben, sind die aus der Interessenvertretung resultierenden wirkungen der sozialen Gruppierungen, namentlich der (Interessen-)Verbănde, im Hinblick auf die Allgemeinwohlzielsetzung zwiespältiger Natur. Auf der einen Seite steht die gewollte Mitarbeit bei der demokratischen Meinungs- und Willensbildung, die sich in einer Staatsentlastung sowie in einem erhöhten öffentlichkeitsgrad niederschlägt. Auf der anderen Seite die gemeinwohlschädlichen Effekte als Folge der (unerwünschten) Einwirkung auf die staatlichen Entscheidungsprozesse, die nahezu ausschließlich Vorteile für bestimmte Gruppen zu Lasten der Allgemeinheit bringen. Zur Beseitigung dieser unerwünschten Externalitäten sind gesetzgeberische Regelungen, aber auch Änderungen der Verhaltensweisen der Politiker gefordert, damit die Aktivitäten der Verbände auf die ihnen im pluralistischen Gemeinwesen zustehenden Bereiche beschränkt bleiben. Nur so kann verhindert werden, daß die der Politik vorbehaltenen Interpretationsspielräume zur Verwirklichung der einzelnen Grundwerte von den Verbänden zur Durchsetzung ihrer Sonderinteressen genützt werden.

Die positiven Externalitäten, die sich aus der gewünschten Mitwirkung an der demokratischen willensbildung ergeben, bekräftigen die über das rein Private herausgehobene öffentliche Rolle der Verbände und Gruppierungen. Die aus der gezielten Interessenvertretung der sozialen Gruppierungen resultierenden, durchaus sehr unterschiedlichen Effekte erhöhen die politische Relevanz dieser Gruppen und untermauern ihre Ansiedlung im Bereich des Offentlichen. Gleichwohl ist die Beurteilung des aus den staatsentlastenden Aktivitäten entstehenden Öffentlichkeitsgrades nur auf den ersten Blick eindeutig; denn - wie schon angedeutet wurde - eröffnet sich über eine intensive Beteiligung an politischen Willensbildungsprozessen, die sich im allgemeinen auf ein hohes Informationsniveau und Spezialwissen der Verbändevertreter stützen kann, für die Verbände ein indirekter Weg, Entscheidungen in ihrem Sinne zu beeinflussen. 
Peter Saile - 978-3-631-75214-2

Downloaded from PubFactory at 01/11/2019 07:01:15AM

via free access 
E. Die Kirchen als intermediăre Finanzgewalten

\section{Vorbemerkungen}

Die ökonomische Literatur hat - ungeachtet der Tatsache, daß der Umfang der kirchlichen Haushalte mit denen der Gebietskörperschaften vergleichbar ist - die Kirchenfisci bislang kaum beachtet. Die stiefmütterliche Behandlung überrascht um so mehr, als zwischen staat und Kirchen sehr vielfältige Beziehungen bestehen und zahlreiche Berührungspunkte in den Aufgabenbereichen vorhanden sind $^{1}$ ).

Adolph Wagner ${ }^{2}$ ) und Albert E. Fr. Schäffle ${ }^{3}$ ) haben die Kirchenfisci sowie die diesen zuzuordnenden Organisationen unter Berücksichtigung der kirchenspezifischen Eigenarten bei der Diskussion der "Gemeinwirthschaften" systematisch gewürdigt und sich grundsätzlich mit den kirchlichen wirtschaften auseinandergesetzt. Im späteren ökonomischen Schrifttum tauchen die Kirchen lediglich noch vereinzelt unter speziellen Fragestellungen auf. So etwa bei Fritz Karl Mann ${ }^{4}$ ) und Walther Herrmann ${ }^{5)}$, die - wenn auch unsystematisch - bei ihrer Diskussion der intermediären Finanzgewalten die Kirchen einbezogen haben. In der finanzwissenschaftlichen Lehrbuchliteratur ${ }^{6}$ ) ist nahezu völlige Fehlanzeige zu vermelden.

Abgesehen von einigen Veröffentlichungen ${ }^{7}$ ) zu speziellen Problemen kirchlicher Finanzen darf allerdings Erich Egner ${ }^{8}$ ) nicht übergangen werden, der in seiner Abhandlung über den "Haushalt" ausführlich auf die Kirchenhaushalte eingeht. Er kritisiert an anderen Darstellungen, daß man den kirchlichen Haushalten nicht gerecht wird, wenn man - wie etwa Mann - die Kirchen als hilfsfiskalische Einrichtungen des Staates betrachtet. Es sei vielmehr unabdingbar, daß man die Kirchenhaushalte vom wesen der Kirche her erfasse ${ }^{9}$ ). Indessen mutet es ebenso zweifelhaft an, wenn man umgekehrt - wie Egner es tut - sich den kirchlichen Auffassungen voll anschließt und diese zum Aus- 
gangspunkt der eigenen finanzwissenschaftlichen tberlegungen macht.

Für ihn sind staat und Kirchen gleichberechtigte höchste Instanzen auf der Welt. Die Bedeutung der Kirchen sieht er vor allem in deren Unverzichtbarkeit für das menschliche Zusammenleben; denn ohne den Einfluß christlichen Gedankengutes befüchtet er - was allerdings nicht einmal Theologen in dieser Form zu behaupten wagen - einen Zerfall des Wertesystems. Die materielle Grundlage für das irdische wirken der Kirchen bilde ihr Haushalt, der sowohl von eigenwiichsigen, d.h. den Kirchen wesensmäßigen Einnahmen wie Spenden, Kollekten, Almosen usw., als auch von fremdwïchsigen, d.h. nicht dem Wesen der Kirchen entspringenden Abgaben wie Steuern, Gebühren usw. gespeist werde und dessen Umfang letztlich die Entfaltungsmöglichkeiten der Kirchen in der Gesellschaft bestimme10).

Obwohl Egner sieht, daß eine vom Staat unabhängige Kirche, die von der Opferbereitschaft ihrer überzeugten Mitglieder getragen wird, viel mehr dem kirchlichen Selkstverständnis gerecht wird, kommt er letztlich nicht über Ansätze hinaus, da er ausschließlich die Probleme der Haushalts- und Finanzwirtschaft diskutiert, die bestehenden Regelungen dagegen unangetastet läßt und sie nicht mit der Frage konfrontiert, ob sie überhaupt wesensgemäß sind.

Die Diskussion der Stellung der Kirchen im Gemeinwesen kann nicht ohne Berücksichtigung des jeweiligen kirchlichen Selbstverständnisses erfolgen. Genauso unverzichtbar ist allerdings die Einbeziehung des konkreten Verhältnisses zwischen Staat und Kirchen, das - wie ein Blick über die Grenzen zeigt sehr unterschiedlich gestaltet sein kann. Die zwischen beiden Bereichen bestehenden Beziehungen sind geprägt von den unterschiedlichen gesellschaftlichen Systemen und treten in einer Spannbreite auf, die von den auf einer weltanschaulichen Basis beruhenden, daher notwendigerweise intoleranten, kirchenverdrängenden Staaten jedweder Couleur bis zu den relativ neu- 
tralen, die Freiheiten des Bürgers respektierenden Demokratien reicht ${ }^{11)}$.

Totalitäre Staaten kirchenfeindlicher weltanschaulicher Prägung neigen $\mathrm{zu}$ einer radikalen Trennung von staat und Kirchen. Die Kirchen werden aus der öffentlichen in die rein private Sphäre verbannt ${ }^{12}$ ). Gerade entgegengesetzt dazu sind die Verhältnisse in jenen Staaten, die das Staatskirchentum oder zumindest Reste davon mit den starken Verzahnungen zwischen dem Staat und einer Kirche beibehalten haben, wobei jedoch die Religionsfreiheit für andere Gemeinschaften weitgehend verwirklicht ist ${ }^{13}$ ). Beide Formen sind allerdings für moderne demokratische staaten, in denen die Religionsfreiheit gewährleistet ist und die Kirchen nahezu völlig unabhängig sind, aber mit dem staat in vielen Bereichen loyal zusammenarbeiten, eher untypisch ${ }^{14}$ ). Die hier anzutreffenden Organisationsformen erstrecken sich vom privatrechtlichen Kultverein, wie etwa in Frankreich, bis hin zu den Körperschaften des öffentlichen Rechts in der Bundesrepublik Deutschland. Entsprechend vielfältig sind die Formen der Finanzierung, derer sich die Kirchen bedienen ${ }^{15}$ ).

Diese kurze Skizzierung der Verhältnisse macht deutlich, daß es keine generell verbindliche Regelung der Beziehungen zwischen Kirchen und Staat gibt; außer dem Selbstverständnis der Kirchen muß man vielmehr die den Kirchen eingeräumte und zukommende Stellung in einem konkreten Gemeinwesen berücksichtigen. Diese Überlegungen werden im folgenden aufgegriffen, indem die aus dem kirchlichen selbstverständnis abgeleiteten und die historisch zugewachsenen Aufgaben auf ihren Öffentlichkeitsgrad hin untersucht werden, um dann mit Hilfe dieses Maßstabes eine Standortbestimmung der Kirchen im Gemeinwesen vorzunehmen. 
Peter Saile - 978-3-631-75214-2

Downloaded from PubFactory at 01/11/2019 07:01:15AM

via free access 
II. Grundlagen und Motive kirchlichen Wirkens

1. Der überweltliche Charakter

Nach übereinstimmender Auffassung aller großen christlichen Kirchen verdankt die Kirche "... ihre Entstehung nicht dem freiwilligen und ausdrücklich erklärten willen der einzelnen bzw. dem Gesamt- oder Mehrheitswillen"16), sondern sie ist von Gott gestiftet und nicht von Menschen begründet ${ }^{17}$ ). Nach Zielen und Mitteln ist sie übernatürlich, wobei ihr ziel darin besteht, "... das durch Christus erlangte Heil allen Menschen zu allen zeiten $z u$ vermitteln"18). Da die Kirche sowohl ihren Ursprung als auch ihr ziel in der Ewigkeit hat ${ }^{19}$ ), ist ihr inneres Wesen, das nur vom glaubenden Christen wahrgenommen werden kann, von außen nicht sichtbar 20 ). Die Kirche ist demnach ein Gegenstand des Glaubens, den niemand sehen und kennen kann, den man nur an der Taufe, den Sakramenten und dem Wort Gottes fassen kann 21), sie ist ein Geheimnis des Glaubens, das nicht streng logisch definiert werden kann 22 ).

Die christlichen Kirchen gründen letztlich in der Hoffnung auf die Erlösung als Vollendung des Reiches Gottes ${ }^{23}$ ). Diese "letzten Dinge" sind rational nicht erklärbar; denn sie beruhen einzig und allein auf dem Glauben an die göttliche offenbarung.

\section{Das weltliche Selbstverständnis}

Die Kirchen sind zwar - wie die vorhergehenden Ausführungen belegen - nicht von dieser Welt, aber sie sind in dieser Welt ${ }^{24}$ ) und treten als soziale Gruppierungen mit weltlichen Organisationsformen innerhalb des Gemeinwesens in Erscheinung 25).

Über die konfessionellen Unterschiede hinweg sind sich die großen christlichen Religionsgemeinschaften in einigen grundlegenden Aussagen über das Wesen der Kirche einig, etwa darüber, daß die Kirche eine stiftung Gottes und nur von dessen willen 
abhängig sei. Sie betrachten die Kirche als Volk Gottes und Leib Christi, der in den Zeichen sichtbar wird, und als Beginn einer neuen, kommenden Welt, des noch unvollendeten Reiches Gottes $^{26}$ ). Die sich dahinter verbergenden Vorstellungen differieren allerdings für die einzelnen Religionsgemeinschaften so sehr, daß es angebracht erscheint, die unterschiedlichen Auffassungen getrennt darzustellen.

Für das Selbstverständnis der katholischen Kirche sind die Metapher des geheimnisvollen Leibes Christi und der Volk-GottesBegriff von zentraler Bedeutung. Christus ist das Haupt, die Kirche als Versammlung der Gläubigen das Volk Gottes, das den Leib dieses Körpers bildet ${ }^{27}$ ). Die theologische Interpretation leitet daraus und aus weiteren Erkenntnisquellen die Grundordnung der katholischen Kirche $a b^{28}$ ). Danach sind es vier Kennzeichen, die das Wesen der katholischen Kirche ausmachen: die Einheit, d.h. die zentralistisch, monokratisch und unitarisch konstituierte Kirche; die Heiligkeit, die beinhaltet, daß die Kirche eine Heilsanstalt göttlichen Rechts ist; die Apostolizität, die die hierarchische Ordnung der katholischen Kirche begrïndet und die besagt, daß die Kirche vom Papst und den Bischöfen geleitet wird und schließlich die Katholizität, die den Anspruch der Allumfassendheit und den weltumfassenden Universalismus des Wirkungsbereiches der katholischen Kirche zum Ausdruck bringt ${ }^{29}$ ).

Die katholische Kirche hat einen strengen hierarchischen Aufbau mit dem Papst an der spitze und trennt strikt zwischen Laien und Klerus. Die ständische Gliederung in Klerus und Laien ist göttlichen Rechts. Der Stand des Klerus ist an bestimmte Weihen gebunden, die ihn berechtigen, sakramentale Handlungen vorzunehmen und die kirchlichen Leitungsämter zu bekleiden. Dem Laien stehen solche Rechte nicht zu. Er ist aktives Glied der Kirche durch die Taufe und hat damit Anteil an der Sendung der Kirche. Er darf jedoch die Sakramente lediglich empfangen und ist nur begrenzt an der Erfüllung des kirchlichen Heilsauftrages beteiligt ${ }^{30}$ ). 
Zwischen den beiden großen evangelischen Bekenntnissen herrscht Übereinstimmung darüber, daß sie bestimmte grundlegende strukturen der katholischen Kirche, nämlich die rechtliche Autorität des Papsttums, das hierarchische Prinzip sowie die Weiheordnung ablehnen 31 ).

Die Kirche ist nach evangelisch-lutherischem Verständnis die Versammlung der Gläubigen und Heiligen und an ihren äußeren Zeichen, der rechten Sakramentsverwaltung und der reinen Predigt des Evangeliums, erkennbar ${ }^{32}$ ). Da aber die wahre Kirche, die "ecclesia spiritualis", der die wahrhaft Gläubigen angehören, ausschließlich Gott bekannt ist und weil es den Menschen nicht zusteht und diese außerdem nicht fähig sind, die wahren Gläubigen zu erkennen, erfüllt die "ecclesia universalis", die "irdische Schauseite" der "ecclesia spiritualis", als die in der Welt existierende Gemeinschaft der getauften Christen die Aufgaben der wahren Kirche in der Welt ${ }^{33}$ ). An der Einheit und Universalität der Kirche hält Luther fest. Für ihn gibt es nur ein Volk Gottes und eine wahre Kirche. Er lehnt allerdings jede hierarchische Ordnung zwischen den einzelnen Gemeindegliedern $\mathrm{ab}$, und an die Stelle der Weiheordnung setzt er das Priestertum aller Gläubigen, das jedoch nicht ausschließt, daß kirchliche Amtsträger die Verkündigung ausüben, um deren geordnete Durchführung zu gewährlejsten ${ }^{34}$ ).

Das Priestertum aller Gläubigen und die Ablehnung einer Hierarchie verschaffen der Kirchengemeinde in der evangelisch-lutherischen Kirche eine überragende Stellung. Pfarrer und Gemeinde sorgen gemeinsam für die Wortverkündigung und die Verwaltung der Sakramente. Die Leitung der Gemeinde erfolgt durch den von der Kirchengemeinde gewählten Kirchengemeinderat, dem der Pfarrer in der Regel automatisch vorsitzt ${ }^{35}$ ). Die Einzelgemeinden sind in Kirchenbezirke zusammengefaßt, deren Aufgabe darin besteht, die ihnen angehörenden Gemeinden zu stärken und diese bei der Erfüllung gemeinsamer Angelegenheiten zu unterstützen. Den nächst größeren Verband bilden die Landeskirchen $\left.{ }^{36}\right)$. Die verschiedenen Abstufungen dürfen jedoch keinesfalls als Hierar- 
chie aufgefaßt werden; denn die verschiedenen Ebenen sind alle Teil der einen Universalkirche und insofern gleichberechtigt ${ }^{37}$ ).

Die Organe der Kirchenbezirke und Landeskirchen setzen sich aus Laien und Geistlichen zusammen und werden überwiegend durch Wahlen gebildet. Namentlich die Landassynode übt mit dem Gesetzgebungsrecht, der Beschlußfassung des Haushalts, der Befassung mit allem, was das kirchliche Leben anlangt und der Wahl der Kirchenleitungsorgane, einschließlich des Bischofs, dessen stellung bei weitem nicht an die Befugnisse der katholischen Amtskollegen heranreicht, wichtige Funktionen aus 38).

Die evangelisch-reformierte Kirche hat die Auffassungen Luthers weitgehend übernommen. Sie betont aber sehr viel stärker, daß zur wahren Kirche nur die "Schar der Erwählten" gehört. Sie sieht deshalb eine besondere Aufgabe der Kirche darin, vorbildlich zu einer sittlichen Erneuerung aller Lebensbereiche, einschließlich der politischen Obrigkeit, beizutragen ${ }^{39}$ ).

Die Konstituierung einer weltlichen Ordnung hat sich ausschließlich an der Heiligen Schrift zu orientieren. Diese Ordnung ist nicht starr, sondern für neuere Schrifterkenntnisse jederzeit offen ${ }^{40}$ ). Dabei beruft sich die Ordnung der reformierten Kirche auf die drei theologischen Rechtsgrundsätze der Herrschaft Christi, der biblischen Weisung sowie auf den Bund der Erwăhlungsgemeinde. Die Herrschaft Christi macht die christliche Liebe zur Grundlage jeglichen menschlichen Kirchenrechts. Sie besagt außerdem, daß allein Christus in der Kirche eine Autorität ist. $\mathrm{Zu}$ ihm haben alle den gleichen $\mathrm{Ab}-$ stand, folglich sind alle Glieder der Kirche gleich. Der für das Selbstverständnis der reformierten Kirche wesentliche Grundsatz der biblischen Weisung bindet die reformierte Kirchenverfassung an die Anerkennung der Heiligen Schrift als die einzige Autorität und Richtschnur. Der theologische Satz des Bundes der Erwählungsgemeinde bringt schließlich zum Ausdruck, daß die Kirche der Ort ist, an dem sich die zum Heil Erwăhlten 
in ihrem Glauben bewähren können. Das kann nur in Freiheit und voller Unabhängigkeit von Weltanschauungen und Obrigkeiten geschehen. Die Ordnung der Kirche muß dabei ein Vorbild für alle anderen menschlichen Sozialgebilde $\operatorname{sein}^{41)}$.

Die Besetzung sämtlicher Organe und Ämter erfolgt in der reformierten Kirche durch Wahlen. Die kirchlichen Leitungsorgane und Ämter, die in der struktur denjenigen der evangelisch-lutherischen Kirche entsprechen, dürfen ebenfalls nicht als Hierarchie aufgefaßt werden, sondern müssen in einem funktionalen sinne als Dienen an der Kirche verstanden werden 42 ).

3. Die Mitgliedschaft in der Kirche

Die Mitgliedschaft in einer Kirche hat einen doppelten Charakter, je nachdem, ob sie vom kirchlichen oder vom staatsrechtlichen Standpunkt aus betrachtet wird. Aus staatsrechtlicher Sicht ist sie insbesondere in den Bereichen, in denen sich Staat und Kirchen berühren, wie z.B. bei der Anstalts- und Militärseelsorge, beim Religionsunterricht und bei der Kirchensteuer, von Bedeutung.

Ausgangspunkt für die staatsrechtliche Regelung der Mitgliedschaft sind Art. 4 GG, der die Religionsfreiheit gewährleistet, und Art. 140 GG, der eine Staatskirche verbietet. Die daraus resultierende religiöse Neutralität des Staates hat nicht nur den Schutz der freien religiösen Betätigung sicherzustellen, sondern auch die negative Religionsfreiheit zu schützen. Das heißt für den Staat, daß er den Kirchen nur Rechte gegenüber solchen Personen verleihen darf, die sich freiwillig dem Zwang der Kirchen unterwerfen, nicht jedoch solchen Personen gegenüber, die einer Kirche nicht angehören wollen 43 ).

Der Staat überläßt den Kirchen (und Religionsgemeinschaften) für ihren Bereich die Regelungen über Eintritt, Mitgliedschaft und Austritt. Um aber zu verhindern, daß die Kirchen Ansprüche, die sich aus der Mitgliedschaft ergeben, gegen den willen der 
betreffenden Personen durchsetzen, gewährt der staat diesen Personen die Möglichkeit des Austritts. Davon bleibt unberührt, ob die Kirchen diese Personen weiterhin als ihre Mitglieder betrachten oder nicht ${ }^{44}$ ).

Die Zugehörigkeit zur Kirche ist in der katholischen Kirche noch nicht abschließend geklärt. Bei aller Verschiedenheit der kirchlichen Lehrmeinungen herrscht allerdings inzwischen weitgehend Einigkeit darüber, daß sich die Diskussion auf die Gliedschaft in der sichtbaren Kirche und auf die äußeren Merkmale der Zugehörigkeit beschränken muß ${ }^{45)}$.

Nach der Enzyklika "Mystici Corporis" ist Glied der Kirche, wer die Taufe empfangen hat, den rechten Glauben bekennt, sich nicht selbst von der Gemeinschaft gelöst hat oder wegen schwerer Verfehlungen von der kirchlichen Autorität verstoßen wurde 46 ). Nach dieser Auffassung kann folglich nur Glied der Kirche sein, wer getauft ist und aus freiem Entschluß der Kirche zugehörig sein will sowie ihre Autorität und Lehre akzeptiert, um nicht ausgeschlossen zu werden 47 ).

Einen endgültigen Austritt aus der Kirche kann es indessen nach der katholischen Lehre nicht geben. Die durch die Taufe begründete Aufnahme in die Gemeinschaft ist unauflösbar. Wer getauft ist, bleibt für immer - zumindest formales, wenn auch nicht tätiges - Glied der Kirche und wird aus dem durch die Taufe begründeten Verpflichtetsein gegenüber der Kirche nicht mehr entlassen. Die Kirche ist aber befugt, die Gliedschaftsrechte ihrer Glieder einzuschränken 48 ).

In der evangelisch-lutherischen Kirche wird die Gliedschaft ebenfalls durch die Taufe begründet. Hinzu kommt allerdings für die Eingliederung in die geistige Kirche die Pflicht, bereitwillig zu hören und zu glauben. Wenn diese freiwillige Bereitschaft nicht vorhanden ist und der Gläubige sich öffentlich von der Kirche lossagt, ruht die Kirchengliedschaft ${ }^{49}$ ). 
Die evangelisch-reformierte Kirche weicht von der lutherischen in der Frage der Kirchengliedschaft lediglich geringfügig $a b$. Die Aufnahme in die Kirche erfolgt ebenso durch die Taufe, die jedoch nicht heilsnotwendig, sondern nur ein zeichen der Gliedschaft in der Kirche ist. Bedeutsamer für die Gliedschaft ist es, daß sich das Kirchenglied zum Wort und Sakrament bekennt und sich der Kirchenzucht unterwirft 50 ).

Zusammenfassend kann festgestellt werden, daß in der Frage der Mitgliedschaft unter den betrachteten Kirchen in den wichtigen Punkten Übereinstimmung herrscht. Die Kirchengliedschaft wird durch die Taufe begründet und für eine volle (geistige, tätige) Gliedschaft kommt die Forderung hinzu, daß der Gläubige die Zugehörigkeit bewußt und freiwillig durch seinen Glauben bezeugt.

Gerade die zuletzt angesprochene Forderung stellt in neuerer Zeit alle großen Kirchen vor Schwierigkeiten. Die Zahl der formellen Mitglieder ist zwar immer noch recht groß, allerdings sinkt der Anteil der am kirchlichen Leben teilnehmenden tätigen Glieder zusehends. Mehr und mehr Glieder werden den Kirchen fremd, ohne aber aus der Kirche auszutreten 51 ). Welche (irrationalen) Motive letztlich ausschlaggebend sind, ob es vielleicht eine Angst vor dem Übernatürlichen ist, bleibt ungewiß.

4. Die besondere Stellung der Kirchen in der Bundesrepublik Deutschland

Die heutige Stellung der Kirchen in der Bundesrepublik Deutschland ist das Resultat einer langen geschichtlichen Entwicklung. Ein richtiges verständnis der vielfältigen und eigengearteten Beziehungen zwischen Staat und Kirche( $n)$ ist ohne Wissen um die historischen Hintergründe kaum möglich 52 ).

Bis zur Reformation war das Verhältnis zwischen Kirche und staat von einem fortwährenden Ringen zwischen den kirchlichen 
Gewaltenträgern, verkörpert durch den Papst, und den weltlichen Machthabern um die Vormachtstellung geprägt. Nach und nach verminderte sich der Einfluß des Papsttums 53). Mit der Reformation und dem Augsburger Religionsfrieden zerbrach die Glaubenseinheit des Reiches endgülig und von da an bestimmte die Religionszugehörigkeit des Landesfürsten die der Untertanen ("cuius regio, eius religio"). Auf evangelischer seite entwickelte sich daraus in der Folgezeit das evangelische Landeskirchentum, das sich durch die Ein- und Unterordnung des evangelischen Kirchenregiments und durch die Dominanz der weltlichen Gewalt auszeichnete. Das weltliche Oberhaupt war zugleich kirchliches Oberhaupt 54 ). Beispielhaft dafür stehen die Verhältnisse im Land Preußen. Die kirchlichen Aufgaben waren im "Allgemeinen Landrecht" geregelt. Der staat betrachtete die kirchlichen Aufgaben als seine eigenen. Auch nach der formalen Trennung von Staat und Kirche durch die Preußische Verfassung von 1850 blieb die enge Verknüpfung von Staat und Kirche erhalten. Der Staat sicherte und erhielt sich seinen Einfluß auf die Kirchen, indem er sie in finanzieller Abhăngigkeit hielt ${ }^{55}$ ).

Ăhnlich wie die jeweiligen Landesfürsten in der evanglischen Kirche dominierten auf katholischer seite faktisch die weltlichen Landesherren, obwohl für die katholische Kirche unverändert die Oberherrschaft des Papststums galt56). Von den Säkularisationen im Anschluß an den Reichshauptdeputationsbeschluß von 1803 wurde die katholische Kirche in besonderem Maße getroffen 57), da sie in deren Gefolge nahezu ihr gesamtes Vermögen verlor. Die evangelischen Landeskirchen wurden von der Säkularisation weniger berührt und ihr landeskirchlicher Status unter der Obrigkeit der weltlichen Landesherren hielt bis 1918 an. Für die katholische Kirche begann dagegen im 19. Jahrhundert eine Art Erneuerung. Sie löste sich mehr und mehr aus der Umklammerung des Staates und erlangte eine größere Unabhängigkeit und Selbständigkeit. Der politische Umstand, daß wegen einschneidender Veränderungen auf der Landkarte konfessionell gemischte Staaten entstanden, hat diese Entwicklung begünstigt. Die Tolerierung nicht nur einer einzigen Religion 
führte schließlich zu einer vollen Religionsfreiheit ${ }^{58}$ ). Gleichzeitig erkannte die katholische Kirche die Möglichkeiten, die ihr die neuen bürgerlichen Freiheiten, namentlich die Glaubens-, Bekenntnis- und die Vereinigungsfreiheit, eröffneten. Sie stellte sich auf den Boden der konstitutionellen Ordnung und "bediente" sich deren Einrichtungen, um so auf politischem und gesellschaftlichem Wege ihre ziele zu verfolgen und durchzusetzen. Ein eindrucksvolles Beispiel kirchlicher Einflußnahme auf staatliche Institutionen bietet die Initiative und letztlich der Erfolg katholischer Abgeordneter bei der Abfassung der die Kirchen betreffenden Regelungen in der Weimarer Reichsverfassung, die später unverändert in das Grundgesetz übernommen wurde ${ }^{59)}$.

Durch die Ubbernahme der Bestimmungen der Weimarer Reichsverfassung hat das Grundgesetz die Entscheidung vermieden, das Verhältnis zwischen Staat und Kirche neu zu regeln $\left.{ }^{60}\right)$. Grundsätzliche Bedeutung hat Art. 4 GG, der die Freiheit des Glaubens, des Gewissens, die Freiheit des religiösen und weltanschaulichen Bekenntnisses und die ungestörte Religionsausübung gewährleistet. Hierin kommt "... zum Ausdruck, daß die staatliche Ordnung selbst nicht auf einem bestimmten Glauben oder Bekenntnis ruht ... Der heutige Standort ist religiös (und weltanschaulich) neutral ... Dementsprechend ist eine Sonderstellung oder Privilegierung eines bestimmten Glaubens oder Bekenntnisses im Rahmen der politischen Ordnung unzulässig"61). Aus staatlich neutraler Sicht handelt es sich bei Religionsgemeinschaften um freiwillige, auf längere Dauer angelegte Vereinigungen mit einer vorhandenen organisatorischen Struktur. Der Anlaß und der Zweck der Vereinigung besteht in der gemeinsamen Religion der Mitglieder. Dabei ist der Begriff Religion auf alles anzuwenden, was sich zu etwas Außerweltlichem, mit kultischen Akten verbundenem Tun, dem "Glauben" an etwas "Heiliges", bekennt. D.h., die Religion beruht "... auf Überzeugungen, die dem modernen, weltanschaulich-religiös neutralen Staat verschlossen sind"62). 
Wie oben (vgl.C.I.) bereits angedeutet wurde, bilden die individuellen Freiheitsrechte, namentlich die Glaubensfreiheit, die Grundlage für die kirchlichen Aktivitäten im Gemeinwesen. Der weltanschaulich neutrale Staat darf sich zwar die Ansichten einzelner gesellschaftlicher Gruppierungen nicht zu eigen machen, er muß aber gegenüber den vielfältigen, insbesondere auch den religiösen Wertvorstellungen seiner Bürger offen sein. Einerseits dafür Sorge zu tragen, daß die Bürger ihren religiösen Interessen nachgehen können, andererseits $z u$ verhindern, daß niemand gegen seinen Willen von den entsprechenden Gruppen vereinnahmt wird, darin ist folglich die Neutralität des pluralistischen Staates zu sehen.

Art. 4 und 5 GG schützen die Gläubigen und die Kirchen davor, in die Privatsphäre gedrängt zu werden, und gewährleisten ihr an die రffentlichkeit gerichtetes wirken. Das Tätigwerden in der Offentlichkeit durch kultische Handlungen, das Werben auch um diejenigen, die der Kirche nicht angehören sowie das karitative Handeln sind Formen kirchlicher Aktivitäten, die untrennbar mit dem Selbstverständnis der Kirchen verbunden sind und deshalb - unter dem Vorbehalt der für alle gültigen Gesetze unter den grundgesetzlichen Schutz fallen 63 ).

Obwohl Art. 140 GG i.v.m. Art. 137 WRV die Trennung von staat und Kirche festschreibt und die Selbständigkeit der Kirchen sowie die eigenverantwortliche Erfüllung ihrer Aufgaben anerkennt, zeigt die Wirklichkeit, daß es, namentlich im sozialen Bereich, zahlreiche Felder gemeinsamer Betätigung gibt. Uberschneidungen lassen sich schon deshalb nicht vermeiden, da ein einseitiges Angebot von Leistungen ausschließlich von seiten des Staates der freien Religionsausübung in gleicher Weise widerspräche, wie ein nur subsidiär wirkender staat die berechtigten Interessen der ein konfessionelles Angebot ablehnenden Bevölkerungsgruppen verletzen würde ${ }^{64}$ ). Außerdem bleibt es den Kirchen unbenommen, ihre Weltanschauungen im Rahmen der gesellschaftlichen Prozesse und der politischen Willensbildung auf die staatliche Sphäre zu übertragen 65 ), sei es, daß sie selbst 
versuchen, Einfluß zu nehmen oder sei es dadurch, daß ihre Mitglieder als Bürger im demokratischen willensbildungsproze $\beta$ die Auseinandersetzungen mit den Problemen der modernen welt auf der Grundlage ihrer religiösen tberzeugungen führen ${ }^{66}$ ). Die Grenze für die Ubernahme religiöser Ansichten durch den Staat liegt allerdings dort, wo Minderheiten, etwa Andersdenkende oder Nichtgläubige, einem Mehrheitswillen unterworfen würden, der ihre Grundrechte verletzte ${ }^{67}$ ).

Die freiheitlichen Regelungen des Grundgesetzes stellen das Wirken der Kirchen in der öffentlichkeit sicher. Insofern könnte eigentlich der ihnen im Grundgesetz verliehene Status einer Körperschaft des öffentlichen Rechts, der heute als Voraussetzung für den zugang zur offentlichkeit entbehrlich ist, entfallen 68). Überhaupt mutet dieser Status etwas zweifelhaft an und scheint nicht so ganz in den Rahmen einer vom Staat unabhängigen Kirche zu passen, zumal die wesentlichen Kennzeichen der Körperschaft des öffentlichen Rechts ${ }^{69}$ ), nämlich staatliche Aufgaben mit hoheitlichen Mitteln unter staatlicher Aufsicht zu erfüllen, auf die Kirchen gerade nicht zutreffen.

Die bisherigen Ausführungen belegen offensichtlich, daß die Kirchen wie die Verbände und andere gesellschaftliche Gruppierungen öffentlich im gesellschaftlichen Raum tätig sind. Damit ist nicht gesagt, daß sie qualitativ mit den weltlichen verbänden auf einer Stufe stehen, weil ihr aus dem öffentlichkeitsanspruch des Evangeliums abgeleitetes Handeln ein anderes ist. Jedoch sind die Kirchen in ihrem weltlichen Dasein in verfassungsrechtlicher Sicht für den weltanschaulich neutralen Staat mit den Verbänden gleichzusetzen 70 ). Denn dadurch, daß sie ihren Offentlichkeitsanspruch entfalten, nehmen sie wie die Verbände und andere Gruppierungen gestaltend Einfluß auf das gesellschaftliche Leben und wirken am Prozeß der politischen Willensbildung mit ${ }^{71}$ ). 
5. Der Offentlichkeitsauftrag der Kirchen

Das Wirksamwerden der Kirchen in der welt leitet sich aus dem Offentlichkeitsanspruch des Evangeliums ab. Die großen Kirchen haben ihrem Selbstverständnis entsprechende Lehren entwickelt, in denen sie ihr Verhältnis zur gesellschaftlichen Umwelt zum Ausdruck bringen.

Die altere katholische Auffassung ging von einer Überordnung der Kirche über den Staat aus ${ }^{72}$ ). Später, in der Enzyklika des Papstes Leo XIII., wurden Staat und Kirche als zwei verschiedene, in ihren Bereichen vollkommene, voneinander unabhängige Gemeinschaften (societates perfectae) betrachtet, denen jeweils für ihren Bereich, der Kirche für die göttlichen, dem Staat für die menschlichen Belange, die höchste Souverănităt zusteht ${ }^{73}$ ). Maßgebliche Neuerungen erfuhr die katholische Lehre mit den Verlautbarungen des II. Vatikanischen Konzils ${ }^{74}$ ). Es geht heute weniger um die Frage der Trennung oder Einheit von Kirche und Staat, sondern darum, wie die zur ungehinderten Durchführung ihres Heils- und Verkündigungsauftrages erforderlichen Entfaltungsmöglichkeiten der Kirche als einer der gesellschaftlichen Kräfte in einer pluralistischen Gesellschaft zu gestalten sind ${ }^{75}$ ). Die Kirche akzeptiert damit einerseits die Wirklichkeit des modernen demokratischen Staates, sie verlangt aber andererseits als Grundlage der Beziehungen zwischen Staat und Kirche die Gewăhrung der individuellen Religionsfreiheit, die institutionelle Freiheit der Kirche sowie die zusammenarbeit von Kirche und Staat im Dienst an demselben Menschen ${ }^{76}$ ).

Die Forderung der individuellen Religionsfreiheit als unverzichtbarer Bestandteil der menschlichen würde impliziert für die katholische Kirche die Toleranz gegenüber Anders- oder Nichtgläubigen; eine gewaltsame Bekehrung scheidet demzufolge aus. Die Kirche hat allerdings im Rahmen der freien Religionsausübung die Möglichkeit, für sich zu werben und zu versuchen, diejenigen Menschen, die ihr nicht angehören, durch tberzeugung zu gewinnen ${ }^{77}$ ). Die katholische Kirche verlangt außerdem vom 
Staat, daß er ihr die volle Freiheit für das kirchliche wirken einräumt, damit sie ihrer Aufgabe, dem Heil der Menschen zu dienen, nachkommen kann. Da nach katholischer Ansicht das kirchliche Dienen auf dieselben Menschen gerichtet ist, für deren wohl auch der staat zu sorgen hat, nur in einem anderen Bereich und mit anderer Rechtfertigung, läßt sich das um so besser erreichen, je intensiver die zusammenarbeit zwischen staat und Kirche gelingt ${ }^{78}$ ). Schließlich beansprucht die katholische Kirche ungeachtet dessen, daß sie die Unabhängigkeit des Staates in weltlichen Belangen anerkennt, für sich als Hüterin der Sittengesetze den politischen Auftrag, den Staat und seine Handlungsweisen ihren sittlichen Wertungen zu unterwerfen ${ }^{79}$ ).

Ihr Verhältnis zum Staat leitet die evangelisch-lutherische Kirche aus der "Zwei-Reiche-Lehre" Luthers ab. Dieser unterschied zwischen dem geistlichen Regiment als dem Reich Gottes zur rechten Hand Gottes, dem das Predigtamt zukommt, und dem weltlichen Regiment als dem Reich Gottes zur linken Hand, das die menschliche Ordnung erfaßt. Während im geistlichen Regiment Christus herrscht, gilt im weltlichen Regiment das Gesetz, das als Anordnung Gottes dafür sorgt, daß Ordnung und Frieden in der Welt gesichert bleiben 80$)$. Die evangelisch-lutherische Kirche ist heute, nachdem sie - auch durch die Erfahrungen im Kirchenkampf - ihre Mitverantwortung für die Welt bekannt hat, bestrebt, von der früheren Betrachtung der beiden Reiche als zwei voneinander unabhängiger Bereiche wegzukommen und diese Lehre in einem Sinne zu interpretieren, wie es einer modernen pluralistischen und demokratischen Gesellschaft angemessen ist $\left.{ }^{81}\right)$. Die Verbindung der beiden Reiche wird darin gesehen, daß der einzelne Christ seine christliche Einstellung, die ihm die Kirche mitgibt, und die Nächstenliebe zum Maßstab für sein weltliches Handeln nimmt. Das heißt nun nicht, daß einem christlichen Staat das wort geredet werden soll, sondern nur, daß der einzelne Christ zu einem Aufbau einer vernünftigen weltlichen Ordnung beitragen soll, in der auch ein Anders- oder Nichtgläubiger seinen platz haben muß ${ }^{82}$ ). 
Die für die evangelisch-reformierte Kirche maßgebliche "Königsherrschaft Christi" ist eine Handlungsanweisung für den Christen und spricht dessen Mitverantwortung für die Gestaltung der Gesellschaft an 83). Da sich die "Herrschaft Christi" auf alle Lebensbereiche erstreckt, muß sich der einzelne Christ in seinem weltlichen Handeln von seiner christlichen tbberzeugung leiten lassen und Verantwortung in der Welt übernehmen ${ }^{84}$ ).

Die ältere "Zwei-Reiche-Lehre", wonach der Christ Bürger zweier Reiche sei und sich den unterschiedlichen Gewalten jeweils unterzuordnen habe, stand im Gegensatz zur Lehre von der "Königsherrschaft Christi", weil sie zu einem unterschiedlichen Verhalten der Christen als Bürger im Staat und als Glieder der Kirchen führte. Dagegen stimmt die neuere Interpretation der "Zwei-Reiche-Lehre", wie sie oben beschrieben wurde, in ihren Kernaussagen mit der Lehre von der "Königsherrschaft Christi" überein ${ }^{85}$ ). Damit sind die Auffassungen der beiden großen evangelischen Kirchen über das Verhältnis zum Staat praktisch identisch. Die daraus abgeleiteten Forderungen, die die evangelischen Kirchen als unabdingbar für ein freies Wirken in der Gesellschaft ansehen, decken sich mit jenen, die bereits für die römisch-katholische kirche herausgestellt wurden ${ }^{86}$ ).

Für die Kirchen ist der Anspruch auf Öffentlichkeit ein wesensmäßig unverzichtbares Element; denn der Verkündigungs- und Sendungsauftrag Christi hat der Kirche in der Welt zur Aufgabe gemacht, die durch Christus gegebene Heilsmöglichkeit allen Menschen anzubieten. Das kann zwangsläufig nicht in der Privatsphäre erfolgen. Um jedermann mit der Predigt und durch tätige werke sozialer, karitativer und politischer Art, die sich aus der Mitverantwortung der Christen und dem Gebot der Nächstenliebe ergeben, zu ereichen, braucht die Kirche die Offentlichkeit ${ }^{87}$ ).

Aus der Universalität des Heilswirkens Gottes folgt für die Kirchen als Stellvertreter Christi die öffentliche Verkündigung als Kern ihres öffentlichen Handelns. Offentliches Handeln in 
der Stellvertretung Christi heißt jedoch außerdem diakonisches Handeln; denn so wie Christus für andere da war, so müssen die Kirchen und der einzelne Christ für andere da sein und ihr verhalten am Gebot der Nächstenliebe ausrichten. Offentliches Handeln beinhaltet folglich für die Kirchen und den einzelnen Gläubigen den Auftrag, in der Gesellschaft zu wirken ${ }^{88)}$. 
Peter Saile - 978-3-631-75214-2

Downloaded from PubFactory at 01/11/2019 07:01:15AM

via free access 
III. Die kirchlichen Funktionen

\section{Wortverkündigung und Sakramentsverwaltung}

Sowohl nach katholischem als auch nach evangelischem Verständnis sind die Verkündigung des Evangeliums und die Sakramentsverwaltung wesensmäßig untrennbar mit dem Sein der Kirche verbunden und damit unverzichtbare Grundfunktionen der Rirchen in der welt ${ }^{89}$ ).

Ihren Ausdruck findet die Wortverkündigung in erster Linie in der Predigt und im Gottesdienst. Zur Wortverkündigung zählt ferner das seelsorgerische Wort, dessen tröstende und ermahnende, auf der Kraft Gottes beruhende Wirkung sich besonders an Kranke, an Abgefallene und an der Kirche Fernstehende richtet $^{90)}$.

Die Sakramentsverwaltung äußert sich in der katholischen Kirche bei der Taufe, der Firmung, der Eucharistiefeier, der Eheschließung, der letzten Ǒlung und bei der Einsegnung91). Auf evangelischer Seite gehören zur Sakramentsverwaltung die Taufe und das Abendmahl. Weitere sakrale Handlungen sind die Konfirmation, die Trauung und die Bestattung ${ }^{92}$ ). Diese kirchlichen Amtshandlungen erlangen neben ihrer eigentlichen Funktion zusehends eine wichtige missionarische Bedeutung, weil viele, die die kirchlichen Amtshandlungen begehren, keine tätigen Kirchenglieder mehr sind. Die Amtshandlungen bieten daher den Seelsorgern eine gute Gelegenheit, mit den der Kirche Entfremdeten Gespräche $z u$ führen und $z u$ versuchen, sie wieder in die Gemeinde zurückzubringen 93 ).

Die Wortverkündigung reicht allerdings über die soeben besprochenen Formen hinaus. Zu ihr werden auch andere kirchlichen Aktivitäten gerechnet, die das gesamte Gemeinwesen angehen und die eine besondere Bedeutung erlangen, weil die Kirchen in enge Berührung zu staatlichen Funktionen kommen. Das ist der Fall bei der Anstalts- und Militärseelsorge, aber auch bei der 
Verkündigung und der Lehre des Wortes Gottes im Erziehungs- und Bildungswesen. Diese speziellen Formen der Verkündigung werden im folgenden gesondert betrachtet.

2. Besondere Formen der Verkündigung

\section{a) Militärseelsorge und Anstaltsseelsorge}

Die Militärseelsorge und die Anstaltsseelsorge können als "klassische", jedoch nicht unproblematische Fälle für die Kooperation von Kirche und staat angesehen werden.

Für die Angehörigen der Streitkräfte sind besondere Regelungen der Seelsorge notwendig, weil sie aus den normalen Lebensverhältnissen herausgelöst sind und Bedingungen unterliegen, die eine freie Religionsausübung erschweren können. Die Aufgabe der Militärseelsorge besteht darin, die freie Religionsausübung unter diesen besonderen Umständen zu gewährleisten 94 ).

Die Militärseelsorge hat eine lange, bis in frühere Zeiten der engen Verknüpfung von Staat und Kirche zurückgehende Tradition 95). Heute ist die Militärseelsorge vertraglich zwischen den Großkirchen und dem Staat geregelt. Entsprechend der verfassungsmäßig gebotenen religiösen Neutralität liegen Inhalt und Durchführung bei den Kirchen während der Staat dafür zu sorgen hat, daß die Religionsausübung grundsätzlich möglich ist96). Die Militärseelsorge umfaßt die Verkündigung, das Halten von Gottesdiensten, kirchliche Amtshandlungen, die Durchführung von Rüstzeiten (auf katholischer Seite Exerzitien), die Mitwirkung bei militärischen Feiern und den lebenskundlichen Unterricht 97 ).

Der lebenskundliche Unterricht offenbart besonders deutlich die mit der Militärseelsorge verbundenen Probleme für das Verhältnis zwischen Staat und Kirche. Er dient der menschlichen Erziehung der Soldaten und ist Bestandteil der militärischen Gesamterziehung. Demzufolge handelt es sich um eine staatliche Ange- 
legenheit. Der Unterricht wird von Militärgeistlichen auf der Grundlage christlicher Werte erteilt $\left.{ }^{98}\right)$. Diese enge $\mathrm{zu}-$ sammenarbeit zwischen Staat und Kirche hat Anlaß zu mancherlei Kritik an der Verfassungsmäßigkeit der Militärseelsorge gegeben, weil man die Neutralitätsverpflichtung des Staates verletzt sah. Die herrschende Meinung geht jedoch davon aus, daß die Militärseelsorge in dieser Form Rechtens sei, da der Staat die Kirchen nur positiv unterstütze ${ }^{99}$ ).

Die starke Verknüpfung von staat und Rirche kommt auch in der "Zwitterstellung" der Militärgeistlichen zum Ausdruck. Mit Ausnahme der Militärbischöfe, die ausschließlich der kirchlichen Leitung unterstehen, sind die Militärgeistlichen einerseits als Amtsträger in kirchlichen Angelegenheiten der Kirche unterstellt und andererseits Beamte des Staates, der die Organisation und Finanzierung der Militärseelsorge übernimmt ${ }^{100}$ ).

Die staatliche Unterstützung der Militärseelsorge ist für die Kirchen ohne zweifel sehr vorteilhaft. Kritik wird deshalb allenfalls vereinzelt laut, obwohl, wie Huber ${ }^{101}$ ) andeutet, die praktizierte Form der Militärseelsorge im Hinblick auf das kirchliche Selbstverständnis problematisch werden kann, und zwar dann, wenn der Staat von den Kirchen eine in jedem Falle zu dem Auftrag der Streitkräfte loyale Durchführung der Militärseelsorge erwartet. Das könnte in einigen Fällen die Unabhängigkeit des kirchlichen Verkündigungsauftrages gefährden. In derartige Konflikte könnten die Militärgeistlichen etwa bei der Beratung und Betreuung von Wehrdienstverweigerern, die bereits bei der Bundeswehr dienen, geraten.

Das Recht auf freie Religionsausübung steht auch all denjenigen $z u$, die krankheitsbedingt oder durch hoheitlichen zwang in ihrer Freiheit eingeschränkt und in Anstalten untergebracht sind. Der Staat hat als Träger der Anstalten dafür Sorge zu tragen, daß die Betroffenen ihren religiösen Bedürfnissen nachkommen können. Die zwischen Kirchen und Staat getroffenen Regelungen für die Anstaltsseelsorge sehen eine ähnlich enge, und damit 
teilweise ebenfalls nicht unproblematische zusammenarbeit wie bei der Militärseelsorge vor. Während in kleineren Anstalten so verfahren wird, daß Seelsorger freien zutritt haben, beschäftigen größere Anstalten fest beim Staat angestellte Anstaltsseelsorger. Auch die Durchführung des Seelsorgeauftrages geschieht in enger Kooperation mit der staatlichen Leitung der Anstalten. So erhalten die Seelsorger z.B. Akteneinsicht oder werden über Krankheitsbilder informiert, um sich intensiv um die einzelnen Personen kümmern zu können 102 ).

b) Verkündigungsauftrag und staatliches Schulwesen

Der Öffentlichkeitsanspruch des kirchlichen Verkündigungsauftrages berührt das staatliche Schulwesen in zweierlei Hinsicht. Neben der später noch zu diskutierenden Regelung in Art. 7 GG, die den Religionsunterricht zum ordentlichen Lehrfach an staatlichen Schulen macht, betonen einige Länderverfassungen (z.B. Art. 12 Abs. 1 Verfassung des Landes Baden-Württemberg) darüber hinaus, daß die schulische Erziehung auf der Grundlage christlicher Werte und Leitvorstellungen erfolgen soll. Damit wird von staatlicher Seite die Bedeutung und der Einfluß des christlichen Gedankengutes auf das gesellschaftliche zusammenleben und die Kultur im abendländischen Raum bekräftigt. So heißt es etwa in Art. 4 Abs. 2 Verfassung des Landes BadenWürttemberg: "Ihre (der Kirchen, Anm. d. Verf.) Bedeutung für die Bewahrung und Festigung der religiösen und sittlichen Grundlagen des menschlichen Lebens wird anerkannt."

Besonders ausgeprägte Vorstellungen über die Mitwirkung an den Bildungszielen des Schulsystems vertritt die katholische Kirche. Sie erhebt unter Berufung auf ihren Heilsauftrag grundsätzlich den Anspruch, an der Erziehung der Schüler auf der Grundlage ihrer Wertvorstellungen mitzuwirken 103) - unbeschadet davon, ob sich diese Forderung in der pluralistischen Gesellschaft gegenüber den anderen Kräften überhaupt durchsetzen läßt. Unter Berücksichtigung der gesellschaftlichen Verhältnisse reduziert sich dieses Ansinnen allerdings darauf, daß die 
katholische Kirche der Gesellschaft ihre "Dienstbereitschaft anbietet". Sie ist wegen der Einsicht in die Undurchsetzbarkeit dieses Verlangens außerdem davon abgerückt, das Schulsystem streng nach Konfessionen zu trennen, will aber für sich die freie Religionsausübung in den öffentlichen Einrichtungen gewahrt wissen 104 ).

Im Vergleich dazu nimmt sich der Anspruch der evangelischen Kirche auf Mitwirkung am staatlichen Schulsystem sehr viel bescheidener aus. Obgleich sie ihre Mitverantwortung im Erziehungswesen geltend macht und sie ihre geistig-moralischen Wertvorstellungen miteinbringen will, ist in ihrer sicht das Schulsystem primär eine staatliche Angelegenheit ${ }^{105}$ ). Nach Auffassung der evangelischen Kirche brauchen die Schulen Freiheit und Unabhängigkeit von bestimmten Ideologien und Bevormundungen. In diesem Freiraum sieht sie für sich als Partner im demokratischen Staat Mitwirkungs- und Betätigungsmöglichkeiten im Bildungs- und Erziehungswesen ${ }^{106}$ ).

Insofern weichen die Ansichten der evangelischen und katholischen Kirche kaum voneinander ab. Beide leiten ihre Mitwirkung und Mitverantwortung im Bildungswesen aus dem Heilsauftrag und dem Offentlichkeitsanspruch der Verkündigung ab und wollen ihre Interessen als in der Offentlichkeit bedeutsame Gruppen gleichberechtigt berücksichtigt wissen. Die rechtlichen Regelungen in den meisten Bundesländern sind diesen Forderungen der Rirchen auch gefolgt, indem in die Bildungsziele die kirchlichen wertvorstellungen aufgenommen wurden und den Kirchen ein Mitspracherecht in Schulfragen eingeräumt wurde ${ }^{107}$ ).

c) Religionsunterricht

In kirchlicher Sicht ist der Religionsunterricht Bestandteil des Verkündigungsauftrages und dient der religiösen Erziehung der Schüler. In neuerer zeit gibt es jedoch Bestrebungen, die den Religionsunterricht nicht nur im Lichte des Verkündigungsauftrages sehen, sondern ihn wesensgemaß als einen Teil des 
schulischen Erziehungsauftrages in die allgemeinen Bildungsziele einfügen wollen. Ihm wïrde dann die Funktion zukommen, den Schülern die christlichen Werte zu erläutern und kirchliche Antworten auf die weltlichen Fragen zu geben ${ }^{108}$ ).

Nach Art. 7 Abs. 3 GG ist der Religionsunterricht an den Schulen, mit Ausnahme der bekenntnisfreien, ordentliches Lehrfach und damit eine Aufgabe des Staates. Das hat zur Konsequenz, daß der Staat die Sach- und Personalkosten sowie die organisatorischen Belange des Religionsunterrichts zu übernehmen hat. Die Bestimmung der Unterrichtsinhalte verbleibt dagegen im Verantwortungsbereich der Kirchen. Erteilt wird der Religionsunterricht entweder von theologisch vorgebildeten staatlichen Lehrkräften oder, falls diese fehlen, von Geistlichen oder anderen Angehörigen der Kirchen, die einen staatlichen Lehrauftrag für den Religionsunterricht erhalten. Die Kirchen verfügen bei der Bestellung der Lehrkräfte, die von ihnen bestätigt werden müssen, ubber ein gewichtiges Mitspracherecht. Ein Lehrer an einer öffentlichen Schule kann allerdings nicht gezwungen werden, gegen seinen Willen Religionsunterricht $\mathrm{zu}$ halten. Außerdem ist den Schülern nach Art. 7 Abs. 2 GG die Teilnahme am Religionsunterricht freigestellt. Bis zum Erreichen der Religionsmündigkeit bestimmen die Eltern, ob ihr Kind am Religionsunterricht teilnimmt oder nicht ${ }^{109}$ ).

Die Rechtfertigung des Religionsunterrichts als staatliche Aufgabe fußt auf dem Gedanken des modernen Kulturstaates. Auch das Schulwesen muß - wie es in den Bildungszielen zum Ausdruck kommt - für alle bedeutsamen geistigen und moralischen Kräfe der Gesellschaft offen sein. Staatliche Neutralität heißt in diesem Falle nicht totale Trennung von Staat und Kirche, sondern vielmehr der Pluralität Genüge zu tun ${ }^{110)}$. Betrachten aber die Kirchen den Religionsunterricht vorrangig als Teil ihres Verkündigungsauftrages, was wohl nicht ganz von der Hand zu weisen ist, selbst wenn versucht wird, den Religionsunterricht in die allgemeinen Bildungsziele zu integrieren, dann wird die obige Rechtfertigung fragwürdig. Wäre nämlich der Religionsun- 
terricht Teil des Verkündigungsauftrages, müßte man ihn wohl eher als Angelegenheit der Kirchen ansehen. Diesem Gedanken dürfte das Berliner Schulgesetz111) gefolgt sein, das den Religionsunterricht den Kirchen, Religions- und Weltanschauungsgemeinschaften als deren eigene Angelegenheit zuweist. Indessen und darin liegt eine gewisse Inkonsequenz - ist die Praxis den übrigen Bundesländern weitgehend angeglichen.

d) Kirchliche Privatschulen

Die Verwirklichung der aus ihrem Selbstverständnis abgeleiteten Bildungs- und Erziehungsziele im Schulwesen ist den Kirchen im Rahmen des grundgesetzlichen Rechts auf Errichtung von Privatschulen nach Art. 7 Abs. 4 GG gegeben. Die Kirchen, insbesondere die katholische, haben davon, wie einige Zahlenangaben belegen, in beträchtlichem Maße Gebrauch gemacht ${ }^{112}$ ).

Ausgehend von dem jedem Menschen zustehenden Recht auf Bildung und Erziehung, namentlich der religiösen und sittlichen, leitet die katholische Kirche für sich eine besondere Rolle im Schulwesen $a b$, weil sie es als ihre Aufgabe ansieht, allen Menschen das Heil zu verkünden und den Gläubigen das Leben Christi mitzuteilen. Aus diesem Grunde lehnt sie ein staatliches Schulmonopol ab und fordert für sich das Recht auf die Errichtung von katholischen Schulen ${ }^{113}$ ).

Die evangelische Kirche beruft sich bei der Forderung nach kirchlichen Privatschulen darauf, daß in einem freiheitlichen System mit einer langen, durch das Christentum maßgeblich beeinflußten Tradition und Kultur das Schulwesen sich dem Christentum nicht verschließen dürfe, sondern ihm offenstehen müsse 114 ).

In staatlicher Sicht sind die von den Kirchen getragenen Schulen Privatschulen. Obgleich das Schulwesen nach Art. 7 GG eine staatliche Angelegenheit ist, übernehmen die Kirchen mit den Privatschulen keine staatliche Aufgabe, allenfalls eine öffent- 
liche. Die Erfüllung einer öffentlichen Aufgabe kann darin gesehen werden, daß die Kirchen als Träger der Privatschulen in einer besonderen öffentlichen Verantwortung stehen und mit der Errichtung von Privatschulen eine "integrierende Funktion für das Staatsganze" erfüllen 115). Die Kirchen nehmen mit der Bildung und dem Betreiben von Privatschulen ein grundgesetzliches Recht wahr, das in besonderem Maße die freiheitliche zielsetzung zum Ausdruck bringt, weil hier Minderheiten die Möglichkeit zur Verwirklichung ihrer Bildungsideen geboten wird, indem Eltern "... ihre Rinder nach anderen als den staatlichen Bildungszielen erziehen .. lassen" können und indem "... privaten Schulträgern und Lehrern" erlaubt wird, "selbstgewählte Bildungsinhalte gemäß den eigenen pädagogischen und didaktischen Gesichtspunkten zu vermitteln"116). Allerdings bleibt es dem Staat unbenommen, daß er "... gewisse Voraussetzungen und Rahmenbedingungen schaffen darf, die bei der Errichtung von Privatschulen zu beachten sind"117).

Umstritten ist die Frage, wie die Privatschulen vom Staat zu behandeln sind. Insbesondere geht es darum, ob dem staat aus der Gewährung des Rechts auf Errichtung von Privatschulen nicht zugleich die Verpflichtung erwächst, die Voraussetzungen für die Schaffung und Erhaltung von Privatschulen sicherzustellen, "... damit das Recht tatsăchlich ausgeübt werden kann"118). Dies wird zumindest für die Ersatzschulen, d.h. bei den in den Lehr- und Erziehungszielen den staatlichen Schulen vergleichbaren Einrichtungen, mit der Begründung bejaht, daß in diesen Fällen der Staat selbst vom Erbringen einer Leistung befreit und von Kosten entlastet wird. Eine staatliche Unterstützung wird außerdem für die Ergänzungsschulen gefordert, die nicht auf erwerbswirtschaftlicher, sondern auf gemeinwirtschaftlicher Basis arbeiten, und zwar mit der Rechtfertigung, daß nur so das Recht auf Errichtung von Privatschulen tatsăchlich gewährleistet sei. Die Privatschulen müßten ansonsten an der Finanzierungsfrage scheitern und damit würde das Recht auf die Errichtung praktisch ausgehöhlt(19). Die Art und Weise, wie die privaten Schulen vom Staat behandelt werden, ist in den einzelnen 
Länderverfassungen geregelt. So etwa in Art. 14 Abs. 2 Verfassung des Landes Baden-Württemberg: "Auf gemeinnütziger Basis arbeitende private mittlere und höhere Schulen, die einem öffentlichen Bedürfnis entsprechen, als pädagogisch wertvoll anerkannt sind und eine gleichartige Befreiung gewahren, haben Anspruch auf Ausgleich der hierdurch entstehenden finanziellen Belastung".

e) Theologische Fakultäten und kirchliche Hochschulen

Die theologischen Fakultäten sind wie alle anderen Fakultäten Bestandteil der Universităt und haben insofern einen primär staatlichen Status. Sie erhalten aber auch einen kirchlichen Status, weil sie außerdem der Ausbildung von Pfarrern und Seelsorgern für die beiden großen Kirchen dienen. Das setzt voraus, daß die Ausbildung auf den von den Kirchen vertretenen Lehren fußt ${ }^{120)}$.

Die Kirchen betrachten die theologische Forschung als den zur Lehre verpflichteten Bestandteil des Verkündigungsauftrages 121). Einzelne Äußerungen von evangelischer Seite gehen sogar so weit, die Aufgaben der Theologie als identisch mit der Predigt anzusehen. Unter beiden genannten Aspekten ist die Theologie alsteil des Verkündigungsauftrages eine reine kirchliche Angelegenheit ${ }^{122}$ ). Aus diesem Selbstverständnis heraus leiten die Kirchen ihre staatlicherseits weitgehend akzeptierten Mitgestaltungsrechte in den theologischen Fakultäten $a b$. Was den Einfluß auf die Lehrinhalte anlangt, sind die evangelischen Fakultäten freier als die katholischen, deren Lehrangebot sich streng an den kirchlichen Vorschriften zu orientieren hat. Besonders deutlich kommt die kirchliche Mitsprache bei der Berufung des Lehrpersonals zum Ausdruck. Eine Berufung auf ein Lehramt oder ein Verbleiben darin ist, obwohl es sich hier um eine rein staatliche Sache handelt, nicht gegen den willen der jeweiligen Kirche möglich, wenn diese Bedenken gegen die Lehre und/oder den Lebenswandel des Lehrers anmeldet ${ }^{123}$ ). 
Die Rechtfertigungen für den staatlichen Status der theologischen Fakultäten liefern einmal die Verpflichtung des Staates zur Ausbildung von Religionslehrern, die daraus folgt, daß der Religionsunterricht ordentliches Lehrfach ist. Allerdings muß diese Ausbildung nicht unbedingt an theologischen Fakultäten erfolgen, sondern kann auch an anderen zu diesem Zweck vom Staat geschaffenen Einrichtungen stattfinden ${ }^{124}$ ). Zum anderen, und das sind die wesentlicheren Begründungen, beruht ihr staatlicher Status vor allem auf der historischen Entwicklung, dem Anspruch der Universität auf die Universalität der die Theologie einschließenden Wissenschaft, ferner auf der Notwendigkeit der Kommunikation der Wissenschaften untereinander und schließlich auf dem Öffentlichkeitsanspruch der Kirchen ${ }^{125) .}$

Neben den theologischen Fakultäten an staatlichen Universitäten unterhalten die Großkirchen kirchliche Hochschulen und Fachhochschulen in eigener Trägerschaft, die weitgehend frei von staatlicher Aufsicht sind. Sie dienten lange Zeit einzig der Aus- und Fortbildung der Geistlichen und Seelsorger. In jüngerer zeit wird jedoch, vornehmlich an kirchlichen Fachhochschulen, verstärkt in sozialen Berufen und Lehrberufen ausgebildet, für die in den Kirchen ein zunehmend größer werdender Bedarf entstanden ist ${ }^{126}$ ).

f) Erwachsenen- und Weiterbildung

Die Kirchen beteiligen sich an der gesamtgesellschaftlichen Aufgabe der Erwachsenenbildung, die sie als Teil ihres Verkïndigungsauftrages ansehen. Ihr Bildungsauftrag entspringt ihrem Selbstverständnis, die Erwachsenen im Glauben zu stärken und zu einem gesellschaftlichen und sozialen Handeln nach christlichen Wertvorstellungen anzuleiten. Sie nehmen durch diesen Dienst am Menschen ihre gesellschaftliche Mitverantwortung in der Welt wahr ${ }^{127}$ ).

Die kirchliche Bildungsarbeit ist strenggenommen in eine rein interne und in eine Beteiligung an der offenen, allgemeinen 
Erwachsenenbildung zu trennen. Die interne dient der religiösen Erziehung und der Verfestigung des Glaubens ihrer Mitglieder und ist daher eine rein kirchliche Angelegenheit. Bei der Mitwirkung an der allgemeinen Erwachsenenbildung konkurrieren die Kirchen dagegen mit zahlreichen anderen freien Trägern ${ }^{128}$ ). Im Unterschied $\mathrm{zu}$ den freien Trägern der Erwachsenenbildung sehen die Kirchen ihre Aufgabe jedoch nicht darauf beschränkt, nur berufliche Kenntnisse und Qualifikationen zu vermitteln, sondern ihnen liegt darüber hinaus daran, die Persönlichkeit des einzelnen zu vervollkommnen ${ }^{129}$ ).

Eine Besonderheit kirchlicher Weiterbildung stellen die evangelischen und katholischen Akademien dar. Die Akademien veranstalten Gesprächskurse über wichtige gesellschaftspolitische Themen, an denen die verschiedenen Gruppen der Gesellschaft teilnehmen. Die Kirchen versuchen in diesem Dialog mit der Gesellschaft die anstehenden Fragen auch unter dem Blickwinkel ihrer aus dem Evangelium abgeleiteten Vorstellungen zu durchleuchten. Sie betrachten die Akademien als ein geeignetes Forum, ihrem Öffentlichkeitsauftrag gerecht zu werden und ihre Wertvorstellungen und Anworten in die gesellschaftliche Diskussion einzubringen ${ }^{130}$ ).

Die Notwendigkeit zur ständigen beruflichen, politischkulturellen und allgemeinen weiterbildung in der heutigen zeit mit schnellen Veränderungen der technischen, sozialen, politischen und wirtschaftlichen Verhältnisse ist unbestritten. Der Staat bejaht die Weiter- oder Erwachsenenbildung als gesamtgesellschaftliche Aufgabe. Ihm steht es jedoch nicht zu, gegenüber dem mündigen Bürger einen Erziehungsanspruch geltend zu machen. In einer freiheitlichen ordnung sind vielmehr die gesellschaftlich bedeutsamen Kräfte gefordert, Bildungsinitiativen zu entwickeln und zu entfalten. Es muß dem Bürger selbst überlassen bleiben, aus dem pluralistischen Angebotsspektrum auszuwählen 131). 


\section{Diakonie}

Die Diakonie"132) als "helfendes Tun" ist die zweite Grundfunktion der kirchen und resultiert aus dem Gebot der Năchstenliebe. Der Begriff Diakonie umschließt die soziale, pflegerische, pädagogische und fürsorgerische Verantwortung der Kirchen 133).

Die Sendung Christi bestand im Dienst an Armen und Schwachen. Daraus leitet sich der zweifache Charakter des kirchlichen Dienstes ab: Zuerst wird er Christus dem Herrn erwiesen, damit aber zugleich auch dem Bruder als dem Nächsten 134 ). Die Diakonie ist deshalb ein unverzichtbarer Wesensbestandteil der Kirchen, weil sie der Verwirklichung des Auftrags der Kirchen zum Dienst am Menschen dient. Daran wird die "dienende Kirche" sichtbar 135). Alle, die an den Gaben Christi Anteil haben, sind untereinander verbunden und zum gegenseitigen Dienst verpflichtet. Die Verpflichtung zum Dienst am Năchsten richtet sich nicht nur an Glaubensbrüder, sondern an alle Bedürftigen 136). Daraus ergibt sich für die Kirchen als von der Nächstenliebe geprägte Gemeinschaften der Auftrag zum Dienst für Gott und den Menschen. Glaube und Gottesliebe sind nicht echt ohne Nächstenliebe, d.h. Nächstenliebe, ist die Verwirklichung der Gottesliebe ${ }^{137}$ ). Zum Dienst am Bedürftigen und Nächsten sind deshalb die Kirchen, aber auch jeder einzelne Christ aufgerufen ${ }^{138}$ ).

Die karitativen Werke der Kirchen oder die der den Kirchen verbundenen sozialen Organisationen haben im sozialen Bereich eine große, den Staat teilweise übertreffende Bedeutung erlangt. Die Kirchen betreiben Krankenhäuser, Kinder- und Jugenddörfer, heilpädagogische Einrichtungen, Heime für Mutter und Kind, Erziehungsheime, Jugend-, Lehrlings-, Studenten- und Altenheime, Erholungsheime sowie Heime für Behinderte. Dazu kommen Tageseinrichtungen wie Sonderschulen, Kindergärten und Altentagesstätten und außerdem verschiedene Formen der offenen Hilfe wie z.B. Gemeindepflegestationen, Jugendhilfeeinrichtungen, Familienpflegestationen, Dorfhelferinnen usw. 139). 
Die christliche Nächstenliebe erstreckt sich wesenhaft weltweit auf wirtschaftliche, soziale und politische Probleme und muß alle Menschen und Nöte erfassen. Die gewährte Hilfe hat das ziel, die Not zu lindern, und sie hat gleichzeitig in der Weise $\mathbf{z u}$ erfolgen, daß sich die Empfänger mit der zeit aus der Abhängigkeit lösen und sich selbst helfen können ${ }^{140)}$.

Für die kirchliche Diakonie als Dienst am Menschen hat immer der Mensch im Mittelpunkt zu stehen 141). Aus kirchlicher sicht liegt hierin ein qualitativ großer Unterschied zu den neutralen sozialen Diensten. Die Rirchen orientieren sich nicht nur an sozialen Sachzielen, sondern sie sehen in ihrem Dienst am Nächsten zugleich die seelsorgerische Aufgabe, sich um das Wohl des ganzen Menschen zu kümmern. Beispielsweise geht es bei einer Rehabilitationsmaßnahme nicht ausschließlich um den ökonomischen Nutzen einer möglichst schnellen wiedereingliederung in den Produktionsproze $\beta$. Daneben steht auch die Sorge um den Menschen, ihm wieder ein Selbstwertgefühl zu vermitteln. Insofern reicht kirchliche Hilfe über neutrale soziale Hilfe hinaus ${ }^{142}$ ). Ein anderes Beispiel sind die von den Kirchen unterhaltenen Kindergärten, die den Kirchen eine gute Gelegenheit geben, über die Kinder auch deren Eltern zu erreichen ${ }^{143}$ ).

Nach kirchlichem Selbstverständnis sind die Liebestätigkeiten, zu denen die karitativen und sozialen Aktivitäten gehören, unverzichtbarer und wesentlicher Bestandteil der den besonderen Schutz des Art. 4 GG genießenden freien Religionsausübung 144). Aus dem Recht der freien Religionsausübung leiten die Kirchen die freie Entfaltung ihres sozialen Wirkens in der Gesellschaft $a b^{145)}$. Sie begründen ihre Forderung mit dem Offentlichkeitsanspruch und mit dem Gebot der staatlichen Neutralität. Um eines pluralistischen Angebots willen lehnen sie ein staatliches Monopol ab. Die soziale Hilfe durch die Kirchen und andere freie Träger sowie staatliche Träger stellt ein pluralistisches Angebot sicher, aus dem jeder die seinen Bedürfnissen und Verhältnissen entsprechende Leistung auswählen kann 146). Damit geraten die Kirchen zwangsläufig in Berührung mit den staatlichen 
Leistungen in diesen Bereichen, so daß es der Abstimmung zwischen staatlichen Trägern einerseits und freien, insbesondere kirchlichen Trägern andererseits bedarf.

Das von kirchlicher Seite immer wieder vorgebrachte Subsidiaritätsprinzip als Rechtfertigung für den Vorrang ihres öffentlichen Wirkens vor dem Staat kann staatlicherseits nicht anerkannt werden. In der Verfassung finden sich keine Hinweise auf eine Verankerung dieses Grundsatzes ${ }^{147}$ ). Charakteristisch für den freiheitlichen Staat ist jedoch, daß er den gesellschaftlichen Kräften ein freies Betätigungsfeld für ihre Aktivitäten überläßt. Dadurch entsteht zwischen dem staatlichen und dem privaten ein öffentlicher Raum ${ }^{148}$ ). Aus dem Ubberlassen eines Freiheitsraumes für die kirchliche Betätigung kann indessen noch kein Anspruch auf staatliche Finanzierung abgeleitet werden 149). Eine staatliche Finanzierung kirchlicher karitativer Aufgaben wäre auch aus theologischer sicht nicht ganz wesensgemäß; denn die "wahre Karitasgesinnung" fordert eine "Liebesgabe", mithin wären Spenden die angemessene Form der Finanzierung. Die Kirchen kommen zwar wegen des enormen Bedarfs nicht umhin, andere Finanzierungsmittel ebenfalls einzusetzen, sie müssen dabei allerdings darauf bedacht sein, eine Wesensüberforderung $\mathrm{zu}$ vermeiden ${ }^{150}$ ).

Probleme für die kirchlichen Aktivitäten können sich überall da ergeben, wo diese mit dem Ausbau und der Ausweitung des Sozialstaates in Berührung gelangen. Durch staatliche Paralleleinrichtungen schafft der Staat zusätzliche Wahlmöglichkeiten. Er könnte auf diese Weise in Verbindung mit gleichzeitigen gesetzlichen Auflagen und Regelungen, wie z.B. der Festlegung von Pflegesätzen, Bedingungen für Zuschüsse, staatliche Aufsichtsrechte usw., nicht nur einen gewissen Einfluß auf kirchliche Werke ausüben, sondern sie mit diesen Gestaltungsmöglichkeiten wirtschaftlich unrentabel machen und damit zur Bedeutungslosigkeit herabstufen ${ }^{151}$ ). Dadurch, daß der Staat seine finanziellen Hilfen von der Erfüllung bestimmter Auflagen abhängig macht, greift er lenkend in die inneren Belange der 
Kirchen ein. So setzen etwa staatliche Finanzierungshilfen für nichtstaatliche Krankenhäuser das Vorhandensein einer bestimmten Bettenzahl oder eines gewissen Mindeststandards voraus. Den Kirchen verbleibt lediglich die Alternative, die Bedingungen zu akzeptieren oder aber bei einer Ablehnung auf die finanzielle Unterstützung zu verzichten. Solchen möglichen mißbräuchlichen Entwicklungen versucht jedoch die gesetzliche Regelung in $\$ 10$ Bundessozialhilfegesetz entgegenzuwirken, die vorschreibt, daß Staat, Kirchen und Wohlfahrtsverbände einer größtmöglichen Effizienz wegen zusammenarbeiten sollen ${ }^{152}$ ).

Das soeben diskutierte Problem kann sich indessen auch andersherum stellen, und zwar dort, wo Versorgungslücken entstehen, weil nicht der Staat, sondern die Kirchen ein Monopol innehaben. Wenn es beispielsweise in bestimmten Regionen ausschließlich kirchliche Kindergärten, Altenheime oder Krankenhäuser gibt, besteht die Gefahr, daß Minderheiten, die keine kirchlichen Leistungen wollen, unterversorgt bleiben ${ }^{153)}$.

4. Mission und Entwicklungspolitik

Der Auftrag zur Mission entspringt dem Verkündigungsauftrag und Selbstverständnis der Kirchen. Nach katholischer Auffassung gilt der Heilswille Gottes allen Menschen. Es ist Aufgabe der Kirche, überall und allen Menschen vom kommenden Reich Gottes zu künden und alle Menschen Christus zuzuführen 154). Nach evangelischem Verständnis ist die Kirche "katholisch", d.h. allgemein. Die Allgemeinheit der Kirche bringt das Dasein und den Dienst der Kirche für die ganze Welt und Menschheit und damit ihren Missionsauftrag zum Ausdruck ${ }^{155)}$.

Die missionarische offenheit beider Kirchen richtet sich nicht an ihre Glieder, sondern an die Menschen, die der Kirche nicht angehören ${ }^{156)}$ ). Mit der Mission streben die Kirchen vorrangig das ziel an, durch die Verkündigung des wortes Gottes und durch die Taufe Nichtgläubige zu bekehren und der Kirche zuzuführen. Insbesondere dann, wenn die Missionstätigkeit in den 
Entwicklungsländern erfolgt, muß sie notwendig von anderen, entwicklungspolitischen Maßnahmen begleitet werden. Analphabetentum, Armut, unterentwickelte wirtschaft usw. bedingen den Aufbau eines Schulwesens und machen soziale und wirtschaftliche Hilfe erforderlich. Hier leisten die Kirchen, wenngleich unter christlichem Vorzeichen und zur Erreichung eigener ziele, gleichzeitig einen wichtigen Beitrag zur Entwicklungspoli$\left.t i k^{157}\right)$. Die von den Kirchen geleistete Entwicklungshilfe gehört wesensmäßig allerdings eher in den Bereich der Diakonie. Beides ist jedoch, wie bereits sichtbar wurde, nicht voneinander zu trennen, denn vom Selbstverständnis der Kirchen her gilt immer auch, daß mit der Hilfe für den Nächsten der Auftrag zur Verkündigung, also zur Mission verbunden sein muß. 
IV. Der Offentlichkeitsgrad kirchlicher Funktionen

1. Die Kirchen als Kollektive

Die hier betrachteten Großkirchen in der Bundesrepublik Deutschland stellen aufgrund ihrer hohen Mitgliederzahl sehr große Kollektive dar. Wie wir oben (C.II.2.) festgestellt haben, unterbleibt bei ökonomisch rational handelnden Individuen in großen Kollektiven in der Regel ein freiwilliges Angebot von Kollektivgütern, weil jedes Kollektivmitglied versuchen wird, die "free-rider-Position" einzunehmen. Eine Bereitstellung erfolgt nur, wenn Zwangsmittel eingesetzt werden oder selektive Anreize wirken. Allerdings ist eine freiwillige Befriedigung gemeinsamer Bedürfnisse in großen Gruppen dann nicht ausgeschlossen, wenn die einzelnen Kollektivmitglieder sich von idealistischen oder altruistischen Motiven leiten lassen.

Die Kirchenglieder gehören ihren Glaubensgemeinschaften freiwillig an, unabhängig davon, ob diese Ansicht mit dem jeweiligen kirchlichen Selbstverständnis über den Status der Kirchengliedschaft übereinstimmt. Da der staat den Bürgern das Recht gewährt, jederzeit aus der Kirche auszutreten, scheidet der Zwang als Instrument aus. Das schließt allerdings nicht aus, daß die Kirchen subtile Formen des Zwangs anwenden können. Dem Wesen und Selbstverständnis der Kirchen entsprechend ist es eine idealistische Verhaltensweise, nämlich der Glaube, der die Kirchenmitglieder dazu bewegt, sich freiwillig in den Kirchen zur gemeinsamen Religionsausübung zusammenzuschließen. Mit ihrem Glauben bekennen sich die Mitglieder aber auch zu den aus dem Offentlichkeitsanspruch des Evangeliums abgeleiteten Aufgaben. Gottes- und Nächstenliebe gebieten es, daß sich kein Kirchenglied der ihm auferlegten Pflichten entzieht.

Nun scheint aber diese Einstellung auf viele Kirchenglieder heute nicht mehr zuzutreffen. Wie die Kirchen selbst betonen, liegt eines ihrer größten Probleme in der abnehmenden Zahl der sich aktiv am kirchlichen Leben beteiligenden Gläubigen, wäh- 
rend gleichzeitig die zahl der nur noch formal der Kirche angehörenden Glieder, die nicht auf bestimmte kirchliche Amtshandlungen verzichten wollen, laufend zunimmt. Ihr freiwilliger Verbleib in den Kirchen läßt sich sicherlich nicht durch die Identifikation mit dem kirchlichen selbstverständnis und den kirchlichen zielsetzungen erklären, denn sonst würden sie aktiv am kirchlichen Leben teilnehmen. In diesen Fällen kann die Mitgliedschaft in der Kirche tatsächlich im Sinne eines selektiven Anreizes wirken, sei es, daß jemand den Austritt aus der Kirche deswegen scheut, weil er mit diesem Schritt soziale Nachteile befürchtet, sei es, daß jemand auf Grund des "Irrationalen", des "Nichtfaßbaren", und der Ungewißheit, was nach dem Tode kommt, davor zurückschreckt, die letzten Brücken zu dem Glauben an eine überweltliche Macht abzubrechen.

Welche Motive letztlich ausschlaggebend für die Mitgliedschaft des einzelnen Gliedes in der Kirche sind, läßt sich nicht feststellen. Bei der Diskussion der Bereitstellung der kirchlichen Leistungen aus ökonomischer Sicht muß jedoch davon ausgegangen werden, daß die Mitglieder freiwillig in der Kirche sind und sie sich einen - wie auch gearteten - Nutzen von ihrer Gliedschaft versprechen. Konsequenterweise müssen die Kirchenglieder dann allerdings die aus dem kirchlichen Selbstverständnis resultierenden Aufgaben der Kirchen befürworten und mittragen. Ein "free-rider-Verhalten" der Kirchenmitglieder kann demnach per definitionem ausgeschlossen werden.

2. Kirchliche Leistungen als Kollektivgüter

a) Leistungen im Bereich des Verkündigungsauftrages

Bei der öffentlichen Verkündigung des Wortes Gottes handelt es sich um eine Kernaufgabe der Kirchen. Zu ihrer Erfüllung entfalten die Kirchen eine Vielzahl von Aktivitäten, die zum überwiegenden Teil in Leistungen für ihre Glieder bestehen, die aber - dem Öffentlichkeitsanspruch des Evangeliums folgend ebenfalls an Nichtmitglieder gerichtet sind. Der Verkündigungs- 
auftrag schließt außerdem die Mitwirkung der Kirchen als gesellschaftlich bedeutsame Kräfte am politischen Willensbildungsprozeß ein. Die Kirchen versuchen auf diese Weise, ihre Wertvorstellungen geltend $\mathrm{zu}$ machen, wie es beispielsweise bei den Bildungszielen im Schulwesen der Fall ist.

aa) Wortverkündigung und Sakramentsverwaltung

Verkündigung des Evangeliums und Sakramentsverwaltung sind unverzichtbare Grundfunktionen der Kirchen, die ihren unmittelbaren Ausdruck im Gottesdienst und in der Spendung der Sakramente finden.

Die Teilnahme am Gottesdienst dient der Befriedigung der religiösen Bedürfnisse. Der "Nutzen" eines Gottesdienstes kommt allen Besuchern zugute. Solange keine Überfüllungsprobleme, d.h. Kapazitätsprobleme, entstehen, wird keiner der Teilnehmenden in der Inanspruchnahme dieser speziellen Leistung beeinträchtigt. Ökonomisch gesehen rivalisiert der "Konsum" nicht. Da es sich bei einem Gottesdienst um eine Veranstaltung handelt, von der derjenige ausgeschlossen werden kann, der keinen Beitrag leisten will, kann die Abgabe der Leistung auf diejenigen begrenzt werden, die bereit sind, dafür einen Preis zu entrichten. Der Nutzen, nämlich die Befriedigung der religiösen Bedürfnisse, kann demnach technisch ohne weiteres durch die Anwendung des Ausschlußprinzips auf die Gruppe der am Gottesdienst Teilnehmenden beschränkt werden.

Bei den kirchlichen Amtshandlungen und Sakramentspendungen kommt der Nutzen ausschließlich dem(n) Empfänger(n) zu. Das Gut rivalisiert im Konsum und das Ausschlußprinzip ist ohne Schwierigkeiten anwendbar. Ökonomisch betrachtet handelt es sich folglich um ein privates Gut.

Die ökonomisch mögliche Anwendung des Ausschlußprinzips widerspräche indessen dem kirchlichen Selbstverständnis vom Öffentlichkeitsauftrag des Evangeliums. Die Kirchen sollen und 
müssen offen sein für alle, nicht nur für ihre Mitglieder. Die Kirchen wenden sich bewußt auch an diejenigen, die nicht mehr aktiv am kirchlichen Leben teilnehmen oder iiberhaupt fernstehen. Den Kirchen ist im Gegenteil daran gelegen, möglichst viele am Wort Gottes und den Sakramenten teilhaben zu lassen, oder, ökonomisch gesprochen, es ist geradezu ihre Absicht, externe Effekte und ein "free-rider-Verhalten" zu erzeugen, um die ihnen Fernstehenden zu erreichen. Von den ihnen angehörenden Gliedern - solange diese nicht vom Recht des Austritts Gebrauch gemacht haben - dürfen die Kirchen indessen erwarten, daß sie nicht nur Gottesdienste und Sakramente in Anspruch nehmen, sondern auch, dem Selbstverständnis der Kirchen entsprechend, freiwillig bereit sind, für die Bereitstellung dieser Leistungen Sorge zu tragen.

Gottesdienstbesuch und Empfang der Sakramente dienen der persönlichen Befriedigung religiöser Bedürfnisse der Gläubigen. Dem Anspruch der Kirchen nach freiem, an die Offentlichkeit gerichtetem wirken kommt der Staat dadurch nach, daß er den einzelnen Gläubigen und den Kirchen die freie Religionsausübung einräumt. In seiner weltanschaulich neutralen Position schützt er jedoch gleichzeitig durch die Sicherung der Möglichkeit eines Austritts aus den Kirchen einzelne davor, gegen ihren willen von den Kirchen beansprucht $z u$ werden. So beläßt letztlich der staat die Entscheidung jedem Individuum selbst, sich entsprechend seinen Präferenzen religiös zu betätigen. Der ర̈ffentlichkeitsgrad dieser kirchlichen Leistungen, der einerseits darauf zurückzuführen ist, daß der Kreis der Nutzer sehr groß ist und andererseits darauf, daß sich die Kirchen als Kollektive bei der Bereitstellung dieser Leistungen altruistisch verhalten, indem sie bewußt Externalitäten über ihren eigenen Wirkungskreis hinaus schaffen, macht unter dem Blickwinkel der Allgemeinwohlverwirklichung keine staatlichen Interventionen erforderlich; denn dem ersten Aspekt des Öffentlichkeitsgrades wird dadurch Rechnurig getragen, daß der Staat die freie Religionsausübung sicherstellt. Der andere Teil des Offentlichkeitsgrades, der auf die bewußt erzeugten Externalitäten zu- 
rückzuführen ist, muß, da altruistische Motive zugrunde liegen, durch gesellschaftliche Steuerungsmechanismen, nämlich durch die Kirchen selbst, internalisiert werden.

bb) Militärseelsorge und Anstaltsseelsorge

Die Verkündigung in Gestalt der Militärseelsorge und der Anstaltsseelsorge dient der freien Religionsausübung in besonderen Lebenslagen. Die Beurteilung des Offentlichkeitsgrades dieser kirchlichen Leistungen entspricht dem, was bereits zum Gottesdienst und zur Sakramentsverwaltung ausgeführt wurde. Der Staat hat die Freiräume für die Befriedigung der religiösen Bedürfnisse der Gläubigen zu gewährleisten und die Entfaltungsmöglichkeiten für das eigenverantwortliche wirken der Kirchen sicherzustellen. Die Leistungsbereitstellung haben die Kirchen zu übernehmen.

Aus ökonomischer Sicht besteht folglich für eine staatliche Finanzierung der Militärseelsorge und der Anstaltsseelsorge, wie die vorhergehende Diskussion gezeigt hat, kein Anlaß. Dieser Anlaß könnte gegeben sein, wenn die Anstaltsseelsorge und die Militärseelsorge unter dem Blickwinkel der Grundwerteverwirklichung von den Kirchen allein unzureichend bewerkstelligt werden würde. Die verfassungsrechtliche Diskussion, die hier nicht weiter vertieft werden kann, zeigt jedoch, daß die Übernahme kirchlicher Funktionen durch den weltanschaulich neutralen Staat nicht unproblematisch ist. Um den öffentlichkeitsgrad exhöhende Externalitäten, zu deren Beseitigung es staatlicher Steuerungsmechanismen bedürfte, würde es sich - und das ist eben verfassungsrechtlich umstritten - nur dann handeln, wenn der Staat ein Interesse daran haben müßte, daß die Religionsausübung auch tatsächlich stattfindet.

Etwas anders sieht es beim lebenskundlichen Unterricht aus, der als Bestandteil der militärischen Gesamtausbildung unstreitbar zur staatlichen Verteidigungsaufgabe gehört. Gäbe der Staat Inhalt und Art der Durchführung vor, bestünde von kirchlicher 
Seite kein Interesse, freiwillig den lebenskundlichen Unterricht abzuhalten. Dadurch aber, daß der Staat die Kosten der Bereitstellung trägt und der Unterricht gleichzeitig auf der Grundlage der christlichen Wertvorstellungen erfolgt, bietet die heutige Regelung den Kirchen die Möglichkeit, durch die Mitwirkung an einer staatlichen Aufgabe ihrem Verkündigungsauftrag nachzukommen. Zerlegt man die "Leistung" lebenskundlicher Unterricht entsprechend diesen Überlegungen nach dem auf die Beteiligten entfallenden Nutzen, so wïrde das bedeuten, daß der Staat nur für einen Teil der Leistung aufkommen müßte. Der andere Teil wäre dem Verkündigungsauftrag der Kirche zuzurechnen; denn aus der Sicht des Staates als Anbieter der Leistung betrachtet, handelt es sich dabei um einen externen Nutzen, der den Kirchen zufließt und folglich bei diesen zu internalisieren wäre.

Sieht man einmal von der tatsächlichen Regelung der Militärseelsorge und der Anstaltsseelsorge ab, dann dient sie in gleicher Weise wie der Gottesdienst der Befriedigung religiöser Bedürfnisse. Der Öffentlichkeitsgrad in Form altruistisch motivierter Externalitäten beruht auf dem kirchlichen Selbstverständnis und ist demzufolge von den Kirchen selbst zu internalisieren. Ein über die Ermöglichung der freien Religionsausübung hinausgehender staatlicher Handlungsbedarf ist nicht vorhanden.

cc) Einfluß auf staatliche Bildungsziele

Die Kirchen sehen in der Mitgestaltung der Bildungsziele die Verwirklichung der ihnen vom Verkündigungsauftrag auferlegten Aufgabe der religiözen Erziehung der Schüler. Ckonomisch gesehen handelt es sich dabei um eine Aktivität, mit der die Kirchen ihre zielsetzungen und Wertvorstellungen im gesamten Gemeinwesen geltend machen wollen. Die Kirchen versuchen auf diese Weise, ihre Interessen, und damit zugleich die ihrer Mitglieder, nach außen zu vertreten und zur Entfaltung $z u$ bringen. Dieses Wirken reicht über die Kirchen als soziale Gruppierungen 
hinaus und berührt das übrige Gemeinwesen. Damit verursachen die Kirchen beim übrigen Gemeinwesen Externalitäten, deren Natur je nach gesellschaftlicher Bewertung unterschiedlich ausfallen kann, die aber auf jeden Fall die politische Relevanz der Kirchen unterstreichen und ihrem Handeln einen hohen öffentlichkeitsgrad verleihen.

Die Vertretung ihrer ziele nach außen entspricht dem kirchlichen Selbstverständnis und liegt in ihrem Interesse. Sie können deshalb keinen Anspruch auf Ausgleich der damit verbundenen Externalitäten erheben. Die Kirchen bringen als gesellschaftliche Kraft ihre Vorstellungen in das Gemeinwesen ein, indem sie ihre Ansichten im politischen Willensbildungsproze $\beta$ äußern. Der Wert der kirchlichen Mitarbeit an den Bildungszielen des Erziehungswesens wird von dem gesamten Gemeinwesen anerkannt. Die dadurch vermittelten geistigen und moralischen Vorstellungen des Christentums sind eine wichtige Grundlage für die Kultur und das Zusammenleben im Gemeinwesen. In der Ermöglichung dieser Beteiligung zeigt sich der pluralistische Kulturstaat, der auch im Bildungswesen für die Wertvorstellungen aller gesellschaftlich bedeutsamen Gruppierungen offen sein muß. Art. 12 Abs. 2 und Art. 4 Abs. 2 der Verfassung des Landes Baden-Württemberg sowie andere Länderverfassungen bringen diese gesellschaftliche Einschätzung der Bedeutung der Kirchen zum Ausdruck. Die offenheit des Bildungssystems hat allerdings Grenzen; denn die Externalitäten sind unter Umständen nicht nur positiver Natur. Einerseits muß die negative Religionsfreiheit gewahrt werden, d.h., niemand darf gegen seinen willen von den Kirchen vereinnahmt werden, andererseits muß der Staat darauf achten, daß der Einfluß der Kirchen auf das pluralistische, jedoch weltanschaulich neutrale staatswesen nicht zu übermächtig wird. In diesen Fällen hat der staat die negativen Folgen des kirchlichen wirkens für das Gemeinwohl zu begrenzen. 
dd) Religionsunterricht

Ökonomisch ist die Leistung Religionsunterricht den konkreten Nutznießern, den Teilnehmern am Religionsunterricht, zurechenbar. Entsprechend ihrem Selbstverständnis, daß der Verkündigungsauftrag jeden $\mathrm{zu}$ erreichen hat, verbietet es sich für die Kirchen, das Ausschlußprinzip auf die Teilnehmer anzuwenden. Einen staatlichen Interventionsbedarf für die auf altruistischem Handeln beruhende Bedarfsdeckung durch die Kirchen gibt es deshalb nicht.

Der Nutzen des Gutes Religionsunterricht bleibt indessen nicht auf die Teilnehmer am Religionsunterricht beschränkt, sondern zeitigt Wirkungen, die über diesen engen Kreis hinausreichen. Positiver Natur sind die Externalitäten, die von der schon erwähnten Bedeutung christlicher Werte für das gesellschaftliche Zusammenleben ausgehen. Zur Vermeidung negativer Externalitäten bedarf es staatlicher Normsetzungen, wie sie z.B. durch das Recht auf Nichtteilnahme am Religionsunterricht auch vorgesehen sind.

Betrachtet man den Religionsunterricht als Teil des kirchlichen Verkündigungsauftrages, dann müßte er als eine kircheneigene Angelegenheit angesehen werden. Kommt die gesellschaftliche Bewertung anhand der Grundwerte, namentlich der Freiheitsverwirklichung im pluralistischen Gemeinwesen in Form der Religionsfreiheit, zu dem Ergebnis, daß im zusammenhang mit den allgemeinen Bildungszielen die christlichen Wertvorstellungen von hohem Nutzen für die Gestaltung des menschlichen Zusammenlebens sind, dann gehen von dem kirchlichen Gut Religionsunterricht beträchtliche positive Externalitäten aus. Daß das Gemeinwesen die Vermittlung von geistigen und moralischen Werten im Bildungswesen für wichtig erachtet, wird nicht zuletzt daraus ersichtlich, daß diejenigen, die nicht am Religionsunterricht teilnehmen, ersatzweise in Ethik unterrichtet werden. Aus diesem Grunde, wie auch daraus, daß ein sehr großer Nutzerkreis tangiert wird, kann auf einen hohen öffentlichkeitsgrad ge- 
schlossen werden. Wenn demzufolge die Bedarfsdeckung vom gesamten Gemeinwesen als erwïnscht erachtet wird, dann sind die aus der politischen Bewertung resultierenden Externalitäten mit staatlichen Maßnahmen zu internalisieren.

Der von den Kirchen erteilte Religionsunterricht enthălt also zwei verschiedene Elemente. Faßt man ihn als Teil des Verkündigungsauftrages auf, widerspräche die Anwendung des Ausschlußprinzips dem kirchlichen Wesen. Die Externalitäten wären vom kirchlichen Selbstverständnis her gewollt und müßten konsequenterweise durch die Kirchen als Kollektive internalisiert werden. Der Religionsunterricht als Teil der freien Religionsausübung wäre eine reine kirchliche Angelegenheit.

Resultiert dagegen aus der gesellschaftlichen Bewertung ein sehr hoher Öffentlichkeitsgrad, dann rückt der Religionsunterricht in die Nähe einer staatlichen Aufgabe. In diesem Falle würden die Kirchen die Leistung an Stelle des Staates erbringen. Konsequenterweise hätte der staat dafür Sorge zu tragen, daß ein entsprechendes Angebot erfolgt. Allerdings dann nicht allein, wenn er hinsichtlich der qualititativen Ausgestaltung des Religionsunterrichts auf das Setzen von umfassenden Normen verzichtet und die Kirchen selbst weitgehend über den Inhalt des Unterrichts bestimmen können. Es müßte in diesem Fall berücksichtigt werden, daß der Religionsunterricht den Kirchen zumindest anteilsweise einen Nutzen stiftet, weil er ihnen die Gelegenheit gibt, ihrem Verkündigungsauftrag nachzukommen. Unter diesem Blickwinkel erscheint die geltende Regelung, wonach der Religionsunterricht ordentliches Lehrfach an den staatlichen Schulen ist und der Staat alleine die gesamten Kosten trägt, nicht ganz folgerichtig, weil das aus dem Verkündigungsauftrag resultierende Eigeninteresse der Kirchen am Religionsunterricht außer acht gelassen wird. 
ee) Kirchliche Privatschulen

Die kirchlichen Privatschulen stellen das Gut Bildung bereit. Der Gutscharakter der Bildung ist im Gegensatz zur Ausbildung, die eher als Investition aufzufassen ist, weil sie normalerweise erst nach ihrem Abschluß für den Empfänger nutzbringend wird, mehr konsumtiver Natur. Die Leistung kommt unmittelbar dem Empfänger zugute und dient in erster Linie dessen menschlicher Vervollkommnung. Jedoch kann nicht immer zwischen Ausbildung und Bildung exakt getrennt werden, weil Ausbildung in der Regel das Vorhandensein eines bestimmten Bildungsniveaus voraussetzt ${ }^{158}$ ).

Das Gut Bildung als Dienstleistung kann prinzipiell privat bereitgestellt werden. Der Anwendung des Ausschlußprinzips steht nichts entgegen, d.h., die Inanspruchnahme kann auf diejenigen begrenzt werden, die bereit sind, für das Gut einen Preis zu bezahlen. Bei einem vielfältigen Bildungsangebot kann der Nachfrager die seinen Präferenzen entsprechenden Bildungsleistungen auswählen.

Die kirchlichen Privatschulen heben sich gegenüber anderen Anbietern von Bildungsleistungen dadurch $a b$, daß bei ihnen christliche Erziehungsziele besondere Berücksichtigung finden.

Obwohl also aus ökonomischer sicht das Gut Bildung ohne weiteres über den Markt bereitgestellt werden könnte, sind dagegen Vorbehalte angebracht, weil zu befürchten wäre, daß die Befriedigung des Bedürfnisses Bildung durch den Markt unter dem Blickwinkel der Grundwerteverwirklichung unteroptimal bliebe. Darauf hat schon Wagner (vgl, oben, B.II.) hingewiesen, als er dafür plädierte, für Gemeingüter, zu denen er die Bildung zählt, mittels "gemeinwirthschaftlicher" Formen zu sorgen, weil hier in der Regel auch andere als ökonomische Kriterien eine Rolle spielen würden. Seine dafür gelieferte Begründung, daß ein großer Teil der Gemeingüter für die Bevölkerung so wichtig sei, daß die Befriedigung für jeden sichergestellt werden 
müsse, trifft zwar unter den heutigen Verhältnissen nicht mehr in gleicher Weise wie im vergangenen Jahrhundert $z u$, doch müßte bei privater Bereitstellung heute ebenfalls damit gerechnet werden, daß zumindest Teile der Bevölkerung die Bedeutung der Bildung für sich und ihre Kinder unterschätzten, weil sie selbst mangels eigener Bildung nicht über die Einsicht verfügten oder mangels finanzieller Möglichkeiten nicht in der Lage wären, diese Bedürfnisse entsprechend angemessen zu befriedigen.

Für eine staatliche Bereitstellung der Allgemeinbildung spricht in einem demokratischen Gemeinwesen ferner die Gleichheit der Bildungschancen als notwendige Bedingung für die Demokratie, weil ohne eine ausreichende Bildung eine Teilnahme am politischen Willensbildungsproze $\beta$ nicht möglich ist. Die Gleichheit der Bildungschancen führt dazu, daß der Grundwert der Gerechtigkeit im Sinne der Gleichheit des politischen Einflusses verwirklicht wird ${ }^{159}$ ). Die Gleichheit der Bildungschancen - nicht $\mathrm{zu}$ verwechseln mit der leistungsunabhängigen gleichen Bildung für alle - dient aber zugleich der sozialen Gerechtigkeit und der Freiheitsverwirklichung, indem sie die Voraussetzungen für die Gleichheit der Ausbildungschancen schafft.

Das Gut Bildung ist zwar konsumtiver und weitgehend privater Natur und könnte über den Markt bereitgestellt werden, jedoch spricht vor allem die Beurteilung anhand der Grundwerte für einen hohen Ǒffentlichkeitsgrad. Die Beseitigung der das ganze Gemeinwesen betreffenden allokativen störung wird durch die staatliche Bereitstellung und das Gebot der Schulpflicht erreicht. Der freiheitlichen zielsetzung eines pluralistischen Gemeinwesens kommt der staat in besonderem Maße nach, indem er nicht als alleiniger Anbieter auftritt, sondern Minderheiten die Möglichkeit zur Errichtung von Privatschulen einräumt, damit diese ihre eigenen Bildungsziele verwirklichen können. Mit diesen Interventionsmechanismen gelingt es dem staat, die allokativen Fehlsteuerungen an ihren Ursachen anzugehen. 
Zur Sicherstellung gewisser Mindestforderungen hat der staat das Aufsichtsrecht über das Schulwesen und setzt für das allgemeine Schulwesen Rahmenbedingungen, deren Einhaltung die Voraussetzung dafür ist, daß die Privatschulen als vollwertige Ersatzschulen anerkannt werden. Dem aus der Grundwerteverwirklichung entspringendem Aspekt des Pluralismus kann indessen nur dann Geltung verschafft werden, wenn der staat hinsichtlich der Bildungsinhalte keine vollständige Normierung vornimmt, sondern den Privatschulen die nötigen Freiräume beläßt, ihren eigenen Bildungsidealen nachzugehen.

Gibt der Staat das Gut Bildung unentgeltlich ab und verlangt er gleichzeitig von den nichtstaatlichen Schulträgern, daß sie dieselben Bildungsinhalte wie die staatlichen Schulen zu vermitteln haben, dann unterbleibt ein nichtstaatliches Angebot, weil für private Anbieter jeglicher Anreiz für einen Preiswettbewerb fehlt. Ein Qualitätswettbewerb scheidet wegen der Einheitlichkeit der Leistung ebenso aus. Sofern also dem Pluralismusgedanken Rechnung getragen werden soll, müssen zum einen die staatlich vorgegebenen Rahmenbedingungen so gesetzt werden, daß die nichtstaatlichen Schulträger bei den Bildungsinhalten einen Spielraum erhalten, der ihnen für ihre Bildungsideale genügend Platz läßt. Nur unter dieser Bedingung kommt ein qualitativ differenziertes Angebot zustande, das den unterschiedlichen Präferenzen der Nachfrager gerecht wird. Da aber der Staat für die Leistung keinen Preis verlangt, ist bei so engen Substitutionsgütern selbst bei qualitativen Unterschieden kaum mit einer nennenswerten Nachfrage nach dem nichtstaatlichen Angebot zu rechnen. Es stellt sich damit die Frage eines weitergehenden staatlichen Handlungsbedarfs.

Mit der staatlichen Úbernahme des Schulwesens und der Schulpflicht internalisiert der staat die vom allgemeinen Bildungswesen ausgehenden Externalitäten. Kommen andere Anbieter hinzu, verringert sich sein Internalisierungsbedarf entsprechend. Das bedeutet für die anerkannten Ersatzschulen, die der pluralistischen Vielfalt wegen erwïnscht sind, daß ihnen der staat für 
die Ubbernahme eines Teils der Bedarfsdeckung Transfers in der Höhe gewăhrt, in der er entlastet wird ${ }^{160}$ ). Für die Ergănzungsschulen trifft das allerdings nicht $z u$, weil es sich bei ihnen ökonomisch gesehen um ein anderes Gut handelt.

Ein seine eigene Kostenentlastung übersteigender Beitrag des Staates an die privaten Schulen ist nicht angemessen. Verursacht nämlich die Bereitstellung eines differenzierten Bildungsangebotes bei den jeweiligen Trägern höhere Kosten als sie bei der staatlichen Bedarfsdeckung anfallen, so sind diese der Besonderheit der angebotenen Leistung zuzurechnen und deshalb den Nachfragern, die Wert auf diese qualitativ unterschiedliche Leistung legen und denen dieser Sondernutzen zum Vorteil gereicht, anzulasten. Die Abgeltung dieses Sondernutzens hat folglich über den Markt oder uber gesellschaftliche Steuerungsmechanismen zu erfolgen.

Diese grundsätzlichen Überlegungen gelten auch für die kirchlichen Privatschulen. Mit dem Unterhalt von Ersatzschulen entlasten die Kirchen den Staat. Sie haben deshalb gegenüber dem Staat einen Anspruch auf finanziellen Ausgleich in Höhe des ansonsten beim Staat verbleibenden Kostenanteils. Sie steuern auBerdem durch die Betonung christlicher Bildungsziele in den kirchlichen Schulen zu einem qualitativ differenzierten Bildungsangebot bei. Die sich aus der Besonderheit der Bildungsleistungen ergebenden zusätzlichen Kosten sind allerdings nicht Bestandteil der staatlichen Ausgleichsleistung. Dieser spezifische Teil der abgegebenen Bildungsleistungen kommt ausschließlich den Schülern der kirchlichen Schulen zugute und müßte den unmittelbaren Leistungsempfängern angerechnet werden.

Das Ausschlußprinzip wäre ohne Schwierigkeiten auf diese spezifische Leistung anwendbar. Es stellt sich allerdings das Problem, ob das mit dem kirchlichen Selbstverständnis zu vereinbaren wäre. Die Kirchen als Träger christlicher Privatschulen könnten zwar von allen Schülern ein schulgeld verlangen, mit dem die Kosten der Eigenheit der kirchlichen Bildungslei- 
stungen abgegolten werden könnten, jedoch wäre zu prüfen, ob das in Einklang mit dem kirchlichen Verkündigungsauftrag steht. Damit der Verkündigungsauftrag im kirchlichen Schulwesen jeden erreichen kann, muß unter Umständen von einer strengen Äquivalenzfinanzierung der unmittelbaren Nutznießer abgesehen werden. Je stärker die Kirchen den Verkündigungsaspekt in ihren Privatschulen betonen, um so mehr ist es Aufgabe der Kirchen als Kollektive und nicht nur der speziellen Nutznießer, für die Bereitstellung $\mathrm{zu}$ sorgen. Auf der anderen Seite darf nicht verkannt werden, daß die Schüler oder deren gesetzliche Vertreter entsprechend ihren Präferenzen genau diese kirchlichen Bildungsleistungen auswählen und mithin bereit sein müßten, dafür zu bezahlen. Eine Abgeltung über spezielle Entgelte wäre deshalb angemessen, zumal dann, wenn die Nutznießer einer Kirche angehören. In den Fällen, in denen die Anlastung beim Nutznießer als zu hoch angesehen wird, müßten die Kirchen für die Finanzierung aufkommen.

Etwas anders als bei den kirchlichen Ersatzschulen liegen die Dinge bei den Ergänzungsschulen und der kirchlichen

Erwachsenenbildung, die ebenfalls einen - wenngleich nicht ganz so hohen - beachtlichen Öffentlichkeitsgrad aufweisen, der vornehmlich auf die funktionale Repräsentanz und auf die idealistische Verhaltensweise der Kirchen bei der Bedarfsdeckung zurückzuführen ist. Maßnahmen des Staates können sich darauf beschränken, die Bedingungen für ein pluralistisches Angebot zu schaffen. Da der Bereich der Erwachsenen- und Weiterbildung primär eine private Angelegenheit ist, haben der Markt oder die gesellschaftlichen Steuerungsmechanismen für die Bedarfsdeckung zu sorgen. Aufgrund der gesamtgesellschaftlichen Bedeutung der Weiterbildung kann allerdings eine staatliche Unterstüzung dieses Bereichs mittels Transfers angebracht sein, um in bestimmten Bereichen ein zusätzliches Angebot oder spezielle zielgruppen $z u$ erreichen. Die staatliche Unterstützung der Kirchen hat deshalb nur in dem Ausmaß zu erfolgen, in dem der Staat selbst durch deren Angebot entlastet wird. 
Diese Entlastung dürte indessen im Vergleich zu den Ersatzschulen deutlich niedriger sein. Eine weitergehende staatliche Beteiligung erscheint auch bei den Kirchen nicht angebracht, weil sonst das bei diesen Aktivitäten sehr viel ausgeprägtere kirchenspezifische Eigeninteresse, ihrem Heils- und Verkündigungsauftrag nachzukommen, nicht genügend gewürdigt wïrde. Ansonsten gelten aber für die Finanzierung kirchlicher Ergänzungsschulen und Akademien prinzipiell dieselben tbberlegungen wie für kirchliche Ersatzschulen. Beispielsweise ist bei der internen Erwachsenenbildung, die vorrangig die Aufgabe der religiösen Erziehung hat, das kirchliche Eigeninteresse dominierend und entsprechend deutlich höher anzusetzen als bei der kirchlichen Beteiligung an der allgemeinen Erwachsenenbildung.

\section{ff) Theologische Fakultäten}

Der doppelte Aspekt, einerseits Erfüllung kirchlicher Funktionen, andererseits Ubbernahme staatlicher Aufgaben, wird bei den theologischen Fakultäten ebenfalls sichtbar. Aus kirchlicher Perspektive ist die theologische Forschung der zur Lehre verpflichtete Bestandteil des Verkündigungsauftrages. Die Lehre muß, da sie zugleich der Ausbildung von Pfarrern und Seelsorgern dient, auf den von den Kirchen vertretenen Auffassungen fußen. Das heißt, die Kirchen bestimmen die Inhalte der theologischen Forschung. Allein unter diesem Blickwinkel betrachtet, erscheinen die theologischen Fakultäten als rein kirchliche Angelegenheiten, die ausschließlich Funktionen erfüllen, deren Nutzen den Kirchen selbst zufließen. Die Ansicht, es handle sich hier um kircheneigene Aufgaben, wird dadurch gestützt, daß an zahlreichen kirchlichen Hoch- und Fachhochschulen dieselben Leistungen von den Kirchen in eigener verantwortung erbracht werden. Insoweit bestünde kein Unterschied $\mathrm{zu}$ anderen großen gesellschaftlichen Gruppierungen, die verbandseigene Fortbildungseinrichtungen und Akademien unterhalten.

Diese Sichtweise berücksichtigt allerdings nur einen Teilaspekt der theologischen Forschung. Sie vernachlässigt insbesondere, 
daß Theologie als Wissenschaft ein unverzichtbarer Bestandteil einer auf Universalität ausgerichteten Universität ist. Geht man davon aus, daß Forschung und Lehre um ihrer Freiheit und Unabhängigkeit willen eine staatliche Aufgabe darstellen, dann weisen die theologischen Fakultaten einen so hohen Offentlichkeitsgrad auf, daß der staat für sie aufkommen müßte. Ob der Staat allein für Errichtung und Unterhalt zu sorgen hat, scheint aber aus zwei Gründen fragwürdig zu sein. Der hohe öffentlichkeitsgrad von Forschung und Lehre geht neben der Bedeutung für die Grundlagenforschung vor allem auf die sicherstellung der Freiheit der Wissenschaft zurück. Gerade letztere ist jedoch bei der theologischen Forschung - bei der katholischen stärker als bei der evangelischen - eingeschränkt, weil durch die Verpflichtung auf die kirchlichen Lehrmeinungen die Kirchen nicht nur über die Lehrinhalte, sondern auch iber die Besetzung des Lehrkörpers entscheidend mitbestimmen. Hinzu kommt das Eigeninteresse der Kirchen an den theologischen Fakultäten, das vornehmlich in deren Funktion für die Ausbildung der Pfarrer und seelsorger besteht. Beide Aspekte führen dazu, daß der auf Grund der gesellschaftlichen Bewertung anhand der Grundwerte ermittelte రffentlichkeitsgrad geringer ist als bei anderen Fakultäten, weil ein nicht unbeträchtlicher Teil der Leistungen der theologischen Fakultäten unmittelbar den Kirchen zuzurechnen ist.

Sieht man zunächst von der historischen Entwicklung und den tatsächlichen Gestaltungen $a b$, bietet es sich an, die theologischen Fakultäten als kirchliche Angelegenheiten zu betrachten. Der staat müßte sich anteilig mittels Transfers an der Bedarfsdeckung in dem Maße beteiligen, in dem ihm auf Grund des Offentlichkeitsgrades Externalitäten zuzurechnen sind. Für diese Lösung würde der tatsächlich ausgeübte starke Einfluß der Kirchen auf die theologischen Fakultäten sprechen. Dem steht allerdings die historisch gewachsene struktur entgegen, die umgekehrt die theologischen Fakuläten - obgleich mit einigen Sonderregelungen - dem staatlichen Bereich zuordnet. Will man es bei dieser zweiten Lösung belassen, dann wäre es aus den er- 
wähnten Gründen angebracht, daß der staat nicht alleine für die theologischen Fakultäten aufkommt, sondern sich die Kirchen gemäß dem Ausmaß ihres eigenen Interesses beteiligen.

\section{b) Karitative Leistungen}

Zur karitativen bzw. diakonischen Betätigung der Kirchen werden die zahlreichen sozialen Aktivitäten der Kirchen gezählt. Das Gebot der Năchstenliebe als Wesensbestandteil des christlichen Glaubens verpflichtet die Kirchen und ihre Glieder zum helfenden Tun am bedürftigen Nächsten, unabhängig davon, ob dieser der Kirche angehört oder nicht. Da es hier um das soziale Wirken der Kirchen als Gruppen geht, werden wir uns im folgenden nur mit der organisierten kirchlichen Sozialarbeit befassen, nicht jedoch mit den von einzelnen Kirchengliedern unabhängig von kirchlichen Organisationen unmittelbar geleisteten wohltätigen Werken.

Die Vielschichtigkeit der sozialen Leistungen macht jedoch eine differenzierte Betrachtung erforderlich. Darunter fallen einerseits Leistungen, die bei ökonomisch rationalem Verhalten vom Markt angeboten werden (können). Vornehmlich die Leistungen im Gesundheits- und Pflegebereich, beispielsweise diejenigen, die in Kindergärten, Krankenhăusern und Altenheimen erbracht werden, sind grundsätzlich marktfähige Güter, die privat bereitgestellt werden können. Der Nutzen ist (nahezu) vollständig individuell zurechenbar und das Ausschlußprinzip funktioniert. Andererseits gehören dazu uneigennützige, dem eigentlichen Wesen der Raritas entsprechende Leistungen, die in unentgeltlichen Hilfen an in Not Geratene und Bedürftige gewährt werden. Im Gegensatz zu den oben erwähnten grundsätzlich marktfähigen Gütern versagt bei den eigentlichen Hilfsleistungen im karitativen Sinne bei ökonomisch rationalem Handeln der Marktmechanismus und eine Unterstützung Bedürftiger unterbleibt. Allerdings darf kaum angenommen werden, daß uneigennützige Motive oder selektive Anreize als Triebkräfte ausreichen, allen in Not Geratenen zu helfen. 
Das Resultat der gesellschaftlichen Selbststeuerung kann aber nicht nur bei den eigentlichen karitativen Hilfsleistungen, sondern auch bei den grundsätzlich marktfähigen sozialen Leistungen - und das wird im folgenden, ohne es im einzelnen zu prüfen, unterstellt - im Hinblick auf die Allgemeinwohlzielsetzung unbefriedigend bleiben. Den Einsatz staatlicher Steuerungsmechanismen können zum einen die Verwirklichung des Gerechtigkeitspostulats sowie zum anderen die Sicherstellung eines Mindestmaßes an materieller Unabhängigkeit als Grundlage für ein menschenwürdiges Leben und als Voraussetzung für die Inanspruchnahme von Freiheitsrechten erforderlich machen. Es stellt sich somit die Frage, welche staatlichen Maßnahmen angebracht sind, um einerseits die durch die Beurteilung anhand der Grundwerte festgestellten allokativen Störungen $\mathrm{zu}$ beseitigen und um andererseits $z u$ vermeiden, daß die sozialen Aktivitäten gesellschaftlicher Gruppierungen unterbunden werden. Der Intensität staatlicher Maßnahmen kommt nämlich unter dem Blickwinkel der Allgemeinwohlverwirklichung eine mehrfache Bedeutung zu. $\mathrm{zu}$ weit gehende staatliche Eingriffe in diese Sphăre stehen im Widerspruch zur freiheitlichen zielsetzung der Eigenverantwortlichkeit und Selbstverwirklichung des Individuums. Es besteht sonst die Gefahr, daß Abhängigkeiten erzeugt und die Empfänger gleichzeitig an die Leistungen gewöhnt werden. Staatliche Zurückhaltung und vorrangig gesellschaftliche Selbststeuerung sind ferner deshalb geboten, weil auf diese Weise dem pluralismusgedanken als Ausdruck der Grundwerteverwirklichung besonders Rechnung getragen wird. Dadurch, daß den gesellschaftlichen Kräften ihre freie Entfaltung eingeräumt wird den Kirchen durch die Freiheit der Religionsausübung -, werden die Bedingungen für ein differenziertes Angebot geschaffen, das den verschiedenen Wertvorstellungen gerecht werden kann.

Die Forderung nach einem vielfältigen, die Eigenverantwortung berücksichtigenden Angebot bei den sozialen Diensten hat für die staatlichen Interventionen zur Konsequenz, daß sie nur subsidiär erfolgen dürfen. Weist die gesellschaftliche Selbststeuerung Mängel auf, ist vor einer staatlichen Bereitstellung 
erst zu prüfen, ob nicht Rorrekturen der gesellschaftlichen Selbststeuerung ausreichen, um zu einer besseren Allgemeinwohlverwirklichung zu gelangen. Bleiben die sozialen Leistungen der nichtstaatlichen Anbieter hinsichtlich Qualität und Umfang hinter dem zurück, was die gesellschaftliche Bewertung für wünschenswert erachtet, dann kann der staat durch die Vorgabe von Standards und mittels Transfers das Angebot entsprechend korrigieren. Liegen die Ursachen des unzureichenden Funktionierens der gesellschaftlichen selbststeuerungsmechanismen in gutsbedingten Externalitäten, dann kann die Korrektur in der Weise erfolgen, daß der staat eine kollektive Bedarfsdeckung durch die betroffene soziale Gruppe mit dem Instrument der Zwangsmitgliedschaft erzwingt.

Außer Zweifel steht im modernen Gemeinwesen nur, daß - sofern keine anderweitigen Unterhaltsverpflichtungen bestehen - der Staat durch die Sicherstellung eines Existenzminimums dafür zu sorgen hat, jedem in Not Geratenen ein menschenwürdiges Leben zu ermöglichen. Bei allen anderen sozialen Leistungen kommt eine staatliche Bedarfsdeckung erst in Betracht, falls die nichtstaatlichen Anbieter nicht in der Lage sind, die Leistungen in der aus der gesellschaftlichen Bewertung resultierenden Qualität und Quantität zu erbringen, und zwar selbst dann nicht, wenn der Staat durch entsprechende Korrekturmaßnahmen der gesellschaftlichen Selbststeuerungsmechanismen versucht, die Leistungen zu beeinflussen.

In diesem ordnungspolitischen Rahmen sind die sozialen Aktivitäten der Kirchen in der Gesellschaft zu sehen. Das Gebot der Nächstenliebe verpflichtet die Kirchen zu sozialem Tun, das ihren Mitgliedern und Nichtmitgliedern zugute kommt. Die von den Kirchen erbrachten sozialen Leistungen unterscheiden sich von denen anderer Träger dadurch, daß sie im Geiste der Nächstenliebe erfolgen. Sie beinhalten daher neben der eigentlichen sozialen Leistung immer auch ein seelsorgerisches Element, das darin besteht, dem Menschen in seiner speziellen Situation den göttlichen Trost zukommen zu lassen. 
Dem Wesen der tätigen Nächstenliebe entsprechen die unentgeltlichen Hilfsleistungen an in Not Geratene. Ganz abgesehen davon, daß die Empfänger gar nicht in der Lage wären, eine Gegenleistung zu erbringen, stünde in diesem Bereich der sozialen Hilfe das kirchliche Selbstverständnis einer Anwendung des Ausschlußprinzips entgegen. Da Entgeltzahlungen der Empfänger unterbleiben, resultieren daraus externe Effekte, die, wenn auch Nichtmitglieder der Kirchen davon profitieren, über die Kirchen als soziale Gruppen hinausreichen. Diese Leistungen erreichen somit einen hohen offentlichkeitsgrad, die damit verbundenen Externalitäten sind indessen nicht vom staat abzugelten, sondern, da sie auf das bewußte Handeln der Kirchen im Sinne der Năchstenliebe zurückzuführen sind, deren Angelegenheit und mithin von den Kirchen bzw. von der Opferbereitschaft ihrer Glieder zu tragen.

Obwohl die Kirchen gerade auf diesem Gebiet ein ihrem Selbstverständnis entsprechendes Betätigungsfeld zur tätigen Nächstenliebe haben, werden sie kaum in der Lage sein, aus eigener Kraft diese umfassende Aufgabe $\mathrm{zu}$ bewältigen. Insbesondere dann, wenn der Staat qualitative und quantitative Mindeststandards für diese Leistungen festlegt, wie es beispielsweise bei der Sozialhilfe mit der gesetzlichen Regelung des Existenzminimums der Fall ist, dürften bei den unentgeltlichen Hilfsleistungen die gesellschaftichen Selbststeuerungsmechanismen überfordert sein, so daß der staat die durch seine Vorgaben entstehende Bedarfsdeckungslücke selbst schließen muß. Die kirchlichen Hilfsleistungen ergänzen die staatlichen und entlasten den Staat in gewissem Umfang. Da die kirchlichen Hilfen nicht so starr an gesetzliche Regelungen angebunden sind wie die staatlichen, ist ihr Einsatz flexibler möglich. Sinnvollerweise sollten sie deshalb in den Fällen eingesetzt werden, wo die staatlichen Maßnahmen Lücken aufweisen oder wo schnelle unbürokratische Hilfe erforderlich ist.

Bei der entgeltlichen Bedarfsdeckung durch soziale Leistungen treten die Kirchen neben anderen Anbietern auf. Qualitativ un- 
terscheiden sich die kirchlichen Leistungen von denen der Mitanbieter vor allem durch das seelsorgerische Element. Eine Internalisierung dieser kirchlichen Besonderheiten bei den von den Kirchen angebotenen sozialen Diensten über den Preismechanismus wiirde allerdings dem Gebot der tätigen Nächstenliebe und dem Verkündigungsauftrag widersprechen. Die Eigenheiten kirchlicher Leistungen sind demzufolge als Teil des offentlichen Wirkens der Kirchen im Rahmen der freien Religionsausübung zu betrachten. Da das spezielle Seelsorgerische allen zugute kommen soll, darf aus kirchlicher sicht niemand durch einen Preis ausgeschlossen werden. Es handelt sich folglich um von den Kirchen bewußt erzeugte Externalitäten, die von den Kirchen als soziale Gruppen zu tragen sind.

Verlangt der staat bei den entgeltlich bereitgestellten Leistungen aufgrund deren Beurteilung anhand der Grundwerte bestimmte qualitative und/oder quantitative Mindestanforderungen, die von den gesellschaftlichen Selbststeuerungemechanismen nicht erfüllt werden, dann hat er für die durch die politische Bewertung entstandene zusätzliche Bedarfsdeckung aufzukommen. Von der Intensität der dazu eingesetzten staatlichen

Steuerungsmechanismen hängt es $\mathrm{ab}$, ob überhaupt ein freiwilliges Angebot der Kirchen und anderer Anbieter zustande kommt. Um sicherzustellen, daß ein den verschiedenen Präferenzen der Nachfrager entsprechendes vielfältiges Angebot erfolgen kann, ist es notwendig, daß die staatlichen Anforderungen hinsichtlich der Qualität der Leistung einen genügenden Spielraum belassen, der es beispielsweise den Kirchen ermöglicht, ihre sozialen Dienste ihrem Wesen entsprechend bereitzustellen.

Kein oder nur ein geringes Angebot der Kirchen ist zu erwarten, falls der Staat die Leistungen zu Preisen unter Selbstkosten abgibt. Zum einen deshalb, weil die Nachfrager bei engen Substituten wahrscheinlich einen deutlich höheren preis für die kirchlichen Güter nicht entrichten würden. Zum anderen könnten die Kirchen, selbst wenn sie bereit wären, ihre den staatlichen Angebotspreis übersteigenden Kosten in uneigennütziger Weise 
selbst zu tragen, wegen ihrer begrenzten finanziellen Möglichkeiten allenfalls mit einem verringerten Leistungsangebot aufwarten. Mit einer solchen Preispolitik würde der Staat auf wirtschaftliche Weise ein pluralistisches Angebot praktisch unmöglich machen. Mit Sicherheit unterbleibt ein Angebot, wenn der Staat für die Leistungen Höchstpreise setzt, die unter den Selbstkosten liegen, und er gleichzeitig so strenge Qualitätsnormen festlegt, daß alle Anbieter identische Leistungen bereitstellen müssen, weil jeglicher Anreiz zu einem Preis- und Qualitătswettbewerb genommen ist.

Setzt man - wie bisher - voraus, daß ein pluralistisches Leistungsangebot einer besseren verwirklichung der freiheitlichen zielsetzung und damit eines höheren Allgemeinwohls entspricht, so scheiden Lösunger aus, die auf ein monopolistisches Angebot hinauslaufen. Bei den Leistungen, die der Staat zu festgesetzten Preisen liefert, die unter den Selbstkosten liegen, muß für die nichtstaatlichen Träger einerseits die Möglichkeit zum Qualitätswettbewerb bestehen; andererseits müßte sich der Staat zumindest anteilig in der Höhe, in der er die von ihm übernommene Bedarfsdeckung subventioniert, an den Kosten der nichtstaatlichen Anbieter beteiligen, weil die nichtstaatlichen Anbieter einen an und für sich staatlichen Anteil der Bedarfsdeckung in dieser Höhe übernehmen und er folglich in diesem Umfang selbst entlastet wird.

Am Beispiel der Krankenhausfinanzierung kann dieser Zusammenhang verdeutlicht werden. Die Pflegesätze als Entgelte für die im Krankenhaus erbrachten Leistungen werden zwischen den Krankenhausträgern und den Krankenkassen vereinbart. Dabei ist gesetzlich festgelegt, daß in die Kalkulation der Pflegesätze nur der laufende Aufwand eingehen darf. Nach dem Krankenhausfinanzierungsgesetz trägt der Staat die Kosten für den Bau, die Erweiterung und die notwendigen Investitionen in den Krankenhäusern. Würde er diese Zuschüsse, die außerdem vom Vorhandensein bestimmter Qualitätsstandards in den Krankenhäusern abhängen, nur den staatlichen Krankenhăusern gewäh- 
ren, hätte das eine Diskriminierung der kirchlichen und sonstigen nichtstaatlichen Krankenhäuser zur Folge, weil eine Kostendeckung durch die festgesetzten Pflegesätze, in deren Berechnungsgrundlage die durch staatliche zuschüsse gedeckten Kosten nicht eingehen, nicht erreicht werden könnte. Sollen kirchliche Krankenhäuser aber wettbewerbsfähig gehalten werden, muß sie der Staat in gleicher Weise unterstützen wie seine eigenen. Voraussetzung für eine Gleichbehandlung mit staatlichen Krankenhäusern ist allerdings, daß die kirchlichen Krankenhäuser den Staat dadurch entlasten, daß er entsprechend weniger Krankenhausleistungen bereitstellen muß. Das ist bei kirchlichen Krankenhäusern gewährleistet, wenn sie hinsichtlich der Leistungen die staatlich verlangten Mindestanforderungen erfüllen und vor allem auch für Nichtmitglieder der Kirchen zugänglich sind ${ }^{161)}$. Nicht von staatlicher Seite abzugelten sind jedoch etwaige höhere Kosten in kirchlichen Krankenhäusern, die auf die Besonderheiten der von den Kirchen angebotenen Leistungen zurückgehen. Diese kommen ausschließlich den Nutzern kirchlicher Einrichtungen zugute und müssen deshalb von diesen, oder, falls das kirchliche Selbstverständnis dem entgegensteht, von den Kirchen übernommen werden.

Wenngleich die öffentliche Bedeutung der Kirchen auf dem Gebiet des Sozialwesens unbestritten und in vielen Bereichen nicht wegzudenken ist, regt sich bei den einzelnen Leistungen ein leichtes Mißbehagen 162). Die Kirchen müssen sich heute nämlich fragen, ob von ihrem Selbstverständnis her Institutionen wie z.B. Krankenhäuser, Kindergärten, Altenpflegeheime noch als tätige Nächstenliebe $z u$ bezeichnen sind; denn die Finanzierungsformen sind - wie die Realität zeigt - weitgehend verweltlicht. Die Kirchen haben im zeitalter der Industrialisierung, als der Sozialstaat noch in weiter Ferne lag, Pionierarbeit auf sozialem Gebiet geleistet. Armenpflege, Krankenhäuser und andere kirchlich getragene Institutionen wurden von wahrer Nächstenliebe geleitet. Im zuge des aufkommenden Sozial- und Wohlfahrtsstaates mit seinen kollektiven Zwangssicherungssystemen entwickelten sich diese kirchlichen Werke immer mehr zu gesell- 
schaftlich bedeutenden "Dienstleistungsunternehmen". Die ursprünglich uneigennützigen Motive, namentlich die auf der Nächstenliebe beruhende Opferbereitschaft der Kirchenglieder, wurden bei den Leistungen, die weitgehend entgeltlich und über Staatszuschüsse finanziert werden, durch ökonomische Kalküle ersetzt.

Aus dem Blickwinkel des gesamten Gemeinwesens sind jedoch die kirchlichen Leistungen trotz dieses Bedeutungswandels wegen ihres Beitrages $z u$ einem pluralistischen Angebot nach wie vor von Bedeutung, weil sie sich durch das ihnen eigene spezifische Moment des Seelsorgerischen von ähnlichen Leistungen des Staates oder anderer Träger abheben und die Kirchen als Kollektive einen sehr großen Teil der Bevölkerung umfassen. Andererseits ist aber auch nicht $\mathrm{zu}$ verkennen, daß die Besonderheiten, vornehmlich bei den Pflegeleistungen, von ihrem ursprünglichen Charakter - wie oben bereits erwähnt wurde - einiges verloren haben 163). Die Ursachen dafür liegen in den vermehrten staatlichen Regelungen und darin, daß die Zahl derjenigen, die ihren Lebenssinn in der uneigennützigen Hilfe am Nächsten sehen, wie z.B. Ordensschwestern, abnimmt und sich das Personal in kirchlichen Institutionen von dem in vergleichbaren anderen kaum noch unterscheidet. Schließlich kommt hinzu, daß trotz der hohen Mitgliederzahlen mehr Kirchenglieder den Leistungen ihrer Kirchen gleichgültig gegenüberstehen. Durch das zusammenwirken dieser Faktoren dürften die qualitativen Unterschiede zwischen kirchlichen und staatlichen Leistungen zusehends geringer werden.

3. Die Anwendbarkeit gesellschaftlicher Selbststeuerungsmechanismen

Die ökonomische Analyse der kirchlichen Funktionen brachte durchweg einen hohen ర̈ffentlichkeitsgrad zutage, der indessen bei den einzelnen kirchlichen Tätigkeitsfeldern auf verschiedene Ursachen zurückzuführen ist. 
Die von den Kirchen im Rahmen ihres Verkündigungauftrages für ihre Glieder, aber auch Nichtmitglieder erbrachten Leistungen erhalten dadurch, daß sie für eine sehr große Zahl von Gläubigen (und Fernstehenden) gedacht sind und dadurch, daß auf Grund des kirchlichen Selbstverständnisses die Bedarfsdeckung auf einer altruistischen Verhaltensweise beruht, einen hohen $\mathrm{Cf}_{-}$ fentlichkeitsgrad. Die Notwendigkeit staatlicher Interventionen besteht grundsätzlich nicht, weil es sich um ureigene Angelegenheiten der Kirchen im Rahmen ihrer freien Religionsausübung handelt, die im pluralistischen Gemeinwesen ein wesentliches Moment der Freiheitsverwirklichung bildet. Die auf altruistischem Handeln beruhenden Externalitäten sind von den Kirchen selbst zu tragen. Ein staatlicher Handlungsbedarf ergibt sich nur insofern, als der Staat den Kirchen die dafür erforderlichen Freiräume bereitstellen muß.

Einen hohen politisch induzierten Öffentlichkeitsgrad weisen die kirchlichen Leistungen auf, die der Staat im Hinblick auf eine bessere Allgemeinwohlverwirklichung ebenfalls bereitstellt bzw. an deren Bereitstellung er aufgrund der gesellschaftlichen Bewertung interessiert ist. Erfolgt keine oder keine vollständige Finanzierung über Entgelte, dann übernehmen die Kirchen einen Teil der vom Staat $z$ besorgenden Bedarfsdeckung und entlasten ihn entsprechend. Sie haben deshalb dem Staat gegenüber einen Anspruch auf finanziellen Ausgleich in Höhe der Entlastung. Die Forderung nach staatlicher Unterstützung ist außerdem berechtigt, wenn zwar ein pluralistisches Angebot erwïnscht ist, der staat indes hinsichtlich der qualitativen Gestaltung der Leistung entsprechend Vorschriften macht und Preise festlegt, die unter den Selbstkosten liegen. In diesen Fällen würde, gemessen an der bestmöglichen Allgemeinwohlverwirklichung, vermutlich kein oder nur ein zu geringes kirchliches Leistungsangebot erfolgen. Der durch kirchliche Besonderheiten geprägte Teil der Leistungen, der als kirchliche Angelegenheit betrachtet werden muß, berührt den staat nicht und ist kirchenintern zu regeln. 
Ein hoher Öffentlichkeitsgrad bei einzelnen kirchlichen Leistungen ist nicht zuletzt auf die politische Relevanz der Kirchen in der Gesellschaft zurückzuführen. Die christlichen Werte haben die abendländische Kultur geprägt und sind heute noch, wenngleich eine zunehmende Gleichgültigkeit gegenüber kirchlichen Moralvorstellungen nicht zu leugnen ist, mit die wesentlichsten Grundlagen für das menschliche Zusammenleben. Den Kirchen kommt insofern die Rolle eines Gewissens der Gesellschaft zu. Die Rirchen selbst bezeichnen das als ihre politische wächterfunktion. Außerdem sind es ein und dieselben Menschen, die dem Staat und den Kirchen angehören und die sich bei ihrem politischen Handeln mehr oder weniger stark von Einstellungen leiten lassen, die von christlichen Idealen beeinflußt sind. Eine generelle Unterstützung der Kirchen kann aber aus dieser öffentlichen Bedeutung nicht abgeleitet werden. Vielmehr muß der weltanschaulich neutrale staat, der den Kirchen die erforderlichen Entfaltungsmöglichkeiten einzuräumen hat, darauf bedacht sein, den politischen Einfluß einzelner Gruppen, auch den der Kirchen, auf das Maß zu beschränken, daß die Neutralität gewahrt bleibt.

Die Analyse der kirchlichen Leistungen hat gezeigt, daß in weiten Bereichen die gesellschaftlichen Selbststeuerungsmechanismen funktionieren bzw. funktionieren können, wenn sie notfalls durch staatliche steuerungsmechanismen unterstützt werden. Am Beispiel der Kirchen wurde außerdem deutlich, daß die intermediären Finanzgewalten als bedeutsame gesellschaftliche Gruppierungen im öffentlichen Raum eine wichtige Funktion erfüllen, weil sie in zahlreichen Bereichen zu einem vielfältigen Angebot an Leistungen beitragen. Es kam aber auch zum Ausdruck, daß das nur möglich ist, wenn der staat den sozialen Gruppierungen den dafür nötigen Freiraum beläßt und lediglich subsidiär eingreift. Eine an unseren Maßstäben gemessene bedenkliche Verknüpfung von Staat und Rirche, deren Ursachen wohl überwiegend in der historischen Entwicklung zu suchen sind, muß allerdings bei der tatsächlichen Gestaltung der Militärseelsorge und der Anstaltsseelsorge, des Religionsunterrichts sowie der theologi- 
schen Fakultäten festgestellt werden. In diesen Bereichen läuft der staat Gefahr, sich über die gebotene Neutralität hinweg die kirchlichen Angelegenheiten zu eigen zu machen. Damit stellt sich letztlich auch die - hier nicht zu beantwortende - Frage nach der Rechtfertigung des für das kirchliche wirken nicht erforderlichen Status als Körperschaft des öffentlichen Rechts und der Finanzierung der Kirchen über die staatlich geregelte Kirchensteuer.

\begin{abstract}
Abschließend bleibt festzustellen, daß der hier gewählte Ansatz eine Möglichkeit bietet, in einem konkreten Gemeinwesen die staatliche, öffentliche und private Sphäre nach ihren Funktionen zu unterscheiden. Es hat sich gezeigt, daß der Ansatz der Föderalismustheorie nicht nur auf regionale, sondern auch auf funktionale Kollektive anwendbar ist. Der verwendete Maßstab des Öffentlichkeitsgrades, der sowohl ökonomische als auch staatsrechtliche Kriterien enthält, kann als sinnvoller Gradmesser für die Beantwortung der Frage verwendet werden, wer bei welchen Aufgaben die Bedarfsdeckung $z u$ übernehmen hat. Da allerdings die konkreten Wertvorstellungen der jeweiligen Gemeinwesen zugrunde gelegt werden, ist die Verteilung der Aufgaben nicht endgültig bestimmt, sondern dem Wandel der Vorstellungen unterworfen. Obwohl der Grundsatz der Subsidiarität im Grundgesetz nicht explizit genannt ist, folgt sowohl aus der ökonomischen als auch aus der staatsrechtlichen Beurteilung der einzelnen Aufgaben, daß die Anwendung des Subsidiaritätsprinzips eine Voraussetzung zur Erreichung der größtmöglichen Allgemeinwohlverwirklichung ist.
\end{abstract}

Unbeantwortet bleibt die Frage nach dem exakten Umfang der nicht vom Marktmechanismus gesteuerten Bedarfsdeckung bei den einzelnen Leistungen. In welchem Umfang eine Leistung bereitgestellt werden soll, bleibt den politischen Entscheidungsprozessen vorbehalten, denen die Grundwerte dafür einen breiten Interpretationsspielraum gelassen haben. 
Peter Saile - 978-3-631-75214-2

Downloaded from PubFactory at 01/11/2019 07:01:15AM

via free access 
Anmerkungen zu Kap. A.

1) $\mathrm{Vgl}$. Mann =Finanzgewalten= $223 \mathrm{ff}$. , insbesondere 224 .

2) $\mathrm{Vgl}$. Herrmann $=$ Finanzgewalten=.

3) $\mathrm{Vgl}$. Smekal =Finanzwirtschaft= 36ff, , insbesondere 42 .

4) Eine Anregung zu diesem Vorgehen liefert Schmidt (=Staatstätigkeit= $26 \mathrm{f}$.), der ausgehend vom geringen Realitätswert der normativen Theorie der öffentlichen Güter für die Bestimmung des Umfangs und der Struktur der Staatsaufgaben vorgeschlagen hat, in Anknüpfung an Adolph Wagner die von den nichtstaatlichen Organisationen bereitgestellten Güter in die Betrachtung einzubeziehen und den Einfluß dieser intermediären Finanzgewalten auf die finanzwirtschaftlichen Aktivitäten des Staates zu untersuchen.

Anmerkungen zu Kap. B.

1) Vgl. dazu seinen grundlegenden Aufsatz =Finanzgewalten=.

2) $\operatorname{Mann}=$ Finanzgewalten $=220$.

3) Vgl. Mann =Finanzgewalten $=224$.

4) $\mathrm{Vgl}$. Mann =Finanzgewalten= $222 \mathrm{f}$.

5) Mann =Finanzgewalten= 224 .

6) Mann =Finanzgewalten $=223$; das Unterstrichene ist im Original gesperrt.

7) Vgl. Mann =Staatswirtschaft $=18 \mathrm{f}$.

8) Vgl. Tiepelmann =Parafiski= 295.

9) Vgl. Weber =Juristische Personen= 449 .

10) Maunz =Kommentar $=$ Art. 87 Rdnr. 64.

11) Vgl. Herrmann =Finanzgewalten $4 \mathrm{ff}$.; Herrmann versteht unter öffentlichen Aufgaben die Aufgaben, die man in der Finanzwissenschaft heute gemeinhin als staatliche $z u$ bezeichnen pflegt.

12) Vgl. Mann =Finanzgewalten $=222 \mathrm{f}$.

13) $\mathrm{Vgl}$. Mann =Staatswirtschaft $=18$; derselbe =Finanzgewalten= 223 sowie Tiepelmann =Parafiski= 295 .

14) $\mathrm{Vgl}$. Mann =Finanzgewalten $=222 \mathrm{f}$.

15) Vgl. Meinhold =Parafisci= $18 \mathrm{ff}$. 
16) Vgl. Stefani =Parafiskalităt= $286 \mathrm{f}$. Stefani gibt eine zusammenfassende Darstellung des Werkes von Morselli. Hier wird nach ihm Morselli zitiert.

17) Vgl. Stefani =Parafiskalität $=290 \mathrm{ff}$.

18) Vgl. Stefani = Parafiskalităt $=289$.

19) Vgl. Stefani =Parafiskalität= 295 .

20) Vgl. Stefani =Parafiskalität $=292 \mathrm{f}$.

21) Vgl. Stefani =Parafiskalität= $292 \mathrm{f}$.

22) Vgl. auch zum folgenden Stefani =Parafiskalität= 293; das Unterstrichene ist im Original kursiv gesetzt.

23) Vgl. B. II. 2.

24) Vgl. Stefani = Parafiskalität= 294 .

25) Vgl. Tiepelmann =Parafiski= 299 sowie Mann =Staatswirtschaft $=19$ und Herrmann $=$ Finanzgewalten $=4$ und 175 .

26) Smekal =Finanzwirtschaft $=44$.

27) Vgl. Smekal =Finanzen= 3 .

28) Vgl. Andreae, Smekal =Parafiskalität=, Smekal =Finanzwirtschaft=, derselbe =Finanzen=.

29) Smekal =Finanzen= 3; das Unterstrichene ist im Original kursiv gesetzt.

30) Lepelmeier =Parafiskalität= 26. Der bei Lepelmeier (=Parafiskalität $=22 \mathrm{f.})$, in abgeschwächter Form bei Smekal (=Finanzwirtschaft $=38 \mathrm{f}$. ), unterschwellig entstehende Eindruck, daß Manns Ansatz ein Reflex der gesellschaftlichen Entwicklung zu einem pluralistischen Gruppenstaat darstellt, kann nicht geteilt werden. Mann hält an seiner engen Fassung des Begriffs der Parafiskalität fest. Eine Verkoppelung mit dem Pluralismus in der Gesellschaft hält er für verfehlt (ausführlich dazu: Mann =Staat=492).

31) Vgl. dazu Smekal =Finanzwirtschaft= $50 \mathrm{ff}$, derselbe $=$ Finanzen $=6 \mathrm{f}$., vgl. auch insbesondere zur Weiterentwicklung und Verfeinerung des Ansatzes von Smekal namentlich hinsichtlich der Abgrenzung gegenüber den rein privaten Organisationen mit Hilfe des Kriteriums Öfentlichkeitsgrad: Lepelmeier =Parafiskalität $=46 \mathrm{ff}$.

32) Vgl. Kirberger =Staatsentlastung=.

33) Vgl. Kirberger =Staatsentlastung= $84 \mathrm{ff}$. 
34) Vgl. Kirberger =Staatsentlastung $=88 \mathrm{ff}$.

35) Vgl. Kirberger =Staatsentlastung= $96 \mathrm{ff}$.

36) Vgl. Kirberger =Staatsentlastung $=99$.

37) $\mathrm{Vgl}$. Kirberger =Staatsentlastung $=90 \mathrm{ff}$.

38) Vgl. Kirberger =Staatsentlastung= $96 \mathrm{ff}$.

39) Vgl. Schmoltzi =Finanzierung= 65 ff. sowie Nachtkamp =Idealtypen= $11 \mathrm{ff}$. , hier $41 \mathrm{ff}$.

40) Vgl. Schmoltzi =Finanzierung= 68 und $75 \mathrm{ff}$.

41) Vgl. v. Beckerath =Geschichte= 417. Ausführlich stellt Gretschmann (=Staatswirtschaft= 20 ff.) die gegenseitigen Einwirkungen von liberaler Staatsauffassung und Wirtschaft dar.

42) Vgl. Mann $=$ Ideale $=203 \mathrm{ff}$.

43) Vgl. v. Beckerath =Geschichte $=417$.

44) $\mathrm{Vgl}$. Mann $=I$ deale $=203 \mathrm{ff}$.

45) $\mathrm{Vgl}$. Mann $=$ Ideale $=208 \mathrm{ff}$.

46) Vgl. v. Beckerath =Geschichte= 417, Gretschmann =Staatswirtschaft $=59 \mathrm{ff}$.

47) Mann $=$ Ideale $=316$.

48) $\mathrm{Vgl}$. Freyer $=$ Hegel $=95 \mathrm{f}$.

49) $\mathrm{Vgl}$. Fecher =Ausgaben $=355$.

50) Vgl. Schmidt =Geschichte $=335 \mathrm{ff}$.

51) Vgl. Schmidt =Geschichte $=335$.

52) Vgl. Schmidt =Geschichte $=335 \mathrm{ff}$.

53) $\mathrm{Vgl}$. v. Hermann =Untersuchungen=.

54) Menger =Grundsätze= .

55) In der ersten Auflage seines Buches von 1871 hat Menger diesen Aspekt bei den Bedürfnissen noch nicht erwähnt. Er macht allerdings ( $\mathrm{S} .74 \mathrm{f}$.) einen Hinweis, der in diese Richtung geht. Bei der Diskussion des Volksvermögens spricht er von der Befriedigung von Bedürfnissen der "Gesamtheit", die er in einer Fiktion als ein einziges Wirtschaftsobjekt betrachtet, obwohl er sieht, daß die 
einzelnen Individuen durchaus sehr unterschiedliche Auffassungen vertreten können.

56) $\mathrm{Vgl}$ v. Hermann =Untersuchungen $=98$.

57) Vgl. Schmidt $=$ Geschichte $=337 \mathrm{f}$.

58) Vgl. Schmidt $=$ Geschichte $=338 \mathrm{ff}$.

59) Schmidt $=$ Geschichte $=338$.

60) $\operatorname{Sax}=$ Grundlegung $=191 \mathrm{f}$.

61) Vgl. Ritschl =Theorie= $41 \mathrm{ff}$.

62) Ritschl =Theorie $=45$.

63) Vgl. Ritschl $=$ Theorie $=45$.

64 ) Vgl. Ritschl $=$ Theorie $=46$.

65) Ritschl =Theorie= 47 .

66) Vgl. Schmidt $=$ Geschichte $=340 \mathrm{f}$.

67) Vgl. Schmidt $=$ Geschichte $=343 \mathrm{f}$.

68) Vgl. Ritschl $=$ Theorie $=47$.

69) Vgl. Ritschl =Theorie= $36 \mathrm{ff}$. Ähnlich etwa auch Schäffle $=$ Bau= 372, der den Grund für die Bildung von gemeinnützigen Vereinen ebenfalls darin sieht, daß der verfolgte Zweck "... die Kräfte eines Einzelnen übersteigt."

70) Vgl. Ritschl $=$ Theorie $=36$.

71) Vgl. Ritschl =Theorie $=40$.

72) Vgl. Schmidt =Geschichte $=346$.

73) Wagner $=$ Grundlegung= 828; das Unterstrichene ist im Original gesperrt.

74 ) Vgl. Wagner $=$ Grundlegung $=829$; das Unterstrichene ist im Original gesperrt.

75) Vgl. Wagner $=$ Grundlegung $=829 \mathrm{f}$.

$76) \mathrm{Vgl}$. Wagner $=$ Grundlegung $=830$.

77) Wagner $=$ Grundlegung $=830$; das Unterstrichene ist im Original gesperrt.

78) Wagner $=$ Grundlegung $=836 \mathrm{f}$; d das Unterstrichene ist im Original gesperrt. 
79) Vgl. Wagner =Grundlegung $=837$.

80) Vgl. De Viti De Marco =Grundlehren= 2 .

81) Vgl. De Viti De Marco =Grundlehren= 5 .

82) Vgl. De Viti De Marco =Grundlehren= 5 .

83) De Viti De Marco =Grundlehren= 6 .

84 ) Vgl. Schmidt $=$ Geschichte $=350 \mathrm{ff}$.

85) Vgl. v. Wieser $=$ Werth $=214$.

86) Vgl. v. Wieser $=$ Werth $=214$.

87) Lindahl =Gerechtigkeit= 51 ff. und passim.

88) Vgl. Schmidt =Geschichte $=353 \mathrm{f}$. Margit Cassel war nicht im Original zugänglich.

89) Vgl. Schmidt $=$ Geschichte $=354$.

90) Vgl. Schmidt =Geschichte $=355$.

91) Vgl. Musgrave =Finanztheorie= 15 .

92) Vgl. Schäffle =Bau= 366 .

93) Vgl. Mann $=$ Ideale $=316$.

94) Vgl. Schäffle =Bau= 367; das Unterstrichene ist im Original gesperrt.

95) Vgl. Schäffle =Bau= $367 \mathrm{ff}$.

96) Vgl. Schäffle $=$ Bau $=369 \mathrm{f}$.

97) Schäffle $=$ Bau= 379 .

98) Vgl. Schäffle =Bau= $371 \mathrm{ff}$.

99) Vgl. Schäffle =Bau= 374 .

100) Vgl. Schäffle =Bau= 379 .

101) v. Wieser $=$ Werth $=214$.

102) v. Wieser $=$ Werth $=215 \mathrm{f}$.

103) Vgl. v. Wieser $=$ Werth $=216 \mathrm{f}$.

104 ) Vgl. Wagner =Grundlegung= 831; das Unterstrichene ist im Original gesperrt. 
105) Vgl. Wagner =Grundlegung= $840 \mathrm{f}$; das Unterstrichene ist im Original gesperrt.

106) Vgl. Wagner $=$ Grundlegung $=838 \mathrm{ff}$.

107) Wagner $=$ Grundlegung $=841 \mathrm{f}$.

108) Vgl. Wagner =Grundlegung= $842 \mathrm{f} . ;$ das Unterstrichene ist im Original gesperrt.

109) Vgl. Wagner =Grundlegung= 851; das Unterstrichene ist im Original gesperrt.

110) Vgl. Wagner =Grundlegung= $858 \mathrm{ff} . ;$ das Unterstrichene ist im Original gesperrt.

111) $\mathrm{Vgl}$. Wagner $=$ Grundlegung $=860 \mathrm{ff}$; das Unterstrichene ist im Original gesperrt.

112) Wagner $=$ Grundlegung $=863$.

113) Vgl. Wagner =Grundlegung= 866; das Unterstrichene ist im Original gesperrt.

114 ) Wagner $=$ Grundlegung $=866$; das Unterstrichene ist im Original gesperrt.

115) $\mathrm{Vgl}$. Wagner $=$ Grundlegung $=866$.

116) Vgl. Wagner $=$ Grundlegung $=868$.

117 ) Vgl. Wagner $=$ Grundlegung $=852$.

118) $\mathrm{Vgl}$. Wagner $=$ Grundlegung $=852$.

119) Vgl. Wagner $=$ Grundlegung $=853 \mathrm{f}$; das Unterstrichene ist im Original kursiv.

120) Vgl. Wagner $=$ Grundlegung $=855 \mathrm{ff}$; das Unterstrichene ist im Original kursiv.

121) Vgl. Wagner $=$ Grundlegung $=844$.

122) Vgl. Wagner $=$ Grundlegung $=847$.

123) Vgl. Wagner $=$ Grundlegung $=848 \mathrm{f}$.

124 ) Vgl. Wagner =Grundlegung $=773$.

125) Vgl. Wagner $=$ Grundlegung $=845$.

126) Etwas schwierig wird diese Abgrenzung allerdings in dem von Ritschl =Theorie= $40 \mathrm{f}$. angeführten Beispiel für ein am Gemeinsinn orientiertes Verhalten, wonach Soldaten bereit sind, für eine höhere Idee ihr Leben hinzugeben. 
127) Sax $=$ Grundlegung $=17 \mathrm{f}$.

128) Vgl. Sax =Grundlegung $=21$.

129) $\mathrm{Sax}=$ Grundlegung $=18 \mathrm{f}$.

130) $\mathrm{Vgl}$. Sax $=$ Grundlegung $=143 \mathrm{ff}$.

131) Sax =Grundlegung= 145 .

132) Vgl. Ritschl =Theorie= $39 \mathrm{f}$. sowie Sax =Grundlegung= 144 .

133) Vgl. Ritschl =Theorie= 41 sowie Schäffle =0ekonomie= 104 .

134) Vgl. Ritschl =Theorie= 56 .

135) Vgl. De Viti De Marco =Grundlehren= 3 .

136) De Viti De Marco = Grundlehren $=6$.

137) De Viti De Marco =Grundlehren $=6$.

138) Vgl. De Viti De Marco =Grundlehren= $7 \mathrm{f}$.

139) Vgl. De Viti De Marco =Grundlehren= 11 .

140) De Viti De Marco =Grundlehren= $12 \mathrm{f}$.

141) Vgl. De Viti De Marco =Grundlehren= 12 .

142) Vgl. De Viti De Marco =Grundlehren= 14 .

143) Vgl. De Viti De Marco =Grundlehren= 16 .

144) Schmidt $=$ Geschichte $=360$.

145) Vgl. Schmidt $=$ Geschichte $=344 \mathrm{f}$.

146) Vgl. z.B. Grochla =Betriebsverband=, derselbe =Betriebsverbindungen=, Niggemann =Verbändelehre=, Engelhardt $=$ Geschichte $=$, Thiemeyer $=$ Gemeinwirtschaft $=, v$. Loesch =Unternehmung= und Gretschmann =Staatswirtschaft= und die dort angegebene Literatur.

Anmerkungen zu Kap. C.

1) Vgl. Scheuner =Staat= 656 und Krautzberger =Erfüllung= goff.

2) Vgl. v. Arnim =Staatslehre $=7$ und Dürig =Kommentar= Art. 1 , Rdnr. 15 .

3) v. Arnim =Staatslehre $=8$. 
4) $\mathrm{Vgl}$. Scheuner $=$ Staat $=657 \mathrm{f}$. und Dürig =Kommentar= Art. 1, Rdnr. 1 ff.

5) Vgl. v. Arnim =Staatslehre= 25 ff.

6) Vgl. Dürig =Kommentar= Art. 1, Rdnr. 46 .

7) Vgl. v. Arnim =Staatslehre $=64 \mathrm{f}$.

8) Vgl. v. Arnim =Staatslehre $=37$.

9) Vgl. v. Arnim $=$ Staatslehre $=66 \mathrm{f}$.

10) Vgl. Scheuner $=$ Verbände $=12 ;$ Rupp $=$ Funktionen $=1253 \mathrm{f}$.

11) Rupp =Funktionen= 1267 ; Rupp betrachtet allerdings einen $\mathrm{zu}$ weit gehenden Einfluß der Verbände ăußerst kritisch.

12) Vgl. Mikat =ordnungsproblematik= 118 .

13) Vgl. Schlaich $=$ Neutralität $=133$.

14) Vgl. Mikat =Ordnungsproblematik= $120 \mathrm{ff}$. sowie Schlaich =Neutralität $=257$ ff.

15) Vgl. Wössner $=$ Bedeutung $=87$.

16) Vgl. Smekal =Finanzwirtschaft $=21$.

17) $\mathrm{Vgl}$. Biedenkopf $=$ Staat $=239 \mathrm{f}$.

18) $\mathrm{Vgl}$. Leßmann =Aufgaben $=50$.

19) Vgl. Smekal =Finanzwirtschaft=.

20) Vgl. Leßmann =Aufgaben $=50 \mathrm{f}$.

21) Vgl. Smekal =Finanzwirtschaft= $24 \mathrm{ff}$.

22) $\mathrm{Vgl}$. Eschenburg =Herrschaft $=$.

23) Vgl. Leßmann =Aufgaben= $133 \mathrm{ff}$. und Herzog =Verbandswesen= $73 f$.

24) =BVerfGE $5=135$ und 198 .

25) Vgl. Biedenkopf =Staat= 238; Bull =Staatsaufgaben= $20 \mathrm{ff}$.

26) Vgl. Biedenkopf $=$ Staat $=244$.

27) $\mathrm{Vgl}$. Bull =Staatsaufgaben= $66 \mathrm{f}$.

28) Vgl. Scheuner $=$ Staat $=660$.

29) $\mathrm{Vgl} \cdot \mathrm{Bull}=$ Staatsaufgaben $=68$. 
30) Scheuner =Staat $=660$; im Original Unterstreichung .

31) Vgl. Hirsch =Funktionen $=31$.

32) Vgl. Leßmann =Aufgaben $=46 \mathrm{f}$.

33) Vgl. Leßmann =Aufgaben= $122 \mathrm{f}$.

34 ) Scheuner $=$ Staat $=660$.

35) Krautzberger =Erfüllung= 85 .

36) Leßmann =Aufgaben= 155; einen Überblick über die Literatur geben insbesondere Bull =Staatsaufgaben=, Krautzberger =Erfüllung=.

37) Nachweis bei Rirberger =Staatsentlastung= $56 \mathrm{f}$.

38) Vgl. Maunz =Aufgaben= 232 .

39) $\mathrm{Vgl}$. Leßmann =Aufgaben= $156 \mathrm{f}$.

40) Vgl. Leßmann =Aufgaben= $155 \mathrm{ff}$. sowie Bull =Staatsaufgaben $=99 \mathrm{f}$.

41) Vgl. Peters =Aufgaben $=877 \mathrm{ff}$.

41a) Peters =Aufgaben $=878$.

42) Vgl. Peters =Aufgaben $=878 \mathrm{f}$.

43) Leßmann =Aufgaben $=164$.

44 ) Vgl. v. Arnim =Staatslehre $=177 \mathrm{f}$.

45) Vgl. v. Arnim =Staatslehre=.

46) Vgl. v. Arnim =Staatslehre= $124 \mathrm{ff}$.und $471 \mathrm{ff}$.

47 ) Vgl. Dürig =Kommentar= Art. 1, Rdnr. 1 ff. und v. Arnim =Staatslehre $=127 \mathrm{f}$.

48) v. Arnim= Staatslehre $=128$.

49) Vgl. v. Arnim =Staatslehre $=128 \mathrm{f}$.

50) Vgl. v. Arnim $=$ Staatslehre $=134 \mathrm{f}$.

51) Vgl. v. Arnim =Staatslehre $=136 \mathrm{f}$.

52) Vgl. v. Arnim $=$ Staatslehre $=139$.

53) Vgl. v. Arnim =Staatslehre= $141 \mathrm{f}$. und passim.

54) Vgl. v. Arnim =Staatslehre= $145 \mathrm{f}$. 
55) Vgl. etwa Pohmer =Politik= $262 \mathrm{f}$.

56) Vgl. v. Arnim =Staatslehre $=162 \mathrm{f}$.

57) Vgl. dazu Pohmer =Politik= $265 \mathrm{f}$.

58) $\mathrm{Vgl} \cdot \mathrm{v} \cdot$ Arnim $=$ Staatslehre $=165 \mathrm{ff}$.

59) Vgl. v. Arnim $=$ Staatslehre $=173$.

60) v. Arnim =Staatslehre= 173; das Unterstrichene ist im Original gesperrt.

61) Vgl. v. Arnim =Staatslehre= 174; das Unterstrichene ist im Original gesperrt.

62) Vgl. v. Arnim =Staatslehre $=471 \mathrm{f}$.

63) Vgl. v. Arnim =Staatslehre $=475 \mathrm{f}$.

64) Vgl. v. Arnim =Staatslehre= $64 \mathrm{f}$; das Unterstrichene ist im Original kursiv.

65) Vgl. v. Arnim =Staatslehre= 476 ff.; der eine ganze Reihe von Gründen für das Staatsversagen anführt.

66) Vgl. v. Arnim $=$ Staatslehre $=472$.

67) Vgl. Dürig =Kommentar= Art. 1, Rdnr. 43 f.; v. Arnim =Staatslehre $=40 \mathrm{ff}$.

68) Vgl. v. Arnim $=$ Staatslehre $=472$.

69) Vgl. v. Arnim =Staatslehre= $474 \mathrm{f}$; ebenfalls das Subsidiaritätsprinzip bejahend, allerdings mit anderer Begründung: Dürig =Kommentar= Art. 1, Rdnr. $53 \mathrm{f}$.

70) Zimmermann $=$ Probleme $=10$.

71) Vgl. etwa Peffekoven =Grundlagen= $611 \mathrm{ff}$.

72) $\mathrm{Vgl}$. Olson =Logik= und Buchanan $=$ Theory= $1 \mathrm{ff}$.

73) $\mathrm{Vgl} . \mathrm{Zimmermann}=$ Probleme $=10 \mathrm{f}$.

74) Vgl. Pohmer =Politik= 271.

75) Vgl. Zimmermann $=$ Probleme $=5 \mathrm{f}$.

76) $\mathrm{Vgl}$. Wittmann $=$ Kriterien $=158$.

77) Vgl. Wittmann =Kriterien= $168 \mathrm{ff}$. und 172 .

78) Vgl. Wittmann =Kriterien= 159. Zur gleichen Einschätzung gelangt Peffekoven =Grundlagen $=610$, der das 
Subsidiaritätsprinzip als "Leerformel" bezeichnet, die durch ökonomische Maßstäbe ausgefüllt werden muß.

79) Vgl. Wittmann =Kriterien= 166 .

80) Vgl. Wittmann $=$ Kriterien $=170$.

81) Vgl. Lepelmeier = Parafiskalität $=3 \mathrm{f}$.

82) Vgl. Pohmer = Politik= 271.

83) Vgl. dazu Zimmermann = Probleme $=7$.

84) $\mathrm{Vgl}$. Kirsch $=$ Verbände $=30$.

85) Vgl. Zimmermann $=$ Probleme $=7$.

86) Vgl. Pohmer = Politik= $271 \mathrm{f}$.

87) Vgl. Zimmermann $=$ Probleme $=14$.

88) Vgl. Zimmermann $=$ Probleme $=14 \mathrm{ff}$.

89) Vgl. Zimmermann $=$ Probleme $=15$.

90) Vgl. Zimmermann $=$ Probleme $=18$.

$91) \mathrm{Vgl}$. Musgrave, Musgrave, Kullmer $=$ Theorie= 54 ; Liedtke $=$ Theorie $=20 ;$ Samuelson $=$ Aspects $=333 \mathrm{f}$.

92) Samuelson $=$ Aspects $=335$.

93) Samuelson $=$ Theory $=387$; das Unterstrichene ist im Original kursiv.

94 ) Vgl. Samuelson $=$ Theory $=388 \mathrm{f}$.

95) Vgl. Musgrave =Theory $=6 \mathrm{ff}$.

96) Musgrave $=$ Theory $=8$. In der zweiten Auflage seiner Finanztheorie hat Musgrave den gleichgroßen Konsum ersetzt durch die Definition "daß der Konsum von $A$ den Konsum von B nicht beeinträchtigt". Damit nimmt er das Kriterium der Nichtrivalität auf. Vgl. Musgrave $=$ Finanztheorie $=8$.

97) $\mathrm{Vgl}$. Musgrave $=$ Theory $=8$.

98) Vgl. Musgrave, Musgrave, Kullmer =Theorie= 55.

99) Vgl. Musgrave =Provision $=307$.

100) Vgl. dazu Liedtke =Theorie= $24 \mathrm{ff}$. und die dort angegebene Literatur. Zur grundsätzlichen Kritik an der Aussagekraft der normativen Theorie der öffentlichen Güter vgl. insbesondere Schmidt $=$ Staatstätigkeit $=4 \mathrm{ff}$. 
101) Vgl. Cansier =Marktversagen $=428 \mathrm{f}$.

102) Timm =Allokationspolitik= 147, vgl. ferner Schlieper $=$ Effekte $=524$.

103) $\mathrm{Vgl}$. Bator =Anatomy $358 \mathrm{ff}$.

104) Vgl. Bator =Anatomy= $363 \mathrm{ff}$, der dazu das "BienenzüchterBeispiel" anführt.

105) $\mathrm{Vgl}$. Bator =Anatomy $=365 \mathrm{ff}$.

106) Pohmer $=$ Politik= 278. Diese unbefriedigende Marktpreisbildung ist auf (fast) ausschließlich fixe Kosten bei der Produktion eines Gutes, wie etwa bei Straßen oder Brücken, zurückzuführen und wïrde eine Bedarfsdeckung zum "Null-Tarif" erfordern. Für eine marktwirtschaftliche Versorgung fehlen folglich Jegliche Anreize. "Deshalb ist in diesen Fällen die kollektive Bedarfsdeckung durch den Staat sinnvoll und (von Ausnahmen abgesehen) auch ubberall üblich."

107) Vgl. Bator =Anatomy $=369 \mathrm{ff}$.

108) Vgl. Krause-Junk $=\mathrm{Abri} \beta=704$.

109) $\mathrm{Vgl}$. Krause-Junk $=\mathrm{Abri} \beta=704$.

110) $\mathrm{Vgl}$. Musgrave $=\mathrm{Goods}=126$ und 136; Samuelson =Expenditure= 102 .

111) Vgl. Cansier =Marktversagen $=429$.

112) $\mathrm{Vgl}$. Krause-Junk $=\mathrm{Abri}=703$.

113) Vgl. Musgrave =Provision $=306 \mathrm{f}$.

114 ) Vgl. dazu etwa Liedtke =Theorie $=28$.

115) Timm =Allokationspolitik= 147. Buchanan =Demand= 33, auf den Timm sich stützt, macht deutlich, daß es nicht "extreme external economies in consumption" sind, die diese speziellen öffentlichen Güter ausmachen, sondern "The spillover benefit, the external economy, may arise wholly from the act of producing the good that is commonly consumed". Das Unterstrichene ist im Original kursiv.

116) Vgl. Liedtke $=$ Theorie $=28$.

117) Vgl. Liedtke =Theorie $=31$.

118) Vgl. Hanusch $=$ Theorie $=110$.

119) Vgl. Liedtke =Theorie= $28 \mathrm{ff}$. 
120) Vgl. Hanusch $=$ Theorie $=44$.

121) Musgrave $=$ Finanztheorie $=15$.

122) Vgl. Musgrave =Finanztheorie $=15$.

123) $\mathrm{Vgl}$. Musgrave =Finanztheorie= 16, Gröbner =Subventionen= 82 sowie die dort angegebene Literatur.

124) Vgl. Musgrave, Musgrave, Kullmer =Finanzen= 77 .

125) Vgl. Musgrave =Finanztheorie= 15 .

126) Vgl. Gröbner =Subventionen $=83$.

127) Vgl. Timm =Allokationspolitik= 149 .

128) Vgl. Musgrave $=$ Finanztheorie $=16$.

129) Vgl. etwa Liedtke =Theorie= $42 \mathrm{f}$, Cansier =Marktversagen= 435 und Gröbner =Subventionen= 82 sowie die dort angegebene Literatur.

130) Vgl. Andel =Diskussion $=212$.

131) Liedtke $=$ Theorie $=43$; ähnlich Cansier =Marktversagen $=435$.

132) Vgl. Liedtke =Theorie= 43 .

133) Eine zusammenfassende Darstellung dieser Ansätze findet sich bei Häuser =Ansätze= $51 \mathrm{ff}$.und Bödecker $=$ Distributionsprobleme $=21 \mathrm{ff}$. Der Grundgedanke findet sich schon bei Sax =Grundlegung=195, der mit seinen Ausführungen zur Bestimmung des Verhältnisses, in dem Individual- und Kollektivbedürfnisse befriedigt werden, inhaltlich auf den Ausgleich der Grenznutzen abstellt.

134) Vgl. Musgrave, Musgrave, Kullmer $=$ Finanzen= $62 \mathrm{f}$.

$134 \mathrm{a}) \mathrm{Vgl}$. Cansier =Marktversagen $=427$.

135) Vgl. Arrow =Choice=.

136) Vgl. Cansier =Marktversagen $=427 \mathrm{f}$.

137) Vgl. die ausführliche Kritik etwa bei Häuser =Ansätze= 51 ff., insbesondere $56 \mathrm{f}$.; Endres =Kosten= $254 \mathrm{ff}$.

137a)Beispiele zu diesem und dem folgenden Abschnitt finden sich bei der Anwendung auf die Kirchen.

138) Vgl. Krause-Junk $=\mathrm{Abri} \beta=701$.

139) Vgl. Coase $=$ Problem= $1 \mathrm{ff}$. Zur Kritik vgl. Cansier $=$ Marktversagen $=430 \mathrm{ff}$. 
140) Krause-Junk $=A b r i \beta=701 \mathrm{f}$.

141) Vgl. Olson =Logik $=1$.

142) Vgl. Olson =Logik= 2 .

143) $\mathrm{Vgl}$. Olson $=\operatorname{Logik}=49 \mathrm{f}$.

144 ) Vgl. Niggemann =Verbändelehre= $64 \mathrm{f}$.

145) Vgl. Olson =Logik= $12 \mathrm{ff}$.

146) Vgl. Olson $=\operatorname{Logik}=34$.

147) Vgl. Olson =Logik= $52 \mathrm{ff}$.

148) $\mathrm{Vgl}$. Olson $=$ Logik $=49 . \mathrm{Vgl} . \mathrm{zu}$ den kleineren und mittleren Gruppen auch Buchanan =Demand $=177 \mathrm{ff}$. Die dort von Buchanan beschriebenen Clubgüter zählen hierzu. Diese zeichnen sich durch einen hohen Grad an Unteilbarkeit und eine beschränkte Zahl an Gruppenmitgliedern aus. D.h., der Charakter eines öffentlichen Gutes ist auf eine kleine Gruppe begrenzt.

149) Vgl. Olson =Logik= $59 \mathrm{ff}$; Weisbrod $=$ Theory $=187$.

150) Vgl. Olson $=$ Logik= $43 \mathrm{ff}$.

151) $\mathrm{Vgl}$. Weisbrod $=$ Theory $=174 \mathrm{ff}$.

152) Vgl. dazu auch Kirsch =Politik= $40 \mathrm{f}$, der am Beispiel der unterschiedlichen Organisationsgrade der Gewerkschaften diese zusammenhänge verdeutlicht.

153) $\mathrm{Vgl}$. Olson $=\operatorname{Logik}=1$.

154) $\mathrm{Vgl}$. Weisbrod $=$ Theory $=187 \mathrm{f}$.

155) Vgl. Harsanyi $=$ Modelle $=52 \mathrm{f}$.

156) Vgl. Harsanyi $=$ Modelle $=69$.

157) Vgl. dazu etwa Becker =Ansatz= 306; diese Argumente finden sich aber auch, ohne daß er sie vertritt, bei olson $=$ Logik $=59 \mathrm{f} . ; 60$, Fußnote 17 sowie 185, Fußnote 91 .

158) Olson $=$ Logik $=158$, Fußnote 91.

159) $\mathrm{Vgl}$. Olson =Logik= 59. Die Einordnung der nicht geldwerten Gegenleistungen als Individualgüter wird im übrigen durch die allgemein anerkannten psychologischen Untersuchungen Maslows gestützt, der die Bedürfnisse der Menschen nach der Dringlichkeit ordnet und soziale Bedürfnisse sowie Streben nach Macht, Ansehen, Ruhm, Prestige oder Selbstverwirklichung als sekundäre Bedürfnisse bezeichnet, die 
der Befriedigung der physiologischen Bedürfnisse nachstehen (Vgl. Kupsch, Marr =Personalwirtschaft= $635 \mathrm{f}$. ).

160) Vgl. Olson =Logik=60, Fußnote 17.

161) Vgl. Olson =Logik= 158 .

162) Vgl. Cansier =Marktversagen $=430 \mathrm{ff}$.

163) Vgl. Schlieper $=$ Effekte $=528$.

164 ) Vgl. Wille $=$ Allkokation $=13$.

165) Vgl. Nachtkamp =Idealtypen $=41 \mathrm{f}$.

166) Vgl. dazu z.B. Wille =Allokation= $6 \mathrm{f}$. sowie die dort angegebene Literatur.

167) Vgl. Timm =Allokationspolitik= $147 \mathrm{f}$.

168) Vgl. Kirsch $=$ Politik= 15 .

169) Vgl. Schlieper $=$ Effekte $=527$; Cansier $=$ Marktversagen $=429$.

170) $\mathrm{Kirsch}=$ Politik= 15 .

171) Vgl. Kirsch $=$ Politik= 15 .

172) Vgl. Cansier =Marktversagen $=433$.

173) Vgl. Schlieper $=$ Effekte $=529$.

174 ) Vgl. Pohmer = Politik= 278 .

175) Vgl. Kirsch = Politik= 15 .

176) Vgl. Timm =Allokationspolitik= $152 \mathrm{ff}$, bei dem sich eine zusammenfassung der Diskussion über die meritorischen Güter befindet.

177) Vgl. Pohmer =Politik= 278 .

178) Koch $=$ Finanzpolitik= 2 .

179) Vgl. Cansier =Marktversagen $=433$.

180) Vgl. Cansier =Marktversagen $=423 \mathrm{f}$.

181) $\mathrm{Vgl}$. Timm =Allokationspolitik= 146 .

182) Vgl. Pohmer =Politik= 278; vgl, auch Schmidt =Geschichte= $261 \mathrm{ff}$.

183) Vgl. Schmidt $=$ Geschichte $=361 \mathrm{ff}$.

184 ) $\mathrm{Vgl}$. Timm =Allokationspolitik= 142 . 
185) Pohmer =Politik= 278 .

186) Vgl. Timm =Allokationspolitik= 173 .

187) Vgl. Timm =Allokationspolitik= 174 .

188) $\mathrm{Vgl}$. Timm =Allokationspolitik= 174 .

189) Vgl. dazu insbesondere Hesse =Staatsaufgaben= $261 \mathrm{ff}$.

190) Vgl. Hesse =Staatsaufgaben= $261 \mathrm{ff}$.

191) $\mathrm{Vgl}$. Hesse =Staatsaufgaben $=307 \mathrm{f}$.

192) Vgl. Nachtkamp =Idealtypen= $44 \mathrm{ff}$; Schmoltzi $=$ Finanzierung $=74$. Einschränkend auch Weisbrod =Theory= 189, der eine staatliche Unterstützung für freiwillige Kollektive vorschlägt, die solche Kollektivgüter bereitstellen, die das staatliche Angebot ergänzen.

193) Vgl. Nachtkamp =Idealtypen= 42 f.; Schmoltzi $=$ Finanzierung $=74 \mathrm{f}$.

194 ) Vgl. dazu die Ausführungen im Kapitel E.

Anmerkungen zu Kap. D.

1) Vgl. dazu die Ausführungen in Kap. C. I.

2) $\mathrm{Vgl}$. Bonus =Aspekte= $51 \mathrm{ff}$. sowie derselbe =Güter= $50 \mathrm{ff}$.

3) $\mathrm{Vgl}$. Bonus $=$ Aspekte $=72$.

4) Bonus = Güter $=63 \mathrm{f}$.

5) $\mathrm{Vgl}$. Bonus $=$ Aspekte $=72$.

6) $\mathrm{Vgl}$. Bonus =Aspekte= $51 \mathrm{ff}$.

7) $\mathrm{Vgl}$. Bonus =Aspekte $=73$.

8) Vgl. Lepelmeier =Parafiskalität $=46 \mathrm{ff}$.

9) Lepelmeier =Parafiskalität $=46$.

10) Vgl. Lepelmeier =Parafiskalität $=77$ und Smekal $=$ Finanzwirtschaft $=56 \mathrm{ff}$.

11) Smekal =Finanzwirtschaft $=57$.

12) Vgl. Lepelmeier =Parafiskalität $=77$.

13) Vgl. Lepelmeier =Parafiskalität= 47 . 
14 ) Vgl. Lepelmeier =Parafiskalität $=77$ sowie zur politischen Relevanz Smekal =Finanzwirtschaft $=59 \mathrm{f}$.

15) Zumindest spricht Lepelmeier Auswirkungen, die über eine bestimmte Gruppe hinausreichen, nicht explizit an. Wenn man von seinen Ausführungen zur funktionalen Repräsentanz (vgl. = Parafiskalität = 77) ausgeht, wo er lediglich unter Berücksichtigung der Trittbrettfahrer-Problematik darauf verweist, daß bei Nicht-Zwangskollektiven die funktionale Repräsentanz nicht notwendig mit dem Organisationsgrad dieser Gruppe übereinstimmen muß. Damit vernachlässigt er die über Zwangs- oder Nicht-Zwangskollektive hinausgehenden Auswirkungen.

16) Vgl. Smekal =Finanzwirtschaft $=59$.

17) Vgl. Smekal =Finanzwirtschaft= 53 ff. und Lepelmeier =Parafiskalität $=80 \mathrm{f}$.

18) Wie bereits oben (vgl. B.I.2.) gesagt wurde, sieht Smekal zwar, daß die Zweiteilung Staat - Individuum die gesellschaftlichen Realitäten nicht erfaßt und er stellt daher zu Recht auf die Dreiteilung Staat - Gesellschaft - Individuum ab, allerdings vernachlëssigt er dabei, daß Staat und Gesellschaft nicht isoliert nebeneinander stehen, sondern miteinander verschränkt sind.

19) Vgl, dazu Homann =Markt= $325 \mathrm{ff}$. , insbesondere $335 \mathrm{ff}$. , der in der Auseinandersetzung mit der Auffassung $v$. Hayeks diesen Aspekt als wesentliches Kennzeichen der Sozialen Marktwirtschaft anführt.

20) Vgl. zu diesem Aspekt der unterschiedlichen Leistungsqualität etwa Badelt =Freiwilligengruppen= 77 oder Scheuner =Tätigkeit $=79$, der auf die Besonderheit kirchlicher Leistungen im Vergleich zu staatlichen Leistungen im karitativen Bereich hinweist.

21) Vgl. Egner =Haushalt= $379 \mathrm{ff}$.

22) Dieser Aspekt findet nicht zuletzt darin seinen Ausdruck, daß Vereinen und anderen Organisationen beim Erfüllen gewisser Voraussetzungen die mit steuerlichen Erleichterungen verbundene Gemeinnützigkeit zuerkannt wird.

23) Vgl. Lepelmeier =Parafiskalität= $78 \mathrm{ff}$.

24 ) Im übrigen beinhaltet dieses Abgrenzungskriterium nach der Dominanz der Steuerungsmechanismen auch die von Smekal verwendeten Maßstäbe der Selbstverwaltung und der finanziellen Unabhängigkeit, die hier im Gegensatz zu Smekal jedoch nicht von außen vorgegeben werden, sondern ein Resultat der Bewertung der einzelnen Aufgaben sind. 
25) Wie wir allerdings gezeigt haben - und worauf insbesondere Olson hingewiesen hat -, sind die altruistischen Motive nur schwer zu erfassen. Denn auch altruistische Verhaltensweisen können durchaus rational sein und dem so Handelnden einen Eigennutz verschaffen, der zwar nicht in einer finanziellen Gegenleisturig besteht, ihm jedoch andere Anreize wie Ansehen, Ruhm, Ehre usw. oder aber Befriedigung von weltanschaulichen bzw. religiösen Wertvorstellungen verschafft. Die hierin zum Ausdruck kommenden verschiedenen Motive, einerseits Anreize durch nicht finanzielle Gegenleistungen, andererseits wohltätiges Verhalten, lassen sich jedoch kaum ermitteln, weil sich die "uneigennützig" Handelnden in dieser Hinsicht eher bedeckt halten.

26) Geht man - wie es Nachtkamp und Schmoltzi getan haben davon aus, daß nicht egoistisches Handeln eine Befriedigung verschafft und insofern Nutzen stiftet, dann wird es fraglich, ob man dann noch sagen kann, wie es Schmoltzi und Nachtkamp tun, daß nicht egoistisch Handelnde bei ihren Entscheidungen soziale Kosten zugrunde legen. Sind die Nutzen nämlich bei ihnen internalisiert, treten folglich aus ihrer Sicht keine Externalitäten auf und ihre Entscheidungskalküle basieren demzufolge nur auf den privaten (Grenz-) Kosten.

27) Für staatliche Normsetzungen hinsichtlich der Qualität der Leistungen und für staatliche Preissetzungen haben wir das oben (vgl. C.II.) bereits gezeigt. Dasselbe gilt aber auch für Steuern und Transfers, bei denen es ebenfalls auf die Ausgestaltung ankommt. Je nachdem, wie restriktiv Empfangs- oder Verwendungsauflagen sind, werden die gesellschaftlichen Steuerungsmechanismen beeinflußt.

28) Namentlich die soziologische, politologische, staatsrechtliche, aber auch die ökonomische Literatur hat sich damit ausführlich befaßt. Verwiesen sei dazu etwa auf Kaiser =Repräsentation=, Wössner =Bedeutung=, Leßmann =Aufgaben=, Eschenburg =Herrschaft=, Schmölders =Verbände=, von Beyme = Interessengruppen=, Buchholz =Interessen=, Dettling =Verbände=, Kirberger =Staatsentlastung=, Blümle, Wittmann =Verbände=, HerderDorneich =Verbandsökonomik= sowie insbesondere Scholz =Kommentar = und die dort angegebene Literatur.

29) Vgl. v. Arnim =Staatslehre= $104 \mathrm{f}$. und $133 \mathrm{f}$.

30) Vgl. Scholz =Kommentar= Art. 9, Rdnr. $8 \mathrm{ff}$.

31) Vgl. Scholz =Kommentar= Art. 9, Rdnr. $13 \mathrm{ff}$.

32) Vgl. Scholz =Kommentar= Art. 9, Rdnr. 16 .

33) Vgl. Kirsch $=$ Politik $=87$. 
34) Vgl. Scholz =Kommentar= Art. 9, Rdnr. 16 sowie v. Arnim =Staatslehre $=285$.

35) Vgl. Kirberger =Staatsentlastung= $117 \mathrm{ff}$.

36) Nur ganz vereinzelt und eher am Rande werden manchmal Kritikpunkte laut, die aber nicht weiter verfolgt werden. $\mathrm{Vgl}$. Kirberger =Staatsentlastung $=28 \mathrm{ff}$. und $330 \mathrm{f}$.

37) $\mathrm{Vgl}$. Schmidt =Entwicklungstendenzen= $213 \mathrm{ff}$.

38) Vgl. Schmidt =Entwicklungstendenzen $=215$.

39) Vgl. Herder-Dorneich $=$ Markt $=59$.

40) Vgl. v. Arnim =Staatslehre $=291$.

41) Vgl. v. Arnim =Staatslehre= 287 ff.; Schmidt =Entwicklungstendenzen $=215 \mathrm{f}$.

42) Vgl. Schmidt =Entwicklungstendenzen= $216 \mathrm{f}$; v. Arnim =Staatslehre $=287 \mathrm{ff}$. Vgl. dazu die empirischen Belege bei Kirberger =Staatsentlastung $=129 \mathrm{ff}$.

43) $\mathrm{Vgl}$. Schmidt =Entwicklungstendenzen= $218 \mathrm{ff}$.

44 ) Vgl. v. Arnim =Staatslehre= 288 und 293. Der Einwand von Bernholz =Verbände $=6 \mathrm{ff}$, , der Einfluß der Verbände auf die Politik werde - trotz der unbestreitbaren Macht und Einflußmöglichkeiten - gemeinhin überschätzt, weil die Politiker auch die nicht Organisierten als wähler sehen und diese nicht vernachlässigt werden dürfen, wird durch die Analyse Schmidts eindeutig widerlegt und überzeugt daher nicht.

45) Vgl. Schmidt $=$ Problematik $=163$.

46 ) Vgl. Schmidt =Entwicklungstendenzen $=217$ und 234; v. Arnim Staatslehre $=484$.

47) Vgl. Schmidt =Problematik= $158 \mathrm{ff}$.

48) Vgl. Schmidt =Entwicklungstendenzen= $239 \mathrm{f}$. Einen Beleg für die teilweise Ohnmacht des Staates und dafür, wie selbstverständlich jeglicher Einfluß der Verbände heute bereits erachtet wird, liefert etwa die Ausführung von Groser (=ökonomie= 241), daß wenn der Staat auf Bereiche trifft, die von starken Verbänden besetzt sind, er dann nur mit diesen, aber nicht gegen diese handeln könne.

Anmerkungen zu Kap. E.

1) Vgl. Egner =Haushalt $=400$. 
2) Vgl. Wagner =Grundlegung= $844 \mathrm{ff}$.

3) Vgl. Schäffle $=B a u=365$ ff.

4) Vgl. Mann =Finanzgewalten= $221 \mathrm{ff} . ;$ derselbe =Staatswirtschaft $=17 \mathrm{ff}$.

5) Vgl. dazu Hermann =Finanzgewalten= $135 \mathrm{ff}$, der zwar den Kirchen ein ganzes Kapitel gewidmet hat, sich jedoch mit einer Betrachtung der kirchlichen Einnahmen begnügt. Insbesondere gilt sein Interesse der Kirchensteuer in Abhängigkeit von der Einkommensteuer.

6) So lehnt etwa Lotz =Finanzwissenschaft $=2$, Fußnote 2 die Berücksichtigung der Kirchen in der Finanzwissenschaft $a b$, weil sie vom staat unabhängige Organisationen seien. Beachtung verdienten sie allenfalls, wenn die Kirchensteuern Rückwirkungen auf das staatliche Steuerwesen zeitigten. Eine Ausnahme macht nur Nöll von der Nahmer =Finanzwissenschaft $=392 \mathrm{ff}$.; der im Anhang seines Lehrbuches kurz die kirchliche Finanzwirtschaft beschreibt.

7) Zu erwähnen sind hier zunächst die in den 50er Jahren erschienenen Dissertationen von Cahrs =Finanzstruktur=, der sich mit den Formen der Kirchenfinanzierung und den kirchlichen Aufgaben auseinandersetzt, sowie von Kaiser =Probleme=, der sich der finanzwissenschaftlichen Probleme der Kirchensteuer annimmt. Ferner eine tubersicht über kirchliche Finanzen von Egner =Finanzen= und die Darstellung zum kirchlichen Finanzausgleich von Bauer =Probleme=. Als Beispiel für intermediäre Finanzgewalten, ohne indessen deren Besonderheiten zu berücksichtigen, zieht Smekal =Finanzwirtschaft $=,=$ Finanzen= die Kirchen heran.

8) Vgl. Egner =Haushalt $=400 \mathrm{ff}$.

9) Vgl. Egner =Haushalt $=404$.

10) $\mathrm{Vgl}$. Egner =Haushalt= $414 \mathrm{ff}$.

11) Vgl. Mantl $=$ Kirche $=1365 \mathrm{ff}$. und v. Campenhausen =Staatskirchenrecht $=185$.

12) Vgl. v. Campenhausen =Staatskirchenrecht $=193 \mathrm{ff}$. sowie Hesse $=$ Kirche $=1151$.

13) Das gilt vor allem für die anglikanische Kirche in England, die lutherischen Staatskirchen in Skandinavien, die Verhältnisse in einigen schweizerischen Kantonen sowie die Vorrangstellung der katholischen Kirche in Spanien und Italien. Vgl. dazu etwa Wolf =Ordnung= 135; Hesse $=\mathrm{Kirche}=1151 \mathrm{f}$. sowie $\mathrm{v}$. Campenhausen =Staatskirchenrecht $=168 \mathrm{f}$.

14) Vgl. Hesse $=$ Kirche= 1152 . 
15) Vgl. Marre =Kirchenfinanzierung= $12 \mathrm{ff}$; Listl $=$ Kirchenbeitrag $=1383 \mathrm{f}$; Hesse $=$ Kirche $=1153$. Außer den "eigenwüchsigen" Einnahmen sind es vor allem Steuern oder Beiträge der Mitglieder, Staatsleistungen und auch Erwerbseinkünfte (insbesondere in den USA). Andere Begünstigungsformen sind die tubernahme kirchlicher Ausgaben durch den Staat (etwa Pfarrerbesoldung in einigen Ländern mit Staatskirchen) oder die Einräumung steuerlicher Privilegien in Form von Steuerbefreiungen und niedrigeren Steuersätzen.

16) Bohatec $=$ Lehre $=370$; das Unterstrichene ist im Original hervorgehoben.

17) Vgl. Bohatec $=$ Lehre= 370; Ratzinger $=$ Kirche $=173$.

18) Ratzinger $=$ Kirche $=173$.

19) Vgl. Bohatec $=$ Lehre $=267$.

20) Vgl. Küng =Kirche $=39$.

21) Vgl. Gloege, Honecker =Kirche= 1118 .

22) Vgl. Mörsdorf =römisch-katholisch= 1134 .

23) $\mathrm{Vgl}$. Wendland =Eschatologie= $358 \mathrm{f}$.

24) Vgl. Huber $=$ Ŏffentlichkeit $=31$.

25) Vgl. Wolf $=$ Kirche $=623$.

26) Vgl. Skydsgaard $=$ Kirche $=183$.

27) $\mathrm{Vgl}$. Steck $=$ Kirche $=630$; Mörsdorf $=$ Kirchenverfassung $=275$.

28) Vgl. Mörsdorf =Kirchenverfassung= 274 .

29) $\mathrm{Vgl}$. Wolf =Ordnung= $52 \mathrm{ff}$.

30) Vgl. Reicke =Kirchenverfassung $=821$; Thul $=$ Kirchenverfassung $=1283$.

31) Vgl. Wolf =Kirchenverfassung der nicht röm.-kath. Kirchen= 277; Friedrich $=$ Kirchenverfassung $=813$.

32) Vgl. Huber =Ŏffentlichkeit $=52$.

33) Vgl. Schmidt $=$ Kirche $=620$; Grundmann, Honecker $=$ Kirche= 1124 .

34) Vgl. Schmidt $=$ Kirche $=619$.

35) Vgl. Hofmann $=$ Gemeinde $=795 \mathrm{f}$. 
36) Vgl. Friedrich $=$ Kirchenverfassung $I I=828$.

37) Vgl. Grundmann =Kirchenverfassung $=1260$.

38) $\mathrm{Vgl}$. Grundmann =Kirchenverfassung= $1261 \mathrm{ff}$; Pirson $=$ Kirchenverfassung $=1256 \mathrm{f}$.

39) Vgl. Schmidt $=$ Kirche $=621$.

40) Vgl. Eßer =Kirche= $1128 \mathrm{ff}$.

41) $\mathrm{Vgl}$. Wolf =Kirchenverfassung= $1272 \mathrm{ff}$.

42) $\mathrm{Vgl}$. Wolf =Kirchenverfassung= $1280 \mathrm{f}$.sowie Eßer $=$ Kirche= $1228 \mathrm{f}$.

43) Vgl. v. Campenhausen =Bedeutung= $610 \mathrm{ff}$.; Schlaich =Neutralität $=198 \mathrm{ff}$.

44 ) Vgl. v. Campenhausen $=$ Bedeutung $=610 \mathrm{ff}$.

45) Vgl. Mörsdorf $=$ Recht $=615 \mathrm{f}$.

46) Vgl. Mörsdorf =Recht $=616 \mathrm{f}$.; derselbe $=$ Kirchengliedschaft $=1175 \mathrm{f}$.

47) Vgl. Mörsdorf =Kirchengliedschaft= $1175 \mathrm{ff} . \mathrm{Vgl}$. zu diesem Problem auch Ratzinger =Kirche $=179$.

48) Vgl. Mörsdorf =Recht= $620 \mathrm{ff}$.

49) Vgl. v. Campenhausen $=$ Recht $=636 \mathrm{ff}$. sowie Maurer $=$ Kirchengliedschaft $=1167 \mathrm{f}$.

50) Vgl. Maurer $=$ Kirchengliedschaft $=1168 \mathrm{f}$.

51) Vgl. Ratzinger $=$ Kirche $=180$ und Maurer $=$ Kirchengliedschaft $=1169$.

52) Vgl. dazu etwa den ausführlichen tuberblick bei v . Campenhausen =Staatskirchenrecht $=15 \mathrm{ff}$. und die dort angegebene Literatur.

53) Vgl. Mantl =Kirche= $1352 \mathrm{ff}$. und v. Campenhausen =Staatskirchenrecht $=21 \mathrm{ff}$.

54) Vgl. Mantl =Kirche= $1352 \mathrm{ff}$. und v. Campenhausen =Staatskirchenrecht $=26 \mathrm{ff}$.

55) Vgl. Brauns =Staatsleistungen= $17 \mathrm{ff}$.

56) Vgl. Mantl =Kirche= 1359 .

57) $\mathrm{Vgl}$. Lederer $=$ Kirchenvermögen $=280$ sowie v. Campenhausen =Staatskirchenrecht $=43 \mathrm{f}$. 
58) Vgl. Mantl =Kirche= $1356 \mathrm{ff}$; v. Campenhausen

=Staatskirchenrecht $=46$ sowie Hesse $=$ Kirche $=1144$.

59) Vgl. Hesse $=\mathrm{Kirche}=1144$.

60) Vgl. Hesse $=$ Kirche $=1157 \mathrm{f}$.

61) Hesse $=$ Kirche $=1160$.

62) Jurina =Religionsgemeinschaften $=588 \mathrm{f}$.

63) Vgl. Schlaich =öffentlichkeitsauftrag= $256 \mathrm{ff}$.

64 ) Vgl. v. Campenhausen =staatskirchenrecht $=73 \mathrm{ff}$.

65) Vgl. v. Campenhausen =Staatskirchenrecht $=64 \mathrm{f}$.

66) $\mathrm{Vgl}$. Hesse $=$ Kirche $=1158 \mathrm{f}$.

67 ) Vgl. v. Campenhausen =Staatskirchenrecht $=64 \mathrm{f}$.

68) Vgl. Schlaich =Öffentlichkeitsauftrag= $257 \mathrm{f}$.

69) Vgl. Maunz =Kommentar= Art. 87, Rdnr. 64 sowie Weber =Juristische Person= 449 .

70) Vgl. Schlaich =Neutralität= $178 \mathrm{ff}$.

71) $\mathrm{Vgl}$. Huber $=$ Ŏffentlichkeit $=540 \mathrm{f}$.

72) $\mathrm{Vgl}$. Hesse $=$ Kirche $=1140 \mathrm{ff}$; Raab $=$ Kirche $=288 \mathrm{ff}$.

73) Vgl. Mikat $=$ Staat $=162$.

74) $\mathrm{Vgl}$. Hesse $=$ Kirche $=1148$.

75) Vgl. Mikat $=$ Staat $=163 \mathrm{ff}$.

76) $\mathrm{Vgl}$. Hesse $=$ Kirche $=1148$.

77) $\mathrm{Vgl}$. Mikat $=$ Staat $=175 \mathrm{ff}$. und Hesse $=$ Kirche $=1148$.

78) $\mathrm{Vgl}$. Hesse $=$ Kirche $=1148 \mathrm{f}$. und Mikat =Staat $=169 \mathrm{ff}$.

79) $\mathrm{Vgl}$. Hesse $=\mathrm{Kirche}=1149$.

80) $\mathrm{Vgl}$. Simon $=$ Staat $=190$.

81) Vgl. Simon $=$ Staat $=191 \mathrm{ff}$.

82) $\mathrm{Vgl}$. Huber =Öffentlichkeit $=452 \mathrm{f}$.

83) Vgl. Wolf =Königsherrschaft $=1318$.

84) Vgl. Huber =ర̆ffentlichkeit $=456$. 
85) $\mathrm{Vgl}$. Huber = Öffentlichkeit= $456 \mathrm{ff}$.

86) Vgl. Simon =Staat $=209 \mathrm{ff}$.

87) Vgl. Schlaich =ర̆fentlichkeitsauftrag= 242 ff. und Pirson = Offentlichkeitsanspruch $=1658 \mathrm{ff}$.

88) Vgl. Huber = రffentlichkeit= $619 \mathrm{ff}$. und $644 \mathrm{f}$.

89) Vgl. Ratzinger =Kirche= 176 und Gloege, Honecker =Kirche= 1117 .

90) $\mathrm{Vgl}$. Wolf =Ordnung= $512 \mathrm{ff}$.

91) $\mathrm{Vgl}$. Wolf $=$ ordnung $=300 \mathrm{ff}$.

92) $\mathrm{Vgl}$. Wolf =Ordnung $=530 \mathrm{ff}$.

93) $\mathrm{Vgl}$. Wilken $=\mathrm{Geld}=104 \mathrm{f}$.

94 ) $\mathrm{Vgl}$. Seiler $=$ Seelsorge $=685 \mathrm{f}$.

95) $\mathrm{Vgl}$. Huber $=$ Øffentlichkeit $=220 \mathrm{f}$.

96) $\mathrm{Vgl}$. Huber = Øffentlichkeit= $259 \mathrm{ff}$. und Seiler =Seelsorge= $686 \mathrm{ff}$.

97) Vgl. Huber $=$ Öffentlichkeit $=272$.

98) $\mathrm{Vgl}$. Seiler $=$ Seelsorge $=695 \mathrm{f}$.

99) Vgl. Seiler $=$ Seelsorge $=688 \mathrm{f}$.

100) Vgl. Seiler $=$ Seelsorge $=686 \mathrm{f}$.

101) Vgl. Huber $=$ Ŏffentlichkeit $=262 \mathrm{ff}$.

102) Vgl. zur Aufgabe und Organisation der Anstaltsseelsorge Albrecht $=$ Anstaltsseelsorge $=701 \mathrm{ff}$.

103) Vgl. Geiger =Schulsystem $=485$.

$104) \mathrm{Vgl}$. Obermayer $=\mathrm{Schule}=2256 \mathrm{f}$.

105) Vgl. Geiger =Schulsystem $=486$.

106) Vgl. Obermayer $=$ Schule $=2257 \mathrm{f}$.

107) Vgl. Geiger =Schulwesen $=493 \mathrm{ff}$.

108) Vgl. Link =Religionsunterricht $=508 \mathrm{ff}$.

109) Vgl. Pieroth $=$ Religionsunterricht $=219 \mathrm{f}$, , Link =Religionsunterricht $=520 \mathrm{ff}$. sowie Maunz =Kommentar= Art. 7, Rdnr. $47 \mathrm{ff}$. 
110) Vgl. Link =Religionsunterricht $=545$.

111) Vgl. zum Berliner Schulgesetz: Pieroth $=$ Religionsunterricht $=2191$.

112) 1975 betrug die Gesamtzahl der Schüler an kirchlichen Privatschulen 250 000. Die evangelische Kirche hatte 1972 328 Schulen mit 41938 Schülern, vorwiegend an Gymnasien, berufsbildenden Schulen und Sonderschulen. Die katholische Kirche hatte 19701072 Schulen mit 199625 Schülern, davon über die Hälfte Gymnasiasten. Vgl. Maunz =Schulträger $=547$, Fußnote 1 .

113) Vgl. Maunz =Schulträger $=548 \mathrm{ff}$.

114) Vgl. Maunz =Schulträger $=551 \mathrm{f}$.

115) $\mathrm{Vgl} \cdot$ Maunz =Schulträger $=552 \mathrm{f}$.

116) Maunz =kommentar= Art. 7, Rdnr. 64 .

117) Maunz =Kommentar $=$ Art. 7, Rdnr. 64.

118) Maunz = Kommentar= Art. 7, Rdnr. 86 .

119) Vgl. Maunz =Schulträger= $556 \mathrm{ff}$. sowie Maunz =Kommentar= Art. 7, Rdnr. 86 ff.

120) Vgl. Weber =Fakultäten $=571$.

121) Vgl. Weber =Fakultäten= $571 \mathrm{f}$.

122) Vgl. Huber =öffentlichkeit $=296$.

123) Vgl. dazu im einzelnen Weber =Fakultäten= $572 \mathrm{ff}$.

124) Vgl. Maunz =Kommentar= Art. 7, Rdnr. 48c.

125) Vgl. ausführlich dazu: Huber =Öffentlichkeit = $329 \mathrm{ff}$. und passim.

126) Vgl. dazu ausführlich Baldus =Hochschulen= $597 \mathrm{ff}$.

127) $\mathrm{Vgl}$. Weides =Akademien $=627 \mathrm{ff}$.

128) $\mathrm{Vgl}$. Weides $=$ Akademien $=628$.

129) Vgl. Weides $=$ Akademien $=631 \mathrm{ff}$.

130) Vgl. Böhme =Akademien= $23 \mathrm{ff}$. dazu auch: Müller

$=$ Akademien $=15 \mathrm{ff}$. sowie Forster $=$ Akademien $=25 \mathrm{ff}$.

131) $\mathrm{Vgl}$. Weides =Akademien $=623 \mathrm{ff}$. und passim.

132) In der Begründung und Rechtfertigung der karitativen Betätigung bestehen zwischen der evangelischen und der 
katholischen Kirche keine wesentlichen Unterschiede. Eine getrennte Darstellung erübrigt sich deshalb. Eine religiöse Begründung der Caritas aus dem Glaubensverständnis der katholischen Kirche heraus hat $v$. Nell-Breuning (=Caritas = 49 und passim abgeleitet. Als wesentlichen Unterschied gegenüber der allgemeinen Wohlfahrt und Fürsorge nennt er bei der Caritas das persönliche Moment, das aus dem Gebot der Nächstenliebe folgt.

133) $\mathrm{Vgl} . \mathrm{v}$. Hase $=$ Diakonie $=467$.

134) Vgl. Meister =Auftrag= $358 \mathrm{f}$.

135) $\mathrm{Vgl}$. Völkl =Diakonie $=9$ und Rinken $=$ Werke $=386$.

136) $\mathrm{Vgl}$. Meister $=$ Auftrag $=366$.

137) Vgl. Völkl =Diakonie= $10 \mathrm{ff}$.

138) Vgl. Völkl =Diakonie= 24 .

139) Vgl. v. Tiling $=$ Werke $=401 \mathrm{ff}$. sowie Rinken $=$ Werke $=383$ ff.

140) $\mathrm{Vgl}$. Völkl =Diakonie $=18$ und Rinken $=$ Werke $=387$.

141) Treffend hat dies v. Nell-Breuning zum Ausdruck gebracht: "Der Wert des Menschen bestimmt sich nicht allein... nach seinem wirtschaftlichen Nutzwert. Dagegen ist die Achtung der Menschenwürde der ärmsten und elendsten, selbst verkommensten Menschen für die menschliche Gesittung und Kultur die unersetzliche und allein tragfähige Grundlage. Am eindruckvollsten und überzeugendsten aber wird diese Achtung kund durch die Aufopferung, mit der die Caritas sich dieser Ärmsten annimmt." (v. NellBreuning $=$ Caritas $=60$ ) .

142) Vgl. Meister =Auftrag= $372 \mathrm{ff}$.

143) $\mathrm{Vgl}$. Wilken $=$ Geld $=68$.

144 ) Vgl. v. Nell-Breuning =Caritas= 60 sowie Stolleis =Sozialstaat $=387 \mathrm{ff}$. und Scheuner =Tätigkeit= $58 \mathrm{f}$.

145) Vgl. Rinken $=$ Werke $=399 \mathrm{f}$.

146) Vgl. Völkl =Diakonie= $22 \mathrm{ff}$.

147) Vgl. Scheuner =Tätigkeit= 62 und Stolleis =Sozialstaat= 397 .

148 ) Vgl. Scheuner $=$ Tätigkeit $=60$.

149) Vgl. Scheuner $=$ Tätigkeit $=60$.

150) Vgl. v. Nell-Breuning =Caritas $=62 \mathrm{ff}$. 
151) Vgl. Scheuner $=$ Tätigkeit $=51 \mathrm{ff}$. und Stolleis Sozialstaat $=389$.

152) Vgl. Stolleis =Sozialstaat $=390 \mathrm{ff}$.

153) Vgl. Stolleis =Sozialstaat $=399 \mathrm{f}$.

154) Vgl. Mörsdorf $=$ Kirche $=1135 \mathrm{ff}$. und 1140.

155) Vgl. Gloege, Honecker =Kirche= 1122 .

156) Vgl. Grundmann, Honecker =Kirche= 1124 .

157) Vgl. Holsten =Mission= $22 \mathrm{f}$. Die Träger kirchlicher Entwicklungshilfe sind zumeist besondere Werke, die über Spenden, Kirchensteuermittel und nicht zuletzt uber staatliche Zuschüsse vorrangig Projekte im Bildungswesen, Gesundheitswesen, in der Landwirtschaft und soziale Einrichtungen finanzieren. Vgl. dazu ausführlicher: Grohs =Entwicklungspolitik= $559 \mathrm{f}$. sowie Wiesebach =Entwicklungshilfe $=417$.

158) Vgl. zur Problematik Bildung und Ausbildung Pohmer $=$ Wissenschaft $=18 \mathrm{ff}$.

159 ) Vgl. zur Bedeutung der Bildung für die Demokratie und die Verwirklichung der politischen Gleichheit v. Arnim $=$ Staatslehre $=85 \mathrm{f}$. und $142 \mathrm{ff}$.

160) Genaugenommen müßte man auf die anteiligen Nutzen und nicht auf die Kosten abstellen.

161) Nicht unproblematisch und vor allem mehr von staatsrechtlicher Bedeutung ist in diesem Zusammenhang die Frage, wie weit der Minderheitsschutz geht. Etwa wenn in bestimmten Regionen oder Gemeinden zwar konfessionelle Krankenhäuser, Altenpflegeheime oder Kindergärten bestehen, die aber von Atheisten oder Andersgläubigen abgelehnt werden und von denen statt dessen religiös und weltanschaulich neutrale Einrichtungen gefordert werden.

162) Auf die Problematik einer "weltlichen Vielgeschäftigkeit" und die daraus resultierenden Gefahren für die eigentlichen Funktionen der Kirchen in der Welt hat Egner =Haushalt $=426$ hingewiesen .

163) Zum Wandel kirchlicher Leistungen vgl. Egner =Haushalt= $379 \mathrm{ff.}$, insbesondere 386 . 
Peter Saile - 978-3-631-75214-2

Downloaded from PubFactory at 01/11/2019 07:01:15AM

via free access 
Albrecht, Karl:

$=$ Anstaltsseelsorge $=$ Anstaltsseelsorge, in: Handbuch des Staatskirchenrechts für die Bundesrepublik Deutschland, Band 2, herausgegeben von Ernst Friesenhahn und Ulrich Scheuner in Verbindung mit Joseph Listl, Berlin 1975, S. 701-719.

Andel, Norbert:

=Diskussion= Zur Diskussion über Musgraves Begriff der "merit wants", in: Finanzarchiv, N. F., Band 28 (1969), S. 209-213.

Andreae, Clemens August und Smekal, Christian: =Parafiskalität= Zur Parafiskalität des österreichischen Gewerkschaftsbundes (OGB), in: Soziale Sicherheit, Goetz Briefs zum 80. Geburtstag, herausgegeben von Josef Broermann und Philipp Herder-Dorneich, Berlin 1968 , S. 301-316.

v. Arnim, Hans Herbert:

$=$ Staatslehre $=$ Staatslehre der Bundesrepublik

Deutschland, München 1984.

Arrow, Kenneth J.:

$=$ Choice= Social Choice and Individual Values, New York 1951.

Badelt, Christoph:

=Freiwilligengruppen = Freiwilligengruppen als Problem der ökonomischen Klubtheorie, in: Kyklos, Vol. 37 (1984), S. 59-81.

Badelt, Christoph:

Institutioneller Wandel in der Bereitstellung Sozialer Dienste, in: Jahrbuch für Neue Politische Okonomie, herausgegeben von Erik Boettcher, Philipp HerderDorneich und Karl Ernst Schenk, 3. Band, Tübingen 1984, S. $122-141$.

Baldus, Manfred:

=Hochschulen = Kirchliche Hoch - und Fachhochschulen, in: Handbuch des Staatskirchenrechts für die Bundesrepublik Deutschland, Band 2, herausgegeben von Ernst Friesenhahn und Ulrich Scheuner in Verbindung mit Joseph Listl, Berlin 1975, S. 597-622.

Bator, Francis M.:

=Anatomy = The Anatomy of Market Failure, in: Quarterly Journal of Economics, Vol. 72 (1958), pp. 351-379. 
Bauer, Dietrich:

=Probleme= Aktuelle Probleme des kirchlichen Finanzausgleichs, in: Finanzarchiv, N. F., Band 36 (1977/78), S. 266-393.

Becker, Gary S.:

=Ansatz= Der ökonomische Ansatz zur Erklärung

menschlichen Verhaltens, tbersetzung von Monika und

viktor Vanberg, Tübingen 1982.

v. Beckerath, Erwin:

=Geschichte= Die neuere Geschichte der deutschen

Finanzwissenschaft (seit 1800), in: Handbuch der

Finanzwissenschaft, Band 1, herausgegeben von Wilhelm

Gerloff und Fritz Neumark, zweite völlig neubearbeitete

Auflage, Tübingen 1952, S. 416-468.

Bernholz, Peter:

=Verbände= Einige Bemerkungen zur Theorie des

Einflusses der Verbände auf die politische

Willensbildung in der Demokratie, in: Kyklos, Band 22

(1969), S. $276 \mathrm{ff}$., wieder abgedruckt in: Verbände, zusammengestellt und herausgegeben von Ernst-Bernd

Blümle und Walter Wittmann, Stuttgart, New York 1976, S. 6-13.

v. Beyme, Klaus:

=Interessengruppen= Interessengruppen in der

Demokratie, München 1965.

Biedenkopf, Kurt H.:

=Staat $=$ Der Staat und die gesellschaftlichen Gruppen,

in: Macht der Verbände - Ohnmacht der Demokratie?,

Beiträge zur Theorie und Politik der Verbände,

herausgegeben von Warnfried Dettling, München, Wien 1976 , S. 237-246.

Blümle, Ernst-Bernd, Wittmann, Walter (Herausgeber):

=Verbände= Verbände, Stuttgart, New York 1976 .

Bödecker, Wilhelm:

=Distributionsprobleme= Allokations - und

Distributionsprobleme bei Kollektivgütern, Meisenheim am Glan 1972 .

Boettcher, Erik:

=Genossenschaften= Genossenschaften I: Begriff und

Aufgaben, in: Handwörterbuch der Wirtschaftswissen-

schaften, Band 3, herausgegeben von Willi Albers u.a.,

Stuttgart u.a. 1981, S. 540-556. 
Böhme, Wolfgang:

=Akademien= Art.: "Akademien, kirchliche. I.

Evangelische", in: Evangelisches Staatslexikon,

begründet von Hermann Kunst und Siegfried Grundmann, herausgegeben von Hermann Kunst, Roman Herzog und

Wilhelm Schneemelcher, 2., vollständig neu bearbeitete und erweiterte Auflage, Stuttgart, Berlin 1975, Sp. 2325 .

Bohatec, Josef:

=Lehre $=$ Calvins Lehre von Staat und Kirche mit besonderer Berücksichtigung des Organismusgedankens, Breslau 1937.

Bonus, Holger:

=Aspekte= Ordnungspolitische Aspekte öffentlicher

Güter, in: Neuere Entwicklungen in den

Wirtschaftswissenschaften, herausgegeben von Ernst

Helmstädter, Schriften des Vereins für Socialpolitik,

N. F., Band 98, Berlin 1978, S. 51-73.

Bonus, Holger:

=Güter= Öfentliche Güter und der Öffentlichkeitsgrad von Gütern, in: Zeitschrift für die gesamte

Staatswissenschaft, Band 136 (1980), S. 50-81.

Brauns, Hans-Jochen:

=Staatsleistungen= Staatsleistungen an die Kirchen und

ihre Ablösung, Inhalt - Grenzen - Aktualität, Berlin

1970 .

Buchanan, James M.:

$=$ Theory= An Economic Theory of Clubs, in:Economica, New Series, Vol. XXXII (1965), pp. 1-14.

Buchanan, James M.:

$=$ Demand $=$ The Demand and Supply of Public Goods, Chicago 1968 .

Buchholz, Edwin H.:

=Interessen= Interessen, Gruppen, Interessengruppen,

Elemente einer wirtschaftssoziologischen

Organisationslehre - unter besonderer Berücksichtigung der deutschen Verbandsforschung, Dissertation Tübingen 1964 .

Bull, Hans Peter:

=Staatsaufgaben = Die Staatsaufgaben nach dem

Grundgesetz, Frankfurt am Main, 1973.

Bundesverfassungsgericht:

=BVerfGE5= Entscheidung des Bundesverfassungsgerichts vom 17.8.1956, Bundesverfassungsgerichtsentscheidungen 5, S. 85-393. 
Cahrs, Hans-Otto:

=Finanzstruktur= Finanzstruktur und Finanzpolitik der evangelischen Kirchen in Deutschland, Dissertation Göttingen 1950 .

v. Campenhausen, Axel, Freiherr:

Kircheneintritt - Kirchenaustritt - Kirchensteuer nach staatlichem und kirchlichem Recht, in: Die Offentliche Verwaltung, 23. Jg. (1970), S. 801-809.

v. Campenhausen, Axel, Freiherr:

=Staatskirchenrecht = Staatskirchenrecht, Ein Leitfaden durch die Rechtsbeziehungen zwischen staat und den Religionsgemeinschaften, München 1973.

v. Campenhausen, Axel, Freiherr: =Bedeutung = Die staatskirchenrechtliche Bedeutung der Kirchenmitgliedschaft, in: Handbuch des Staatskirchenrechts für die Bundesrepublik Deutschland, 1. Band, herausgegeben von Ernst Friesenhahn und Ulrich Scheuner in Verbindung mit Joseph Listl, Berlin 1974, S. 609614 .

v. Campenhausen, Axel, Freiherr:

Die Kirchengliedschaft nach dem Recht der evangelischen Kirche, in: Handbuch des Staatskirchenrechts für die Bundesrepublik Deutschland, 1. Band, herausgegeben von Ernst Friesenhahn und Ulrich Scheuner in Verbindung mit Joseph Listl, Berlin 1974, S. 635-644.

Cansier, Dieter:

=Marktversagen= Marktversagen und staatliche

Güterbereitstellung als Merkmale öffentlicher Güter, in: Public Finance, Vol. XXVII (1972), pp. 421-437.

Coase, Ronald:

=Problem= the Problem of Social Cost, in: Journal of Law and Economics, Vol. III, (1960), pp. 1-44.

Dettling, Warnfried (Herausgeber):

=Verbände $=$ Macht der Verbände - Ohnmacht der Demokratie, Beiträge zur Theorie und Politik der Verbände, München, Wien 1976.

Dürig, Günter:

=Kommentar= Kommentar zum Grundgesetz, Art. 1, in:

Maunz-Dürig, Band I, Art. 1-15, von Theodor Maunz, Günter Dürig u.a., München 1983, Stand: 22. Lieferung, Sept. 1983.

Egner, Erich:

=Finanzen= Art.: "Kirchliche Finanzen", in: Handwörterbuch der Sozialwissenschaften, Band 5, herausgegeben von Erwin v. Beckerath u.a., Stuttgart, Göttingen und Tübingen 1956 , S. 632-640. 
Eqner, Erich:

=Haushalt= Der Haushalt, Eine Darstellung seiner volkswirtschaftlichen Gestalt, 2., umgearbeitete Auflage, Berlin 1976 .

Endres, Alfred:

=Kosten= Ökonomische Grundprobleme der Messung sozialer Kosten, in: List Forum, Band 11 (1981/82), S. 251-269.

Engelhardt, Werner Wilhelm:

=Geschichte= Genossenschaften II: Geschichte, in: Handwörterbuch der Wirtschaftswissenschaften, Band 3, hrsg. von Willi Albers u.a., Stuttgart u.a. 1981, s. 557-571.

Eschenburg, Theodor:

=Herrschaft $=$ Herrschaft der Verbände?, Stuttgart 1955 .

Eßer, Hans Helmut:

=Rirche= Art.: "Kirche, I. B. Reformiert", in:

Evangelisches Staatslexikon, begründet von Hermann Kunst und Siegfried Grundmann, herausgegeben von Hermann Kunst, Roman Herzog und Wilhelm Schneemelcher, 2., vollständig neu bearbeitete und erweiterte Auflage, Stuttgart 1975, Sp. 1125-1133.

Fecher, Hans:

=Ausgaben= Ausgaben, öffentliche I: Ansätze zu ihrer Analyse, in: Handwörterbuch der Wirtschaftswissenschaft, Band 1, herausgegeben von Willi Albers u.a., Stuttgart u.a. 1977, s. 334-349.

Forster, Karl:

=Akademien= Art.: "Akademien, kirchliche, II. katholische", in: Evangelisches Staatslexikon, begründet von Hermann Kunst und Siegfried Grundmann, herausgegeben von Hermann Kunst, Roman Herzog und wilhelm Schneemelcher, 2., vollständig neu bearbeitete und erweiterte Auflage, Stuttgart, Berlin 1975, Sp. 25-27.

Freyer, Hans:

=Hegel= Art.: "Hegel, G.W.F.", in: Handwörterbuch der Sozialwissenschaften, Band 5, herausgegeben v. Erwin v. Beckerath u.a., Stuttgart, Tübingen und Göttingen 1956, S. 94-96.

Friedrich, Otto D.:

=Kirchenverfassung= Art.: "Kirchenverfassung, I. B. Evangelische Kirche", in: Evangelisches Kirchenlexikon, kirchlich-theologisches Handwörterbuch, Band 2, herausgegeben von Heinz Brunotte und Otto Weber, Göttingen 1958, Sp. 813-818. 
Friedrich, Otto D.:

=Kirchenverfassung II= Art.: "Kirchenverfassung, II. C. Evangelische Kirche", in: Evangelisches Kirchenlexikon, kirchlich-theologisches Handwörterbuch, Band 2, herausgegeben von Heinz Brunotte und Otto Weber, Göttingen 1958, Sp. 825-831.

Geiger, Willi:

=Schulsystem = Kirchen und staatliches Schulsystem, in: Handbuch des Staatskirchenrechts in der Bundesrepublik Deutschland, Band 2, herausgegeben von Ernst Friesenhahn und Ulrich Scheuner in Verbindung mit Joseph Listl, Berlin 1975, S. 483-502.

Gloege, Gerhard, Honecker, Martin: =Kirche= Art.: "Kirche, I. Evangelisch A. Lutherisch", in: Evangelisches Staatslexikon, begründet von Hermann Kunst und Siegfried Grundmann, herausgegeben von Hermann Kunst, Roman Herzog und Wilhelm Schneemelcher, 2., vollständig neu bearbeitete und erweiterte Auflage, Stuttgart, Berlin 1975, Sp. 1117-1122.

Gretschmann, Klaus :

=Staatswirtschaft= Steuerungsprobleme der staatswirt schaft, Berlin 1981 .

Grochla, Erwin:

=Betriebsverband= Betriebsverband und Verbandsbetrieb, Wesen, Formen und Organisation der Verbände aus betriebswirtschaftlicher Sicht, Berlin 1959.

Grochla, Erwin:

=Betriebsverbindungen= Betriebsverbindungen, Berlin 1969 .

Gröbner, Bruno F.: Subventionen= Subventionen, Eine Analyse, Göttingen 1983.

Grohs, Gerhard:

=Entwicklungspolitik= Art.: "Entwicklungspolitik", in: Evangelisches Staatslexikon, begründet von Hermann Kunst und Siegfried Grundmann, herausgegeben von Hermann Kunst, Roman Herzog und Wilhelm Schneemelcher, 2., vollständig neu bearbeitete und erweiterte Auflage, Stuttgart, Berlin 1975, Sp. 556-561.

Groser, Manfred:

=Ökonomie= Ökonomie parastaatlicher Institutionen, in: Jahrbuch für Neue Politische Okonomie, herausgegeben von Erik Boettcher, Philipp Herder-Dorneich und KarlErnst Schenk, 2. Band, Tübingen 1983, S. 239-253. 
Grundmann, Siegfried:

=Kirchenverfassung= Art.: "Kirchenverfassung I. C.

Lutherische Kirche", in: Evangelisches Staatslexikon, begründet von Hermann Kunst und Siegfried Grundmann, herausgegeben von Hermann Kunst, Roman Herzog und Wilhelm Scheemelcher, 2., vollständig neu bearbeitete und erweiterte Auflage, Stuttgart, Berlin 1975, Sp. 12571272 .

Grundmann, Siegfried, Honecker, Martin:

=Kirche= Art.: "Rirche, I. Evangelisch. A. Lutherisch 5. Die Rechtsnatur der Kirchen", in: Evangelisches Staatslexikon, begründet von Hermann Kunst und Siegfried Grundmann, herausgegeben von Hermann Kunst, Roman Herzog und Wilhelm Schneemelcher, 2., vollständig neu bearbeitete und erweiterte Auflage, Stuttgart, Berlin 1975, Sp. 1122-1125.

Häuser, Karl:

=Ansätze= Ưber Ansätze zur Theorie der Staatsausgaben, in: Beiträge zur Theorie der öffentlichen Ausgaben, herausgegeben von Herbert Timm und Heinz Haller, Schriften des Vereins für Socialpolitik, N. F., Band 47, Berlin 1967, S. 36-65.

Hanusch, Horst:

=Theorie= Theorie des öffentlichen Gutes, Allokative und distributive Aspekte, Göttingen 1972.

Harsanyi, John C.:

$=$ Modelle= Modelle der rationalen politischen Entscheidung versus funktionalistiche und konformistische Theorien, in: Ökonomische Theorie der Politik, herausgegeben von Werner $W$. Pommerehne und Bruno S. Frey, Berlin, Heidelberg und New York, 1975, S. 50-80.

v. Hase, Hans-Christoph:

=Diakonie= Art.: "Diakonie", in: Evangelisches

Staatslexikon, begründet von Hermann Kunst und siegfried Grundmann, herausgegeben von Hermann Kunst, Roman Herzog und Wilhelm Schneemelcher, 2., vollständig neu bearbeitete und erweiterte Auflage, Stuttgart, Berlin 1975, Sp. 467-470.

Herder-Dorneich, Philipp:

=Markt= Der Markt und seine Alternativen in der freien Gesellschft, Ökonomische Theorie des Pluralismus, Hannover, Wien und Freiburg 1968.

Herder-Dorneich, Philipp:

=Verbandsökonomik= Zur Verbandsökonomik, Ansätze zu einer ökonomischen Theorie der Verbände, Berlin 1973. 
v. Hermann, Friedrich-Bened. Wilhelm:

=Untersuchungen= Staatswirthschaftliche Untersuchungen, Zweite nach dem Tode des Verfassers erschienene, vermehrte und verbesserte Auflage, München 1870 .

Herrmann, walther:

=Finanzgewalten= Intermediäre Finanzgewalten, Eine Analyse deutscher hilfsfiskalischer Gebilde im ersten Jahrzehnt nach der Stabilisierung, Jena 1936.

Herzog, Roman:

=Verbandswesen = Das Verbandswesen im modernen Staat, in: Macht der Verbände - Ohnmacht der Demokratie?, Beiträge zur Theorie und Politik der Verbände, herausgegeben von Warnfried Dettling, München, Wien 1976, S. 6980 .

Hesse, Günter:

=Staatsaufgaben= Staatsaufgaben, Zur Theorie der

Legitimation und Identifikation staatlicher Aufgaben, Baden-Baden 1979 .

Hesse, Konrad:

=Kirche= Art.: "Kirche und Staat", in: Evangelisches Staatslexikon, begründet von Hermann kunst und Siegfried Grundmann, herausgegeben von Hermann Kunst, Roman Herzog und Wilhelm Schneemelcher, 2, vollständig neu bearbeitete und erweiterte Auflage, Stuttgart, Berlin 1975, Sp. 1140-1154.

Hirsch, Joachim:

=Funktionen= Die öffentlichen Funktionen der

Gewerkschaften, Eine Untersuchung zur Autonomie sozialer Verbände in der modernen Verfassungsordnung, Stuttgart 1966.

Hofmann, Werner:

=Gemeinde= Art.: "Gemeinde (in der Kirche)", in:

Evangelisches Staatslexikon, begründet von Hermann

Kunst und Siegfried Grundmann, herausgegeben von Hermann Kunst, Roman Herzog und Wilhelm Schneemelcher, 2., vollständig neu bearbeitete und erweiterte Auflage, Stuttgart, Berlin 1975, Sp. 794-797.

Holsten, Walter:

=Mission= Art.: "Äußere Mission", in: Evangelisches

Staatslexikon, begründet von Hermann Kunst und Siegfried Grundmann, herausgegeben von Hermann Kunst, Roman Herzog und Wilhelm Schneemelcher, 2., vollständig neu bearbeitete und erweiterte Auflage, Stuttgart, Berlin 1975, Sp. 21-23. 
Homann, Karl:

=Markt $=$ Markt, Staat und Freiheit im Liberalismus, in: Jahrbuch für Neue Politische Ökonomie, herausgegeben von Erik Boettcher, Philipp Herder-Dorneich und KarlErnst Schenk, 2. Band, Tübingen 1983, S. 325-350.

Huber, Wolfgang:

$=$ Offentlichkeit= Kirche und Offentlichkeit, Stuttgart 1973.

Imhof, Eckard Paul:

Was in "God's own country" Gottes ist .... in:

Monatsblätter für freiheitliche wirtschaftspolitik, 16 . $\mathrm{Jg} \cdot(1970)$, S. 207-210.

Isensee, Josef:

Staatsleistungen an die Kirchen und

Religionsgemeinschaften, in: Handbuch des Staatskirchenrechts für die Bundesrepublik Deutschland, Band 2, herausgegeben von Ernst Friesenhahn und Ulrich Scheuner in Verbindung mit Joseph Listl, Berlin 1975, S. 51-90.

Jurina, Josef:

=Religionsgemeinschaften= Die Religionsgemeinschaften mit privatrechtlichem Status, in: Handbuch des Staatskirchenrechts für die Bundesrepublik Deutschland, Band 1, herausgegeben von Ernst Friesenhahn und Ulrich Scheuner in Verbindung mit Joseph Listl, Berlin 1974, S. 587-605.

Kaiser, Hans:

$=$ Probleme $=$ Die finanzwirtschaftlichen Probleme der Kirchensteuer unter besonderer Berücksichtigung ihrer Entwicklung während der letzten 25 Jahre in Deutschland, Dissertation Göttingen 1952.

Kaiser, Joseph H.:

=Repräsentation= Die Repräsentation organisierter Interessen, Berlin 1956.

Kirberger, Wolfgang:

=Staatsentlastung = Staatsentlastung durch private Verbände, Die finanzpolitische Bedeutung der Mitwirkung privater Verbände bei der Erfüllung öffentlicher Aufgaben, Baden-Baden 1978.

Kirsch, Guy:

=Politik= Okonomische Theorie der Politik, Tübingen, Düsseldorf 1974 .

Kirsch, Guy:

=Verbände $=$ Verbände als Produzenten von Kollektivgütern, in: Verbände, zusammengestellt und herausgegeben von Ernst-Bernd Blümle und walter Wittmann, Stuttgart, New York 1976, S. 22-36. 
Klein, Hans H.:

Zum Begriff der öffentlichen Aufgabe, in: Die öffentliche Verwaltung, 18. Jg. (1965), S. 755-759.

Koch, Woldemar:

=Finanzpolitik= Finanzpolitik und Einkommenspolitik, Beitrag zum Problem der Kriegsfinanzen, in: Finanzarchiv, N. F., Band 8 (1941), S. 1-28.

Krause-Junk, Gerold:

$=A b r i \beta=A b r i \beta$ der Theorie von den öffentlichen Gütern, in: Handbuch der Finanzwissenschaft, Bd. I, herausgegeben von Fritz Neumark unter Mitwirkung von Norbert Andel und Heinz Haller, Dritte, gänzlich neubearbeitete Auflage, Tübingen 1977, S. 687-711.

Krautzberger, Michael:

=Erfüllung= Die Erfüllung öffentlicher Aufgaben durch Private, Zum Begriff des staatlichen Bereichs, Berlin 1971.

Küng, Hans :

=Kirche= Die Kirche, Zweite Auflage, Freiburg, Basel und Wien 1968.

Kupsch, Peter Uwe, Marr, Rainer:

=Personalwirtschaft= Personalwirtschaft, in:

Industriebetriebslehre, Entscheidungen im Industriebetrieb, herausgegeben von Edmund Heinen, Siebte, vollständig überarbeitete und erweiterte Auflage, Wiesbaden 1983, S. 627-767.

Lederer, Josef :

=Kirchenvermögen= Art.: "Kirchenvermögen", in: Lexikon für Theologie und Kirche, Band 6, begründet von Michael Buchberger, unter dem Protektorat von Michael Buchberger und Hermann Schäufele, herausgegeben von Josef Höfer und Karl Rahner, Zweite, völlig neu bearbeitete Auflage, Freiburg 1961, Sp. 279-283.

Lepelmeier, Dirk:

=Parafiskalität= Soziale Sicherung und Parafiskalität, Zur Einkommensumverteilungsproblematik im Bereich der Sozialversicherung, Frankfurt, Bern und Cirencester/U.R. 1979.

Leßmann, Herbert:

=Aufgaben= Die öffentlichen Aufgaben und Funktionen privatrechtlicher Wirtschaftsverbände, Sozialer Befund, rechtliche Einordnung und Kontrolle, Köln u.a. 1976.

Liedtke, Cornelius:

$=$ Theorie $=$ Theorie der öffentlichen Güter und optimale

Struktur einer Föderation, Berlin 1972. 
Lindahl, Erik:

=Gerechtigkeit= Die Gerechtigkeit der Besteuerung, Eine Analyse der Steuerprinzipien auf Grundlage der Grenznutzentheorie, Lund 1919.

Link, Christoph:

=Religionsunterricht= Religionsunterricht, in: Handbuch des Staatskirchenrechts für die Bundesrepublik Deutschland, Band 2, herausgegeben von Ernst Friesenhahn und Ulrich Scheuner in Verbindung mit Joseph Listl, Berlin 1975, S. 503-546.

Listl, Joseph:

=Kirchenbeitrag= Art.: "Kirchenbeitrag", in: Katholisches Soziallexikon, herausgegeben von Alfred Klose, Wolfgang Mantl und Valentin Zsifkovitis, 2, gänzlich überarbeitete und erweiterte Auflage, Innsbruck u.a. 1980 , Sp. 1383-1386.

v. Loesch, Achim:

=Unternehmung= Die gemeinwirtschaftliche Unternehmung, Vom antikapitalistischen Ordnungsprinzip zum marktwirtschaftlichen Regulativ, Köln 1977.

Lotz, Walther:

=Finanzwissenschaft= Finanzwissenschaft, Zweite umgearbeitete Auflage, Tübingen 1931.

Mann, Fritz Karl:

=Finanzgewalten $=$ Die intermediären Finanzgewalten und ihr Einfluß auf Deutschlands finanzielle Belastung, in: Jahrbücher für Nationalökonomie und Statistik, III. Folge, 74. Band (129. Band), 1928 II, S. 219-237.

Mann, Fritz Karl:

Deutsche Finanzwirtschaft, Jena 1929.

Mann, Fritz Karl:

=Staatswirtschaft $=$ Die Staatswirtschaft unserer zeit, Eine Einführung, Jena 1930.

Mann, Fritz Karl:

$=$ Ideale $=$ Steuerpolitische Ideale, Jena 1937, Nachdruck Stuttgart 1978 .

Mann, Fritz Karl:

Die intermediären Finanzgewalten und der pluralistische Staat, in: Soziale Verantwortung, Festschrift für Goetz Briefs zum 80. Geburtstag, herausgegeben von Josef Broermann und Philipp Herder-Dorneich, Berlin 1968, S. 481-492. 
Mantl, Wolfgang:

=Rirche= Art.: "Kirche und Staat", in: Katholisches Soziallexikon, herausgegeben von Alfred Klose, Wolfgang Mantl und Valentin Zsifkovitis, 2., gänzlich überarbeitete und erweiterte Auflage, Innsbruck u.a. 1980, Sp. 1346-1383.

Marré, Heiner:

$=$ Kirchenfinanzierung $=$ Die Kirchenfinanzierung in Kirche und Staat der Gegenwart. Die Kirchensteuer im internationalen Umfeld kirchlicher Abgabensysteme und im heutigen Sozial- und Kulturstaat Bundesrepublik Deutschland, Essen 1982 .

Maunz, Theodor:

=Kommentar $=$ Kommentar zum Grundgesetz, Art. 7, in: Maunz-Dürig, Band I, Art. 1-15, von Theodor Maunz, Günter Dürig u.a., München 1983, Stand: 22. Lieferung, Sept. 1983 .

Maunz, Theodor:

=Kommentar= Kommentar zum Grundgesetz, Art. 87, in: Maunz-Dürig, Band III., Art. 83-146, von Theodor Maunz, Günter Dürig u.a., München 1983, Stand: 22. Lieferung, Sept. 1983.

Maunz, Theodor:

=Aufgaben= Der öffentliche Charakter der kirchlichen Aufgaben, in: Festschrift für Ernst Forsthoff zum 70 . Geburtstag, herausgegeben von Roman Schnur, München 1972, S. 229-240.

Maunz, Theodor:

=Schulträger = Kirchen als Schulträger, in: Handbuch des Staatskirchenrechts für die Bundesrepublik Deutschland, Band 2, herausgegeben von Ernst Friesenhahn und Ulrich Scheuner in Verbindung mit Joseph Listl, Berlin 1975, S. 547-586.

Maurer, wilhelm:

=Kirchengliedschaft= Art.: "Kirchengliedschaft I.

Evangelisch, A. Theologisch", in: Evangelisches Staatslexikon, begründet von Hermann Kunst und Siegfried Grundmann, herausgegeben von Hermann Kunst, Roman Herzog, Wilhelm Schneemelcher, 2., vollständig neu bearbeitete und erweiterte Auflage, Stuttgart, Berlin 1975, Sp. 1167-1169.

Meinhold, Helmut:

=Parafisci= Fiskalpolitik durch sozialpolitische Parafisci, Tübingen 1976 .

Meister, Johannes:

=Auftrag = Der Auftrag der Kirchen zu sozial-caritativem Handeln, in: Zeitschrift für evangelisches Kirchenrecht, Band 18 (1973), S. 354-376. 
Menger, Carl:

=Grundsätze= Grundsätze der Volkswirtschaftslehre, 2 . Auflage, Wien, Leipzig 1923.

Mikat, Paul:

=ordnungsproblematik= Die religionsrechtliche

Ordnungsproblematik der Bundesrepublik Deutschland, in: Handbuch des Staatskirchenrechts für die Bundesrepublik Deutschland, Band 1, herausgegeben von Ernst Friesenhahn und Ulrich Scheuner in Verbindung mit Joseph

Listl, Berlin 1974, S. 107-141.

Mikat, Paul:

Staat = Das Verhaltnis von Kirche und Staat nach der Lehre der katholischen Kirche, in: Handbuch des Staatskirchenrechts für die Bundesrepublik Deutschland, Band 1, herausgegeben von Ernst Friesenhahn und Ulrich Scheuner in Verbindung mit Joseph Listl, Berlin 1974, S. 143-187.

Mörsdorf, Klaus : =Kirchenverfassung= Art.: "Kirchenverfassung, I. Ratholische Kirche", in: Lexikon für Theologie und Kirche, Band 6 , begründet von Michael Buchberger, unter dem Protektorat von Michael Buchberger und Hermann Schäufele, herausgegeben von Josef Höfer und Karl Rahner, zweite, völlig neu bearbeitete Auflage, Freiburg 1961, Sp. 274-277.

Mörsdorf, Klaus :

=Recht $=$ Die Kirchengliedschaft nach dem Recht der katholischen Kirche, in: Handbuch des Staatskirchenrechts für die Bundesrepublik Deutschland, Band 1, herausgegeben von Ernst Friesenhahn und Klaus Scheuner in Verbindung mit Joseph Listl, Berlin 1974, S. 615-634.

Mörsdorf, Klaus :

=Kirchengliedschaft= Art.: "Kirchengliedschaft. II. Katholisch", in: Evangelisches Staatslexikon, begründet von Hermann Kunst und Siegfried Grundmann, herausgegeben von Hermann Kunst, Roman Herzog und wilhelm Schneemelcher, 2., vollständig neu bearbeitete und erweiterte Auflage, Stuttgart, Berlin 1975, Sp. 1175-1176.

Mörsdorf, Klaus:

=Römisch-Katholisch= Art.: "Rirche. II. Römisch-katholisch", in: Evangelisches Staatslexikon, begründet von Hermann Kunst und Siegfried Grundmann, herausgegeben von Hermann Kunst, Roman Herzog und wilhelm Schneemelcher, 2., vollständig neu bearbeitete und erweiterte Auflage, Stuttgart, Berlin 1975, Sp. 1133-1140. 
Miiller, Eberhard:

=Akademien= Art.: "Akademien, Evangelische", in:

Evangelisches Soziallexikon, im Auftrag des Deutschen

Evangelischen Kirchentages, herausgegeben von Friedrich

Karrenberg, 5. Auflage, Stuttgart, Berlin 1965, Sp. 1517 .

Musqrave, Richard A.:

$=$ Theory $=$ The Theory of Public Finance, A Study in Pu-

blic Economy, New York, Toronto and London 1959.

Musqrave, Richard A.:

Goods = Provision for Social Goods, in: Public Economics, An Analysis of Public Production and Consumption and their Relalations to the Private Sector, Proceedings of a Conference held by the International Economic Association, Edited by J. Margolis and H. Guitton, London u.a. 1969, pp. 124-144.

Musqrave, Richard A.:

=Finanztheorie= Finanztheorie, ins Deutsche übertragen von Lore Kullmer unter Mitarbeit von Hans Fecher, 2., ergänzte und verbesserte Auflage, Tübingen 1969.

Musqrave, Richard A.:

=Provision= Provision for Social Goods in the Market System, in: Public Finance, Vol. XXVI (1971), S. 304320 .

Musqrave, Richard A. Musgrave, Peggy B. , Kullmer, Lore: $=$ Theorie $=$ Die öffentlichen Finanzen in Theorie und Praxis, 1. Band, Tübingen 1975.

Muthesius, Volkmar:

"Was Gottes ist ..." , in: Monatsblätter für freiheitliche wirtschaftspolitik, 16. Jg. (1970), S. 24-28.

Nachtkamp, Hans Heinrich:

=Idealtypen= Idealtypen von Fiskalsystemen, in:

Finanzsysteme: Ideal - und Realtypen - Gesundheitswesen und Hochschulbildung, herausgegeben von Karl Häuser, Schriften des Vereins für Socialpolitik, N. F., Band 135, Berlin 1983, S. 11-55.

Niggemann, Jürgen:

=Verbändelehre $=$ Verbändelehre bei Goetz Briefs, Ein Beitrag $z u$ einer allgemeinen Theorie der Verbände, Berlin 1971.

v. Nell-Breuning, Oswald: =Caritas $=$ Caritas, in: Zur Sozialen Frage, herausgegeben von Hermann Sacher und Oswald von Nell-Breuning, Wörterbuch der Politik, Heft III, zweite, neubearbeitete Auflage, Freiburg 1958, Sp. 45-74. 
v. Nell-Breuning, Oswald:

Christliche Soziallehre, in: Freiheit und Ordnung, Soziale Fragen der Gegenwart, herausgegeben vom Heinrich Pesch-Haus, Heft 38, Mannheim 1964.

v. Nell Breuning, Oswald:

Katholische Soziallehre, in: Katholische und evangelische Soziallehre, Ein Vergleich, herausgegeben von Heinz Budde, Recklinghausen 1967, S. 7-33.

Nöll von der Nahmer, Robert:

=Finanzwissenschaft $=$ Lehrbuch der Finanzwissenschaft, Band 1, Allgemeine Finanzwissenschaft, Köln und Opladen 1964.

Obermayer, Klaus:

=Schule= Art.: "Schule und Kirche", in: Evangelisches

Staatslexikon, begründet von Hermann Kunst und Siegfried Grundmann, herausgegeben von Hermann Kunst, Roman Herzog, und Wilhelm Schneemelcher, 2., vollständig neu bearbeitete und erweiterte Auflage, Stuttgart, Berlin 1975, Sp. 2254-2259.

Olson, Mancur, Jr.:

=Logik= Die Logik des kollektiven Handelns, Kollektivgüter und die Theorie der Gruppen, Tübingen 1968.

Peffekoven, Rolf:

$=$ Grundlagen $=$ Finanzausgleich I: Wirtschaftstheoretische Grundlagen, in: Handwörterbuch der Wirtschaftswissenschaft, Band 2, herausgegeben von Willi Albers u.a., Stuttgart u.a. 1980, S. 608-636.

Peters, Hans:

=Aufgaben= Öffentliche und staatliche Aufgaben, in:

Festschrift für Hans Carl Nipperdey zum 70. Geburtstag, 21. Januar 1965, herausgegeben von Rolf Dietz und Heinz Hübner, Band II, München, Berlin 1965, S. 877-895.

Pieroth, Bodo:

=Religionsunterricht= Art.: "Religionsuntericht", in:

Evangelisches Staatslexikon, begründet von Hermann

Kunst und Siegfried Grundmann, herausgegeben von Hermann Kunst, Roman Herzog und Wilhelm Schneemelcher, 2., vollständig neu bearbeitete und erweiterte Auflage,

Stuttgart, Berlin 1975, Sp. 2191-2194.

Pirson, Dietrich:

=ర̆ffentlichkeitsanspruch= Art.:

"Öffentlichkeitsanspruch", in: Evangelisches Staatslexikon, begründet von Hermann Kunst und Siegfried Grundmann, herausgegeben von Hermann Kunst, Roman Herzog und Wilhelm Schneemelcher, 2., vollständig neu bearbeitete und erweiterte Auflage, Stuttgart, Berlin 1975, Sp. 1658-1663. 
Pirson, Dietrich:

=Kirchenverfassung= Art.: "Kirchenverfassung I. B. Allgemeine Grundsätze", in: Evangelisches Staatslexikon, begründet von Hermann Kunst und Siegfried Grundmann, herausgegeben von Hermann Kunst, Roman Herzog und Wilhelm Schneemelcher, 2, vollständig neu bearbeitete und erweiterte Auflage, Stuttgart, Berlin 1975, Sp. 1253-1257.

Pohmer, Dieter:

=Wissenschaft = Wissenschaft und Wirtschaftskraft, in: 30 Jahre Hochschulverband, Reden und Referate zum $30 j a ̈ h r i g e n ~ B e s t e h e n$ auf dem Hochschulverbandstag vom 4 . bis 6. März 1980 in Hannover, Schriftenreihe Forum des Hochschulverbandes, Heft 22, Bonn 1980, S. 15-28.

Pohmer, Dieter:

=Politik= Finanzwissenschaft III: Politik, in:

Handwörterbuch der Wirtschaftswissenschaft, Band 3, herausgegeben von willi Albers u.a., Stuttgart u.a. 1981 , S. 261-286.

Raab, Heribert:

=Kirche= Art.: "Kirche und Staat", in: Lexikon für Theologie und Kirche, Band 6, begründet von Michael Buchberger, unter dem Protektorat von Michael Buchberger und Hermann Schäufele herausgegeben von Josef Höfer und Karl Rahner, zweite völlig neu bearbeitete Auflage, Freiburg 1961, Sp. 288-295.

Ratzinger, Josef:

=Kirche= Art.: "Kirche II. Die Lehre des kirchlichen Lehramtes", in: Lexikon für Theologie und Kirche, Band 6 , begründet von Michael Buchberger, unter dem Protektorat von Michael Buchberger und Hermann Schäufele herausgegeben von Josef Höfer und Karl Rahner, zweite, völlig neu bearbeitete Auflage, Freiburg 1961, Sp. 172183 .

Rauscher, Anton:

Soziallehre, kirchliche, in: Handwörterbuch der Wirtschaftswissenschaft, Band 7, herausgegeben von willi Albers u.a., Stuttgart u.a. 1977, S. 41-51.

Reicke, Siegfried:

=Kirchenverfassung= Art.: "Kirchenverfassung II. B. Römisch-katholische Kirche", in: Evangelisches Kirchenlexikon, kirchlich-theologisches Handwörterbuch, Band 2, herausgegeben von Heinz Brunotte und Otto Weber, Göttingen 1958, Sp. 821-824. 
Rinken, Alfred:

$=$ Werke $=$ Die karitativen Werke und Einrichtungen im Bereich der katholischen Kirche, in: Handbuch des

Staatskirchenrechts für die Bundesrepublik Deutschland, Band 2, herausgegeben von Ernst Friesenhahn und Ulrich

Scheuner in Verbindung mit Joseph Listl, Berlin 1975,

S. 383-400.

Ritschl, Hans:

=Theorie= Theorie der Staatswirtschaft und Besteuerung, Reine Theorie der Staatswirtschaft und allgemeine Steuerlehre, Bonn, Leipzig 1925.

Rupp, Hans Heinrich:

=Funktionen= Die "öffentlichen" Funktionen der Verbände und die demokratisch-repräsentative Verfassungsordnung, in: Macht und okonomisches Gesetz, Zweiter Halbband, herausgegeben von Hans $\mathrm{K}$. Schneider und Christian Watrin, Schriften des Vereins für Socialpolitik, N.F., Band 74/II, Berlin 1973, S. 1251-1268.

Samuelson, Paul A.:

$=$ Theory $=$ The Pure Theory of Public Expenditure, in: Review of Economics and Statistics, Vol. XXXVI (1954), pp. 387-389.

Samuelson, Paul A.:

=Exposition= Diagrammatic Exposition of a Theory of Public Expenditure, in: The Review of Economics and Statistics, Vol. XXXVII (1955), pp. 350-356.

Samuelson, Paul A.:

=Aspects $=$ Aspects of Public Expenditure Theories, in:

Review of Economics and Statistics, Vol. XI (1958), pp. 332-338.

Samuelson, Paul A.:

=Expenditure $=$ Pure Theory of Public Expenditure, in: Public Economics, An Analysis of Public Production and Consumption and their Relations to the Private Sector, Proceedings of a Conference Held by the International Economic Association, Edited by J. Margolis and $\mathrm{H}$. Guitton, London u.a. 1969, pp. 98-123.

Sax, Emil:

=Grundlegung= Grundlegung der theoretischen Staatswirtschaft, Wien 1887 .

Schäffle, Albert E.Fr.: =0ekonomie= Das gesellschaftliche System der menschlichen Wirthschaft, Ein Lehr- und Handbuch der ganzen politischen Oekonomie einschließlich der Volkswirtschaftspolitik und Staatswirthschaft, 3 ., durchaus neu bearbeitete Auflage in zwei Bänden, zweiter Band, Tübingen 1873 . 
Schäffle, Albert E.Fr.:

$=$ Bau $=$ Bau und Leben des socialen Körpers, Dritter Band, Neue, zum Theil ungearbeitete Ausgabe, Tübingen 1881.

Scheuner, Ulrich:

$=$ Verbände $=$ Der staat und die Verbände, in: Der staat und die Verbände, Gespräch veranstaltet vom Bundesverband der Deutschen Industrie in Köln am 27. Mărz 1957, herausgegeben von Wilhelm Beutler, Gustav Stein und Hellmuth Wagner, Heidelberg 1957, S. 10-18.

Scheuner, Ulrich:

Staat= Art.: "Staat" in: Handwörterbuch der

Sozialwissenschaften, Band 12, herausgegeben von Erwin v. Beckerath u.a., Stuttgart, Tübingen und Göttingen 1965, S. 653-664.

Scheuner, Ulrich:

=Tätigkeit= Die karitative Tätigkeit der Kirchen im heutigen Sozialstaat, Verfassungsrechtliche und Staatskirchenrechtliche Fragen, in: Essener Gespräche zum Thema Kirche und Staat, herausgegebenvon Joseph Krautscheidt und Heiner Marrl, Aschaffendorf, Münster 1974 , S. 43-71.

Schlaich, Klaus:

=Neutralität= Neutralität als verfassungsrechtliches

Prinzip, vornehmlich im Kulturverfassungs- und

Staatskirchenrecht, Tübingen 1972.

Schlaich, Klaus:

= Offentlichkeitsauftag= Der Offentlichkeitsauftrag der Kirchen, in: Handbuch des Staatskirchenrechts für die Bundesrepublik Deutschland, Band 2, herausgegeben von Ernst Friesenhahn und Ulrich Scheuner in Verbindung mit Joseph Listl, Berlin 1975, Sp. 231-272.

Schlieper, Ulrich:

=Effekte= Externe Effekte, in: Handwörterbuch der Wirtschaftswissenschaft, Band 2, herausgegeben von Willi

Albers u.a., Stuttgart u.a. 1980, S. 524-530.

Schmidt, Kurt:

=Geschichte $=$ Zur Geschichte der Lehre von den

Kollektivbedürfnissen, in: Systeme und Methoden in den

Sozialwissenschaften, Erwin v. Beckerath zum 75. Ge-

burtstag, herausgegeben von Norbert Kloten u.a., Tübingen 1964 , S. 335-362.

Schmidt, Kurt:

=Entwicklungstendenzen= Entwicklungstendenzen im

demokratischen Gruppenstaat, in: Finanzarchiv, N.F.,

Band 25 (1965), S. 213-241. 
Schmidt, Kurt:

=Problematik= Zur ordnungspolitischen Problematik

wachsender Staatsausgaben, in: Beiträge zur Theorie der öffentlichen Ausgaben, herausgegeben von Herbert Timm und Heinz Haller, Schriften des Vereins für Socialpolitik, N.F., Band 47, Berlin 1967, S. 126-173.

Schmidt, Kurt:

=Staatstätigkeit= Kollektivbedürfnisse und Staatstätigkeit, in: Theorie und Praxis des finanzpolitischen Interventionismus, Fritz Neumark zum 70. Geburtstag, hrsg. von Heinz Haller, Lore Kullmer, Carl S. Shoup, Herbert Timm, Tübingen 1970, S. 4-27.

Schmidt, Rurt Dietrich:

=Kirche= Art.: "Kirche, III. Reformatorischer

Kirchenbegriff und dessen Fortbildung", in: Evangelisches Kirchenlexikon, Kirchlich-theologisches Handwörterbuch, Band 2, herausgegeben von Heinz Brunotte und Otto Weber, Göttingen 1958, Sp. 618-626.

Schmölders, Günter:

=Verbände $=$ Das Selbstbild der Verbände, Empirische Erhebung über die Verhaltensweisen der Verbände in ihrer Bedeutung für die wirtschaftspolitische Willensbildung in der Bundesrepublik Deutschland, Berlin 1965.

Schmoltzi, Ulrich:

=Finanzierung= Zur Finanzierung privater Organisationen ohne Erwerbscharakter. Monolithisches staatliches Güterangebot versus vielfältiges Angebot, in: Beiträge zur gesamtwirtschaftlichen Allokation, Allokationsprobleme im intermediären Bereich zwischen öffentlichem und privatem Wirtschaftssektor, herausgegeben von Eberhard Wille, Frankfurt am Main, Bern und New York 1983, S. 65-87.

Scholz, Rupert:

=Kommentar= Kommentar zum Grundgesetz, Art. 9, in: Maunz-Dürig, Band I, Art. 1-15, herausgegeben von Theodor Maunz, Günter Dürig u.a., München 1983, Stand 22. Lieferung, Sept. 1983.

Seiler, Rudolf:

=Seelsorge $=$ Seelsorge in Bundeswehr und Bundesgrenzschutz, in: Handbuch des Staatskirchenrechts für die Bundesrepublik Deutschland, Band 2, herausgegeben von Ernst Friesenhahn und Ulrich Scheuner in Verbindung mit Joseph Listl, Berlin 1975, S. 685-700. 
Simon, Helmut:

=Staat $=$ Das Verhältnis von Kirche und Staat nach der

Lehre der evangelischen Kirche, in: Handbuch des

Staatskirchenrechts für die Bundesrepublik Deutschland, Band 1, herausgegeben von Ernst Friesenhahn und Ulrich Scheuner in Verbindung mit Joseph Listl, Berlin 1974, S. 189-212.

Skydsqaard, Kirsten E.:

=Kirche= Art.: "Kirche IV. Außerkatholisches Verständnis", in: Lexikon für Theologie und Kirche, Band 6, begründet von Michael Buchberger, unter dem Protektorat von Michael Buchberger und Hermann Schäufele herausgegeben von Josef Höfer und Karl Rahner, zweite, völlig neu bearbeitete Auflage, Freiburg 1961, Sp. 183-186.

Smekal, Christian:

=Finanzwirtschaft= Die Finanzwirtschaft intermediärer Gruppen, Innsbruck 1969.

Smekal, Christian:

=Finanzen= Finanzen intermediärer Gewalten (Parafisci), in: Handwörterbuch der Wirtschaftswissenschaft, Band 3, herausgegeben von Willi Albers u.a., Stuttgart u.a. 1981 , S. $1-17$.

Sombart, Werner:

Grundformen des menschlichen Zusammenlebens, in: Handwörterbuch der Soziologie, herausgegeben von Alfred Vierkandt, unveränderter Neudruck, Stuttgart 1959, S. 221-239.

Steck, Karl Gerhard:

=Kirche= Art.: "Kirche, V. Der Kirchenbegriff, B. der römisch-katholischen Kirche", in: Evangelisches Kirchenlexikon, kirchlich-theologisches Handwörterbuch, Band 2, herausgegeben von Heinz Brunotte und Otto Weber, Göttingen 1958, Sp. 629-632.

Stefani, Giorgio:

=Parafiskalität= Voraussetzungen und Entwicklungen der Parafiskalität im Werk Emanuele Morsellis, Ubersetzung aus dem Italienischen von Antonio Montaner, in: Finanzarchiv, N.F., Band 15 (1954/55), S. 286-298.

Stolleis, Michael:

=Sozialstaat= Sozialstaat und karitative Tätigkeiten der Kirchen, in: Zeitschrift für evangelisches Kirchenrecht, Band 18 (1973), S. 376-404.

Thiemeyer, Theo:

=Gemeinwirtschaft= Gemeinwirtschaft, in: Handwörterbuch der Wirtschaftswissenschaft, Band 3, herausgegeben von Willi Albers u.a., Stuttgart u.a. 1981, S. 525-540. 
Thul, Ewald:

=Kirchenverfassung= Art.: "Kirchenverfassung, II. Römisch-katholische Kirche", in: Evangelisches Staatslexikon, begründet von Hermann Kunst und Siegfried Grundmann, herausgegeben von Hermann Kunst, Roman Herzog und Wilhelm Schneemelcher, 2., vollständig neu bearbeitete und erweiterte Auflage, Stuttgart, Berlin 1975, Sp. 1281-1293.

Tiepelmann, Klaus:

=Parafiski= Parafiski, in: Das Wirtschaftsstudium, 1975 , S. 295-300.

v. Tiling, Peter:

$=$ Werke $=$ Die karitativen Werke und Einrichtungen im Bereich der evangelischen Kirche, in: Handbuch des Staatskirchenrechts für die Bundesrepublik Deutschland, Band 2, herausgegeben von Ernst Friesenhahn und Ulrich Scheuner in Verbindung mit Joseph Listl, Berlin 1975, S. 401-416.

Timm, Herbert:

=Allokationspolitik= Finanzwirtschaftliche

Allokationspolitik, in: Handbuch der Finanzwissenschaft, Band III, herausgegeben von Fritz Neumark unter Mitwirkung von Norbert Andel und Heinz Haller, Dritte, gänzlich neubearbeitete Auflage, Tübingen 1981, S. 135255 .

De Viti De Marco, Antonio:

$=$ Grundlehren $=$ Grundlehren der Finanzwirtschaft, Tübingen 1932 .

Völkl, Richard:

=Diakonie $=$ Caritative Diakonie als Auftrag der Kirche, in: Essener Gespräche zum Thema Staat und Kirche, herausgegeben von Joseph Krautscheidt und Heiner Marre, Aschaffendorf, Mïnster 1974, S. 9-24.

Wagner, Adolph:

=Grundlegung= Grundlegung des politischen Oekonomie, Dritte wesentlich um-, theilweise ganz neu bearbeitete und stark erweiterte Auflage, Erster Theil, Zweiter Halbband, Leipzig 1893.

Weber, Werner:

=Juristische Personen= Juristische Person (II), Juristische Personen des öffentlichen Rechts, in: Handwörterbuch der Sozialwissenschaften, Band 5, herausgegeben von Erwin v. Beckerath u.a., Stuttgart, Göttingen und Tübingen 1956, S. 449-452. 
Weber, Werner:

=Fakultäten= Theologische Fakultäten, staatliche Pädagogische und Philosophisch-Theologische Hochschulen, in: Handbuch des Staatskirchenrechts für die Bundesrepublik Deutschland, Band 2, herausgegeben von Ernst Friesenhahn und Ulrich Scheuner in Verbindung mit Joseph Listl, Berlin 1975, S. 569-596.

Weides, Peter:

=Akademien= Erwachsenenbildung und Akademien, in: Handbuch des Staatskirchenrechts für die Bundesrepublik Deutschland, Band 2, herausgegeben von Ernst Friesenhahn und Ulrich Scheuner in Verbindung mit Joseph Listl, Berlin 1975, S. 623-681.

Weippert, Georg:

Art.: "Gruppe", in: Handwörterbuch der Sozialwissenschaften, Band 4, herausgegeben von Erwin v. Beckerath u.a., Stuttgart, Tübingen und Göttingen 1965, S. 718725 .

Weisbrod, Burton A.:

=Theory $=$ Toward a Theory of the Voluntary Non-Profit Sector in a Three-Sector Economy, in: Altruism, Morality, and Economic Theory, Edited by Edmund S. Phelps, New York 1975, pp. 171-195.

Wendland, Heinz Dietrich:

=Eschatologie= Art.: "Eschatologie", in: Evangelisches Soziallexikon, im Auftrag des Deutschen Evangelischen Kirchentages herausgegeben von Friedrich Karrenberg, 5. Auflage, Stuttgart, Berlin 1965, Sp. 358-362.

Wiesebach, Horst P.:

=Entwicklungshilfe= Entwicklungspolitik II:

Entwicklungshilfe, in: Handwörterbuch der Wirtschaftswissenschaft, Band 2, herausgegeben von Willi Albers u.a., Stuttgart, u.a. 1980, S. 407-421.

v. Wieser, Friedrich:

=Werth= Der natürliche Werth, Wien 1889 .

Wilken, Waldemar:

=Geld= Unser Geld und die Kirche, München 1964.

Wille, Eberhard:

=Allokation= Gesamtwirtschaftliche Allokation zwischen "Markt- und Staatsversagen" - ein ordnungspolitischer Uberblick, in: Beiträge zur gesamtwirtschaftlichen Allokation, Allokationsprobleme im intermediären Bereich zwischen öffentlichem und privatem Wirtschaftssektor, herausgegeben von Eberhard Wille, Frankfurt am Main, Bern und New York 1983, S. 1-28. 
Wittmann, Walter:

=Kriterien= Kriterien für die Aufgabenverteilung zwi-

schen öffentlichen Körperschaften, in: Sozialwissen-

schaften im Dienste der Wirtschaftspolitik, Wilhelm

Bickel zum 70. Geburtstag, herausgegeben von Heinz Hal-

ler, Gerold Hauser und Heidi Schelbert-Syfrig, Tübingen

1973 , S. 157-173.

Wittmann, walter:

Empirische Theorien von Kollektiven, in:

Wirtschaftswissenschaftliches Studium, 5. Jg. (1976),

S. 67-71.

Wössner, Jacobus:

=Bedeutung $=$ Die ordnungspolitische Bedeutung des

Verbandswesens (Die Verbands-Gesellschaft), Tübingen 1961.

Wolf, Erik:

=Ordnung = Ordnung der Kirche, Lehr- und Handbuch des Kirchenrechts auf ökumenischer Basis, Frankfurt 1961.

Wolf, Erik:

=Kirchenverfassung der nicht röm. kath. Kirchen= Art.:

"Kirchenverfassung II. Kirchenverfassung der nicht röm.-kath. Kirchen, in: Lexikon für Theologie und Kirche, Band 6 , begründet von Michael Buchberger, unter dem Protektorat von Michael Buchberger und Hermann Schäufele herausgegeben von Josef Höfer und Karl Rahner, zweite, völlig neu bearbeitete Auflage, Freiburg 1961, Sp. 277-279.

Wolf, Erik:

=Kirchenverfassung= Art.: "Kirchenverfassung, I. D. Reformierte Kirche", in: Evangelisches Staatslexikon, begründet von Hermann Kunst und Siegfried Grundmann, herausgegeben von Hermann Kunst, Roman Herzog und wilhelm Schneemelcher, 2., vollständig neu bearbeitete und erweiterte Auflage, Stuttgart, Berlin 1975, Sp. 12721281 .

Wolf, Ernst:

=Kirche= Art.: "Kirche", in: Handwörterbuch der

Sozialwissenschaften, Band 5, herausgegeben von Erwin von Beckerath u.a., Stuttgart, Göttingen und Tübingen 1956 , S. 623-628.

Wolf, Ernst:

=Königsherrschaft= Art.: "Königsherrschaft Christi", in: Evangelisches Staatslexikon, begründet von Hermann Kunst und Siegfried Grundmann, herausgegeben von Hermann Kunst, Roman Herzog und Wilhelm Schneemelcher, 2., vollständig neu bearbeitete und erweiterte Auflage, Stuttgart, Berlin 1975, Sp. 1317-1319. 
Zimmermann, Horst:

$=$ Probleme $=$ Allgemeine Probleme und Methoden des Finanzausgleichs, in: Handbuch der Finanzwissenschaft, Band 4, herausgegeben von Fritz Neumark unter Mitwirkung von Norbert Andel und Heinz Haller, Dritte, gănzlich neubearbeitete Auflage, Tübingen 1983, S. 4-52. 


\section{FINANZWISSENSCHAFTLICHE SCHRIFTEN}

Band 1 Werner Steden: Finanzpolitik und Einkommensverteilung. Ein Wachstums- und Konjunkturmodell der Bundesrepublik Deutschland. 1979.

Band 2 Rainer Hagemann: Kommunale Finanzplanung im fơderativen Staat. 1976.

Band 3 Klaus Scherer: Maßstäbe zur Beurteilung von konjunkturellen Wirkungen des öffentlichen Haushalts. 1977.

Band 4 Brita Steinbach: "Formula Flexibility" - Kritische Analyse und Vergleich mit diskretionărer Konjunkturpolitik. 1977.

Band 5 Hans-Georg Petersen: Personelle Einkommensbesteuerung und Inflation. Eine theoretisch-empirische Analyse der Lohn- und veranlagten Einkommensteuer in der Bundesrepublik Deutschland. 1977.

Band 6 Friedemann Tetsch: Raumwirkungen des Finanzsystems der Bundesrepublik Deutschland. Eine Untersuchung der Auswirkungen der Finanzreform von 1969 auf die Einnahmenposition der untergeordneten Gebietskorperschaften und ihrer regionalpolitischen Zieladåquanz. 1978.

Band 7 Wilhelm Pfăhler: Normative Theorie der fiskalischen Besteuenung. Ein methodologischer und theoretischer Beitrag zur Integration der normativen Besteuerungstheorie in der Wohlfahrtstheorie. 1978.

Band 8 Wolfgang Wiegard: Optimale Schattenpreise und Produktionsprogramme für offentliche Unternehmen. Second-Best Modelle im finanzwirtschaftlichen Staatsbereich. 1978.

Band 9 Hans P. Fischer: Die Finanzierung des Umweltschutzes im Rahmen einer rationalen Umweltpolitik. 1978.

Band 10 Rainer Paulenz: Der Einsatz finanzpolitischer Instrumente in der Forschungs- und Entwicklungspolitik. 1978.

Band 11 Hans-Joachim Hauser: Verteilungswirkungen der Staatsverschuldung. Eine kreislauftheoretische Inzidenzbetrachtung. 1979.

Band 12 Gunnar Schwarting: Kommunale Investitionen. Theoretische und empirische Untersuchungen der Bestimmungsgründe kommunaler Investitionstătigkeit in NordrheinWestfalen 1965-1972. 1979.

Band 13 Hans-Joachim Conrad: Stadt-Umland-Wanderung und Finanzwirtschaft der Kernstädte. Amerikanische Erfahrungen, grundsătzliche Zusammenhånge und eine Fallstudie für das Ballungsgebiet Frankfurt am Main. 1980.

Band 14 Cay Folkers: Vermőgensverteilung und staatliche Aktivităt. Zur Theorie distributiver Prozesse im Interventionsstaat. 1981.

Band 15 Helmut Fischer: US-amerikanische Exportförderung durch die DISC-Gesetzgebung. 1981.

Band 16 Gūnter Ott: Einkommensumverteilungen in der gesetzlichen Krankenversicherung. Eine quantitative Analyse. 1981.

Band 17 Johann Hermann von Oehsen: Optimale Besteuerung. (Optimal Taxation). 1982.

Band 18 Richard Kőssler: Sozialversicherungsprinzip und Staatszuschüsse in der gesetzlichen Rentenversicherung. 1982.

Band 19 Hinrich Steffen: Zum Handlungs- und Entscheidungsspielraum der kommunalen Investitionspolitik in der Bundesrepublik Deutschland. 1983.

Band 20 Manfred Scheuer: Wirkungen einer Auslandsverschuldung des Staates bei flexiblen Wechselkursen. 1983. 
Band 21 Christian Schiller: Staatsausgaben und crowding-out-Effekte. Zur Effizienz einer Finanzpolitik keynesianischer Provenienz. 1983.

Band 22 Hannelore Weck: Schattenwirtschaft: Eine Möglichkeit zur Einschrânkung der offentlichen Verwaltung? Eine Okonomische Analyse. 1983.

Band 23 Wolfgang Schmitt: Steuern als Mittel der Einkommenspolitik. Eine Ergånzung der Stabilitắspolitik? 1984.

Band 24 Wolfgang Laux: Erhöhung staatswirtschaftlicher Effizienz durch budgetăre Selbstbeschrănkung? Zur Idee einer verfassungsmăßig verankerten Ausgabengrenze. 1984.

Band 25 Brita Steinbach-van der Veen: Steuerinzidenz. Methodologische Grundlagen und empirisch-statistische Probleme von Lănderstudien. 1985.

Band 26 Albert Peters: Okonomische Kriterien für eine Aufgabenverteilung in der Marktwirtschaft. Eine deskriptive und normative Betrachtung für den Allokationsbereich. 1985.

Band 27 Achim Zeidler: Moglichkeiten zur Fortsetzung der Gemeindefinanzreform. Eine theoretische und empirische Analyse. 1985.

Band 28 Peter Bartsch: Zur Theorie der lăngerfristigen Wirkungen 'expansiver' Fiskalpolitik. Eine dynamische Analyse unter besonderer Berücksichtigung der staatlichen Budgetbeschrănkung und ausgewăhlter Möglichkeiten der ơffentlichen Defizitfinanzierung. 1986.

Band 29 Konrad Beiwinkel: Wehrgerechtigkeit als finanzpolitisches Verteilungsproblem. Möglichkeiten einer Kompensation von Wehrungerechtigkeit durch monetăre Transfers. 1986.

Band 30 Wolfgang Kitterer: Effizienz- und Verteilungswirkungen des Steuersystems. 1986.

Band 31 Heinz Dieter Hessler: Theorie und Politik der Personalsteuem. Eine Kritik ihrer Einkommens- und Vermögensbegriffe. 1987.

Band 32 Wolfgang Scherf: Die beschătigungspolitische und fiskalische Problematik der Arbeitgeberbeitrăge zur Rentenversichenung. Eine Auseinandersetzung mit der Kritik an der lohnbezogenen Beitragsbemessung. 1987.

Band 33 Andreas Măstle: Die Steuerunion. Probleme der Harmonisierung spezifischer Gütersteuern. 1987.

Band 34 Günter Ott: Internationale Verteilungswirkungen im Finanzausgleich der Europăischen Gemeinschaften. 1987.

Band 35 Heinz Haller: Zur Frage der zweckmäßigen Gestalt gemeindlicher Steuern. Ein Diskussionsbeitrag zur Gemeindesteuerreform. 1987.

Band 36 Thomas Kuhn: Schlūsselzuweisungen und fiskalische Ungleichheit. Eine theoretische Analyse der Verteilung von Schlússelzuweisungen an Kommunen. 1988.

Band 37 Walter Hahn: Steuerpolitische Willensbildungsprozesse in der Europăischen Gemeinschaft. Das Beispiel der Umsatzssteuer-Harmonisierung. 1988.

Band 38 Ulrike Hardt: Kommunale Finanzkraft. Die Problematik einer objektiven Bestimmung kommunaler Einnahmemőglichkeiten in der gemeindlichen Haushaltsplanung und im kommunalen Finanzausgleich. 1988.

Band 39 Jochen Michaelis: Optimale Finanzpolitik im Modell überlappender Generationen. 1989.

Band 40 Bernd Raffelhüschen: Anreizwirkungen der sozialen Alterssicherung. Eine dynamische Simulationsanalyse. 1989.

Band 41 Berend Diekmann: Die Anleihe- und Darlehenstransaktionen der Europåischen Gemeinschaften. 1990.

Band 42 Helmut Kaiser: Konsumnachfrage, Arbeitsangebot und optimale Haushaltsbesteuerung. Theoretische Ergebnisse und mikroökonometrische Simulation für die Bundesrepublik Deutschland. 1990. 
Band 43 Rüdiger von Kleist: Das Gramm-Rudman-Hollings-Gesetz. Ein gescheiterter Versuch der Haushaltskonsolidierung. 1991.

Band 44 Rolf Hagedorn: Steuerhinterziehung und Finanzpolitik. Ein theoretischer Beitrag unter besonderer Berücksichtigung der Hinterziehung von Zinsertrăgen. 1991.

Band 45 Cornelia S. Behrens: Intertemporale Verteilungswirkungen in der gesetzlichen Krankenversicherung der Bundesrepublik Deutschland. 1991.

Band 46 Peter Saile: Ein ökonomischer Ansatz der Theorie der intermediären Finanzgewalten Die Kirchen als Parafisci. 1992.

Band 47 Peter Gottfried: Die verdeckten Effizienzwirkungen der Umsatzsteuer. Eine empirische allgemeine Gleichgewichtsanalyse. 1991.

Band 48 Andreas Burger: Umweltorientierte Beschäftigungsprogramme. Eine Effizienzanalyse am Beispiel des "Sondervermőgens Arbeit und Umwelt". 1992.

Band 49 Jeanette Malchow: Die Zuordnung verteilungspolitischer Kompetenzen in der Europåischen Gemeinschaft. Eine Untersuchung aufgrund einer Fortentwicklung der ókonomischen Theorie des Föderalismus. 1992. 
Peter Saile - 978-3-631-75214-2

Downloaded from PubFactory at 01/11/2019 07:01:15AM

via free access 